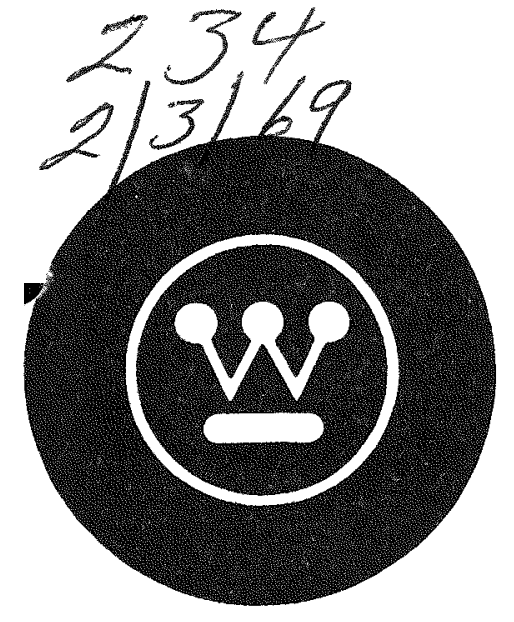

641

WANL 3800-25

UC-33

WANL-PR-SS-022

Westinghouse Astronuclear Laboratory

PHASE 1

Quarterly Progress Report

September 1, 1968 through November 30, 1968 Prepared for the

\title{
U.S.ATOMIC ENERGY COMMISSION
}

AEC Contract AT 30-1-3800

Prepared December 20, 1968
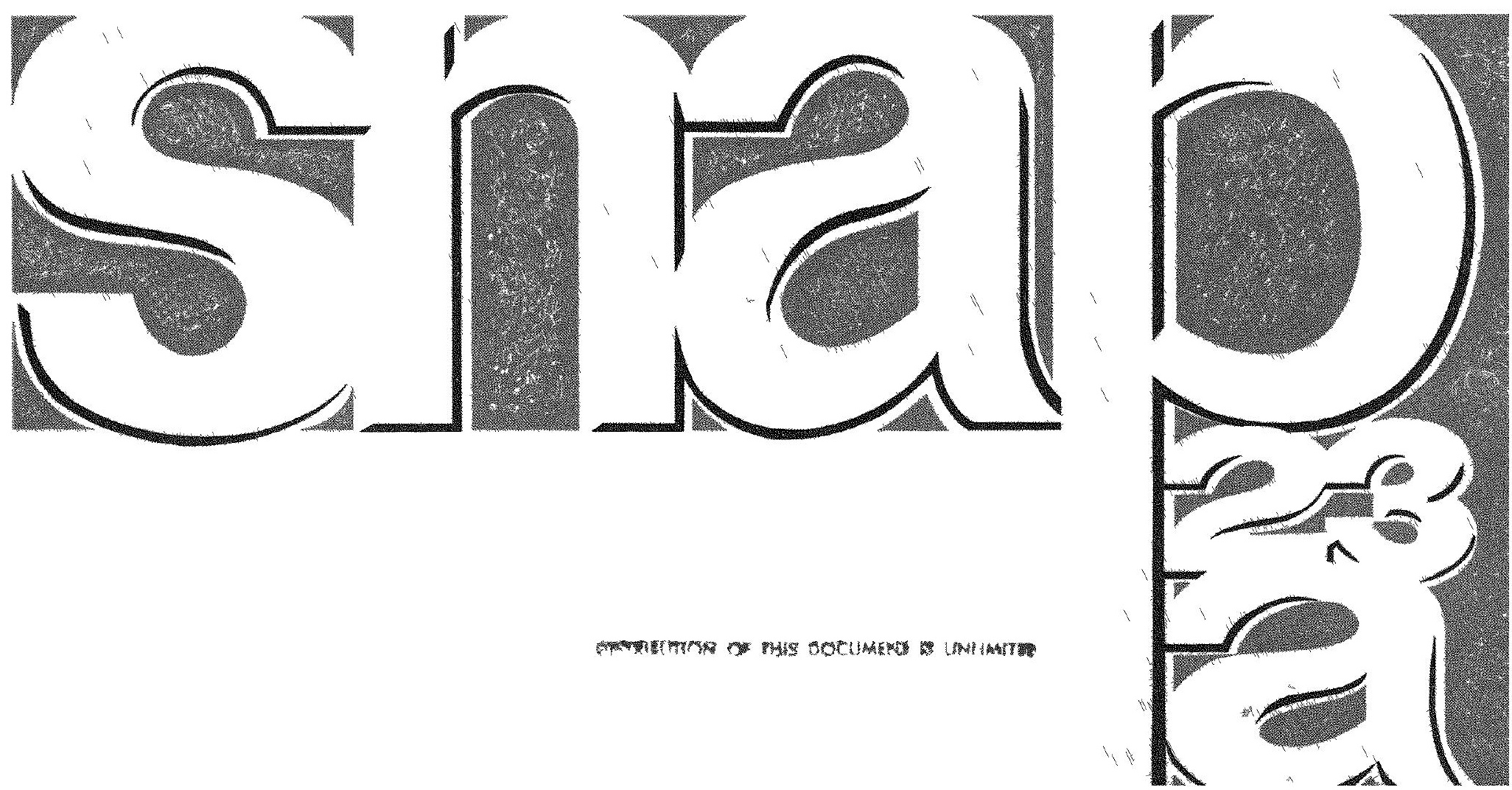


\section{DISCLAIMER}

This report was prepared as an account of work sponsored by an agency of the United States Government. Neither the United States Government nor any agency Thereof, nor any of their employees, makes any warranty, express or implied, or assumes any legal liability or responsibility for the accuracy, completeness, or usefulness of any information, apparatus, product, or process disclosed, or represents that its use would not infringe privately owned rights. Reference herein to any specific commercial product, process, or service by trade name, trademark, manufacturer, or otherwise does not necessarily constitute or imply its endorsement, recommendation, or favoring by the United States Government or any agency thereof. The views and opinions of authors expressed herein do not necessarily state or reflect those of the United States Government or any agency thereof. 


\section{DISCLAIMER}

Portions of this document may be illegible in electronic image products. Images are produced from the best available original document. 


\section{LEGAL NOTICE}

This report was prepared as an account of Covernment sponsored work. Neither the United States, nor the Commission, nor any person acting on behalf of the Commission:

A. Makes any warranty or representation, expressed or implied, with respect to the accuracy, completeness, or usefulness of the information contained in this report, or that the use of any information, apparatus, method, or process disclosed in this report may not iniringe privately owned rights; or

B. Assumes any liabilities with respect to the use of, or for daxiages resulting from the use of any information, apparatus, method, or process disclosed in this report.

As used in the above, "person acting on behalf of the Commission" includes any employee or contractor of the Commission, or employee of such contractor, to the extent that such employee or contractor of the Commission, or employee of such contractor prepares, disseminates, or provides access to, any information pursuant to his employment or contract with the Commission, or his employment with such contractor.

Printed in the United States of America

Available from

Clearinghouse for Federal Scientific and Technical Information

National Bureau of Standards, U. S. Department of Commerce

Springfield, Virginia 22151

Price: Printed Copy $\$ 3.00$; Microfiche $\$ 0.65$ 
WANL 3800-25

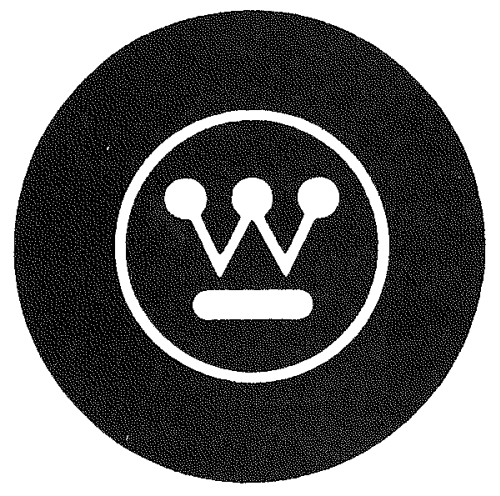

UC-33

WANL-PR-SS-022

Westinghouse Astronuclear Laboratory

PHASE 1

Quarterly Progress Report

September 1, 1968 through November 30, 1968 Prepared for the

U.S.ATOMIC ENERGY COMMISSION

AEC Contract AT 30-1-3800

Prepared December 20, 1968

PREPARED BY:

W.8. 29 uguas

SNAP-23A PROJECT MANAGER

SYSTEMS AND TECHNOLOGY

LEGAL NOTICE

Lo Th1s report was prepared as an account of Government sponsored work. Nether

States, nor the Commission, nor any persou acting on behalf of the cal we respect to the accuA. Makes any warranty or representation, expressed or implied, wh th respect the the use racy, completeness, or usefuthess of the of any information, apparatus, method, or process drsctosed in this repo privately owned rights, or B As unformation, apparatus, method, or process disclosed in this report. As used in the above, "person acting on behall of hextent that As ur contractor of the Commission, or employee of such con mon ployee or cone or contractor of the Commission, or employee ol such colsment or contract duch omates, or provides access to, any information pursuant with the Commesion, or his employment with such contractor.

INFORMATION CATEGORY

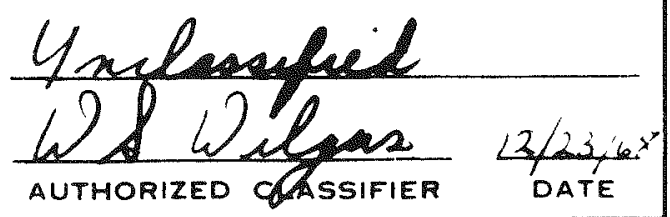


April 2, 1969

U. S. Atomic Energy Commission

Division of Technical Information Extension

P. O. Box 62

Oak Ridge, Tennessee 37830

Subject: Corrected Pages of Progress Report for Quarter Ended November 30, 1968

AEC Report No. WANL-3800-25

Contract No. AT (30-1)-3800, SNAP-23A Program - Phase 1

Gentlemen:

Enclosed are four pages for substitution in AEC Report No. WANL-3800-25 previously furnished for TID -4500 , Category UC-33 distribution on January 29, 1969. This report was prepared under Contract AT(30-1)-3800, SNAP-23A Program and the substitute pages are being forwarded at the direction of the cognizant AEC Operations Office.

As noted on the enclosed Publication Release Form, AEC Patent Clearance for the substitute pages has not been obtained and you will be advised directly from the AEC when Patent clearance has been granted.

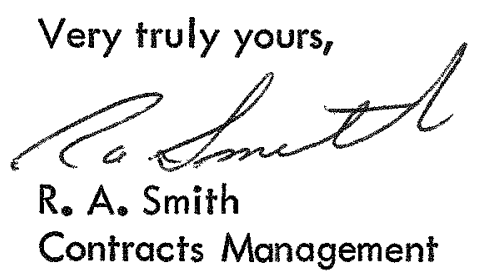

Enclosures

Contracts Management

cc: Mr. L. Wasser, AEC-NYOO (w/copy Publication Release Form)

Mr. S. J. Seiken, AEC-RDT, Washington, D. C. (w/copy Publicarion Release Form) USAEC, Assistant General Counsel for Patents, Washington, D. C. (w/copy Publication Release Form)

RAS:pan 
page blank

ii 
Q. Astronuclear

\section{PREFACE}

This report is the seventh quarterly progress report on the SNAP-23A Project, Advanced Terrestrial Radioisotope Power Systems, under Contract AT(30-1)-3800 authorized by the United States Atomic Energy Commission. Phase 1, estimated to cover the period from December 2, 1966 through August 15, 1969, is being conducted by the Astronuclear Laboratory of the Westinghouse Electric Corporation under the direction of the Atomic Energy Commission

This document reports progress for the period from September 1, 1968 to November 30 , 1968. 
page blank 


\section{TABLE OF CONTENTS}

Section

$\underline{\text { Page }}$

PROGRAM MANAGEMENT

Subtask 115 - Program Management

Subtask 140 - Liaison Engineering

2

PRODUCT ASSURANCE

Subtask 210 - Reliability

Subtask 220 - Quality Control

Subtask 310 - Systems Engineering

EMS Testing

PMS Design

PMS Analysis

3-6

Subtask 315 - System Analysis

3-6

EMS Rebuild and Test Evaluation

3-6

Shipping Cask Conceptual Design

Subtask 320 - Mechanical Design

Summary

Scope of Final EMS Rebuild Work Tasks

Securing Instrumentation and Power Leads

Heat Source Subassembly Helium Pressurization and Monitoring

Sealing and Pressure Monitoring of Insulated Base Assembly

EMS Rebuild Shock and Vibration Tests Successfully Completed

Preparation of EMS Unit for Shock and Vibration Test

System Vibration Characteristics

Shock and Vibration Testing 


\section{TABLE OF CONTENTS (CONTINUED)}

Section

Page

Subtask 340 - Thermal Analysis $\quad 3-30$

Experimental Mockup System Test Results $\quad 3-30$

Thermal Data During Mechanical Test $\quad 3-44$

Experimental Determination of Thermal Properties of the Insulation Materials - Spherical Insulation Tests 3-49

Min-K 2000 Properties $\quad 3-50$

Min-K 2002 Properties 3-59

Projected Improvements in Heat Losses for PMS 3-59

Subtask 350 - Thermoelectric Analysis 3-64

Interface Meetings 3-64

Subtask 390 - Capsule Design and Development 3-65

Fueling of SNAP-23A Capsule 3-65

Capsule Component Fabrication 3-65

Capsule Component Tolerance Study $\quad 3-76$

Tantalum Diffusion Barrier $\quad 3-79$

Capsule Axial Expansion Analysis $\quad 3-79$

4 MATERIALS AND COMPONENT TESTING 4-1

Subtask 410 - Materials Engineering and Testing 4-1

Tasks Performed 4-1

Spherical Insulation Test $\quad 4-2$

Compatibility Trials $\quad 4-2$

U-8Mo Oxidation Test $\quad 4-9$

U-8Mo Stress-Rupture Program 4-10

Subtask 415 - Heat Source Radiation Evaluation 4-13 
TABLE OF CONTENTS (CONTINUED)

Section

5

SYSTEM DEVELOPMENT

Subtask 510 - System Development

Multiple Heater Verification

EMS Three Point Thermal Test

EMS Base Assembly Test

EMS Shock and Vibration Testing

Test Setup

Instrumentation

Test Procedure

6

SAFETY ANALYSIS

Subrask 610 - Safety Analysis

SNAP-23A Explosive Environments

Impact Analysis

Subtask 640 - Safery Review

Heat Source Design Requirements

Generator Design Requirements
Page

5-1

5-1

5-1

5-4

5-4

5-8

5-8

5-11

$5-11$

6-1

6-1

6-6

6-15

6-18

6-20

6-20

\section{REFERENCES}




\section{LIST OF ILLUSTRATIONS}

Figure

3-1

3-2

3-3

\section{$-2$}

Closeup of Power Lead and Instrumentation Lead Routing and Attachment Scheme

Vibration Test Curve

Measured Magnification Factor in Lateral Direction

Heat Source and Instrumentation Losses

\section{EMS/PMC-IA System Thermal Performance Test}

Heat Loss Distributions Krypton Filled Base Assembly

Section of Polar Plane in Sphere, Showing Thermocouple Locations of Min-K 2000 Material

Thermal Conductivity of Min-K 2000 Filled with Argon (1 Atmosphere) 


\section{LIST OF ILLUSTRATIONS (Continued)}

Figure

Page

Comparison of Thermal Conductivity Data Min-K 2000 vs Min-K 2002 Under Evacuated Conditions

Thermal Conductivity of Min-K 2002 Filled with Argon (1 Atm)

Thermal Conductivity of Min-K 2002 Filled with Air (As Assembled)

PMC-1A Converter Efficiency from EMS Measurements

Liner Tubes and End Caps

Shell Cylinders and End Caps

Welding of Liner Subassemblies

Microphotographs of Capsule-End Welds Transverse View TX Magnification

Welding Shell Subassemblies

Diffusion Barrier Details

3-36 Capsule Temperature Profile During Fabrication

4-1 Drawing Showing Location of Thermocouples Relative to Interfaces Between Min-K 2002 in Spherical Insulation Test No. 2. (Numbers in parentheses are the As-received Thickness of Min-K 2002 Sheet.)

4-5 Microphotograph of Interface Between Flame Sprayed W - Coating on a U-8Mo Substrate Before Thermal Exposure

4-6 Microphotograph of U-8Mo Flame Sprayed Ta Showing NonAdherence of Ta Before Thermal Exposure (100X)

4-7 Microphotograph of U-8Mo Flame Sprayed with W Showing Coating Adherence After Thermal Exposure

4-8 Microphotograph of Interface Between Flame Sprayed Ta Coating on U-8Mo Substrate After Thermal Exposure

4-9 Microphotograph of Surface of U-8Mo Exposed to $180^{\circ} \mathrm{F}$ Water for 24 Hours

4-10 (a-b) U-8Mo Water Oxidation Sample Shown Before and After Exposure to 180 Degree Water for 24 Hours 


\section{LIST OF ILLUSTRATIONS (Continued)}

Figure

4-11

SNAP-23A Shield-Dose Measurement Position

Page

5-1

Multiple Heater Unit During Assembly - Before Test

4-16

5-2

Multiple Heatei Unit - After Test

$5-2$

$5-3$

SNAP-23A Rebuilt EMS Ready for Thermal Tests

$5-3$

5-4

SNAP-23A Test Facility

5-5

$5-6$

SNAP-23A Power Supply and Control System

Radial Axis Test Setup for Shock and Vibration Tests

Radial Axis Test Setup

Axial Test Setup

Typical Input Shocks

5-10 Frequency Vs. Ratio of Accelerometers on Radiator Flange to Control

Temperature Profile Expected in Insulation

Effect of Yield on Peak Overpressure and Peak Reflected Overpressure

6-7 Temperature Differential Across Tantalum-U-8Mo Shield Interface Gap as a Function of Gap Thickness for Air and Helium Cover Gases at Various Assumed Uranium Emissivities 


\section{LIST OF TABLES}

Table

$\underline{\text { Page }}$

3-1

PMS Weights

3-7

3-2

SNAP-23A EMS - Thermal Test Points Summary

SNAP-23A EMS - Thermal Test Point Summary

SNAP-23A EMS - Thermal Test Point Summary

Summary of System Performance

Estimated EMS Thermal Performance

SNAP-23A PMC-IA Revised Test Station Loss

Weld Penetration of Capsule Shell Welds (End Cap to Shell Tube)

4-1 Spherical Insulation Test Data Collected During Reporting Period 
(2) Astronuclear

Laboratory

\section{PROGRAM MANAGEMENT}

Subtask 110 - Project Management

Meetings were held with the AEC during this quarter concerning revision of the Phase I Project Plan. WANL initiated preparation of Revision 4 of the Project Plan. This effort included the revision of all subtask descriptions, summary information, and a revised management network in accordance with the guidelines and comments received from the AEC. An informal meeting was held with the AEC on October 25, 1968 to review the approach to the preparation of Revision 4 of the Project Plan and the status of the EMS electrical heat source failure topical report.

Meetings were held with $3 \mathrm{M}$ on October 3, 1968 and October 29, 1968. At these meetings, agreements were reached between WANL and $3 M$ covering PMC-2 and PMS. The preliminary Interface Control Drawing was issued on November 1, 1968. Formal submittal of this drawing to the AEC is scheduled for the early part of the next quarter.

Meetings were held with ORNL covering the inspection techniques for fuel capsule closure welds and the plans for the shield effectiveness test. WANL personnel witnessed the welding of the first fueled SNAP-23A capsule and the shield effectiveness test.

On November 25, 1968 WANL made a presentation to the AEC on the design changes proposed for the SNAP-23A PMS. The proposed design changes were approved by the AEC for incorporation in PMS. As a result of this meeting, preliminary work has been initiated on evaluating the programmatic and schedular effects of fueling PMS with a $\mathrm{SrTiO}_{3}$ fuel capsule。

Significant testing activities completed during this quarter included:

1) EMS Thermal Performance Tests

2) Base Assembly Insulation Environmental Test

3) EMS Shock and Vibration Test

4) PMS Shield Effectiveness Test

Documentation forwarded to the AEC during the past quarter included: 
W Astronuclear

Route Cards

570-7-0 Final Assembly

570-7-4 Power Lead Exit Modification

570-7-5 T/C Repair

570-7-11A Heat Source Reassembly

570-7-12 EMC-1 Disassembly

570-7-13 Hot Leak Test

570-7-14 Base and Heat Source Reassembly

570-7-16 Cold Leak Test

570-7-19 T/C Repair Cavity Fill

570-7-21 Power Lead Exit Modification

Drawings

100 E 390 Heater Wire Rework

100 E $393 \quad$ Plates

388 D $046 \quad$ Heat Source Bushing

388 D 047 Firerod Heater Cartridge

388 D 048 Thermocouple

576 F $760 \quad$ Heater Wire

615 B 615 Thermocouple Strap

$711 \mathrm{~J} 618$ Heat Source Container

$711 \mathrm{~J} 626$ Heat and T/C Installation

Publications

WANL-3800-21 June-August Quarterly Progress Report

WANL-3800-22 September Progress Report

WANL-3800-23 October Progress Report

Revision Sheets PMS Shield Effectiveness Test

WANL-3800-20 
(2) Astronuclear

\section{Procedures}

EMSN-3 Rev. 1 Experimental Mockup System (EMS) Thermal Performance Test Procedure

EMSN-3A Rev。 1 Experimental Mockup System (EMS) Base Assembly Performance Test Procedure

EMSN-3B Rev。 1 Experimental Mockup System (EMS) Shock and Vibration Test Procedure

Subtask 115 - Program Management

The key work items accomplished during this reporting period include normal technical and management activities and liaison efforts. Liaison efforts with WANL and ORNL. (Oak Ridge National Laboratory) have continued.

Subrask 140 - Liaison Engineering

Liaison activities during this quarter have been directed toward the development of final definitions of the PMS converter and shield designs, coordination of the shipping container designs, and monitoring the fueled capsule fabrication.

Meetings were held with $3 M$ to define the mechanical and thermal interface requirements for the incorporation of a new converter, designated PMC-2, into the PMS. Most of the mechanical requirements were incorporated in a new interface control drawing, WANL drawing 914E462. Formal submittal of this drawing to the AEC is scheduled early in the next quarter. The primary converter dimensions are unchanged from previous designs.

Work is underway to define the thermal interface requirements in terms of a converter thermoelectric design which, when operating in the PMS, will yield an output power of 61 watts with an efficiency of 7.7 percent or greater under EOL conditions. The definition of the pertinent EOL operating conditions will include the consideration of converter degradation as a function of the maximum operating temperature and of overall system efficiency over a range of converter operating temperatures.

Discussions held with Hittman Associates regarding the shipping container design identified the fact that previous experience in designing the SNAP-7 shipping container 
is being utilized in the SNAP-23A container design. A single unit is being designed to accommodate either the heat source assembly alone or the complete system.

Two trips were made to ORNL. Discussions were held regarding the correlation of destructive and non-destructive inspection techniques for fuel capsule closure welds and the plans for the shield evaluation test. In addition, the welding of the first fueled SNAP-23A capsule and the shield evaluation test operations were witnessed. The results of these meetings are discussed in detail in the pertinent sections of this report. 
Q20 Astronuclear

\section{PRODUCT ASSURANCE}

Subtask $210-$ Reliability

Reliability reviews have been made for:

1) ECO's specifying various modifications of the rebuilt EMS, mostly concerned with external fixturing. These were found to be satisfactory.

2) A design modification of the heater qualification test fixture to provide for watercooling of the power lead extensions. This was found satisfactory.

3) The procedure for torquing down the Belleville spring, specifying torque and displacement limits, and the use of a lubricant to eliminate galling at the bolt inferface, thus obtaining a more accurate loading force.

4) The procedure for the Base Assembly Thermal Performance Tests, involving evacuation and backfilling with various gases. Valve opening and closing sequences were clarified per Reliability request.

5) The detailed procedures for the EMS performance test. A suggestion was made and incorporated to cover contingencies in the event of gross leakage of helium from the heat source.

6) The procedures for the EMS shock and vibration test. The fact that the line of action of the horizontal thruster does not pass through the center of gravity of the EMS was explored and found to have been satisfactorily taken into account. The mounting fixtures are able to handle the resulting inertial torques, and it was determined that the test arrangement realistically represents the manner in which shock and vibration would be experienced during transport. The means of attachment of the accelerometers was reviewed and found satisfactory.

7) The Assembly route cards for the multiple heater qualification test fixture. A modification of the preparation sequence was suggested to assure high cleanliness.

Reliability participated in the review of the conceptual design for the PMS. A Reliability document illustrating assessment of structural reliability (based on materials strength and applied stress distributions) was given to the Design group to aid in their development of the PMS design. 
Effort was initiated to update the Failure Mode Analysis.

The results of EMS testing were reviewed and discussed with the appropriate design and analytical groups. Results so far appear to be consistent with expectations based upon earlier predictions for the EMS as presently constituted.

A reliability analysis was performed to see what the risks would be if the PMS were to use four heater power leads instead of six as in the present EMS. The benefits would be reduced fabrication costs and an improvement in the accuracy of our thermal analysis by reducing the system losses associated with the tubulations.

The most serious drawback associated with the four lead scheme was determined to be the need to disconnect the power supply center-tap from ground in the event a grounding fault developed near one end of a heater cartridge winding (which is necessarily connected to one side of the power supply output). This would increase the voltage swing to ground, as the power supply would now be effectively grounded at one side, and the risk of arcing in the circuits remaining in operation would be increased.

Of some concern from a reliability point of view has been the continuous leakage of helium from the heat source since the time the system reached operating temperatures at the start of the performance tests. The leakage appears to come from a number of minor leaks, each too small to be individually detected by local sniffing. It had been anticipared that the leak rate might increase during the shock and vibration tests, and consideration was given to reducing the positive helium pressure as far as possible without incurring arcing inside the heat source, to minimize gas loss and the extraneous heat loss this entails.

Corona tests were performed at the Westinghouse $R$ \& D Center on the heater verification assembly, which is a reasonable prototype of the heater in the EMS. Tests were run in air and in helium at normal atmospheric pressure and room temperature, with 60 cycle ac voltage applied between the heater windings and the case. The lowest volfage at which a minimal indication of breakdown was found was $170 \mathrm{~V}$ (rms) in helium and $305 \mathrm{~V}$ in air. Since much more care was taken in the actual EMS heater than in the verification rig to eliminate small electrical gaps and sharp points, it is felt that for the relatively low voltages used for EMS, there is little risk of spontaneous arcing incurred by lowering the heat source helium pressure from $\sim 30$ to 5 psig. 
Subtask 220 - Quality Control

The significant activities which occurred during this quarter were:

1) Quality Engineering reviewed ECO's and Assembly Route Cards as presented.

2) The Bellville washer, used to apply pressure between the jacket stud and the converter, galled against the bolt during assembly. The problem was resolved by removing the sharp edge from the Bellville washer.

3) Source inspection was performed on the second shield and shield plug which were being rough machined at Machining Technology Corporation. The parts were found to be acceptable.

4) The required performance testing of the rebuilt SNAP unit was performed without unusual difficulty. The results of the test will be reported by other groups.

5) A leak in the heat source developed during shock and vibration. At the time this report was written, the leak rate was approximately 50 std. cu $\mathrm{ft} /$ day helium at 6 psi and $\mathrm{BOL}$ temperature. 
(W) Astronuclear

Laboratory

\section{SYSTEM DESIGN}

Subtask $310-$ Systems Engineering

Systems engineering activities this quarter included the coordination of EMS test plans and procedures, monitoring and "on-line" evaluation of EMS tests, and preliminary PMS design analysis and planning. An initial evaluation was made of the feasibility for fueling the PMS instead of operating it with electrical heating.

EMS Testing

The EMS tests in general followed the plans specified in the Integrated Test Plan, WANL-3800-20, although some modifications were made during the course of the tests. Four basic thermal steady-state data points (Subtask 340, Table 3-2) were obtained in order to map system thermal performance over a range from $\mathrm{BOL}$ conditions to a point below $\mathrm{EOL}$ conditions.

Testing was initiated September 9. The first data point was obtained with a nominal 900 watt input. Using preliminary analyses of converter and system performance at this point, an approximate EOL data point was specified using a nominal gross system input power (including instrumentation losses) of 1112 watts. This resulted in converter temperatures, and heat flows only slightly above the nominal EOL design values. Since calculations indicated that the application of the $1.282 \mathrm{Sr}-90$ decay correction factor would not result in excessive converter temperatures, the BOL heater input power was specified as 1.282 times the actual input power for the EOL point, or 1439 watts. An intermediate data point was specified for an input power of 1286 watts, the midpoint between the BOL and EOL power inputs. The BOL data point was obtained on September 20.

Preliminary analysis of these data points indicates that the BOL efficiency of the heat source is about 82 percent versus the goal of 86 percent. The radiator, however, is more efficient than was originally assumed, and the converter efficiency appears to be slightly above the design value. The net effect of these variations yields an overall EOL system efficiency of 6.5 percent, which is close to the goal of 6.6 percent. 
In interpreting these data, several conditions and assumptions must be recognized.

1) The gross power input necessarily includes the power required to compensate for heat losses from thermocouple and power leads. These losses are substantial, amounting to 110 watts at $\mathrm{EOL}$ and 140 watts at $\mathrm{BOL}$.

2) The values of heat throughput and efficiency for the PMC converter were obtained from $3 M$ test data for PMC-1A. This is not an exact method, but it utilizes the most accurate data available, and it shows consistency with observed radiator temperatures.

3) Uncertainties and error bands for various measurements lead to an overall error band on the system heat loss of about \pm 25 watts, or about \pm 2.5 percent of the net system power input。 (See Subtask 340.)

After completing the preliminary evaluation of the thermal data, the next phase of testing was initiated. This involved variations in the base assembly insulation cover gas. The first step was to evacuate the base assembly to the point where no further thermal changes occur. It was found that the available access to the base assembly for evacuation and backfilling was sufficient to achieve a complete cover gas changes within the limits of detection by thermal performance evaluation. Pumping times of approximately 48 hours were sufficient to reduce the residual gas level to about 500 to 1000 microns. This is well below the level at which thermal conductivity effects in the base assembly could be detected and results in negligible contamination when the cover gas is changed. Thermal data point information was recorded and evaluated for vacuum, dry nitrogen backfill, vacuum, and krypton backfill. Data from all of the thermal test points are summarized in Subtask 340, Table 3-2.

Analyses of cover gas samples taken at the initial BOL data point (principally $\mathrm{Kr}$ ) with the subsequent nitrogen backfill, and with the new krypton backfill are:

\begin{tabular}{|c|c|c|c|}
\hline Gas mol \% & Initial Fill & $\mathrm{N}_{2}$ Backfill & Kr Backfill \\
\hline $\mathrm{Kr}$ & 71.74 & --- & 99.38 \\
\hline $\mathrm{N}_{2}$ & 23.17 & 99.98 & 0.46 \\
\hline A & 0.28 & 0.01 & 0.16 \\
\hline $\mathrm{O}_{2}$ & 0.48 & $-\cdots$ & -.-- \\
\hline $\mathrm{CO}_{2}$ & 3.90 & 0.01 & --- \\
\hline $\mathrm{He}$ & 0.43 & --.- & -- \\
\hline
\end{tabular}


It has been concluded that the greater apparent success of these backfilling operations in comparison with the initial backfill (prior to the initial EMS operation) is probably due to the higher temperatures present in the most critical portion of the base assembly (adjacent to the heat source assembly). The initial backfill was conducted with the base assembly at a uniform temperature of approximately $850^{\circ} \mathrm{F}$, whereas, the insulation temperature approached $1400^{\circ} \mathrm{F}$ during system testing. Current plans call for making another gas analysis after several weeks of operation with the final $\mathrm{Kr}$ backfill in order to make certain the current conclusions are not invalidated by a long-term diffusion of gas into and out of the insulation microstructure.

Preliminary evaluation of the test results (described in Subtask 340) showed that on a relative basis 1) there was no apparent thermal difference between the initial and final krypton backfills, 2) there is a difference in BOL heat loss of about 65 watts between a vacuum and a nitrogen backfill, and 3) a krypton backfill reduces the difference to about 25 watts. Although krypton backfill is relatively less effective than would be predicted on the basis of previous insulation data, krypton still has a significant advantage over nitrogen (or air) and remains the reference fill gas for the PMS base assembly design.

The final set of short-term tests included shock and vibration testing. Prior to moving the system to the shock and vibration test area, several actions were taken to modify or fasten down test instrumentation leads, power leads, and other test equipment to prevent their failure from jeopardizing the test. This effort proved to be completely successful since no failures were experienced during the test. Details of these modifications appear in Subtask 320.

The thermal performance of the system was basically unchanged during these testso The one change that did occur is attributable to an increase in the helium leak rate that took place while the system was undergoing the most severe lateral vibration. The exact location of this leak is not known, although it is known to be somewhere within the area covered by the rain shield insulation. The most probable location of the leak is at one of the many welded joints in the thermocouple and power lead extension tubes. On the basis of the observed leak rate (about $2 \mathrm{ft}^{3} / \mathrm{hr}$ at $4 \mathrm{psig}$ ) the hole is equivalent to a 0.016 diameter circular hole. This 
leak causes an increase in heat loss of about 40 watts of which an identifiable heat loss of about 12 watts is due to the heat content to helium flowing through the heat source and the balance is due to a probable increase in the installation conductivity in the rain shield area. A decrease in system temperatures consistent with a heat loss of this magnitude has been observed.

The leak has not caused any significant impairment in system operation. Since there are reasons to believe that the leak is associated with components required only for tesi purposes, the system has not been shut down and disassembled to locate the source of the leak.

It is planned to place the EMS on life test for the remainder of the contract period.

\section{PMS Design}

A review was made of the overall system design to establish areas in which the PMS design should differ from the EMS. Examining the various requirements and objectives for the system, several changes were recommended. The major recommendations were:

1) Increase the top and bottom heat source insulation thickness - 2 inches on top and 1.5 inch on the bottom.

2) Use Min-K 2002 in place of Min-K 2000。

3) Strengthen the struts to raise the resonant frequency higher above $50 \mathrm{cps}$.

4) Retain the present heat source jacket and base assembly can shapes, except where modified by (1) above.

5) Lengthen the radiator fins to the extent allowable by (1) above ( 2 inches on end of outer radius of fins).

6) Consider fueling the PMS instead of using an electrical heat source.

In examining these items, the sixth obviously has the greatest ramifications on the system design. This recommendation will be persued in depth during the next quarter. The logic in proceeding directly to a fueled system is based on a) the achievement of thermal performance that matches predictions and is close to the ultimate system objectives, b) on the demonstrated ability of the system to withstand shock and vibration, c) on the completion of the fuel capsule design and on the production of a fueled capsule, and d) on the confirmation of the shield effectiveness. 
Another aspect of the relative advantages and disadvantages of a fueled versus an unfueled PMS is the type and reliability of data that can be obtained. Reliability considerations have led to the elimination of all instrumentation inside the heat source assembly. This eliminates the capability of determining temperature drops across the various interface. The EMS data, however, do not indicate any problems in this area. At the same time, the elimination of the shunt heat paths through the instrumentation and power lead fubulations will remove significant uncertainties in the system heat balance. The net effect will be an increase in the accuracy of overall system performance evaluations.

Instrumentation will be retained on the outside of the heat source assembly jacket, inside and outside the base assembly, and on the radiator. The total number of instrumented points, however, will be considerably less than on the EMS. Converter instrumentation probably will be reduced also, and formal discussions to specify converter instrumentation will be with $3 M$ during December.

The bases for the 1 st and 5 th recommendations are discussed below and in Subtask 340 , those for the 3rd recommendation are in Subtask 330, and those for the 4th in Subtask 320. The use of Min-K 2002 in place of Min-K 2000 was selected for several reasons. Initial interest in its use was caused by indication of reduced conductivity in comparison with Min-K 2000, although the latest spherical insulation test data indicates that the 10 percent decrease in thermal conductivity which was expected may not be realized. These results are not consistent with Johns-Manville data; therefore, a thorough inspection of the test apparatus is being made. The cost of the material is much greater than for Min-K 2000. The primary interest is in its potential for an eventual reduction in base assembly cost through the elimination of a high temperature bake-out and through the use of molded shapes that can eliminate the expensive process of machining and fitting together a large number of sheets of insulation. Both of the latter advantages result from the absence of binders which, in Min-K 2000, must be driven off at high temperatures. It is believed that most of the insulation can be pressed directly into the base assembly if sufficient units are to be built to justify amortization of the special tooling required. 


\section{PMS Analysis}

The system analysis code was checked against EMS test data and was found to give a reasonable agreement with the data. In the course of performing this checkout, the geometry routines in the code provided an updated estimate of the system weight. Approximations used in these routines are, in general, no better than \pm 5 percent in accuracy but are useful on a comparative basis in monitoring the effects of system design changes on component weights. The latest tabulation for the PMS (Table 3-1) indicates a total weight of about 1220 pounds. The weight of the EMS, calculated on a similar basis, is about 1115 pounds.

The system code was used to evaluate the effects of additional axial insulation and of fin extensions (see Subtask 340) on overall system performance. Figure 3-1 shows the results of the insulation thickness evaluation. These data are not normalized exactly to the EMS data, but represent closely the expected performance changes. The projected increase of 2 inches in the top insulation and 1.5 inch in the bottom insulation yields a net reduction of 50 watts in EOL heat losses. The fin extension analysis indicated that a 2 inch extension (corresponding to the 2 inch increase in top insulation) reduces the required $\mathrm{EOL}$ heat source power by about 7 watts. This analysis is based on the use of PMC-1A characteristics and could be modified slightly by the PMC-2A characteristics.

Further system analyses are planned in the process of selecting a converter design that is applicable to the fueled PMS.

Subtask 315 - System Analysis

EMS Rebuild and Test Evaluation

Hitman Associates has assisted WANL by providing technical support during the EMS pretest planning and testing period.

Shipping Cask Conceprual Design

The objective of this effort has been to establish a dual purpose shipping cask for the SNAP-23A generator and the heat source assembly. The previous quarterly progress report 
TABLE 3-1

PMS WEIGHTS

\begin{tabular}{|l|c|}
\hline Components & Weight (lb) \\
\hline Fueled Capsule & 30.0 \\
Diffusion Barrier & 1.0 \\
Shield & 726.5 \\
Heat Accumulator & 149.4 \\
Heat Source Jacket & 13.5 \\
Base Assembly Can & 110.0 \\
Insulation & 87.0 \\
Radiator Cover & 19.0 \\
Struts & 3.0 \\
Radiator Assembly & 36.0 \\
Power Conditioning & 10.0 \\
Converter & 35.0 \\
& $1221.6 \mathrm{lb}$ \\
\hline
\end{tabular}




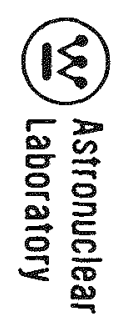

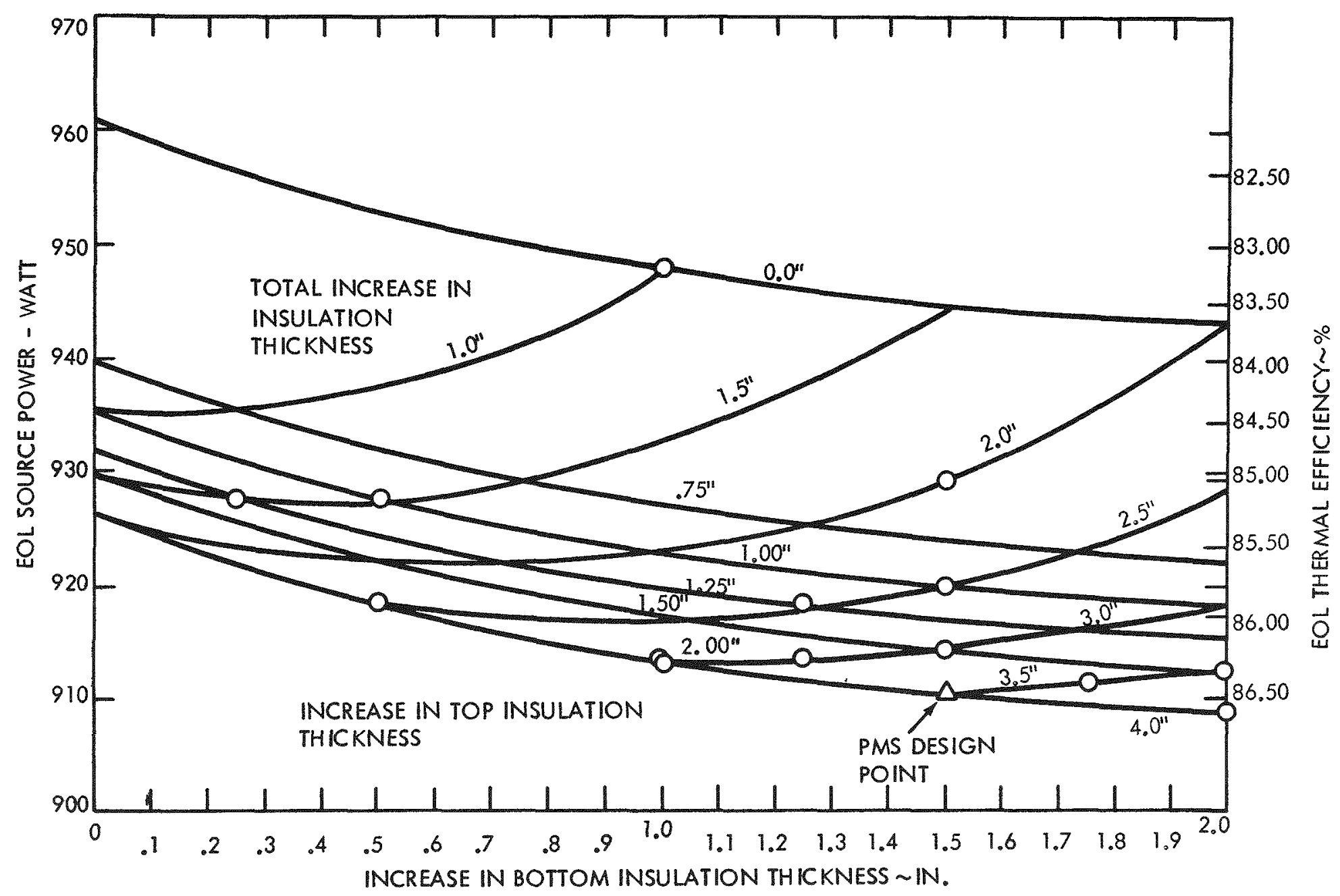

Figure 3-1. Effect of Insulation Thickness on System Heat Losses 
(Ref. 1) outlined a conceptual design and established the feasibility of this concept. Subsequent efforts on this task have been performed to verify the cask's structural integrity under accident conditions and to define a thermal model utilizing the Hittman Associates' TAP-4 computer code.

The shipping cask conceptual design for the SNAP-23A heat source/generator has been revised slightly from that configuration shown in Ref. 1. The basic crash frame remains the same, but the crash cage has been replaced by an upper crash frame. The revised shipping cask design is illustrated in Figure 3-2. In addition to the above revision, the inner support structure has been modified to incorporate an upper strut frame for added support in an upside-down impact situation. These modifications resulted from a preliminary structural analysis which uncovered a potential problem with the upside-down impact mode.

The heat source-cask thermal model is complete and computer runs are being conducted to verify the preliminary thermal analysis. The TAP-4 nodal array is illustrated in Figure 3-3 for the heat source-cask configuration. The generator-cask model is similar to the revised generator model (Subtask 610) but with the addition of shipping cask outer surface nodes and modified connectors between the generator surface and the cask surface.

Anticipated computer runs for the heat source (HS) and the generator (Gen) shipping casks will include:

1) Steady-state, $80^{\circ} \mathrm{F}$ ambient temperature (HS, Gen)

2) Variable sand height (HS)

3) Upside-down with reduced sand level (HS)

4) Variable sand conductivity (HS)

5) $1475^{\circ} \mathrm{F}$ one-half hour fire (HS, Gen)

6) $1850^{\circ} \mathrm{F}$ one-half hour fire ( $\left.\mathrm{HS}, \mathrm{Gen}\right)$

Subtask 320 - Mechanical Design

Summary

Major emphasis this quarter was applied in providing engineering liaison coverage, as required in support of the test program and identifying and solving work tasks to be 


\section{We Astronuclear}

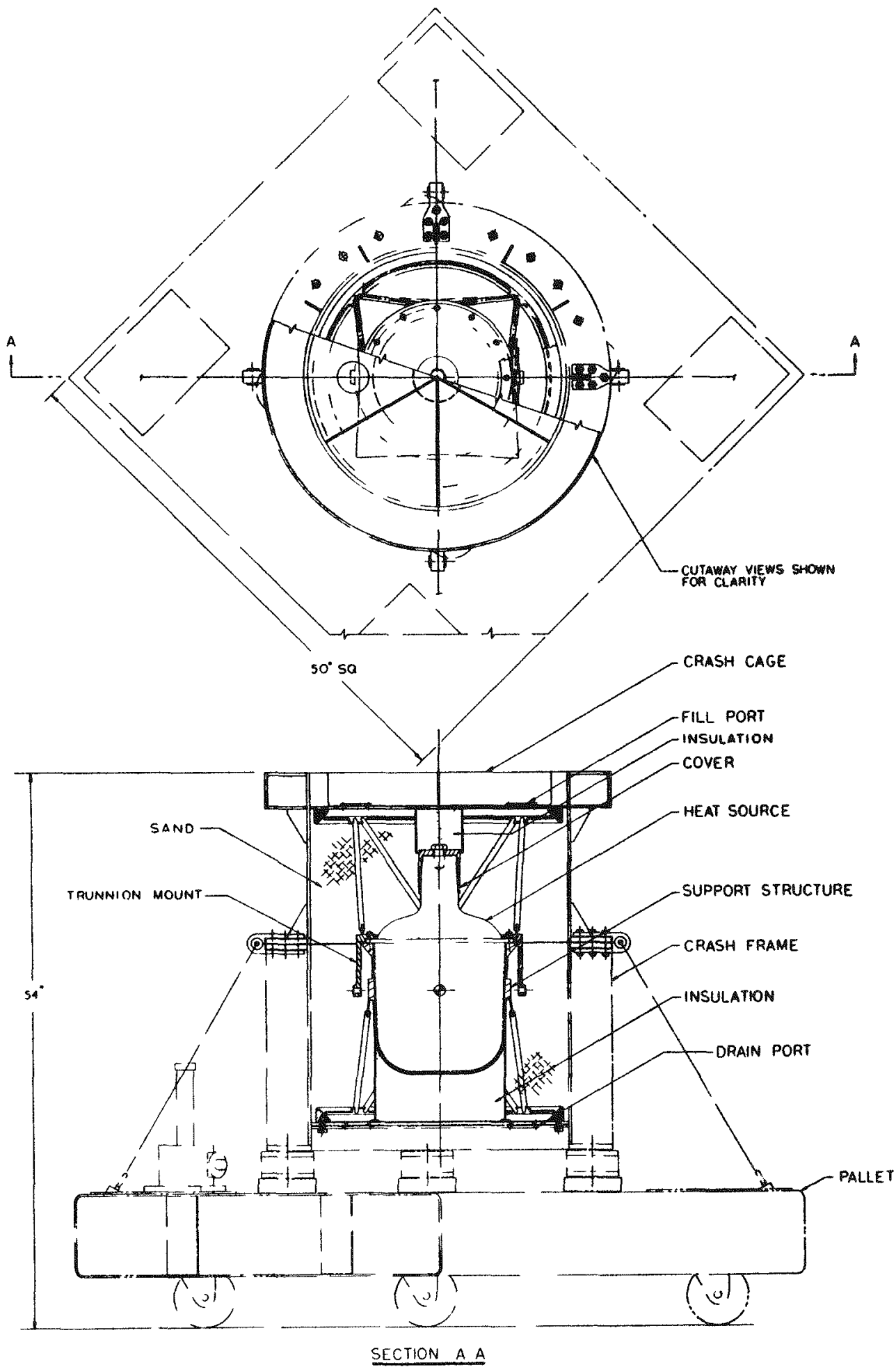

Figure 3-2. SNAP-23A Shipping Cask Conceptual Design (Revision 1) 


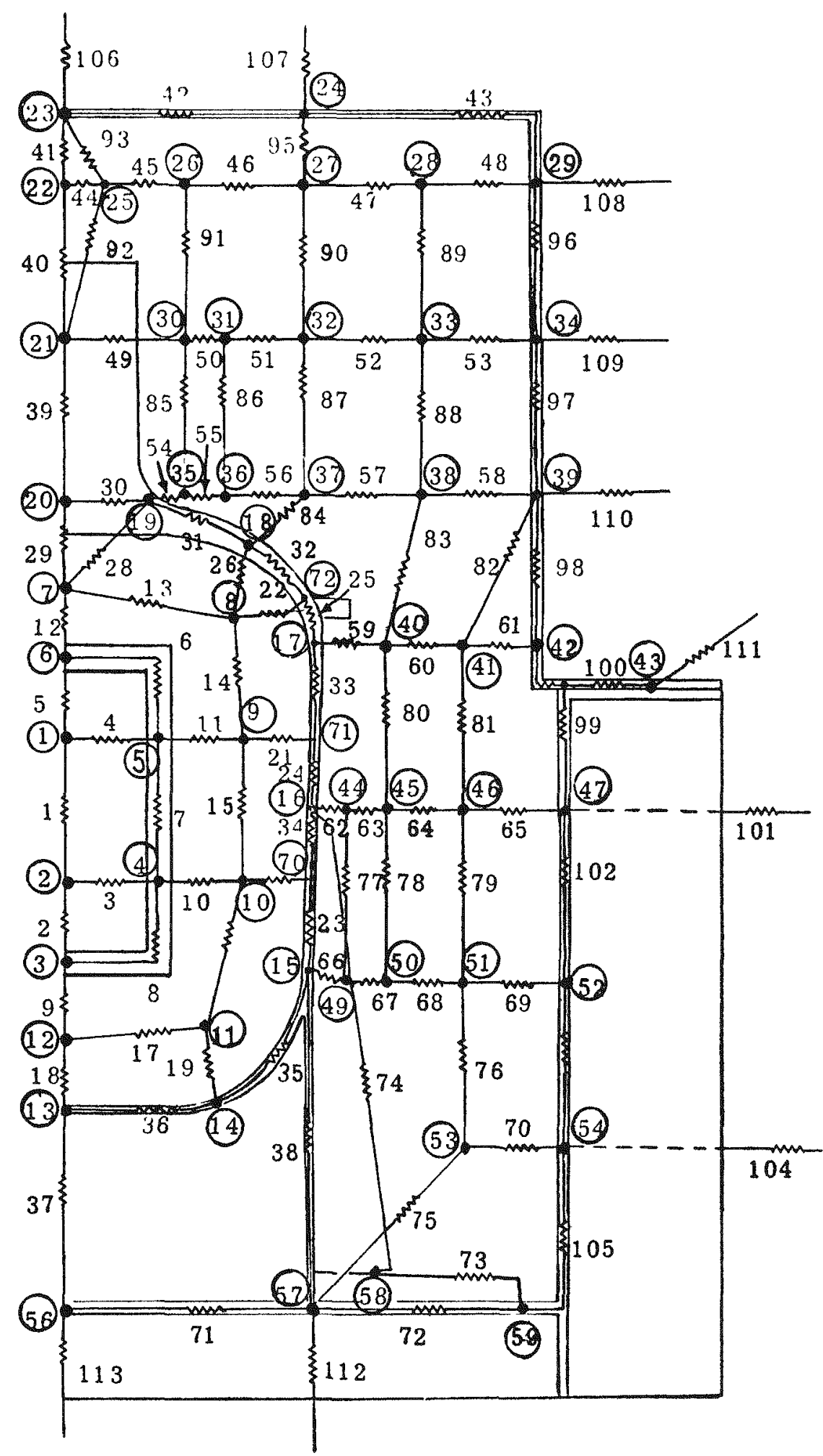

Figure 3-3. Heat Source Shipping Cask TAP-4 Nodal Network 
accomplished before shock and vibration testing. Many small and rather detailed but significant problem areas were studied and solution provided to insure timely and meaningful dynamic testing.

Shock and vibration testing was successfully completed with no observable structural damage or change of systems performance characteristics.

\section{Scope of Final EMS Rebuild Work Tasks}

In preparation for shock and vibration testing, a review was made to identify and complete all remaining necessary and related work items.

The EMS assembly is heavily instrumented for laboratory testing and, in addition, is equipped with numerous supply lines and valves to monitor or vary system pressures. In addition to the instrumentation wiring and tubing, the system also has electrical heater wiring which must be attached to stationary equipment in the test cell. None of these extemal connections are representative of a real isotope fueled SNAP-23A system. They do, however, attach the mockup unit to the facility. In addition, they must flex as the unit moves during a dynamic test. Some of the lines are critical, and their failure could cause significant system damage. Others are important enough to require that the testing be halted for their repair should they fail.

Therefore, considerable effort was expended to ensure that these lines were properly prepared for dynamic testing. Locking devices were used on all mechanical attachments such as instrumentation brackets. Valves and excess tubing were removed whenever possible. Cantilevered parts were shortened as much as possible. All cantilevered tube ends were shortened to less than $2-1 / 2$ inches and all other tube lengths greater than 6 inches were provided with intermediate support or damping. Instrumentation lines were laced down or taped at frequent intervals to prevent whipping. Every reasonable effort was made to rigidly support all components so that their natural frequencies would far exceed the maximum test frequency of 50 cps. 
Many decisions made regarding this phase of work involved a reexamination of prior work, weighing it against the increased knowledge now available from EMS static performance test experience. A much simpler and therefore more expedient approach to these peripheral problems was followed for static performance testing as the requirements were far less stringent, mechanically speaking, than for dynamic testing.

Securing Instrumentation and Power Leads

Instrumentation and power lead tubulation members and associated bracketry were provided to stiffen the tubulation members to have a resonant frequency significantly above the $50 \mathrm{cps}$. A closeup of the instrumentation and power leads and the method of attachment

A closeup of the instrumentation and power leads and the method of attachment in the area of the fubulation and associated bracketry is shown in Figure 3-4. These and similar modifications in other areas on the insulated base assembly were performed to prevent wire breakage due to whipping during dynamic testing.

As shown in Figure 3-5, the heat source subassembly thermocouples were bundled and routed back along the tubulation support bracket, down the periphery of the insulated base assembly, and laterally across the vibration test plate. Clamps, lacing, and tape were used to insure that movement of the EMS unit and test plate during shock and vibration would not cause damage to wiring or connections.

In a similar fashion, as shown in Figure $3-6$, the insulation base assembly thermocouple leads emanating from the instrumentation feed-through ports were routed and secured to prevent shock and vibration damage.

Figure 3-7 shows the power lead routing scheme. The nickel conductor lead was cut at a distance of approximately one-half inch from the support member. The stripped end of the soft strand extension lead wire was locally wrapped in a spiral fashion and soft soldered to the end of the single conductor nickel lead wire. The wire splice region was then insulated with plastic shrinkable tubing. The routing and securing of the power lead extension was accomplished in a manner similar to that described for the thermocouple leads. 


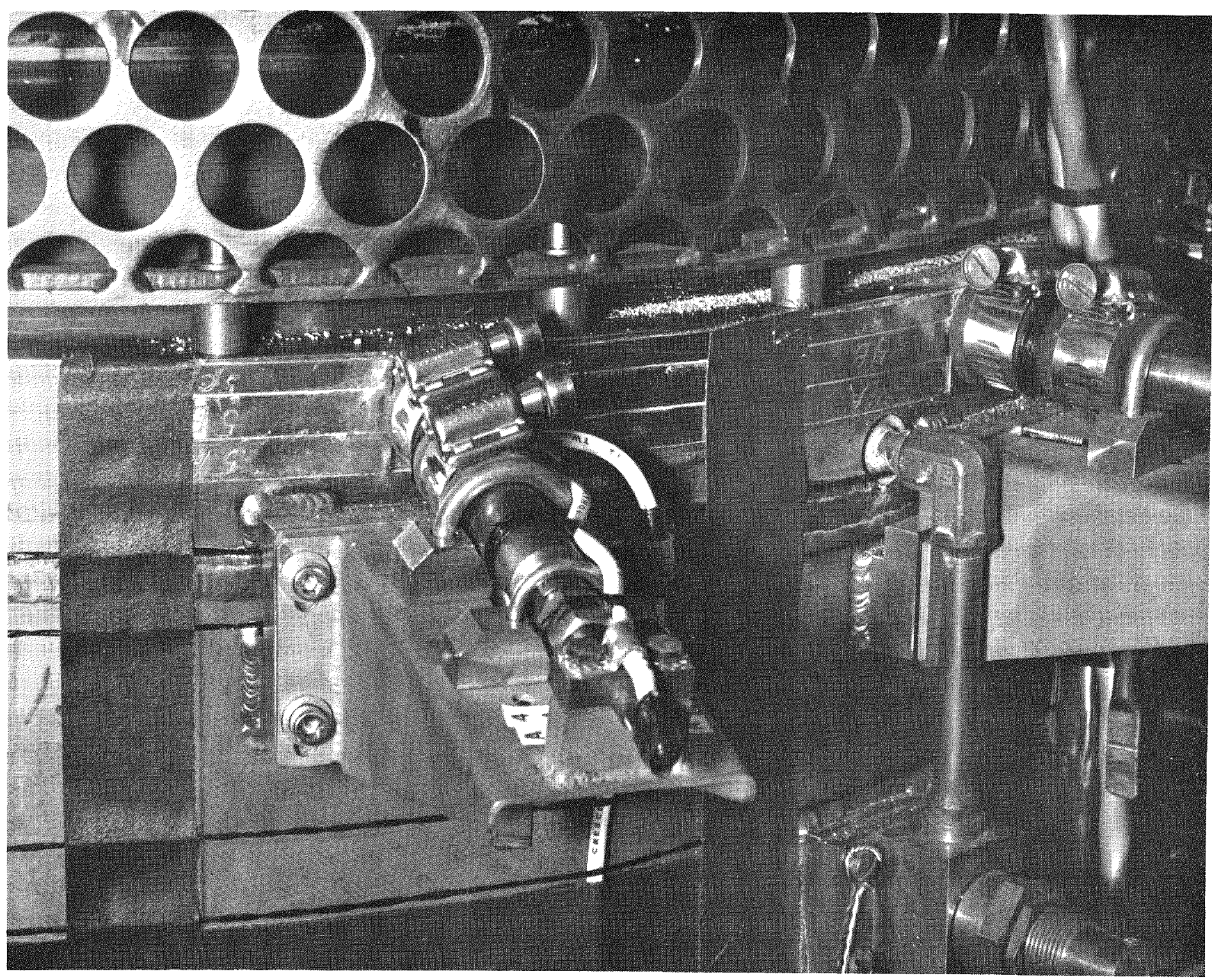

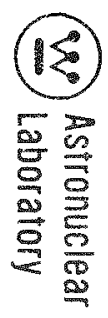

Figure 3-4. Closeup of Power Lead and Instrumentation Lead Routing and Attachment Scheme 

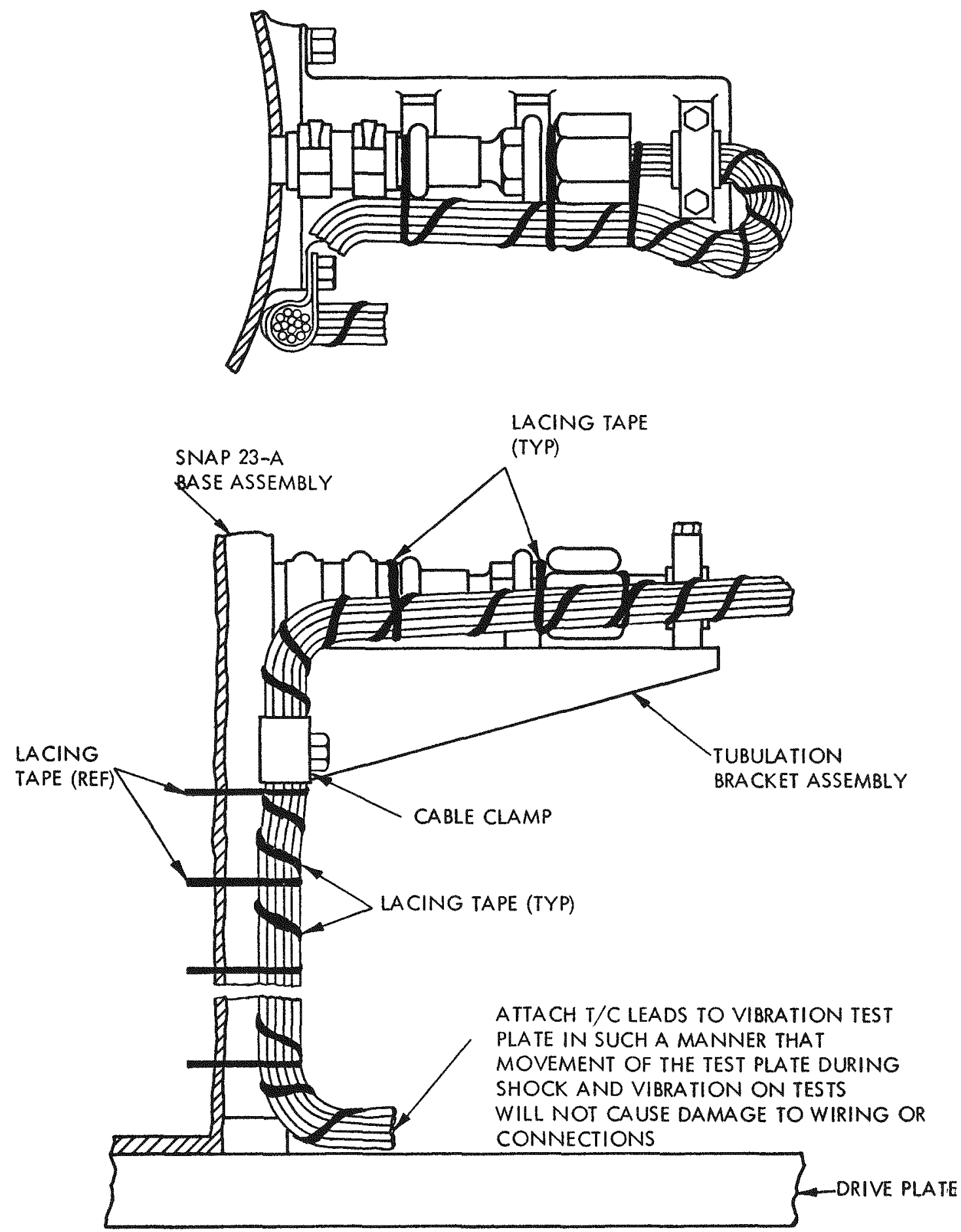

$612690-108$

Figure 3-5. Heat Source Subassembly Thermocouple Lead Routing Scheme 

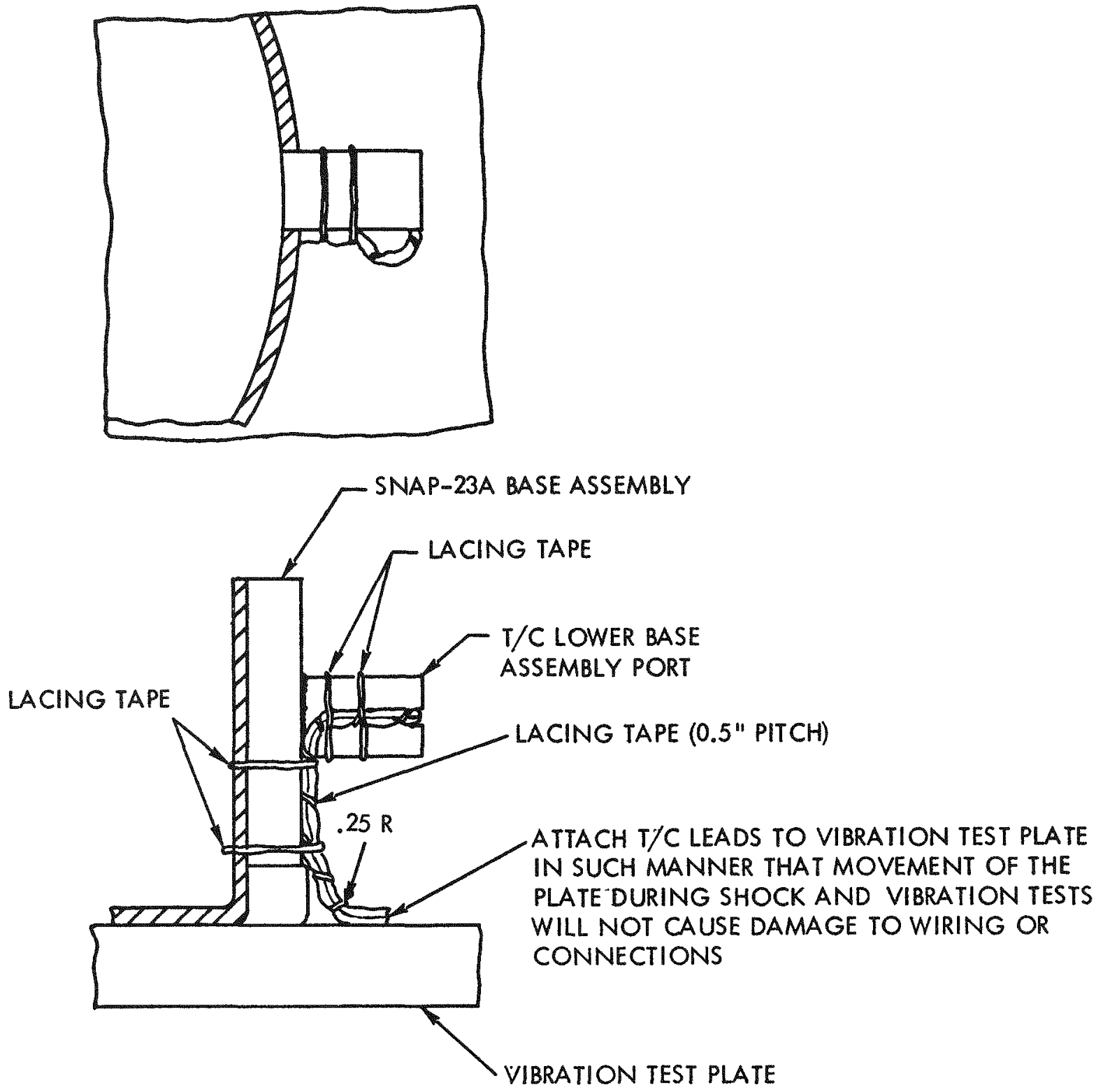

$612690-8 B$

Figure 3-6. Insulated Base Assembly Thermocouple Mounting Scheme 

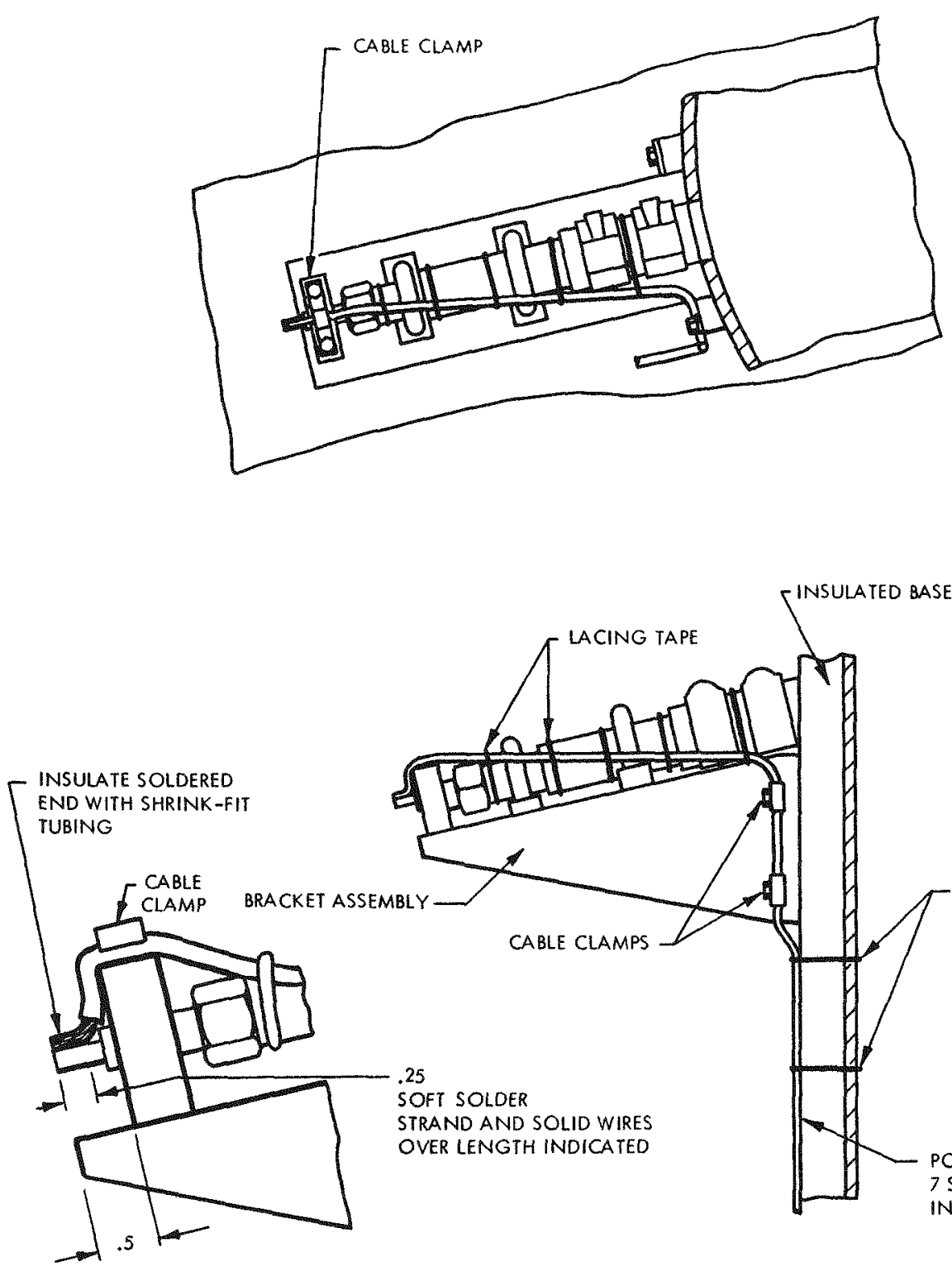

SOFT SOLDER

STRAND AND SOLID WIRES

OVER LENGTH INDICATED

POWER LEAD NO 12

7 STRAND COPPER WIRE

INSULATED 18 FEET LONG

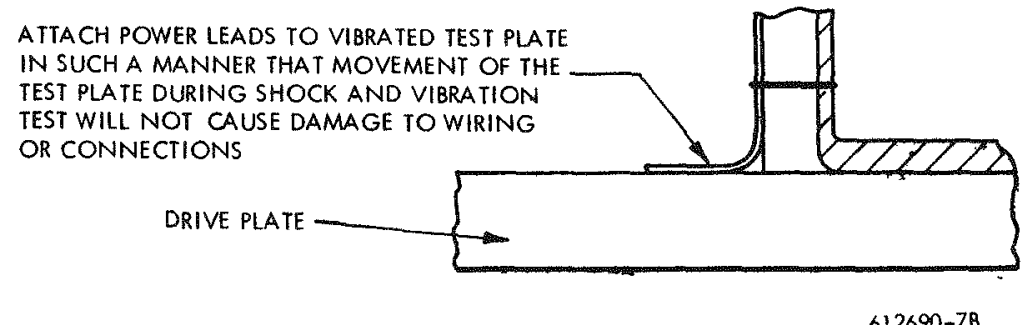

Figure 3-7. Heater Power Lead Installation 
These measures taken to secure instrumentation and power leads to prevent wire breakage were successful. There were no instances of wire breakage or malfunction of any of the supporting test equipment attached to the EMS unit itself or to transition lines or tubes installed between the EMS dynamic test unit and the stationery test laboratory equipment.

\section{Heat Source Subassembly Helium Pressurization and Monitoring}

During processing of the heat source subassembly, prior to the start of EMS rebuild thermal performance testing, the heat source evacuation and pressurization manifold was installed to the jacket enclosure at four locations. These locations were at the pressure monitoring tube (as installed on the original EMS unit) and the three thermocouple tubulation members。

For two of the three thermocouple tubulation members, this provision was made to ensure adequate evacuation of the thermocouple repair splice cavities and allow backfilling with helium to prevent corrosion damage to the splice area. In the third case, the thermocouple tubulation member housed the newly installed heater thermocouples (no splices), and thus provided direct pressure access to the heater cavity. This was a potential advantage when carrying out the heater bakeout procedure.

It was originally anticipated that a situation might develop during heater bakeout which would require pressure purging of the heat source jacket enclosure. This would have required use of both the monitor tube and the heater thermocouple fubulation access to the heater cavity. On the basis of gas samples taken during the bakeout procedure, it was found unnecessary to purge. The originally specified evacuation and backfilling procedure was found to be adequate.

For EMS rebuild thermal performance testing, a heat source evacuation and pressurization manifold was reinstalled to the three tubulation members and the pressure monitoring tube. The manifold remained in place throughout static systems performance testing and was considered advantageous from the standpoint of providing flexibility of helium pressurization control through valving in the event of some unforeseen difficulty. Its presence also furnished protection against oxidation damage of the repaired thermocouple leads by guaranteeing a 
helium environment in the thermocouple repair splice cavity. This cavity was effectively isolated from the heat source subassembly jacket enclosure due to the existence of the closure plate which remained from the original EMS build. The closure plate was braze-sealed to the metal sheathed thermocouples and to the jacket thermocouple bosses and functioned originally as a hermetic seal.

It was concluded that the added complexity of the heat source subassembly evacuation and backfill manifold could not be justified for shock and vibration testing. Problems did not arise during static systems performance testing which in any way required manipulation of the manifold valves. Also, the repaired thermocouple yield was low, and the few successfully repaired thermocouples had already served their principal usefulness during static thermal performance testing. Therefore, a judgement was made to remove the manifold before shock and vibration testing and terminate by seal welding all three helium manifold connections to the thermocouple tubulation members. The need remained, however, to retain the heat source subassembly monitoring tube connection to insure maintenance of the internal helium pressure environment.

It was concluded in early stages of the EMS rebuild design that provisions must be made for heat source subassembly internal helium pressurization control. One purpose was to minimize the possibility of air entering the heat source subassembly enclosure and causing damage to internal components due to oxidation should a leak develop. Another purpose of equal magnitude was to enhance the operating reliability of the heater assembly by reducing the tendency of electrical arcing of the power leads to heater assembly internals. The operating pressure level of $30 \pm 5$ psig was selected as a best compromise to yield an adequate margin of safety with regard to the potential arcing problem, yet not overpressure the heat source subassembly jacket enclosure which is creep limited at operating temperature.

Due to the relatively small total void volume of the heat source subassembly, it was deemed necessary to furnish an external helium supply source to maintain the required internal helium operating pressure. Even a small leak could have reduced the internal heat source pressure to an unacceptable level long before the test series could be completed. Therefore, 
to prevent unnecessary delays should a leak develop in the heat source jacket during testing, a helium supply line was atfached to the heat source subassembly pressure monitoring tube externally mounted valve (designated $V-1$ ). The simplest possible helium supply installation was made for static testing of the EMS rebuild unit. Supporting test equipment was provided to maintain the internal pressure of the heat source subassembly. This equipment had the capability of adding or removing helium fill gas without introducing air or other contaminants into the system. During systems performance testing, a small leak did develop, but caused no problem. The static test version of the heat source subassembly helium supply system performed very satisfactorily. Prior to shock and vibration testing, the helium monitoring and supply system design was revised and upgraded to satisfy the more rigorous requirement of dynamic testing.

The dynamic test version of the heat source assembly helium monitoring and supply line, as depicted in Figure 3-8, consisted primarily of a stainless steel tube routed from the existent shut-off valve (designated as $V-1$ ) to a pressure transducer and outboard shut-off valve (Figure 3-8) . Both components were hard mounted to the test fixture plate. Because the EMS unit was also hard mounted to the test fixture drive plate, no relative motion could occur in the region of the relatively inflexible metal tubing. The "hard" portion of the tubing between valve $V-1$ and the outboard shut-off valve was thus well secured to the periphery of the insulated base assembly and to the drive plate to prevent free vibration of the tube itself during dynamic testing.

A flexible length of plastic tubing was connected between the drive plate mounted shut-off valve and the helium supply bottles. This allowed relative movement of the test unit and drive plate combination with respect to the stationary surroundings thus preventing damage to the supply line. The shut-off valve was specified to be normally in the closed position during testing so that if the supply line were severed, a rapid loss of helium from the heat source would not occur. The heat source subassembly internal pressure was continuously monitored during testing by keeping valve V-1 (schematically located between the heat source subassembly and the drive plate mounted shut-off valve) open at all times. The $V-1$ valve was used in 


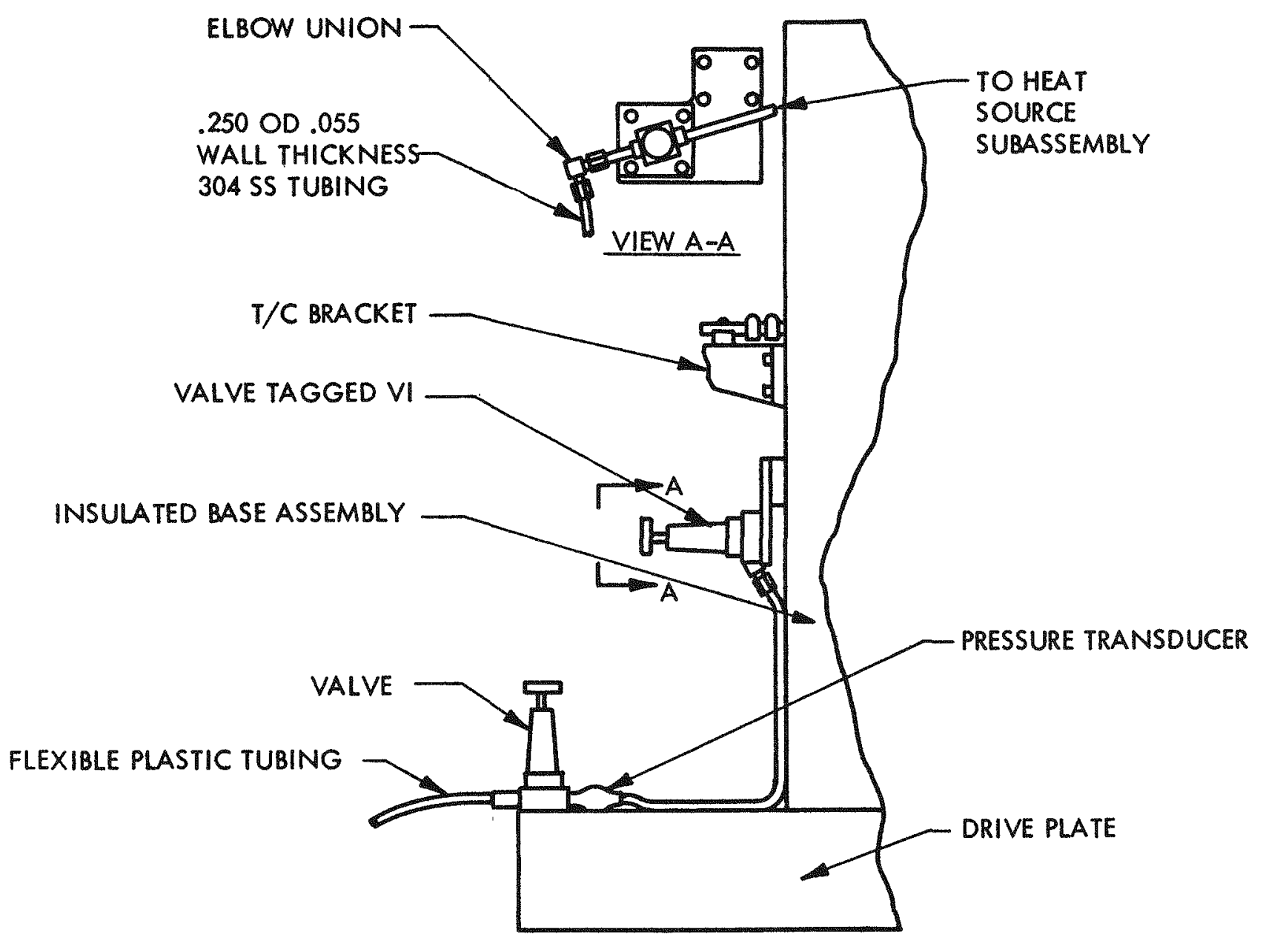

$612690-6 B$

Figure 3-8. Heat Source Assembly, Helium Monitoring, and Supply Line 


\section{Q Astronuclear

early stages of heat source subassembly processes and testing but served no useful purpose during dynamic testing. Removal of the $V-1$ valve from the system, on the other hand, would have involved reevacuation and backfilling of the heat source subassembly which was considered undesirable. It was, therefore, allowed to remain in the system since its presence created no problem.

With regard to dynamic testing, the logic was pre-established that if cracks developed in the heat source subassembly, leakage would be detected by a gradual drop in the pressure as indicated by pressure transducer readings. If a leak developed in the heat source subassembly, high enough to require continuous but not excessive gas flow, the drive plate mounted valve would be opened to the helium supply bottles and the test continued; if the leak would become so great that the pressure could not be maintained in the heat source, the test would be discontinued.

During the maximum g-level phase of vibration testing, the small leak which originally developed during static performance testing increased in magnitude but had no adverse effect upon satisfactory completion of dynamic testing. The dynamic test version of the helium monitoring and supply system performed satisfactorily, suffering no malfunction or damage.

\section{Sealing and Pressure Monitoring of Insulated Base Assembly}

Insulated base assembly thermal testing immediately preceded shock and vibration testing of the EMS rebuild unit. Prior to initiation of the insulated base assembly thermal tests, appropriate modifications were identified and incorporated into the un it to accommodate the test requirement of changing the cover gas. These modifications consisted of removing the crimped and seal-welded portion of the insulated base assembly evacuation tubes and reattaching the evacuation and backfilling manifold assembly.

Upon completion of base assembly thermal testing, and before the start of shock and vibration testing, a pressure transducer was installed between one of the four valves and the manifold (Figure 3-9). This addition was made just before final evacuation and backfilling with krypton. The pressure transducer functionally replaced the pressure gauge previously used 


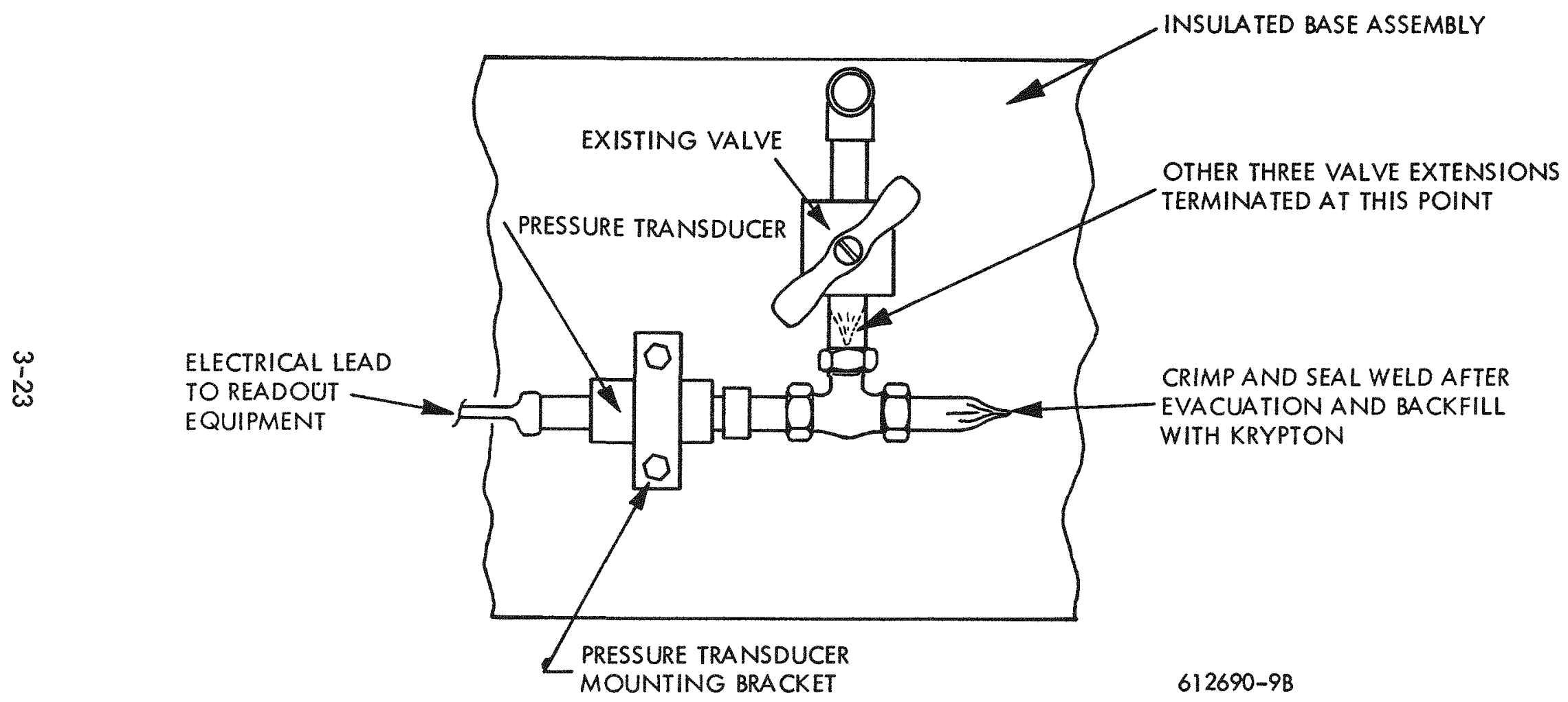

Figure 3-9. Insulated Base Assembly Pressure Transducer Installation 
for monitoring purposes during static performance testing. This substitution was necessary because the pressure gauge was not rated for the dynamic testing environment. The pressure transducer selected, however, was rated far in excess of EMS shock and vibration test levels.

Upon completion of the final evacuation and backfilling of the insulated base assembly with krypton, three of the four evacuation valve extensions were hermetically sealed and the manifold removed. The fourth valve extension, however, terminated at the pressure transducer. Thus, for shock and vibration testing, the insulated base assembly was effectively transformed into a sealed unit having no external plumbing connections to the test stand.

\section{EMS Rebuild Shock and Vibration Tests Successfully Completed}

The SNAP-23A 60-watt system design itself has not received major emphasis this reporting period as it has been well covered in previous progress reports. The more recent work tasks which are herein reported in some detail were associated with peripheral items not directly associated with the basic design itself, but nevertheless were significant from the standpoint of contributing to successful test performance with no failures or delays. All shock and vibration testing has now been successfully completed according to contractually specified portions of MIL-STD-810A, thus experimentally demonstrating that the SNAP-23A 60-watt system does meet the requirements for which it was designed. No identifiable resonances were noted over the range of frequencies tested. No structural damage or change in systems performance characteristics were noted throughout the entire range of testing. For a more detailed discussion of dynamic testing, refer to Subtasks 330 and 510.

Subrask 330 - Stress Analysis

Preparation of EMS Unit for Shock and Vibration Test

A detailed effort was applied in this area to ensure that no problem would develop during shock and vibration testing which would delay or in any way obscure the obtaining of meaningful dynamic test data. The detailed work items are reported in Subtask 320 . 


\section{System Vibration Characteristics}

The SNAP-23A unit must be capable of withstanding both shock and vibration conditions modified from MIL-STD-810A. The EMS unit was designed to withstand a triangular shock rising to $5 \mathrm{~g}^{\prime} \mathrm{s}$ in 10 milliseconds, and sinusoidal vibration of 1.3 to $5 \mathrm{~g}$ 's applied at frequencies between 5 and $50 \mathrm{cps}$. Detailed discussions of the test setup are presented in Subtask 510. Figure 3-10 shows the input $g$ level versus frequency for the vibration test. The unit is designed to withstand these dynamic conditions as applied to any axis.

The configuration of the assembly is such that it is not desirable to provide excessive support to the heat source since the heat source support structure provides a direct conductive path for heat loss. The base assembly and other external components such as the radiator protective cover could be and were stiffened so that their natural frequencies were high compared to the $50 \mathrm{cps}$ level. Thus these components could be sized for $10 \mathrm{~g}$ 's (maximum amplification under $5 \mathrm{~g}$ shock pulse) since resonance under sinusoidal testing at or below $50 \mathrm{cps}$ would not occur.

The insulation around the heat source is soft and crumbly without any appreciable resilience. It does not support the heat source nor does it provide appreciable damping. The support truss was sized to be structurally adequate yet to minimize the heat loss. Thus the truss stiffness was purposely minimized in order to decrease the heat loss through the truss to as low a level as possible consistent with a reliable structure.

The stress analysis of the truss indicated that with a rigidly held base assembly ring the natural frequency of the heat source would be $74 \mathrm{cps}$ laterally and $107 \mathrm{cps}$ axially. The shock transmissibility (heat source $g$ level divided by in put $g$ level) was predicted to be between 0.4 and 1.5 depending on system damping (1.2 laterally and 1.5 axially undamped)。 The magnification factor (heat source $g$ level divided by input $g$ level) during sinusoidal cycling was predicted to be about 1.9 laterally and 1.4 axially for the zero damping case. The maximum truss stress predicted was 23,700 psi. This stress was developed in the lateral vibration test at $50 \mathrm{cps}$ and was considered satisfactory since the yield strength of the Inconel 600 truss tubes is about 27,000 psi at operating temperature. 


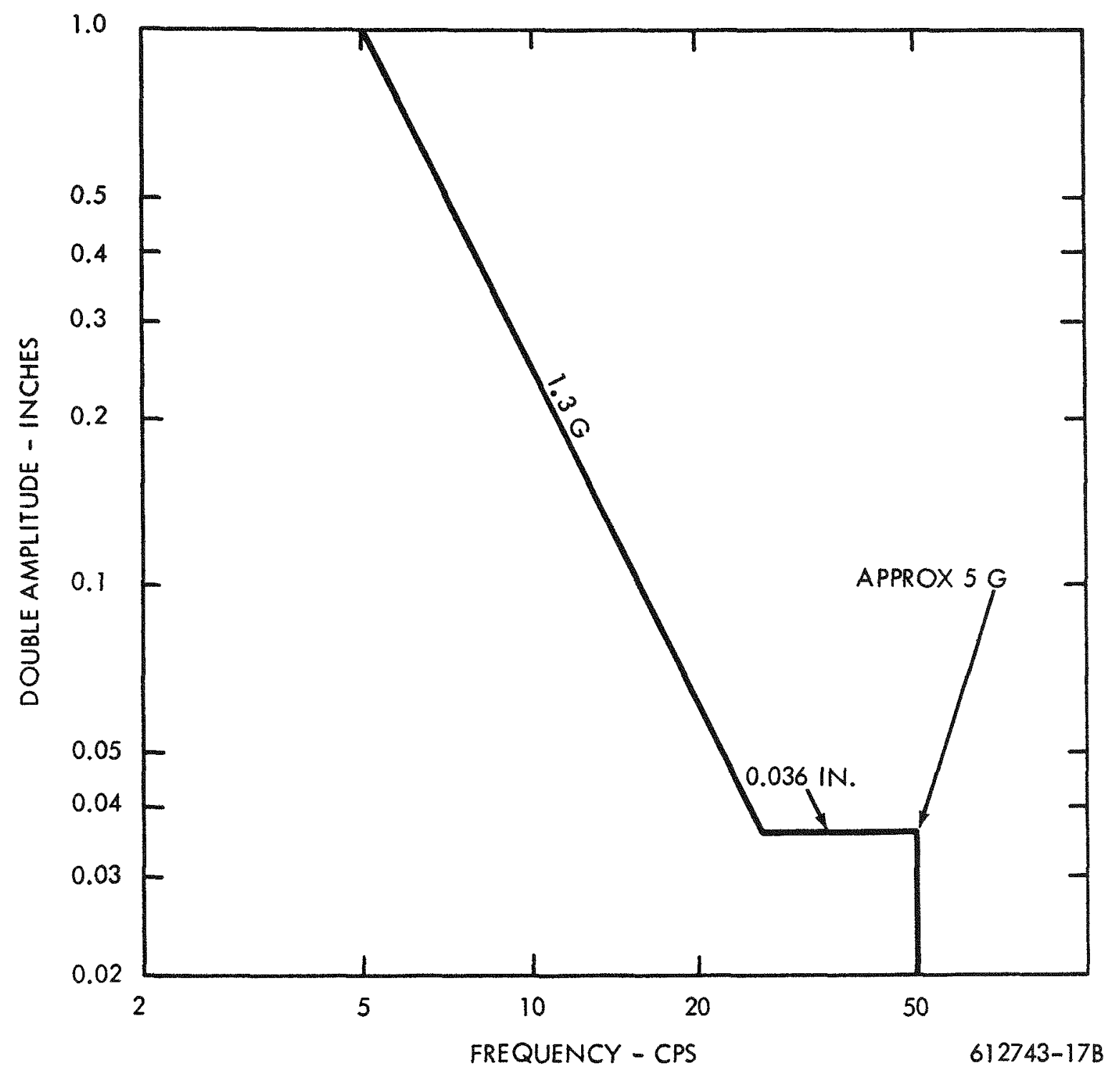

Figure 3-10. Vibration Test Curve 


\section{Shock and Vibration Testing}

The shock and vibration tests of the EMS unit were successfully completed during this period. Both shock and sinusoidal excitations were applied along each of two perpendicular axes. One axis coincided with the vertical centerline of the assembly. The other axis represented a typical lateral axis. Since the unit is basically symmetrical in the lateral direction, a second lateral test, specified by MIL-STD-810A and originally planned, was not performed.

Photos and drawings of the test setup are presented in Subtasks 320 and 510 of this report. No problems occurred in any of the shock tests, lateral or axial. The axial vibration tests went smoothly and no difficulty was experienced in maintaining the desired sinusoidal input. Some difficulty in maintaining the desired sinusoidal excitation, however, was experienced at the higher frequencies in the lateral vibration test.

Three $5 \mathrm{~g}, 10$ millisecond, triangular shock waves were applied in both directions along each axis ( 6 shocks per axis or 12 total shocks) in the shock tests. These tests appeared very uneventful to the observer. The data indicated an attenuation of the input $g$ level at the converter. The shock transmissibility ranged from about 0.5 to 0.8 . This implies that there was some damping in the system.

The vibration tests were more impressive to the observer since the amplitude was quite visible at the low frequencies $( \pm 0.5$ inch) and the sound quite audible at the high frequencies. The input excitation was varied with frequency as shown in Figure 3-10. Three complete sweeps were performed through the full frequency range along each axis. No indications of resonance were noted. Figures 3-11 and 3-12 show the magnification factor versus frequency for the two axes. The average measured value at $50 \mathrm{cps}$ for the lateral axis was about 3 , and for the axial axis about 1.5. Note the wide scatter of data in the lateral direction compared to the axial direction. It is believed that some of the scatter may be due to the setup for coupling the shakers to the system in the horizontal tests. The input acceleration records for the horizontal tests show significant spikes superimposed on the basic sinusoidal wave form. This would tend to indicate slipping and sticking due to slight movements of the system on the slip table. 
Q Astronuclear
Laboratory

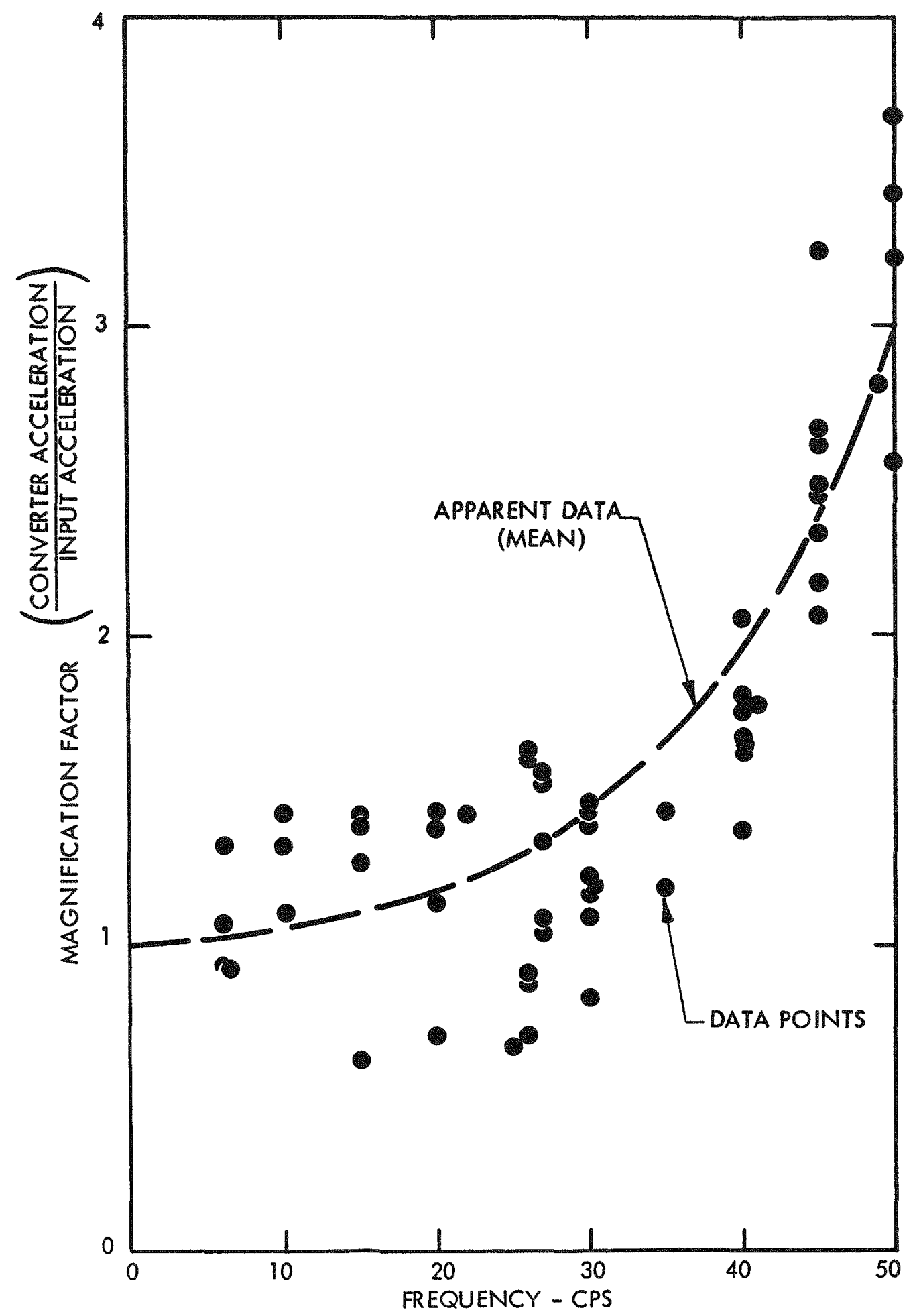

Figure 3-11. Measured Magnification Factor in Lateral Direction 

(2) Astronuclear

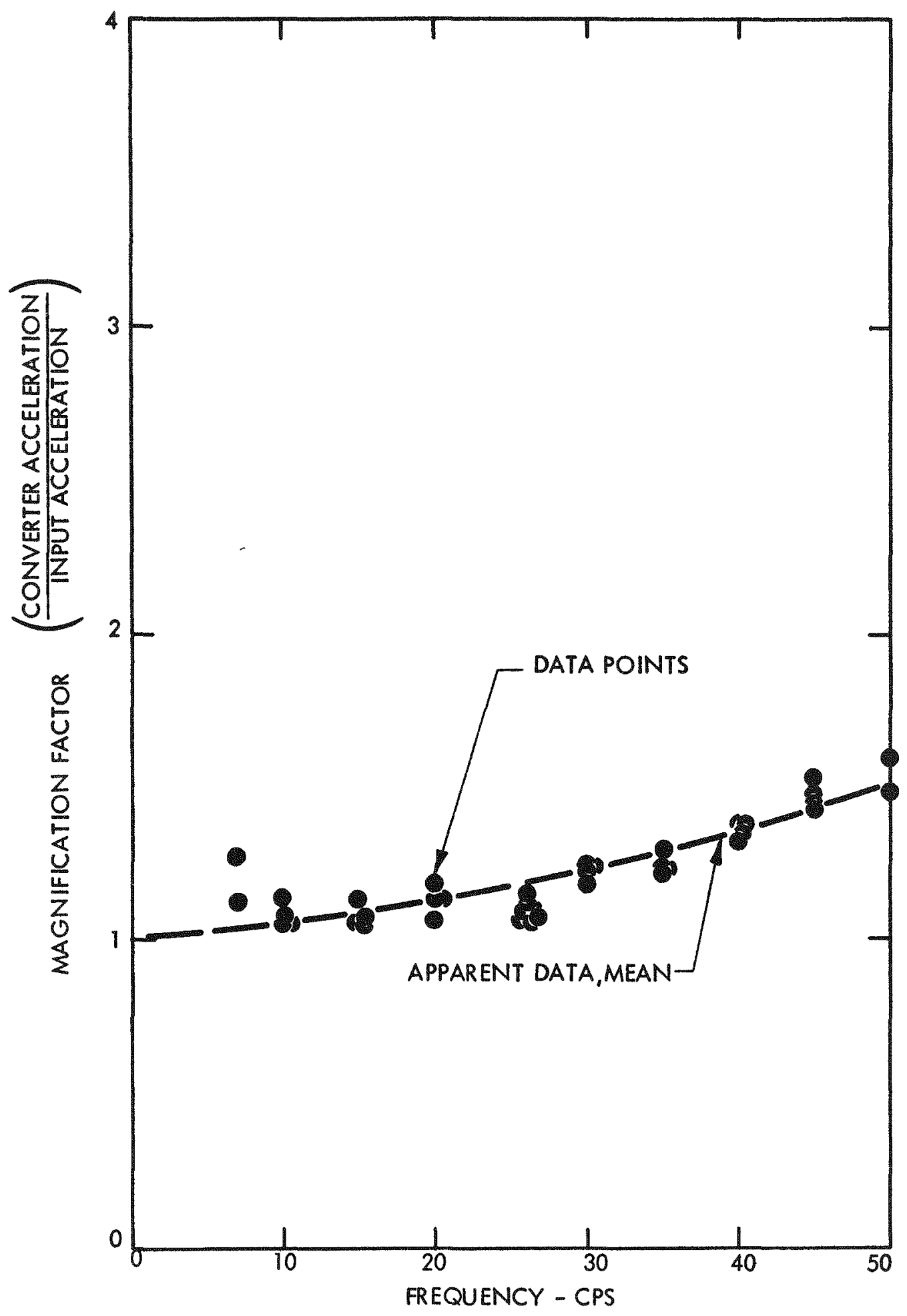

Figure 3-12. Measured Magnification Factor in Axial Direction 
These measured values of magnification factor do not agree precisely with the comparable original predicted values of 1.9 and 1.4. The fact that the measured values are higher than predicted tends to indicate that the natural frequencies are lower than predicted. The difference between the measured 1.5 and predicted 1.4 in the axial direction can be explained by the reduction in natural frequency of the system due to the weight increase from the time of the original prediction and also to the presence of flexibilities in the test setup. The difference between the lateral values cannot at this time be explained but further analysis is in progress to establish the cause of this difference.

Subtask 340 - Thermal Analysis

During this period the 4 point thermal, environmental, and mechanical tests were completed for the experimental mockup system. Sufficient test data was obtained from these tests to estimate system performance at BOL and EOL operating conditions with the base assembly insulation exposed to vacuum and various gaseous environments. Furthermore, sufficient data was obtained during the mechanical tests to determine the effects, if any, of shock and vibration on system performance. Thermal performance estimates for each of these tests are presented.

Spherical insulation test results were obtained for Min-K 2000 plus some data for Min-K 2002. The insulation thermal conductivity was evaluated by a method of analysis modified from the analysis reported for the previous quarter. Based on the results of these EMS and insulation tests and previously calculated data on heat losses, projected improvements in the design for PMS were made to reduce system thermal losses.

\section{Experimental Mockup System Test Results}

The experimental mockup system was placed on test during this reporting period. The first series of tests performed were the 4 point thermal tests. Table 3-2 presents a summary of thermal test points that were obtained during these tests and the environmental tests. This table is updated from Table 3-1 presented in the October progress report (WANL-3800-23) with respect to the system power input. Previously the system power measurements presented in the October progress report were taken from voltmeter and ammeter readings. Since the 
TABLE 3-2

SNAP-23A EMS - THERMAL TEST POINTS SUMMARY

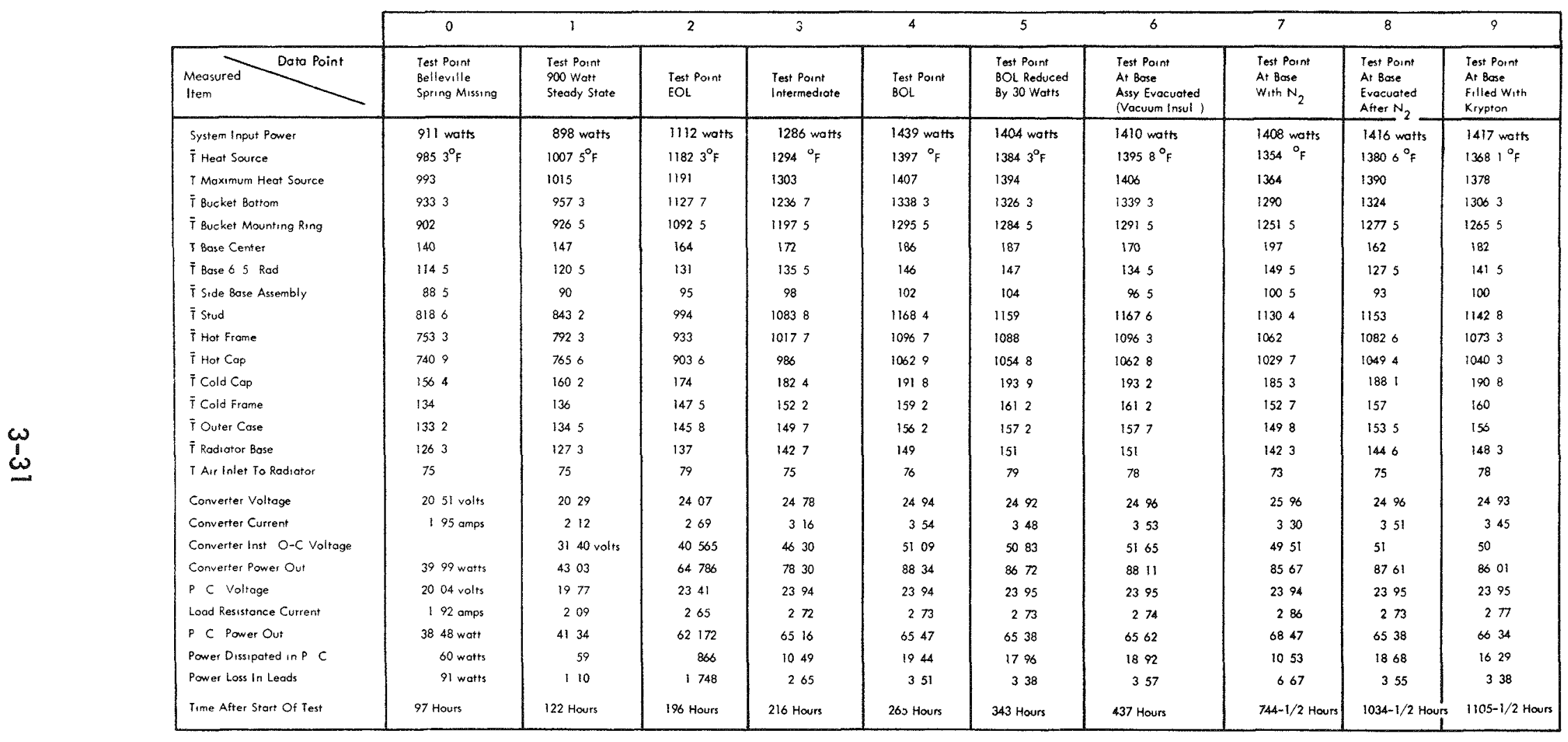


calibration of these meters was \pm 3 percent while the recorded wattmeter data were calibrated to within \pm 0.5 percent, the latter are used for indicating the gross system power input. Tables 3-2, 3-3, and 3-4 show the wattmeter power inputs.

After an initial indication of system operation was obtained at 898 watts gross electrical power input to the system, an estimate of the gross input conditions was made to obtain an EOL system input condition where the converter would operate at a 890 to $900^{\circ} \mathrm{F}$ average hot cap temperature and be near the desired nominal system design conditions. Actual thermal stability was achieved at $903.6^{\circ} \mathrm{F}$ average hot cap temperature and was accepred as the EOL condition rather than manipulating the power input to more closely match the nominal EOL temperatures. The BOL condition was then defined as the system operating condition where the gross electrical power input was 1.282 times the EOL gross electrical power input.

Test points were also taken at an intermediate power level between BOL and EOL and at BOL-30 watts power. The latter power level was established as a preferred power level for comparison of insulation environments without danger of overheating the converter hot caps. The insulation environment for these tests was approximately 72 percent krypton and 23 percent nitrogen (actual environments are described in Subtask 310). The remaining data points summarized in Table 3-2 represent environmental tests with thermal data taken of the system with insulation environments of vacuum, nitrogen, and krypton, respectively. Thermal data points taken during the lateral shock and vibration tests are summarized in Table 3-3. For these tests the insulation environment was krypton. The power level was intended to be $(B O L-30)$ watts; however, the first four data points were taken at (BOL-60) watts power input. The vertical shock and vibration tests were performed at (BOL-30) watts with the krypton environment.

Estimates of the EMS thermal performance were made for each of the data points presented in Tables 3-2, 3-3, and 3-4. Based on recorded data for system input power, converter hot and cold cap temperatures, and converter power output the converter efficiency, heat source efficiency, and heat source heat losses were predicted. The procedure for these 
TABLE 3-3

SNAP-23A EMS - THERMAL TEST POINT SUMMARY

MECHANICAL TESTS

\begin{tabular}{|c|c|c|c|c|c|c|c|}
\hline \multirow[b]{2}{*}{$\underbrace{\text { Data Pcint }}_{\substack{\text { Measured } \\
\text { Item }}}$} & \multirow{2}{*}{\begin{tabular}{l}
\multicolumn{1}{c}{ Al } \\
Test Point \\
Pre-3Pt. \\
Lateral \\
Shock Test \\
\end{tabular}} & \multicolumn{2}{|c|}{ First Run } & \multirow{2}{*}{$\begin{array}{l}\text { A4 } \\
\text { Test Point } \\
\text { After } 3 \text { Sweep } \\
\text { Lateral } \\
\text { Vibration Test } \\
\end{array}$} & \multicolumn{2}{|c|}{$\begin{array}{rr}\text { A5 } & \text { A6 } \\
& \text { Second Run } \\
\end{array}$} & \multirow{2}{*}{\begin{tabular}{l}
\multicolumn{1}{c}{ A7 } \\
Test Point \\
After 3Pt. \\
Lateral \\
Shock Test \\
\end{tabular}} \\
\hline & & $\begin{array}{l}\text { Test Point } \\
\text { After } 3 \text { Pt. } \\
\text { Lateral } \\
\text { Shock Test } \\
\end{array}$ & $\begin{array}{l}\text { Test Point } \\
\text { Pre-3 Sweep } \\
\text { Lateral } \\
\text { Vibration Test } \\
\end{array}$ & & $\begin{array}{l}\text { Test Point } \\
\text { After } 3 \text { Sweep } \\
\text { Lateral } \\
\text { Vibration Test }\end{array}$ & $\begin{array}{l}\text { Test Point } \\
\text { Pre-3Pt. } \\
\text { Lateral } \\
\text { Shock Test }\end{array}$ & \\
\hline System Input Power & 1379 Watts & 1381 Watts & 1383 Watts & 1381 Watts & 1412 Watts & 1411 Watts & 1411 Wats \\
\hline $\bar{T}$ Heat Source & $1364.8^{\circ} \mathrm{F}$ & $1362.5^{\circ} \mathrm{F}$ & $1358{ }^{\circ} \mathrm{F}$ & $1356{ }^{\circ} \mathrm{F}$ & $1361.5^{\circ} \mathrm{F}$ & $1336{ }^{\circ}{ }_{F}$ & $1335^{\circ} \mathrm{F}$ \\
\hline T Maximum Hear Source & $1375^{\circ} \mathrm{F}$ & $1373^{\circ} \mathrm{F}$ & $1368^{\circ} \mathrm{F}$ & $1366^{\circ} \mathrm{F}$ & $1371{ }^{\circ} \mathrm{F}$ & $1346{ }^{\circ} \mathrm{F}$ & $1345^{\circ} \mathrm{F}$ \\
\hline $\bar{T}$ Bucket Boftom & $1298^{\circ} \mathrm{F}$ & $1294^{\circ} \mathrm{F}$ & $1289.6^{\circ} \mathrm{F}$ & $1289.6^{\circ} \mathrm{F}$ & $1296.6^{\circ} \mathrm{F}$ & $1267.6^{\circ} \mathrm{F}$ & $1266.6^{\circ} \mathrm{F}$ \\
\hline $\bar{T}$ Bucket Mounting Ring & $1262^{\circ} \mathrm{F}$ & $1260^{\circ} \mathrm{F}$ & $1255.5^{\circ} \mathrm{F}$ & $1254{ }^{\circ} \mathrm{F}$ & $1257^{\circ} \mathrm{F}$ & $1229^{\circ} \mathrm{F}$ & $1228^{\circ} \mathrm{F}$ \\
\hline T Base Center & $184^{\circ} \mathrm{F}$ & $183^{\circ} \mathrm{F}$ & $182^{\circ} \mathrm{F}$ & $183^{\circ} \mathrm{F}$ & $182^{\circ} \mathrm{F}$ & $179^{\circ} \mathrm{F}$ & $179^{\circ} \mathrm{F}$ \\
\hline$\overline{\mathrm{T}}$ Base $6.5^{\prime \prime} \mathrm{Rad}$ & $139^{\circ} \mathrm{F}$ & $139^{\circ} \mathrm{F}$ & $138^{\circ} \mathrm{F}$ & $139.5^{\circ} \mathrm{F}$ & $137^{\circ} \mathrm{F}$ & $135.5^{\circ} \mathrm{F}$ & $135.5^{\circ} \mathrm{F}$ \\
\hline $\bar{T}$ Side Base Assembly & $110^{\circ} \mathrm{F}$ & $111.5^{\circ} \mathrm{F}$ & $106^{\circ} \mathrm{F}$ & $109.5^{\circ} \mathrm{F}$ & $106^{\circ} \mathrm{F}$ & $108^{\circ} \mathrm{F}$ & $107.5^{\circ} \mathrm{F}$ \\
\hline $\bar{T}$ Stud & $1146.8^{\circ} \mathrm{F}$ & $1141.5^{\circ} \mathrm{F}$ & $1137.5^{\circ} \mathrm{F}$ & $1136.7^{\circ} \mathrm{F}$ & $1137.7^{\circ} \mathrm{F}$ & $1112.5^{\circ} \mathrm{F}$ & $1109.7^{\circ} \mathrm{F}$ \\
\hline$\overline{\mathrm{T}}$ Hot Frame & $1069^{\circ} \mathrm{F}$ & $1067^{\circ} \mathrm{F}$ & $1062^{\circ} \mathrm{F}$ & $1060^{\circ} \mathrm{F}$ & $1059.5^{\circ} \mathrm{F}$ & $1038{ }^{\circ} \mathrm{F}$ & $-1038{ }^{\circ} \mathrm{F}$ \\
\hline $\bar{T}$ Hot Cap & $1041^{\circ} \mathrm{F}$ & $1039.4^{\circ} \mathrm{F}$ & $1034.5^{\circ} \mathrm{F}$ & $1033.3^{\circ} \mathrm{F}$ & $1036.4^{\circ} \mathrm{F}$ & $1013.9^{\circ} \mathrm{F}$ & $1012.6^{\circ} \mathrm{F}$ \\
\hline$\overline{\mathrm{T}}$ Cold Cap & $200.7^{\circ} \mathrm{F}$ & $201.2^{\circ} \mathrm{F}$ & $200.3^{\circ} \mathrm{F}$ & $199.5^{\circ} \mathrm{F}$ & $201.5^{\circ} \mathrm{F}$ & $197.6^{\circ} \mathrm{F}$ & $197.7^{\circ} \mathrm{F}$ \\
\hline$\overline{\mathrm{T}}$ Cold Frame & $166.5^{\circ} \mathrm{F}$ & $166.7^{\circ} \mathrm{F}$ & $166^{\circ} \mathrm{F}$ & $167.2^{\circ} \mathrm{F}$ & $166.7^{\circ} \mathrm{F}$ & $165.7^{\circ} \mathrm{F}$ & $165.7^{\circ} \mathrm{F}$ \\
\hline T̃ Outer Case & $165.7^{\circ} \mathrm{F}$ & $166^{\circ} \mathrm{F}$ & $165.7^{\circ} \mathrm{F}$ & $166.2^{\circ} \mathrm{F}$ & $167.5^{\circ} \mathrm{F}$ & $164.7^{\circ} \mathrm{F}$ & $164.7^{\circ} \mathrm{F}$ \\
\hline $\bar{T}$ Radiotor Base & $159.6^{\circ} \mathrm{F}$ & $159^{\circ} \mathrm{F}$ & $159^{\circ} \mathrm{F}$ & $160^{\circ} \mathrm{F}$ & $162.6^{\circ} \mathrm{F}$ & $158.6^{\circ} \mathrm{F}$ & $158.6^{\circ} \mathrm{F}$ \\
\hline T Air Inlet to Radiator & $86^{\circ} \mathrm{F}$ & $86^{\circ} \mathrm{F}$ & $86^{\circ} \mathrm{F}$ & $86^{\circ} \mathrm{F}$ & $87^{\circ} \mathrm{F}$ & $84^{\circ} \mathrm{F}$ & $86^{\circ} \mathrm{F}$ \\
\hline Converter Voltrage & 25.92 Volts & 25.42 Volts & 24.92 Volts & 24.87 Volts & 24.88 Volts & 24.84 Volts & 24.85 Volts \\
\hline Converter Current & 3.20 AMPS & 3.26 AMPS & 3.30 AMPS & 3.26 AMPS & 3.29 AMPS & 3.21 AMPS & 3.20 AMPS \\
\hline Converter Inst. O-C Voltage & 49.77 Volts & 49.54 Volts & 49.29 Volts & 49.21 Volts & 49.44 Volts & 47.74 Volts & 47.68 Volts \\
\hline Converter Power Out & 82.94 Watts & 82.87 Watts & 82,24 Watts & 81.08 Watts & 81.85 Wotts & 79.74 Watts & 79.52 Watts \\
\hline Converter Internal Resistonce & 7.45 OHMS & $7.40 \mathrm{OHMS}$ & 7.39 OHMS & 7.47 OHMS & 7.47 OHMS & 7.13 OHMS & 7.13 OHMS \\
\hline P. C. Voltage & 23.96 Volts & 23.96 Volts & 23.96 Volts & 23.96 Volts & 23.96 Volts & 23.96 Volts & 23.96 Volts \\
\hline Load Resistance Current & 2.86 AMPS & 2.79 AMPS & 2.73 AMPS & 2.73 AMPS & 2.73 AMPS & 2.72 AMPS & 2.72 AMPS \\
\hline P. C. Power Out & 68.52 Watts & 66.85 Watts & 65.41 Watts & 65.41 Watts & 65.41 Watts & 65.17 Watts & 65.17 Wotts \\
\hline Power Dissipated in P. C. & 8.15 Watts & 11.26 Watts & 13.66 Watts & 12.70 Watts & 13.42 Watts & 11.74 Watts & 11.50 Watts \\
\hline Power Loss in Leads & 6.27 Watts & 4.76 Watts & 3.17 Watts & 2.97 Watts & 3.02 Watts & 2.83 Watts & 2.85 Watts \\
\hline $\begin{array}{l}\text { Time After Start of Mechanical } \\
\text { Test }\end{array}$ & 101 Hours & 105 Hours & 124 Hours & 126-1/2 Hours & 150 Hours & 167 Hours & 169 Hours \\
\hline
\end{tabular}


TABLE 3-4

SNAP-23A EMS - THERMAL TEST POINT SUMMARY

MECHANICAL TESTS

(Vertical Shock \& Vibration)

\begin{tabular}{|c|c|c|c|c|}
\hline $\begin{array}{l}\text { Measured Data Point } \\
\text { Item }\end{array}$ & $\begin{array}{l}\text { Test Point } \\
\text { Pre } 6 \mathrm{Pt} \\
\text { Vertical } \\
\text { Shock } \\
\end{array}$ & $\begin{array}{l}\text { Test Point } \\
\text { After } 6 \text { Pt } \\
\text { Vertical } \\
\text { Shock } \\
\end{array}$ & $\begin{array}{l}\text { Test Point } \\
\text { Between lst \& } \\
\text { 2nd Vertical } \\
\text { Vibration Sweeps } \\
\end{array}$ & $\begin{array}{l}\text { Test Point } \\
\text { After Vertical } \\
\text { Vibration Sweeps }\end{array}$ \\
\hline System Input Power & 1411 Watts & 1410 Watts & 1410 Watts & 1410 Watts \\
\hline$\overline{\mathrm{T}}$ Heat Source & $1326.5^{\circ} \mathrm{F}$ & $1329.2^{\circ} \mathrm{F}$ & $1325.4^{\circ} \mathrm{F}$ & $1325.4^{\circ} \mathrm{F}$ \\
\hline T Maximum Heał Source & $1342 .^{\circ} \mathrm{F}$ & $1338 .^{\circ} \mathrm{F}$ & $1334 .^{\circ} \mathrm{F}$ & $1334 .{ }^{\circ} \mathrm{F}$ \\
\hline$\overline{\mathrm{T}}$ Bucket Bottom & $1258 .^{\circ} \mathrm{F}$ & $1259.3^{\circ} \mathrm{F}$ & $1254.6^{\circ} \mathrm{F}$ & $1254.6^{\circ} \mathrm{F}$ \\
\hline$\overline{\mathrm{T}}$ Bucket Mounting Ring & $1220 .^{\circ} \mathrm{F}$ & $1223 .^{\circ} \mathrm{F}$ & $1215^{\circ} \mathrm{F}$ & $1215 .{ }^{\circ} \mathrm{F}$ \\
\hline T Base Center & $178 .{ }^{\circ} \mathrm{F}$ & $178 .^{\circ} \mathrm{F}$ & $179 .{ }^{\circ} \mathrm{F}$ & $178 .^{\circ} \mathrm{F}$ \\
\hline $\bar{T}$ Base 6.5" Rad & $137^{\circ} \mathrm{F}$ & $137.5^{\circ} \mathrm{F}$ & $132.5^{\circ} \mathrm{F}$ & $134.5^{\circ} \mathrm{F}$ \\
\hline $\bar{T}$ Side Base Assembly & $110.5^{\circ} \mathrm{F}$ & $118.5^{\circ} \mathrm{F}$ & $106.5^{\circ} \mathrm{F}$ & $107 .^{\circ} \mathrm{F}$ \\
\hline $\bar{T}$ Stud & $1105 .^{\circ} \mathrm{F}$ & $1101.2^{\circ} \mathrm{F}$ & $1102.4^{\circ} \mathrm{F}$ & $1102 .^{\circ} \mathrm{F}$ \\
\hline$\overline{\mathrm{T}}$ Hot Frame & $1030.0^{\circ} \mathrm{F}$ & $1032 .^{\circ} \mathrm{F}$ & $1025.5^{\circ} \mathrm{F}$ & $1024 .{ }^{\circ} \mathrm{F}$ \\
\hline$\overline{\mathrm{T}}$ Hot Cap & $1006.6^{\circ} \mathrm{F}$ & $1008.5^{\circ} \mathrm{F}$ & $1003.7^{\circ} \mathrm{F}$ & $1003.6^{\circ} \mathrm{F}$ \\
\hline $\bar{T}$ Cold Cap & $198.2^{\circ} \mathrm{F}$ & $199.5^{\circ} \mathrm{F}$ & $197.5^{\circ} \mathrm{F}$ & $198.3^{\circ} \mathrm{F}$ \\
\hline$\overline{\mathrm{T}}$ Cold Frame & $166.2^{\circ} \mathrm{F}$ & $167.2^{\circ} \mathrm{F}$ & $163.2^{\circ} \mathrm{F}$ & $165 .^{\circ} \mathrm{F}$ \\
\hline$\overline{\mathrm{T}}$ Outer Case & $166 .{ }^{\circ} \mathrm{F}$ & $167 .^{\circ} \mathrm{F}$ & $165 .^{\circ} \mathrm{F}$ & $166 .{ }^{\circ} \mathrm{F}$ \\
\hline$\overline{\mathrm{T}}$ Rodiator Base & $160 .{ }^{\circ} \mathrm{F}$ & $162 .{ }^{\circ} \mathrm{F}$ & $159 .^{\circ} \mathrm{F}$ & $160 .{ }^{\circ} \mathrm{F}$ \\
\hline T Air Inlet to Radiator & $88^{\circ} \mathrm{F}$ & $87 .^{\circ} \mathrm{F}$ & $81 .^{\circ} \mathrm{F}$ & $81 .{ }^{\circ} \mathrm{F}$ \\
\hline Converter Voltage & 24.85 Volts & 24.85 Volts & 24.85 Volts & 24.86 Volts \\
\hline Converter Current & 3.17 Amps & $3.16 \mathrm{Amps}$ & 3.16 Amps & 3.15 Amps \\
\hline Converter Inst. O-C Voltage & 47.11 Volts & 47.18 Volts & 46.92 Volts & 46.95 Volts \\
\hline Converter Power Out & 78.77 Watts & 78.53 Watts & 78.52 Watts & 78.31 Watts \\
\hline Converter Internal Resistance & $6.956 \mathrm{Ohms}$ & $7.066 \mathrm{Ohms}$ & 6.984 Ohms & $7.012 \mathrm{Ohms}$ \\
\hline P.C Voltage & 23.96 Volts & 23.96 Volts & 23.96 Volts & 23.96 Volts \\
\hline Load Resistance Current & 2. 72 Amps & 2.72 Amps & 2.71 Amps & 2.71 Amps \\
\hline P. C. Power Out & 65.17 Watts & 65.17 Watts & 64.93 Watts & 64.93 Watts \\
\hline Power Dissipated in P. C. & 10.78 Watts & 10.54 Watts & 10.78 Watts & 10.54 Watts \\
\hline Power Loss in Leads & 2. 82 Watts & 2.82 Watts & 2.81 Watts & 2. 84 Watts \\
\hline $\begin{array}{l}\text { Time After Start of Mechanical } \\
\text { Test }\end{array}$ & $\begin{array}{l}289 \text { Hours } \\
11-19-68 \\
11: 45 \text { A.M. }\end{array}$ & $\begin{array}{l}293 \text { Hours } \\
11-19-68 \\
3: 30 \text { P.M. }\end{array}$ & $\begin{array}{l}312 \text { Hours } \\
11-20-68 \\
10: 20 \text { A.M. }\end{array}$ & $\begin{array}{l}313 \text { Hours } \\
11-20-68 \\
11: 35 \text { A.M. }\end{array}$ \\
\hline
\end{tabular}




\begin{tabular}{|c|c|c|c|c|c|c|c|c|c|c|c|c|c|c|c|c|c|c|c|c|}
\hline \multirow[b]{2}{*}{ TEST POINT } & \multicolumn{5}{|c|}{$\frac{4 \text { POINT THERMAL }}{3}$} & \multicolumn{4}{|c|}{$\frac{\text { ENVIRONMENTAL }}{7}$} & \multicolumn{5}{|c|}{ 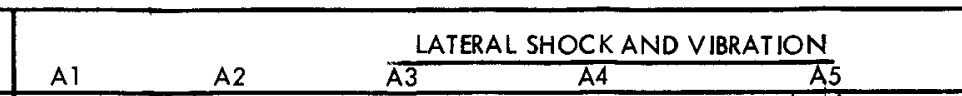 } & \multirow[b]{2}{*}{ 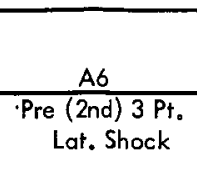 } & \multirow[b]{2}{*}{$\begin{array}{l}\text { Af After } 3 \text { Pfo. } \\
\text { Lat. Shock }\end{array}$} & \multicolumn{4}{|c|}{$\frac{\text { VERTCAL SHOCK AND VIBRATION }}{B 2}$} \\
\hline & $\begin{array}{l}900 \mathrm{~W} \\
\mathrm{~K}_{\mathrm{r}-\mathrm{N}_{2}}\end{array}$ & $\frac{2}{\mathrm{COLI}_{\mathrm{K}-\mathrm{N}}}$ & $\begin{array}{l}\text { Interedediat } \\
\mathrm{Kr}_{\mathrm{r}-\mathrm{N}}\end{array}$ & $\begin{array}{l}\mathrm{B}^{\mathrm{BOL}} \\
\mathrm{Kr}-\mathrm{N}_{2}\end{array}$ & $\begin{array}{l}\mathrm{BOC-30} \\
\mathrm{K}-\mathrm{N} \mathrm{N}_{2}\end{array}$ & \begin{tabular}{|l} 
Bol-30 \\
Vocum \\
vout
\end{tabular} & & & ${ }_{\mathrm{K} r \mathrm{OO}-30}^{\mathrm{BO}}$ & $\begin{array}{l}\text { PA Pre } \\
\text { trat. Sinock }\end{array}$ & $\begin{array}{l}\text { After } 3 \mathrm{PP} \\
\text { Lat. Shock }\end{array}$ & $\begin{array}{l}\text { Preas Sweep } \\
\text { lat. Vib. }\end{array}$ & 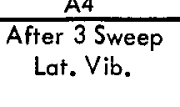 & $\begin{array}{l}\text { Affer }(2 \mathrm{dnd}) 3 \text { S Sweep } \\
\text { Lot. Vib. }\end{array}$ & & & $\begin{array}{l}\text { Preb Pr. } \\
\text { Vert. Shock }\end{array}$ & $\begin{array}{l}\text { Aber } 6 \text { Prt. } \\
\text { Vert. Shock }\end{array}$ & $\begin{array}{l}\text { Between istis 2nd } \\
\text { Vert. Vib. Sweop }\end{array}$ & $\begin{array}{ll}\text { After vert. } \\
\text { Vib. Sweep }\end{array}$ \\
\hline $\begin{array}{l}\text { System Input } \\
\text { Power }\end{array}$ & 898 & 1112 & 1286 & 1439 & 1404 & 1410 & 1408 & 1416 & 1417 & $\mid 1379$ & 1381 & 1383 & 1381 & 1412 & 1411 & 1411 & 1411 & 1410 & 1410 & 1410 \\
\hline $\begin{array}{l}\text { Hot Cap } \\
\text { Temperature }\end{array}$ & 765.6 & 903.6 & 986 & 1062.9 & 1054,8 & 1062.8 & 1029.7 & 1049.4 & 1040.3 & $\mid 1041$ & 1039.4 & 1034.5 & 1033.3 & 1036.4 & 1013.9 & 1012.6 & 1006.6 & 1008.5 & 1003.7 & 7003.6 \\
\hline $\begin{array}{l}\text { Cold Cop } \\
\text { Temperature }\end{array}$ & 160.2 & 174 & 182.4 & 191.8 & 193.9 & \begin{tabular}{|l|l|} 
& 193.2 \\
\end{tabular} & 185.3 & 188.1 & 190.8 & 200.7 & 201.2 & 200.3 & 199.5 & 201.5 & 197.6 & 197.7 & 198.2 & 1999.5 & 197.5 & 198.3 \\
\hline $\begin{array}{l}\text { Converter } \\
\Delta T\end{array}$ & 605.4 & 729.6 & 803.6 & 871.1 & 860.9 & \begin{tabular}{|l|}
869.6 \\
\end{tabular} & 844.4 & 861.3 & 849.3 & 840.3 & 838.2 & 834.2 & 833.7 & 834.8 & 816.2 & 814.8 & 808.4 & 809 & 806,2 & 805.3 \\
\hline $\begin{array}{l}\text { Converter } \\
\text { Power Out }\end{array}$ & 43.03 & 64.79 & 78.3 & 88.34 & 86.72 & 88.11 & 85.67 & 87.61 & 86,01 & 82.94 & 82.87 & 82.24 & 81.08 & 81.85 & 79.74 & 79.52 & 78.77 & 78.53 & 78.52 & 78.31 \\
\hline $\begin{array}{l}\text { leat to } \\
\text { Converter }\end{array}$ & & 821 & 900 & 1013 & 993 & 1013 & 965 & 993 & 973 & 957 & 953 & 945 & 945 & 945 & 917 & 915 & 910 & 910 & 904 & 904 \\
\hline $\begin{array}{l}\text { Colvererer } \\
\text { Eficiencery }\end{array}$ & & 0.0789 & 0.0870 & 0.0872 & 0.0873 & 0.0869 & 0.0887 & 0.0882 & 0.0883 & 0.0866 & 0.0869 & 0.0870 & 0.0887 & 0.0865 & 0.0869 & 0.0869 & 0.0865 & 0.0863 & 0.0868 & 0.0866 \\
\hline $\begin{array}{l}\begin{array}{l}\text { notstume } \\
\text { Losseses }\end{array}\end{array}$ & & 110 & 125 & 140 & 139 & 140 & 134 & 138 & 136 & 136 & 136 & 135 & 135 & 135 & 131 & 130 & 129 & 128 & 127 & 127 \\
\hline $\begin{array}{l}\text { Net Stytem } \\
\text { Input Pover }\end{array}$ & & 1002 & 1161 & 1299 & 1265 & 1270 & 1274 & 1278 & 1281 & 1243 & 1245 & 1248 & 1246 & $12 \pi$ & 1280 & 1281 & 1282 & 1282 & 1283 & ${ }_{1283}$ \\
\hline $\begin{array}{l}\text { Heat oforre } \\
\text { Heat Loss }\end{array}$ & & 181 & 261 & 286 & 272 & 257 & 309 & 285 & 308 & 286 & 292 & 303 & 301 & 336 & 363 & 366 & 372 & 372 & 379 & 379 \\
\hline $\begin{array}{l}\text { Heat Solurce } \\
\text { Efficiency }\end{array}$ & & 0.819 & 0.775 & 0.7798 & 0.785 & 0.798 & 0.758 & 0.777 & 0.759 & 0.770 & 0.766 & 0.757 & 0.758 & 0.741 & 0.716 & 0.714 & 0.710 & 0.710 & 0.705 & 0.705 \\
\hline
\end{tabular}


page blank 
calculations is outlined below and incorporated the use of component test performance data for the PMC-IA converter (supplied by $3 \mathrm{M}$ ) and a conservative estimate of the instrumentation losses.

1) Obtain system input power, converter hot and cold cap temperatures and converter power output from test point summary.

2) From PMC-1A test data determine the heat flowing to the converter as a function of the hot cap to cold cap temperature differential (Figure 3-13). *

3) Calculate converter efficiency from the ratio of converter power output to converter heat input.

4) Determine the instrumentation losses from Figure 3-14 which is a curve of instrumentation losses versus converter hot cap temperature. The bottom line of the band width is used to ensure a conservative estimate of heat source losses.

5) Calculate the net system input power from the difference between the system input power and instrumentation losses.

6) Calculate heat source heat loss from the difference between the net system input power and converter heat input.

7) Calculate heat source thermal efficiency from the ratio of converter heat input to net system input power.

The curve of instrumentation losses was calculated based on the configuration of power lead and thermocouple lead tubes, and the temperature profiles as computed by the $T \varnothing S S$ model under test conditions. The items included in this calculation were: losses from instrumentation ports to rain shields, thermal radiation through lead tubes, conduction through the tube walls and helium gas in the tubes.

Table 3-5 presents a summary of the thermal performance estimated by the above procedure for each thermal data point based on the data presented in Tables 3-2, 3-3, and 3-4. Under EOL system operating conditions as defined from the 4 point thermal tests for the

* Corrections to the PMC-IA performance data as described in Subtask 350 and agreed to by $3 \mathrm{M}$ indicated that the converter input should be 3 watts more at EOL, and 5 watts more at $\mathrm{BOL}_{\text {, than }}$ what is shown in Figure 3-13. 


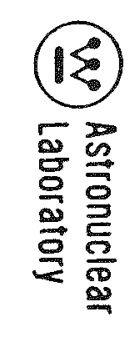

$\omega$
$\omega$
$\infty$

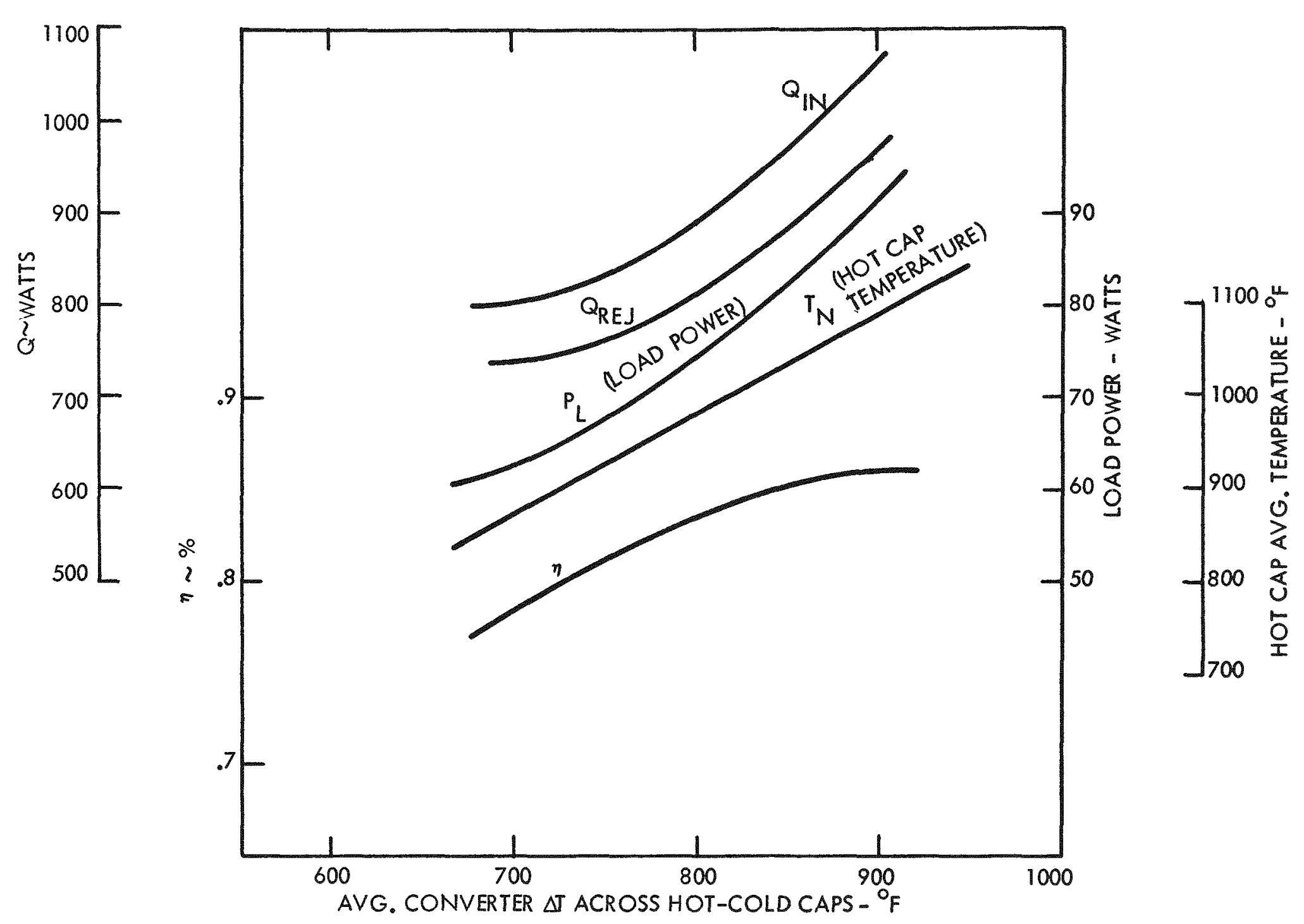

Figure 3-13. 3M PMC-IA Converter Test Performance 


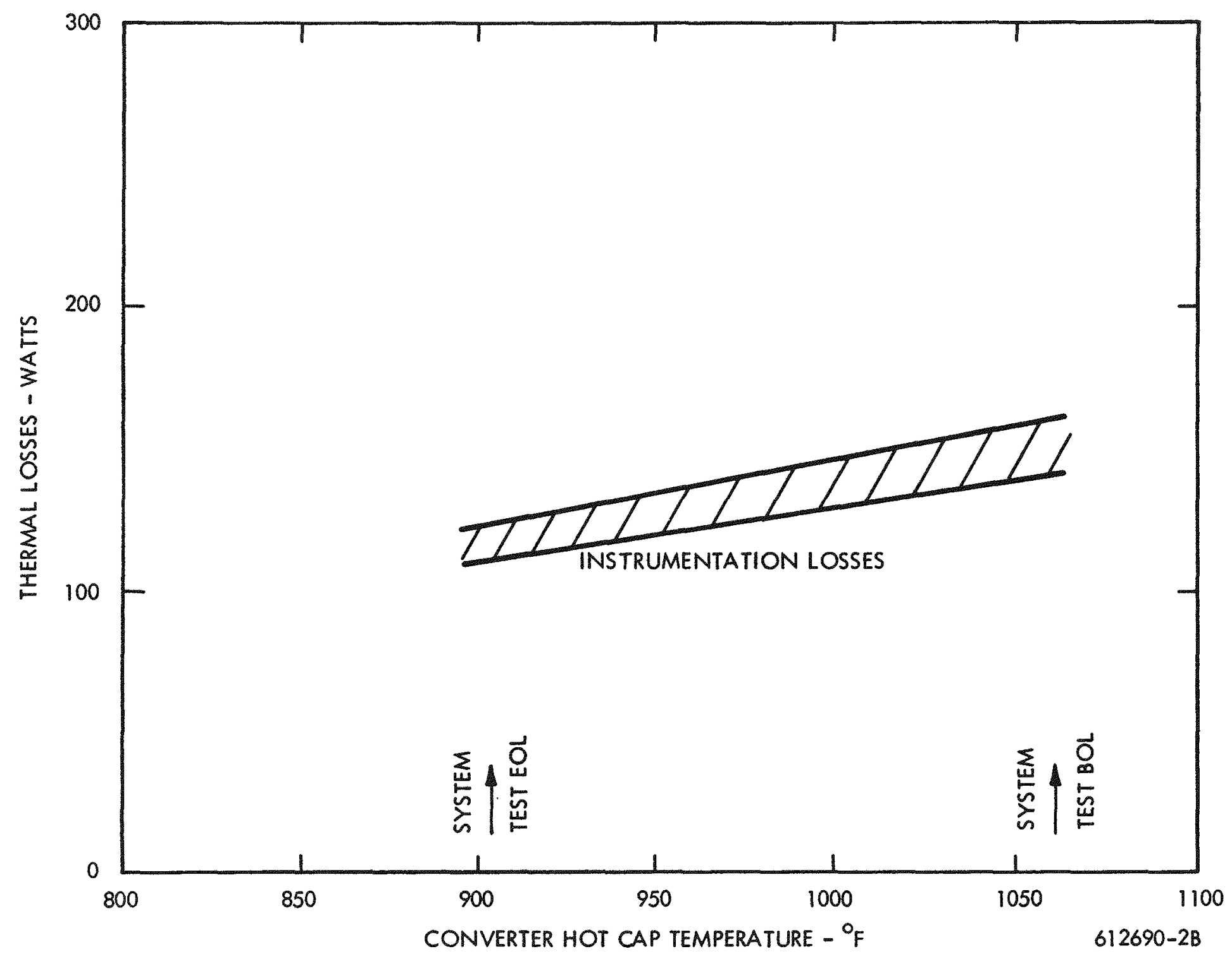

Figure 3-14. Heat Source and Instrumentation Losses 
EMS with a $\mathrm{Kr}-\mathrm{N}_{2}$ backfilled insulation, the electrical output power of the converter is 64.79 watts. The heat to the converter was estimated to be 821 watts for a converter efficiency of 7.89 percent. System instrumentation losses were estimated at 110 watts. The net system input power was 1002 watts, and the heat source efficiency was estimated to be 81.7 percent. The thermal losses from the heat source were calculated to be 181 watts. The thermal loss goal for the system based on component effectiveness of 7.7 percent for the converter and 86 percent for the heat source was calculated as:

$$
Q=\frac{61 \text { watts }}{(0.077)(0.86)}-\frac{(61)}{(0.077)}=129 \text { watts }
$$

This indicates that a reduction of 52 watts in heat source heat losses is required to meet the design goal.

An analysis was performed on this EOL data point to determine the accuracy to which the heat flow and heat loss terms could be predicted from the test measurements and procedure used. The following components were considered as contributions to errors.
1) EMS gross power measurement
$+0.5 \%$
2) Hot cap and cold cap temperature measurement
$\pm 0.25 \%$
3) Calculation of instrumentation and power lead heat
$+10 \%$ losses (Based on estimates of errors in model and insulation conductivity)
$-0 \%$
4) Use of converter component test data for converter input power (Based on measurement error and methods for data
$+1 \%$
$-2.5 \%$ interpretation)

The resultant effect of these errors upon the heat source heat loss prediction was 181 watts \pm 13 percent ( \pm 24 watts).

At BOL conditions where the system thermal input is the required 1.282 times the EOL system thermal input, the gross thermal input was 1439 watts. The net system thermal input was 1299 watts and the converter heat input was 1013 watts. Heat losses from the heat source were predicted to be 286 watts and the heat source efficiency was 78.0 percent. 
The effect of insulation exposed to vacuum and various gaseous environments was evaluated based on the data presented in Table 3-2. Figure 3-15 is a plot of the system thermal input as a function of the converter hot cap average temperature. The lower dashed line represents the predicted performance required for meeting the design goal of 86 percent heat source thermal efficiency. Included in this total are insirumentation losses estimated for this system as shown in Figure 3-14.

Curve $A$ in Figure 3-15 represents four data points taken for the system with a $\mathrm{Kr} / \mathrm{N}_{2}$ filled insulation. Two data points representing the system with an evacuated insulation are shown by Curve B. One of the points fill above the krypton-nitrogen curve. This data point could not be justified theoretically and was not weighted in the analysis of an evacuated system. The single nitrogen data point is plotted and extrapolated to the $\mathrm{BOL}$ temperature level by Curve $D$ plotted locally parallel to the $\mathrm{Kr} / \mathrm{N}_{2}$ backfilled Min-K 2000 performance line. The Krypton filled Min-K 2000 data points are shown to fall in line with the $\mathrm{Kr} / \mathrm{N}_{2}$ data which was explained in WANL 3800-23.

Based on the previous results shown in Figure 3-15 and tabulated in Table 3-5, a preliminary estimate of the system performance at $B O L$ and EOL conditions was made for the various environmental conditions. The comparison is presented in Table 3-6. For this evaluation, system results were obtained for a $1063^{\circ} \mathrm{F}$ hot cap average temperature at $\mathrm{BOL}$ and a $904^{\circ} \mathrm{F}$ hot cap average temperature at EOL. At BOL, gross system heat inputs for each of the environments were obtained from Figure 3-15. Heat flow to the converter, converter power output, and instrumentation losses for each of the environments were the same as the $\mathrm{Kr} / \mathrm{N}_{2}$ environment since the hot cap temperature is the same. Using the calculation procedure established for Table 3-5 the heat flow summary was completed. For $E O L$ conditions the gross power inputs were obtained for each environment by ratioing the difference in gross power inputs between $\mathrm{Kr} / \mathrm{N}_{2}$ and other environments by the power factor 1.282. Results for the $\mathrm{Kr} / \mathrm{N}_{2}$ filled system at EOL as presented in Table 3-5 provided the converter performance data. The remainder of the table was obtained by the calculation procedure. Referring to Table $3-6$, the results of this analysis indicated that backfilling 


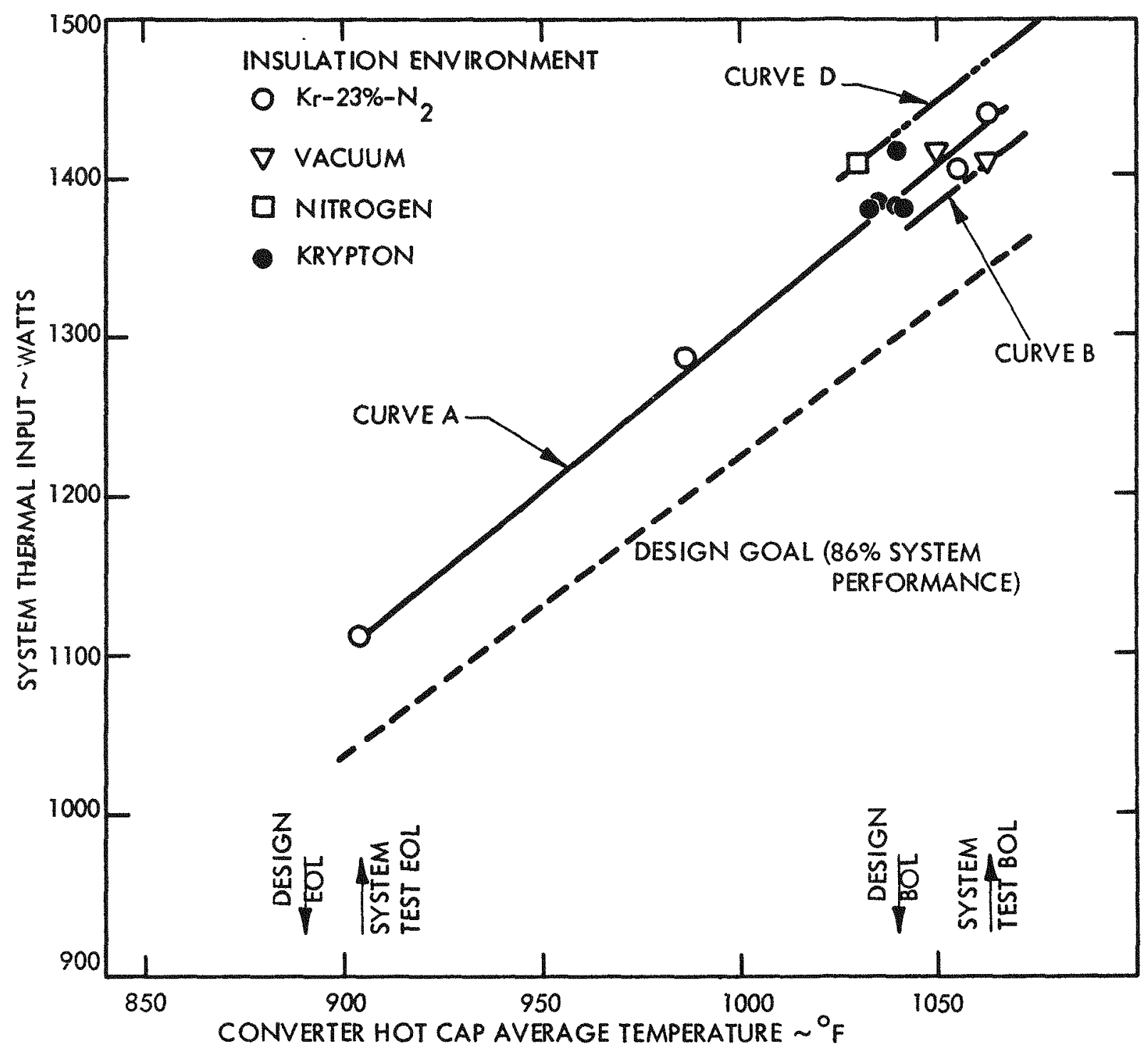

Figure 3-15. EMS/PMC-1A System Thermal Performance Test 
TABLE 3-6

ESTIMATED EMS THERMAL PERFORMANCE

(Environmental Test Results)

\begin{tabular}{|c|c|c|c|c|c|c|c|c|}
\hline \multirow[b]{2}{*}{ Location } & \multicolumn{4}{|c|}{$\mathrm{BOL}$} & \multicolumn{4}{|c|}{ EOL } \\
\hline & $\mathrm{Kr} / \mathrm{N}_{2}$ & Vacuum & $\mathrm{N}_{2}$ & $\mathrm{Kr}$ & $\mathrm{Kr} / \mathrm{N}_{2}$ & Vacuum & $N_{2}$ & $\mathrm{Kr}$ \\
\hline Hot Cap Temperature $\left({ }^{\circ} \mathrm{F}\right)$ & 1063 & 1063 & 1063 & 1063 & 904 & 904 & 904 & 904 \\
\hline $\begin{array}{l}\text { Gross System Input Power } \\
\text { (Watts) }\end{array}$ & 1435 & 1410 & 1475 & 1435 & 1112 & 1093 & 1143 & 1112 \\
\hline $\begin{array}{l}\text { Instrumentation Losses } \\
\text { (Watts) }\end{array}$ & 140 & 140 & 140 & 140 & 110 & 110 & 110 & 110 \\
\hline $\begin{array}{l}\text { Net System Input Power } \\
\text { (Watts) }\end{array}$ & 1295 & 1270 & 1335 & 1295 & 1002 & 983 & 1033 & 1002 \\
\hline $\begin{array}{l}\text { Converter Output } \\
\text { (Watts) }\end{array}$ & 88.3 & 88.3 & 88.3 & 88.3 & 64.8 & 64.8 & 64.8 & 64.8 \\
\hline $\begin{array}{l}\text { Heat Flow to Converter } \\
\text { (Correction to } 3 \mathrm{M} \text { Performance) }\end{array}$ & $\begin{array}{l}1010 \\
(+5)\end{array}$ & $\begin{array}{l}1010 \\
(+5)\end{array}$ & $\begin{array}{l}1010 \\
(+5)\end{array}$ & $\begin{array}{l}1010 \\
(+5)\end{array}$ & $\begin{array}{l}818 \\
(+3)\end{array}$ & $\begin{array}{l}818 \\
(+3)\end{array}$ & $\begin{array}{l}818 \\
(+3)\end{array}$ & $\begin{array}{c}818 \\
(+3)\end{array}$ \\
\hline Heat Source Thermal Efficiency & 78.0 & 79.5 & 75.7 & 78.0 & 81.6 & 83.2 & 79.2 & 81.6 \\
\hline System Losses & 280 & 255 & 320 & 280 & 181 & 162 & 212 & 181 \\
\hline System Loss Goal & $\leftarrow$ & -165 & 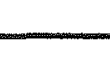 & & & -129 & & \\
\hline
\end{tabular}


the insulation system with krypton resulted in approximately a 40 watt reduction in heat source losses at BOL and 31 watts at EOL in system losses as compared to a nitrogen-filled system (equivalent to dry air). An additional savings of 25 watts BOL and 19 watts EOL is obtained by evacuating the system. The approximate estimate of an additional reduction in heat source heat losses to meet the 86 percent thermal efficiency goal is 52 watts at EOL.

Based on the heat source heat losses calculated from test data and the distribution of heat losses predicted by T $\varnothing S S$ calculations for the system prediction, estimates were made of the breakdown of heat losses for the BOL and EOL conditions. Figures 3-16 and 3-17 present the heat flow distributions for systems with a nitrogen-filled base assembly and a krypton filled base assembly, respectively. The heat loss terms affected by the change in environments are obviously the heat losses to the bottom and side of the base assembly. The krypton filled system at EOL reduces side heat loss by 21 watts and bottom heat losses by 10 watts. At BOL the krypton-filled system at EOL reduces side heat loss by 21 watts and bottom heat losses by 10 watts. At BOL the krypton-filled system at EOL reduces side and bottom losses by 28 watts and 12 watts, respectively.

\section{Thermal Data During Mechanical Test}

Shock and vibration testing of the experimental mockup system was completed during the latter part of the reporting period. A summary of the thermal test points is presented in Tables 3-3 and 3-4. Table 3-3 presents the thermal data points taken during the lateral shock and vibration tests. Table 3-4 presents the thermal data points taken during the vertical shock and vibration tests. Fairly good thermal stability was indicated during the lateral shock and vibration tests until an apparent helium leak in the heater area developed. At this point all recorded temperatures from the converfer hot cap through the sfud to the heat source dropped approximately $30^{\circ} \mathrm{F}$. A breakdown of the heat flow indicated approximately a 30 watt initial increase in heat losses. Initial estimate of the helium leak rate was approximately $2.5 \mathrm{std} \mathrm{ft}^{3}$ /hour. For this rate approximately 12 watts could be removed by the helium. Another source for the increase in heat losses is the possible leakage of helium into the non-sealed insulation under the rain shield resulting in an increase of the effective thermal 
TABLE 3-6A

COMPARISON OF DESIGN VALUES WITH ESTIMATED

LOSSES FROM EMS MEASUREMENTS

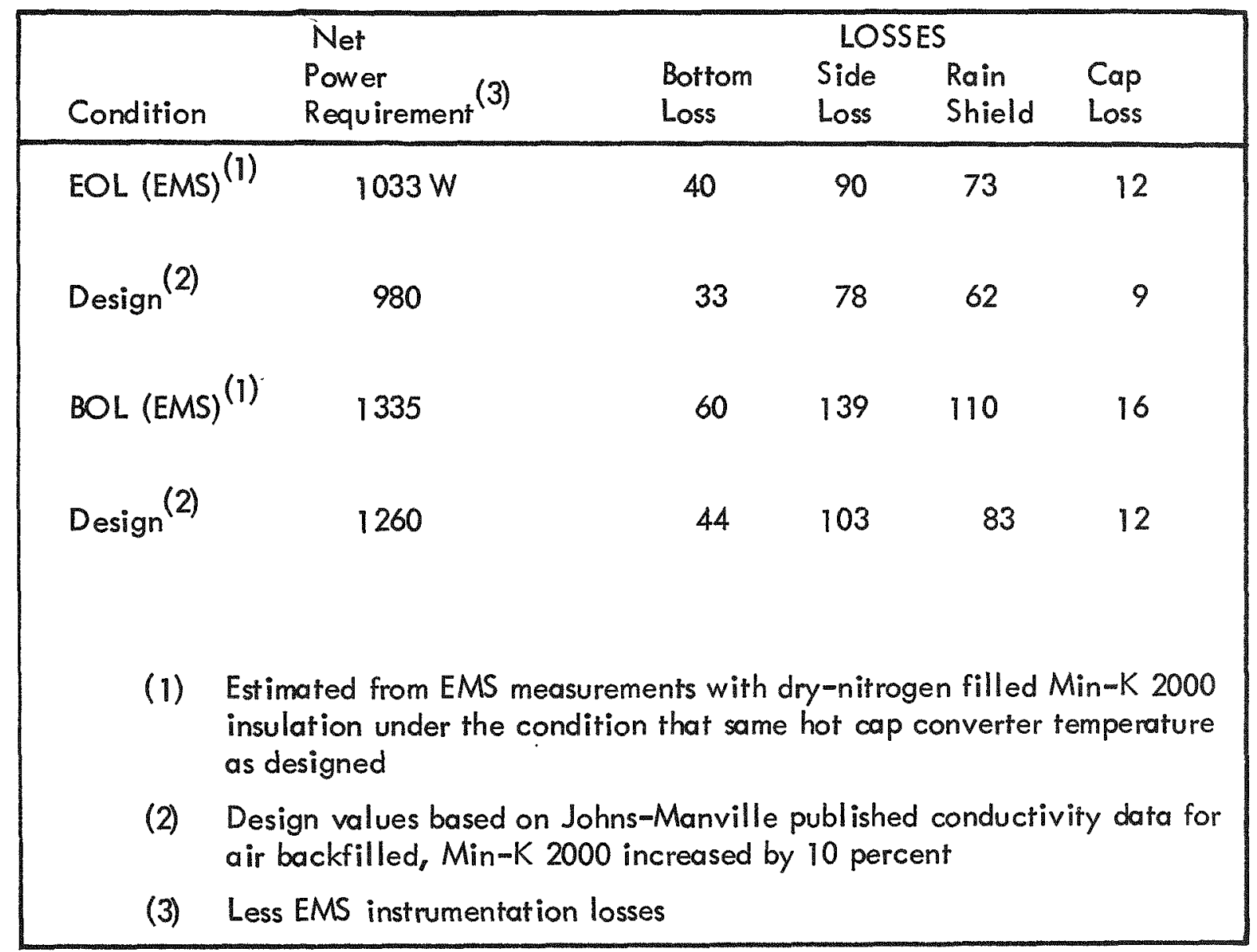


$12 W(16 W)$

Q Astronuclear

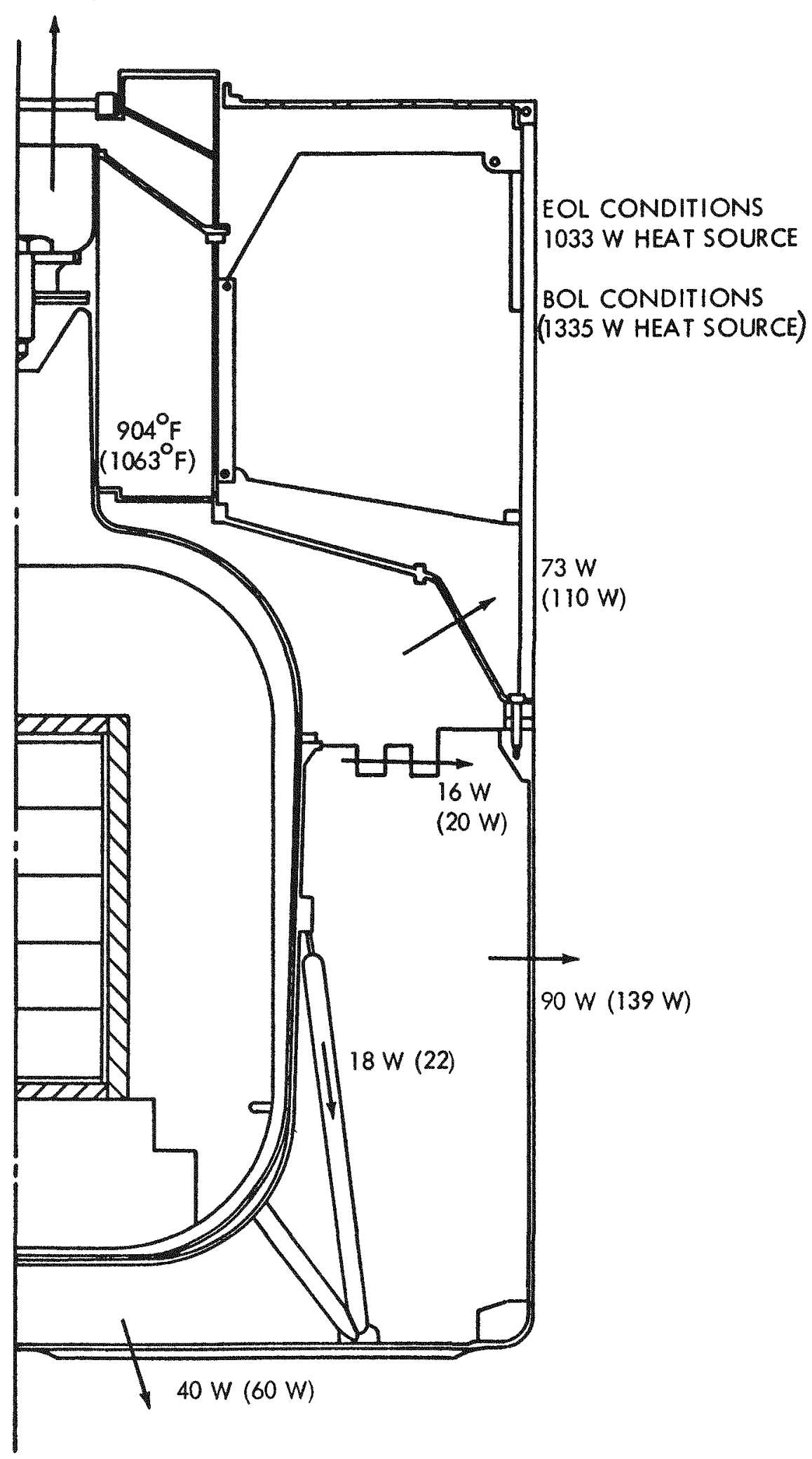

Figure 3-16. Heat Loss Distributions Nitrogen Filled Base Assembly 
(W) Astronuclear

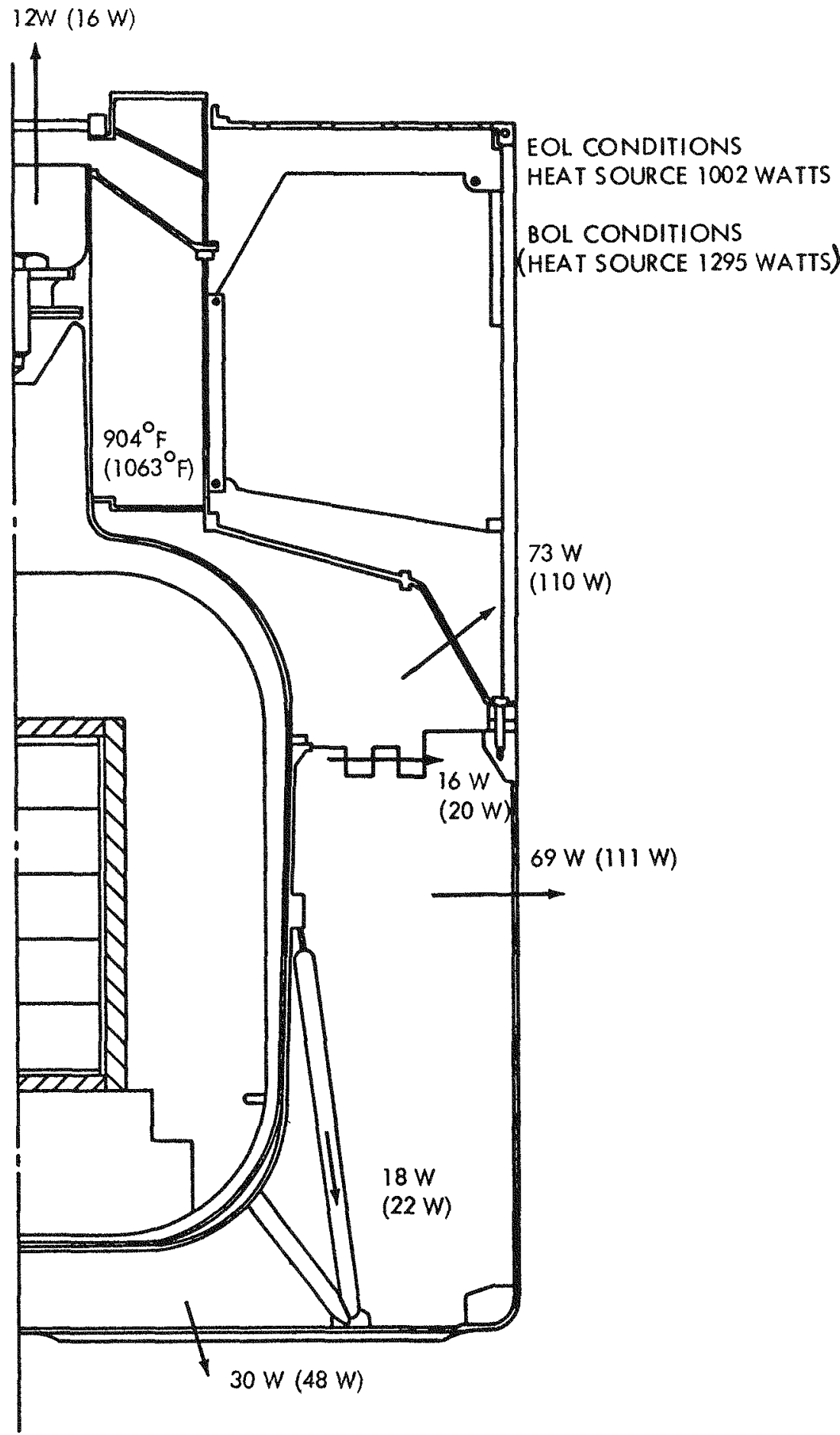

Figure 3-17. Heat Loss Distributions Krypton Filled Base Assembly 
conductivity of the insulation. Because of the limited amount of data for helium-filled Min-K plus the lack of knowledge of the amount of helium in the rain shield insulation, the effective conductivity change is not readily evaluated. Calculated data presented for heliumfilled Min-K presented in a Johns-Manville Quarterly Report (ALO-3633-1) for a $1100^{\circ} \mathrm{F}$ mean temperature indicated a factor of 3 increase in Min-K thermal conductivity for heliumfilled Min-K over air-filled Min-K. This magnitude indicates that the increase in heat source heat losses could readily be attributed to partial helium leakage in the rain shield insulation.

After a $30^{\circ} \mathrm{F}$ drop in the converter hot cap, accumulator, shield, and heater temperatures in the first 16 hours after the leak developed, an additional $10^{\circ} \mathrm{F}$ drop was observed in the same temperatures over the next 140 hours until completion of the vertical shock and vibration test. There was an increase in heat loss from nominal 30 watts to 40 watts. Part of this drop was attributed to a slight drop in ambient conditions. Although no significant effects were observed during the test of the shock and vibration on converter and system performance outside of the helium leak, thermal analyses were performed to look for any other effects in the performance of the system components and interface between the components; none were observed。

Three interfaces that were potential problem areas were instrumented to provide an indication of their thermal resistances and thus their effect on performance. These include the copper stud to converter interface, converter to radiator interface and the accumulator to biological shield interface. Based on data presented in Table 3-2, Figure 3-18 is a plot of the interface drops from the stud to the converter and from the converter to the radiator. Although there is scatter in the data, mean interface temperature drops for these two interfaces were readily determined for the $900-1060^{\circ} \mathrm{F}$ hot cap temperature range. Over this range a mean temperature drop of $70^{\circ} \mathrm{F}$ was observed for the stud-converter interface. For the converter-radiator interface a mean temperature drop of $6^{\circ} \mathrm{F}$ was observed. Because of the lack of data from key thermocouples the interface temperature drop was not determined for the accumulator to biological shield. Comparison of calculated results (T $\varnothing S S$ ) to test results 
(2) Astronuclear

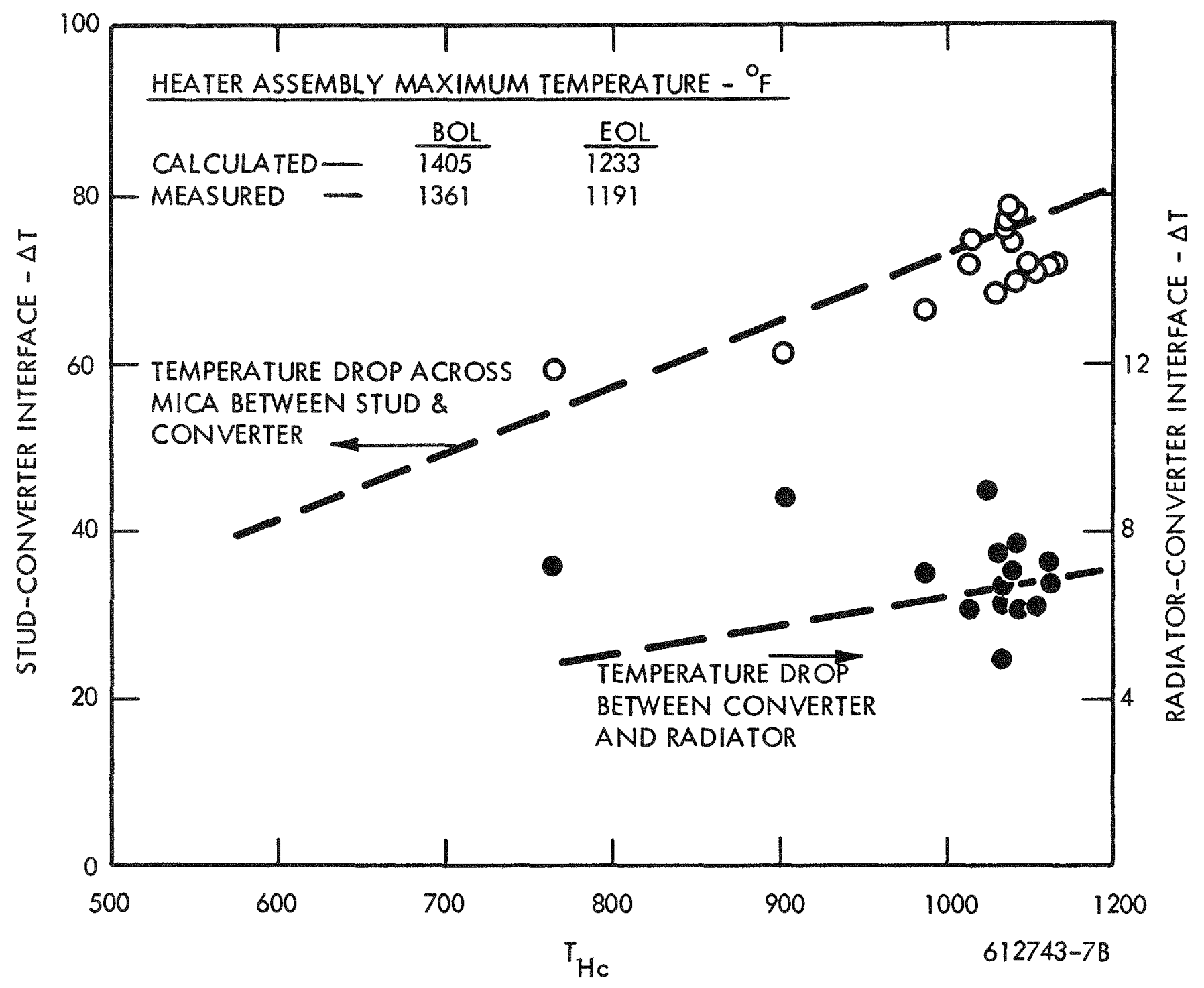

Figure 3-18. Effect of Interfaces on SNAP-23A System Thermal Performance 
for hot cap temperatures of $904^{\circ} \mathrm{F}$ and $1063^{\circ} \mathrm{F}$ (representing EOL and BOL conditions, respectively), however, indicated that the peak heat source temperatures, as measured, were lower than the calculated temperatures at both EOL and $\mathrm{BOL}$ conditions $\left(1405^{\circ} \mathrm{F}\right.$ calculated versus 1361 measured at $\mathrm{BOL} ; 1233^{\circ} \mathrm{F}$ calculated versus $1191^{\circ} \mathrm{F}$ measured at EOL). At present there is not a complete match of heat flow terms and system temperatures since the calculated results ( $T \varnothing S S$ ) have not been updated to include the PMC-1A converter performance and since the interface conditions for the stud to converter and converter to radiator are not matched with test results. The difference in peak heat source temperatures, therefore, are not entirely attributed to the accumulator-shield interface.

\section{Experimental Determination of Thermal Properties of the Insulation Materials - Spherical Insulation Tests}

The spherical insulation tests were performed (Subtask 410) and analyzed during this reporting period. These tests consist of two series of measurements, the first series being made with Min-K 2000 material in different atmospheres, e.go, air, argon, nitrogen, and under vacuum, and the second series of experiments, with Min-K 2002 in air and argon atmospheres and under vacuum. Further experiments with krypton will be performed. All data have been analyzed, and are reported in terms of the thermal conductivity as a function of temperature.

To evaluate the temperature effect and the effect of material orientation with respect to heat flow, the method of analysis was modified from what was reported in the previous quarterly progress report, WANL-3800-21 (p. 3-29)。 Local thermal conductivities were calculated from:

$$
q=k(4 \pi) \frac{t_{1}-t_{2}}{\left(\frac{1}{r_{1}}-\frac{1}{r_{2}}\right)}
$$

where $k$ = thermal conductivity

$r_{1}, r_{2}=$ radii within the spherical body

${ }^{t} p^{\prime} t_{2}=$ temperatures at radial locations $r_{1}$ and $r_{2}$, respectively

$q=$ heat flow rate, Btu/time (assumed uniform in all radial directions) 
Using the measured four temperatures in each radial direction, the temperature profile was correlated in terms of $t v s$. $\left(\frac{l}{r}\right)$. The thermal conductivity, $k_{1}$ of the material between $r_{1}$ and $r_{2}$ can be readily calculated from the slope of the profile.

Thermocouple measurements are obtained in locations as shown in Figure 3-19. Because of the layer construction of the insulation material, the heat flow from the heater surface (inner sphere) to the outer cooling surface is through different angles with respect to the direction of pressing. Thus, the temperature profiles in the directions $1-2-3-4$, 5-6-7-8 and 9-10-11-12 are all different. In the analysis, profiles 1-2-3-4 and 9-10-11-12 are taken as representative profiles in the direction parallel to, and perpendicular to, that of pressing, respectively. Thermal conductivity values determined in these two directions are shown in the attached figures by different symbols.

\section{Min-K 2000 Properties}

Values of thermal conductivity for Min-K 2000 under various atmosphere conditions are shown in Figures 3-20,3-21,3-22 and 3-23. Figure 3-20 represents data obtained with air-filled insulation. Two series of measurements were taken, one at the initial heatup as assembled (data were taken in the period of first 24 days) and the second taken after several evacuations and refillings with dry gases (4 months after initial heatup). Twocorrelations are shown with the curve representing the data from the second series being about 10 to 14 percent lower than that of the first series. This suggests that moisture content in the air after several evacuations and refillings has been minimized; and the results of the second series also approximate closely with the dry nitrogen-filled condition (Figure 3-22). It should be noted, however, that these results are still somewhat higher than experimental results of Dynatech (WANL-3800-16) and published data of Johns-Manville (ALO$3633-1,1966)$.

Figure 3-21 shows the thermal conductivity data of Min-K 2000 under an evacuated condition. This figure represents data obtained at three different times after each refill. The results obtained by Dynatech were again shown in the figure by the dotted line (WANL3800-16). A slightly higher conductivity is also indicated, as before, while the functional relationship with temperature is very similar. Similar results with nitrogen and argon are 


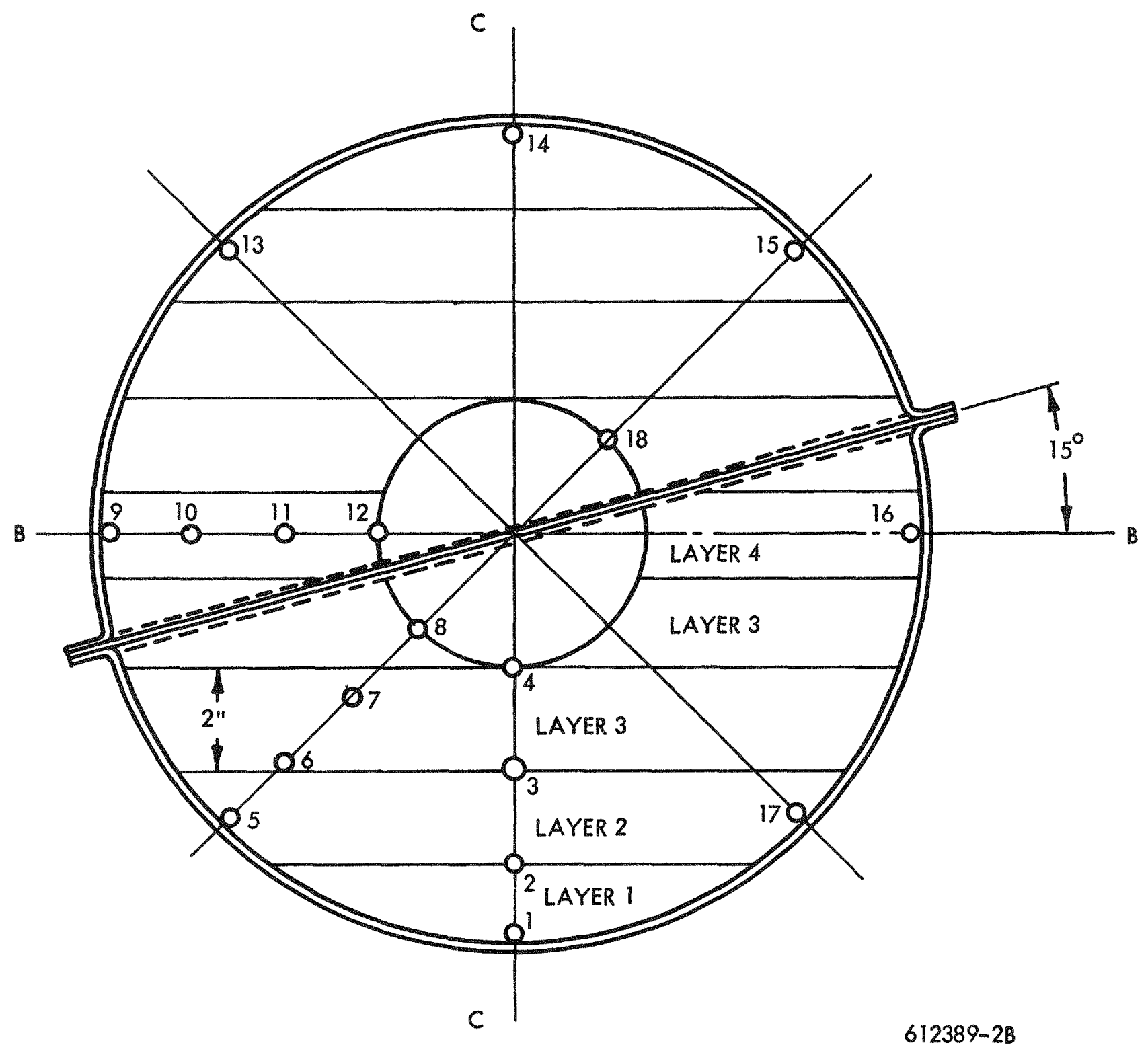

Figure 3-19. Section of Polar Plane in Sphere, Showing Thermocouple Locations of Min-K 2000 Material 


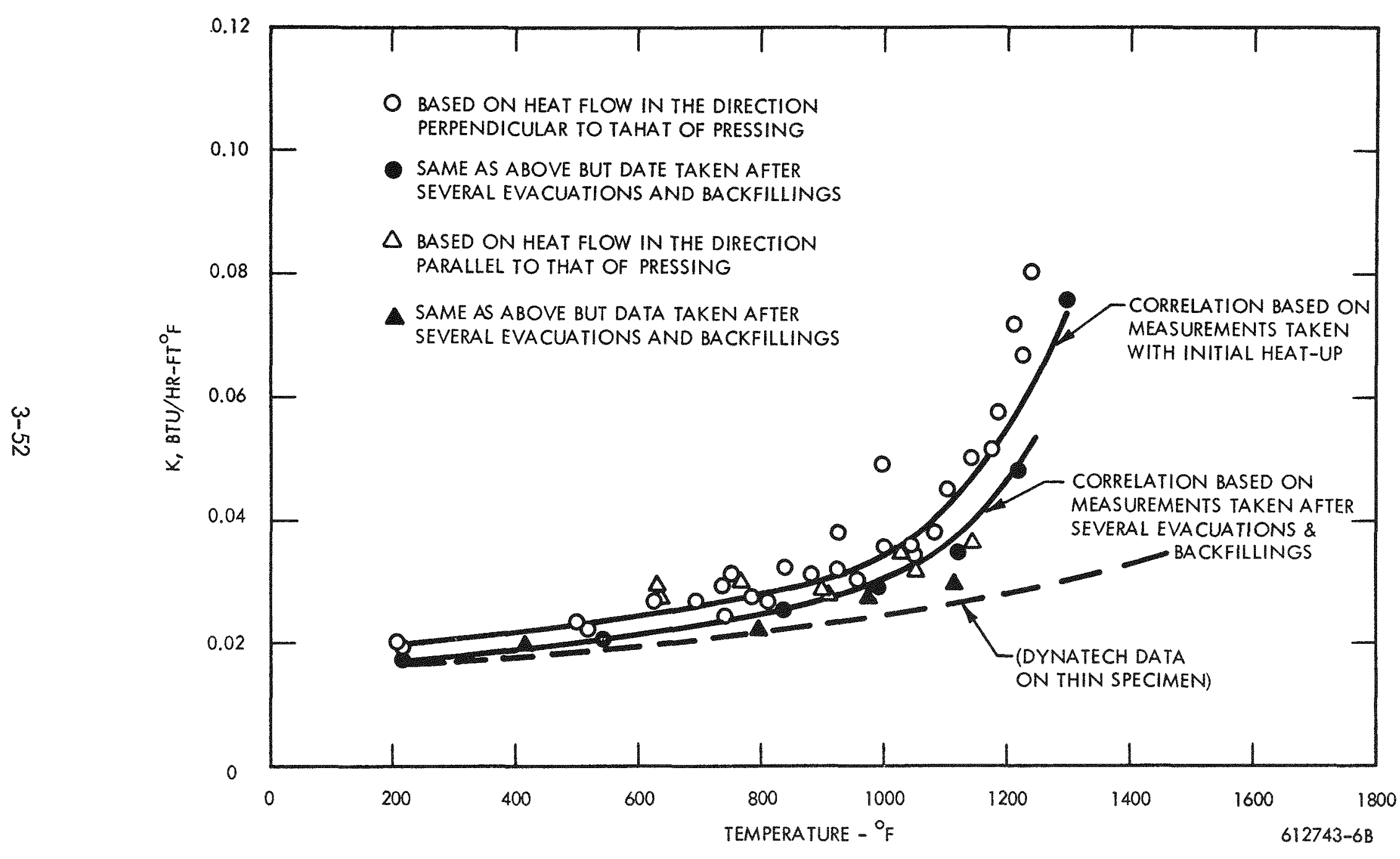

Figure 3-20. Thermal Conductivity of Min-K 2000 Filled with Air (As Assembled) 


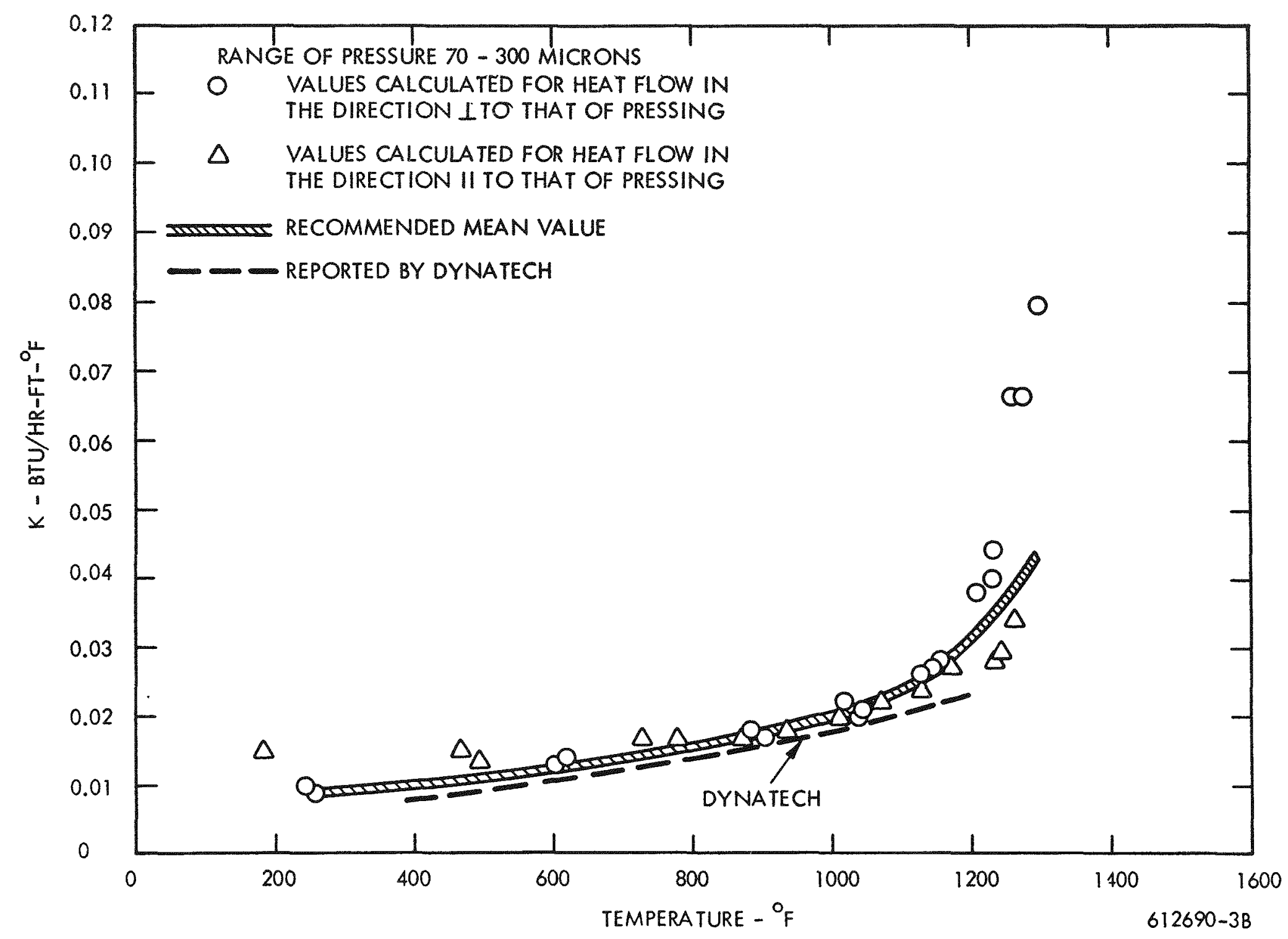

Figure 3-21. Thermal Conductivity of Min-K 2000 Under Evacuated Condition 


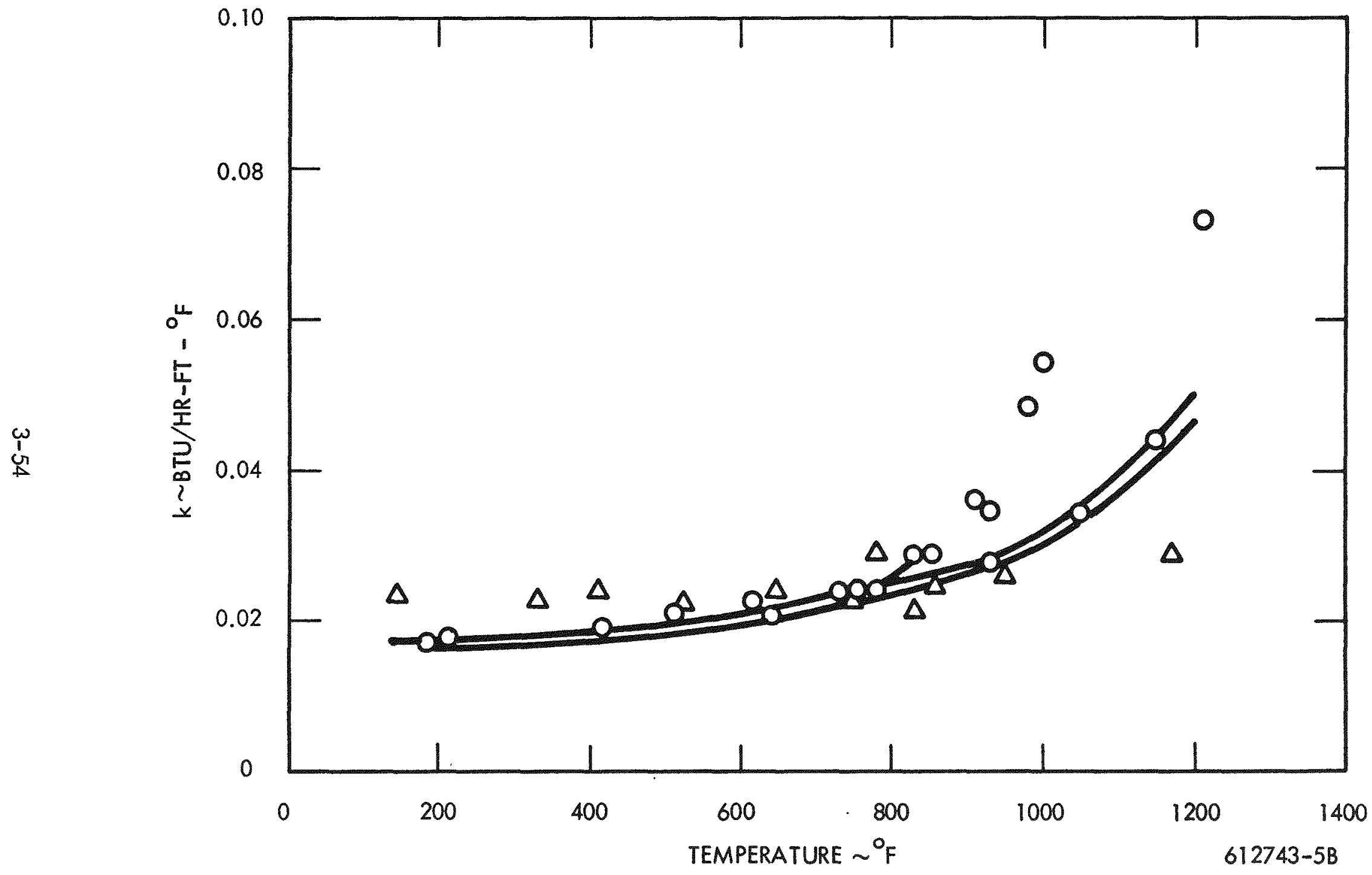

(15)

흠용

Figure 3-22. Thermal Conductivity of Min-K 2000 Filled with Nitrogen (2 Atmosphere) 


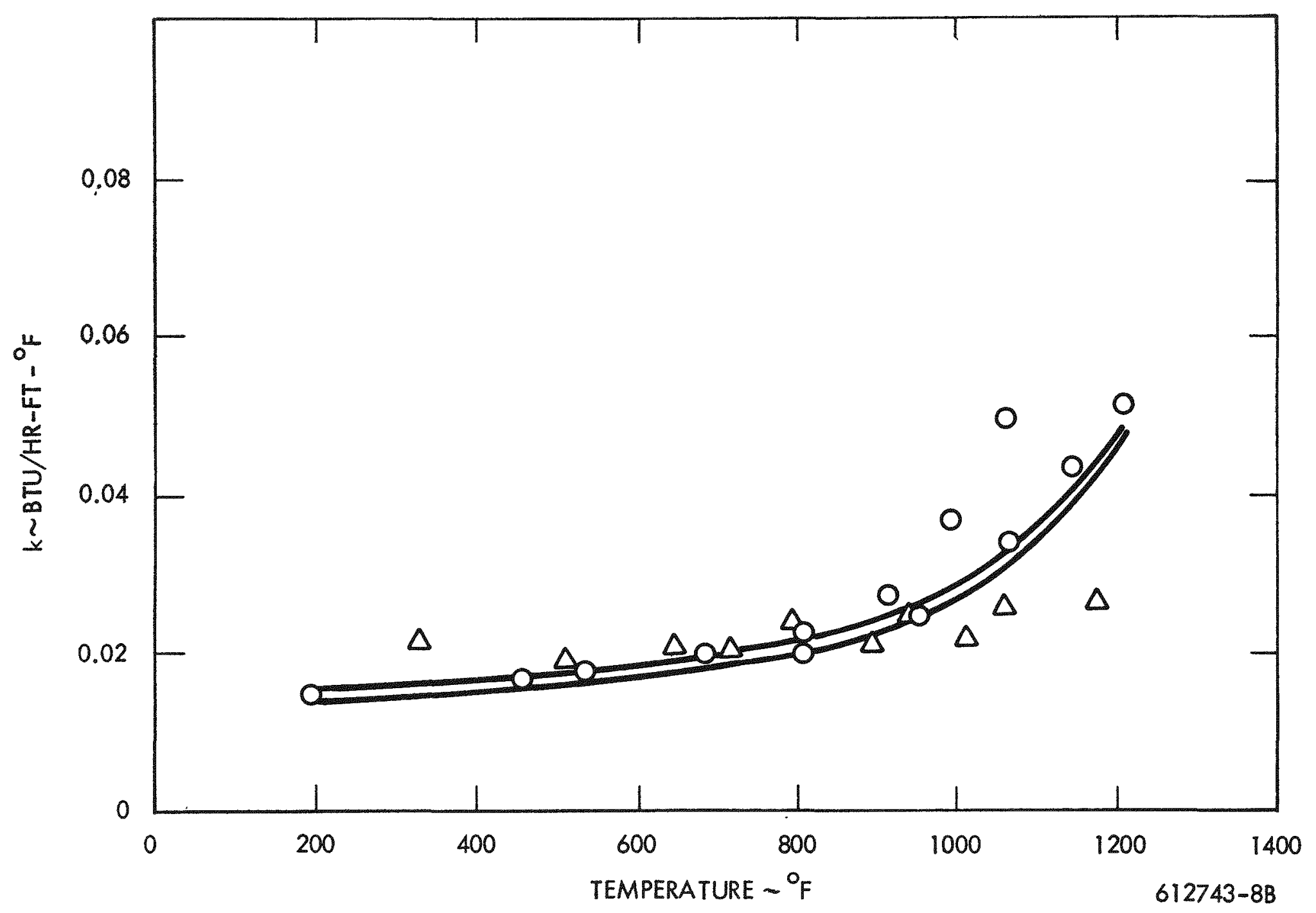

Figure 3-23. Thermal Conductivity of Min-K 2000 Filled with Argon (1 Atmosphere) 
shown in Figures 3-22 and 3-23. These results are summarized in Figure 3-24 for comparison. The conductivities of Min-K 2000 under various conditions are found to be in the following order: air (highest conductivity), nitrogen, argon, and vacuum (lowest).

As mentioned previously, different symbols used in the figures indicate the difference in properties due to the direction of heat flow with respect to direction of pressing during fabrication. As shown in most figures at temperatures above $1000^{\circ} \mathrm{F}$ the thermal conductivity values in the direction perpendicular to that of pressing, $k(1)$, become higher than that in the direction parallel to that of pressing, $k(I I)$. A maximum ratio of $k(1)$ to $k(11)$ of 1.3 to 1.5 was found at high temperature locations. On the other hand, the opposite is shown at low temperatures which represent measurements at outer radii. This is believed to be incorrect and resulted from the effect of conduction through the container surface which influences the temperature reading at the outer radius. No quantitative evaluation of the orientation effect on the thermal conductivities can be made based on these spherical tests. This is because the arrangement of material in the sphere exhibits a complex orientation configuration, not amenable to simple analysis. It is anticipated that molded forms of this insulation material may be desirable from cost reduction viewpoints; additional experiments would be required to evaluate its properties.

From Figure 3-24 the relative value between Min-K 2000 as assembled in air and the same insulation in an evacuated system can be obtained. To illustrate this effect upon the thermal conductivity of the insulation, the ratio of $(k)_{\text {air }}$ to $(k)_{\text {vac }}$ is shown in Figure 3-25 at various temperatures. Ratios as high as 2.1 were observed at low temperatures $\left(\Delta t=400^{\circ} \mathrm{F}\right)$ with decreasing ratios calculated at higher temperature levels. This is expected as at high temperatures the radiation effect becomes more important than the contribution due to gas conduction. Also shown in the figure are the dotted lines representing ratios of $(k)_{\text {dry air }}$ to $(k)_{\text {vac }}$ and results of measurements with the thin-layer techniques by Dynatech and Johns-Manville, including one set of data recently reported by Johns-Manville for Min-K 2002. It is shown that results from the spherical insulation tests agree with the thinlayer specimen tests on the effect of air in the insulation. If a linear relationship is assumed with in the temperature range, a ratio $(k)_{\text {air }} /(k)_{\text {vac }}$ of 1.8 to 2.0 can be used for the temperature conditions encountered in the SNAP-23A base assembly. It is interesting to show that 


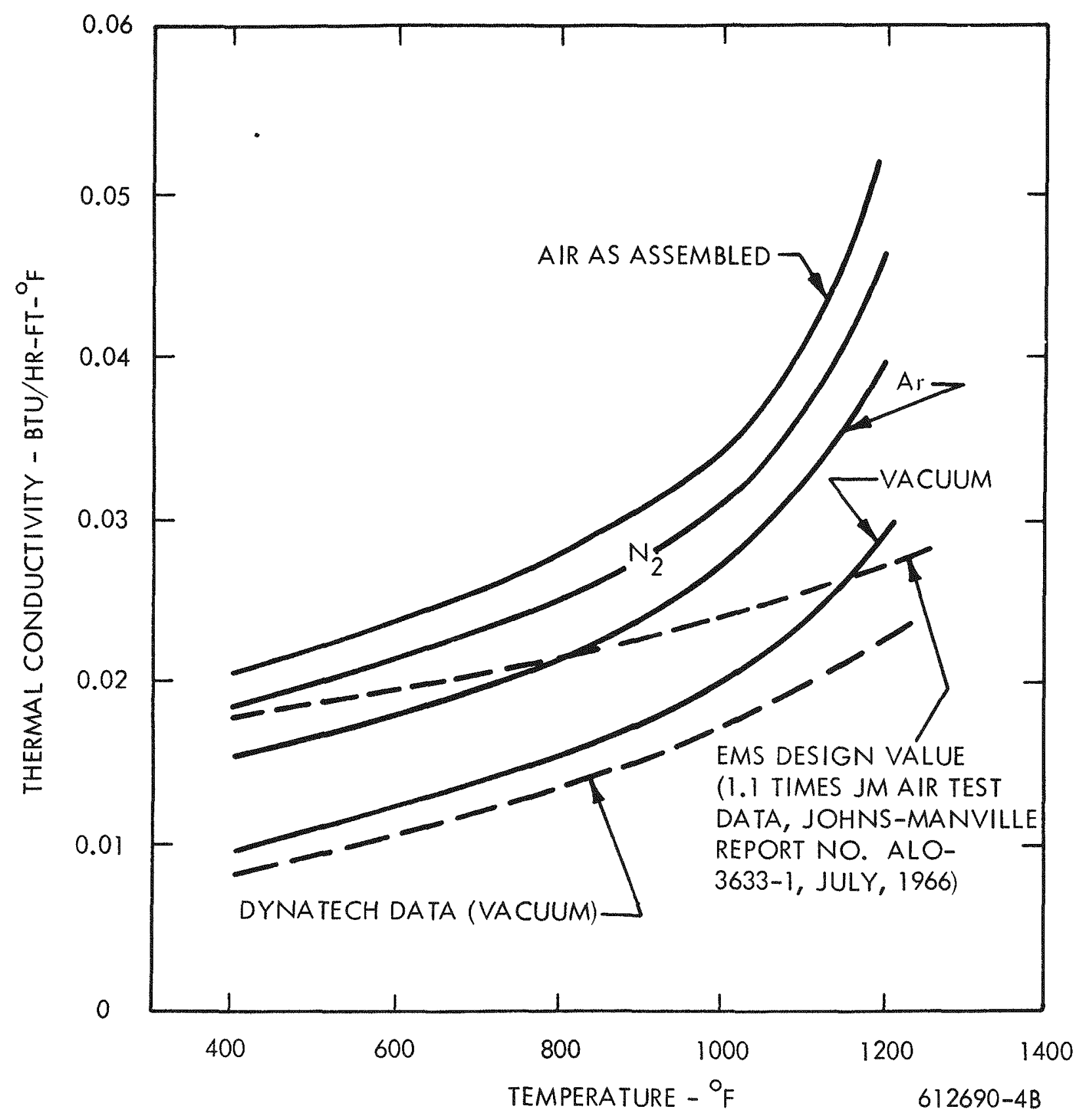

Figure 3-24. Results of Spherical Insulation Tests with Min-K 2000 


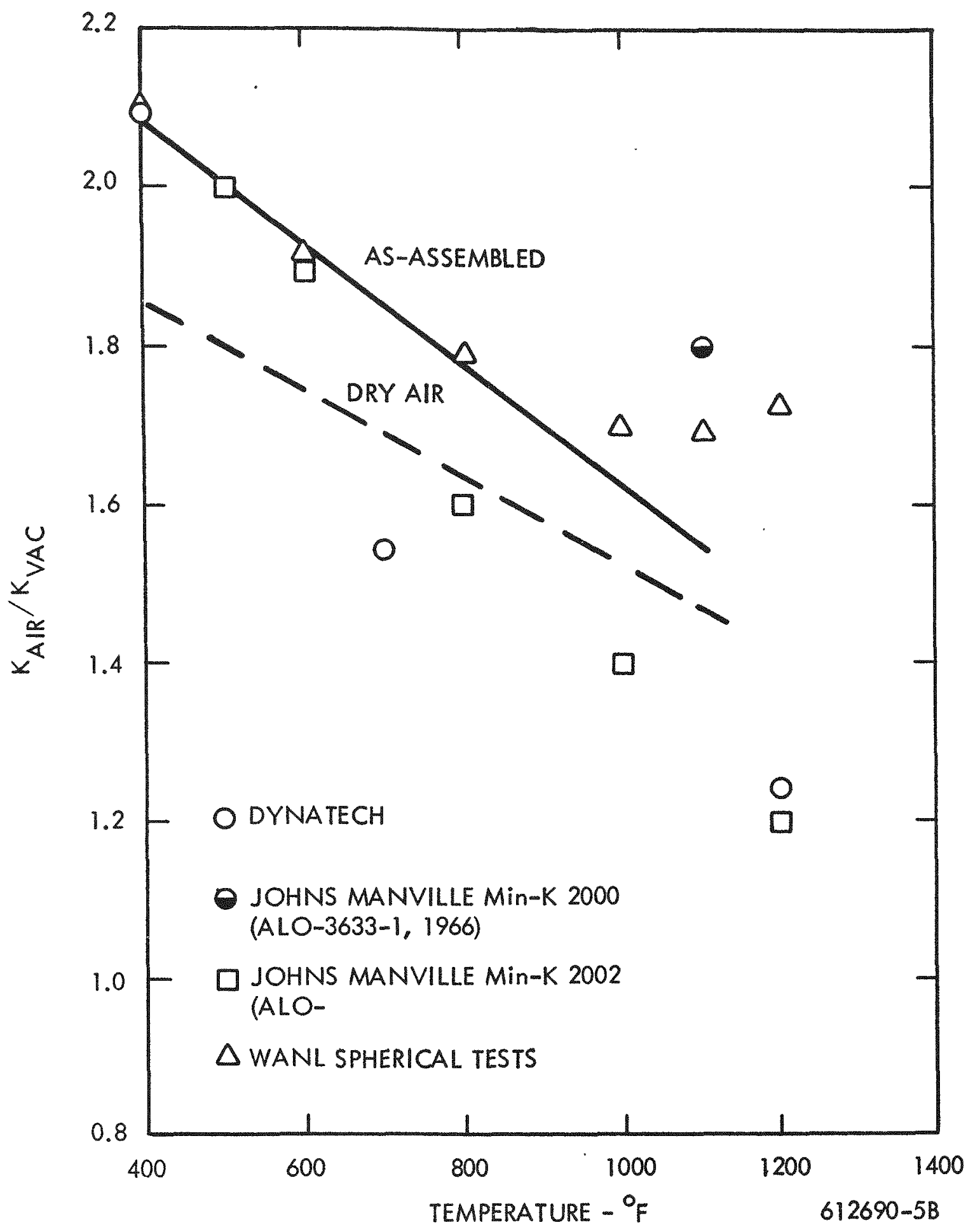

Figure 3-25. Comparison of Thermal Conductivities for Min-K 2000 Filled with Air and Under Vacuum 
based on this ratio and the fact that about 49 percent of the surface losses in EMS is due to base assembly insulation loss, then the difference between dry nitrogen backfilled and evacuated EMS base assembly data would be 55 watts which agrees with the actual measured value of $50-65$ watts.

\section{Min-K 2002 Properties}

Additional spherical insulation tests on Min-K 2002 material were made with airfilled, argon-filled and vacuum conditions. The apparatus was similar to that for Min-K 2000 except the radial locations of thermocouples 2, 3, 6, 7, 10, and 11 were moved closer to the heating surface for better evaluation of temperature profiles. The results are analyzed and shown in Figures $3-26,3-27$ and $3-28$. Figure $3-26$ shows thermal conductivities of Min-K 2002 under evacuated conditions and are compared with similar data for Min-K 2000, in the pressure range of 70 to 300 microns. Contrary to the reported data from Johns-Manville, the comparison indicates no distinguishable difference between these two materials. It was noticed that with Min-K 2002, non-uniform temperature existed at the outer surface and an inspection of the insulation inside the sphere will be made after the experiments with the nitrogen atmosphere. The fact that Min-K 2002 material is castable, however, still makes this material more advantageous than Min-K 2000. Figure 3-27 represents thermal conductivity data of Min-K 2002 filled with argon and Figure 3-28 represents that of Min-K 2002 filled with air as assembled. These figures show similar comparisons with Min-K 2000. Further tests will be with nitrogen and krypton backfilling.

\section{Projected Improvements in Heat Losses for PMS}

As a result of the EMS testing and based on previous parametric analyses, certain improvements in the system design have been proposed for the prototype mockup system. These improvements are intended to reduce heat source and system losses for meeting the design goals. For an electrical power output from the converter of 61 watts, a converter efficiency of 7.7 percent and a heat source efficiency of 86 percent, the heat loss goal for PMS is 129 watts. The EMS test results for a system with a krypton filled base assembly insulation indicated a heat loss of 181 watts at EOL conditions. Assuming a one watt 


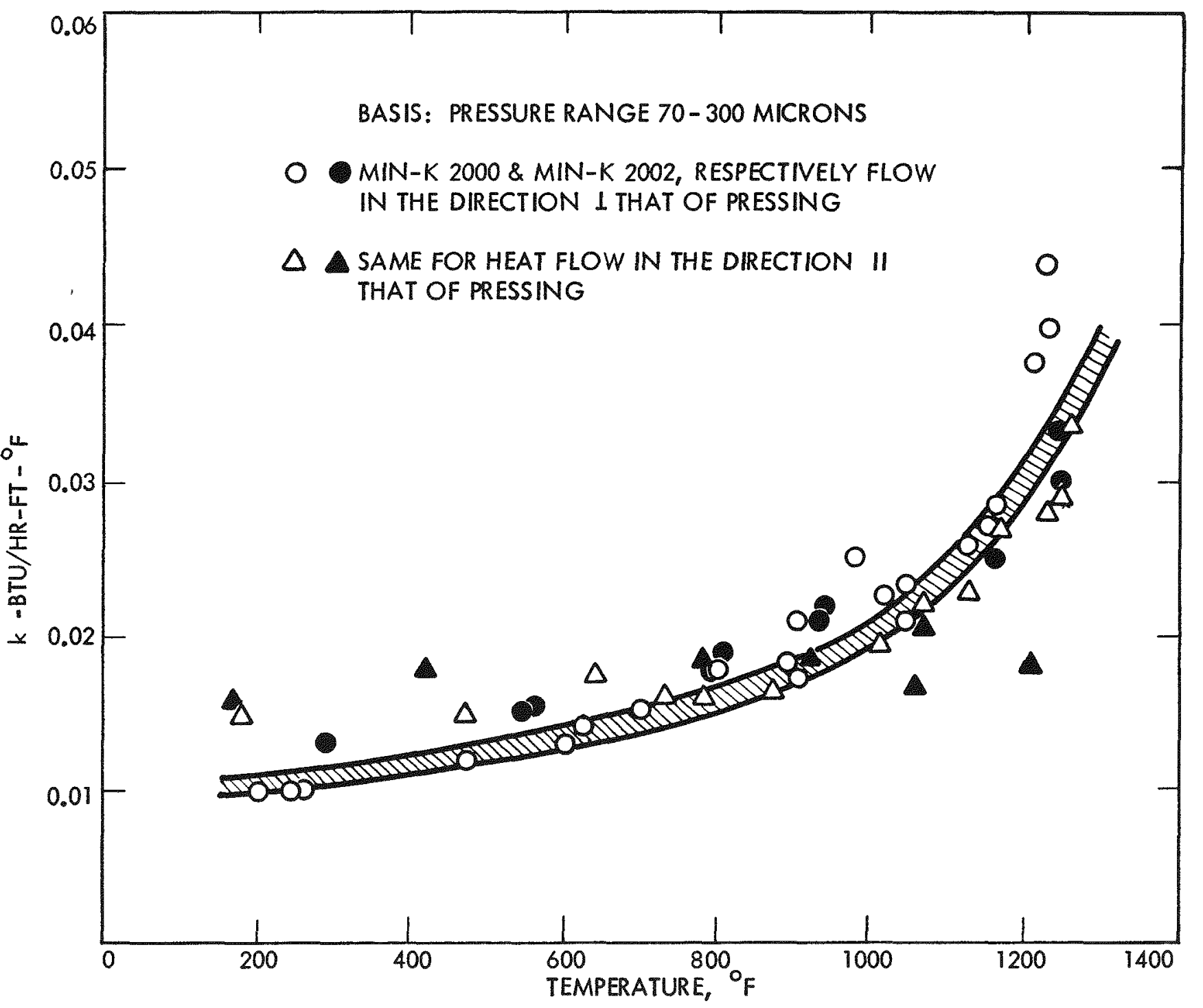

(15)

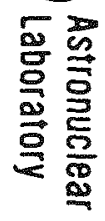

Figure 3-26. Comparison of Thermal Conductivity Data Min-K 2000 vs Min-K 2002 Under Evacuated Conditions 


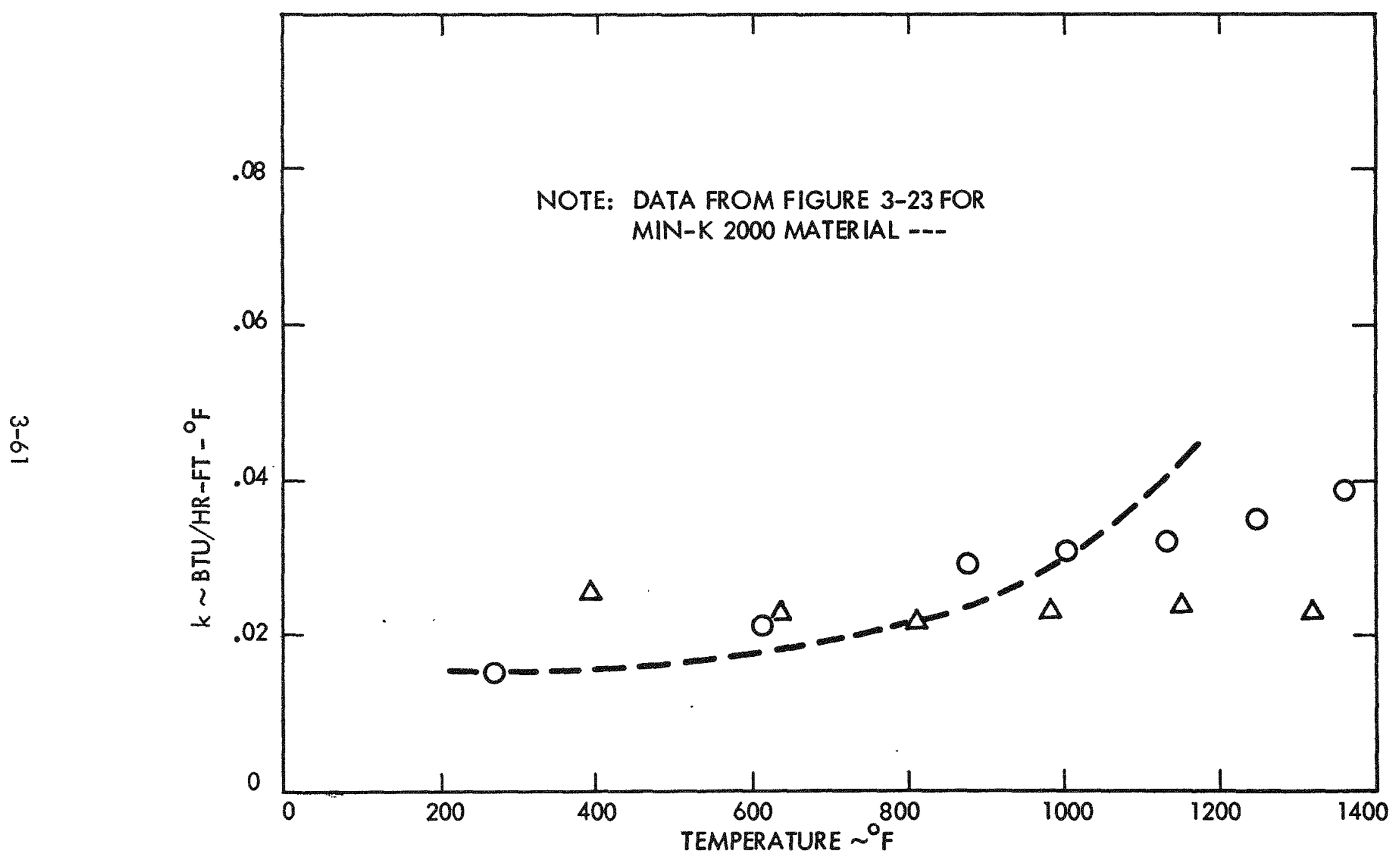

Figure 3-27. Thermal Conductivity of Min-K 2002 Filled with Argon (1 Atm) 


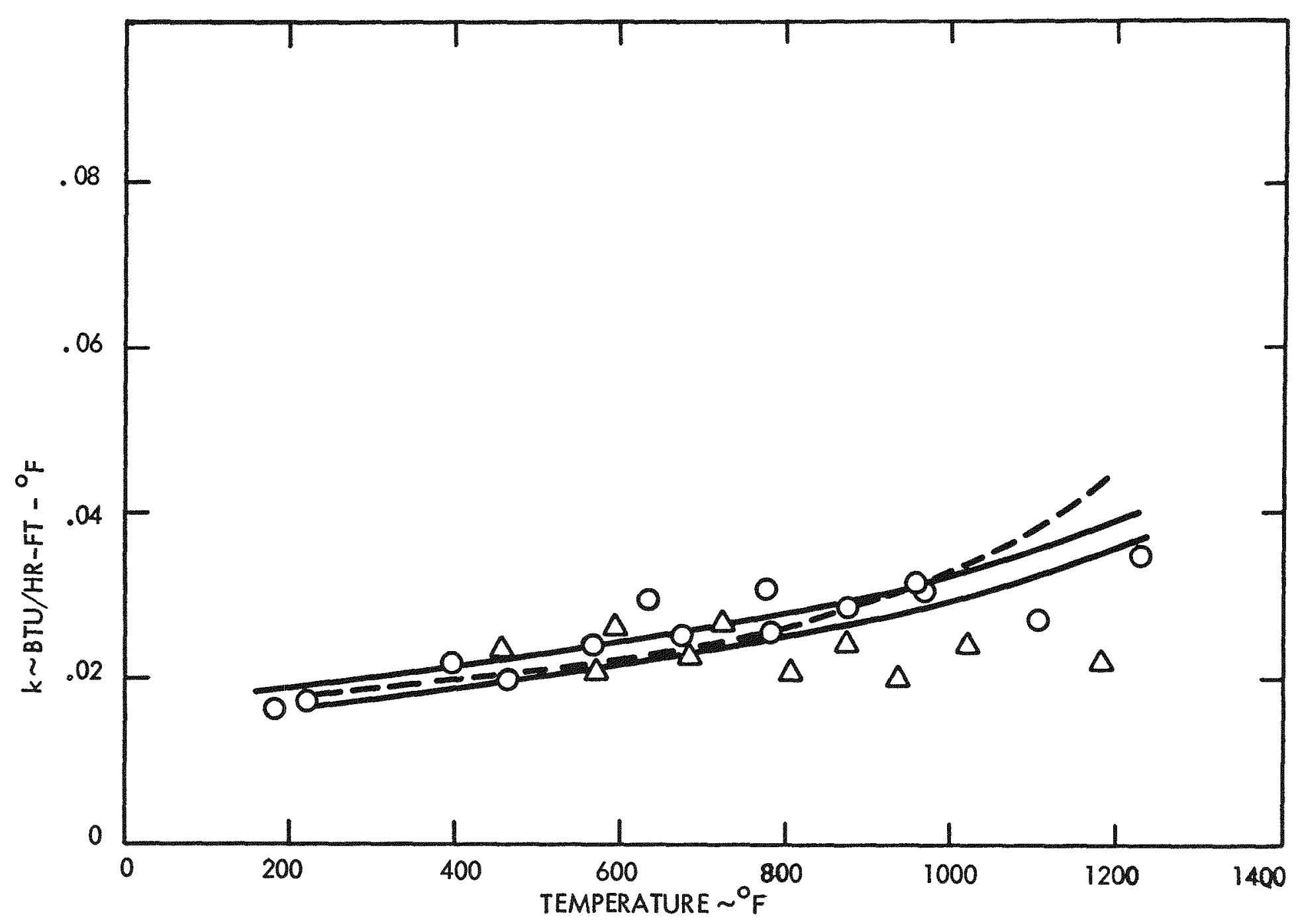

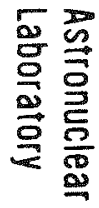

Figure 3-28. Thermal Conductivity of Min-K 2002 Filled with Air (As Assembled) 
correction for base assembly instrumentation losses, the corrected EMS heat losses were 180 watts. An error analysis indicated that the heat losses predicted from the EMS tests could be in error as much as \pm 24 watts. The current deficit in EMS performance therefore was estimated to be between 27 and 75 watts.

Three changes were recommended for the PMS design to reduce the PMS heat losses. Based on the parametric analyses presented in the previous reporting periods and on the EMS test results, these changes listed below would result in the accompanying reductions in heat losses:
1) Increased neck insulation thickness ( 2 inches) - 31 watts
2) Increased bottom insulation thickness ( 1.5 inches) - 13 watts
3) Change from Min-K 2000 to Min-K 2002 - 5 watts

A total saving in heat losses of 49 watts from these changes was projected. The 5 watt reduction for changing to Min-K 2002, however, was based on thermal conductivity data published by Johns-Manville. Recent data from the spherical insulation tests do not indicate any distinguishable differences between Min-K 2000 and 2002. This 5 watt reduction may not be achievable. With the increase in insulation thickness around the neck and tapered to the present base assembly height, room was available for increasing the length of the radiator without decreasing the space available between the radiator and rain shield for air to enter.

A two inch increase in fin height was estimated to result in a decrease in the radiator base temperature of $8.5^{\circ} \mathrm{F}$. Applying this $8.5^{\circ} \mathrm{F}$ to the converter $\Delta T$, it was estimated that a sufficient increase in converter efficiency can be realized so as to reduce the converter heat requirement and thus system heat requirements by 8 watts.

Based on the projected improvements in PMS heat losses for the three insulation design changes plus the projected improvement in converter performance due to the radiator design change, a possible reduction of 52 to 57 watts in heat losses is estimated. Due to uncertainties in the effective conductivity of the insulation around the instrumentation and power leads in the base assembly, a further reduction of up to approximately 20 watts might be realized when a fueled system is built, thus eliminating the power and instrumentation leads. 


\section{Subtask 350 - Thermoelectric Analysis}

Interface Meetings

An interface meeting was held between WANL and $3 M$ on October 3,1968 . Because of the availability, 304 stainless steel was selected for the interfacing piece parts of the PMC-2. In addition, it was recommended that this material selection be upgraded, as required, for future converters used in systems exposed to long-term field environmental conditions.

Details were established concerning the procedures for identifying and routing the converter instrumentation and power leads of the WANL top cover onto the PMC-2 converter at $3 M$. The coordination of the design data input requirements and the integrated design approach were discussed and documented in the minutes of this meeting.

An interface meeting between WANL and $3 M$ was held on October 29, 1968. A topic of discussion in this meeting was the range of BOL hot junction temperatures for the $\mathrm{PMC}-2$ converter. This range has been changed to extend from $1100^{\circ} \mathrm{F}$ to $1020^{\circ} \mathrm{F}$. The $1100^{\circ} \mathrm{F}$ temperature is the maximum BOL junction temperature established early in the program. The $1020^{\circ} \mathrm{F}$ temperature was selected as a lower limit based on preliminary degradation considerations. Based on EMS test data and a review of the power dissipation requirements of the power conditioning circuit, EOL converter power output was selected to be 61 watts. Also based upon EMS test results, the stud axial temperature drop was se. it $36^{\circ} \mathrm{F}$ and $30^{\circ} \mathrm{F}$ at $\mathrm{BOL}$ and EOL respectively for the PMC design.

Questions related to $3 M^{\prime}$ s converter test evaluation heat flow apportionment were also discussed at the interface meeting with $3 M$. The sign convention for the net upper boundary and lower boundary heat transfer as shown in the PMC-1 end item documentation was in error. It was agreed that this would result in a small reduction in test stand thermal losses of approximately five watts at BOL and three watts at EOL. A minor discrepancy between WANL and $3 \mathrm{M}$ on treatments of the heat flow at the lower converter flange was not resolved. The $3 M$ Company agreed to comment on the heat flow logic by November 12, 1968. $3 \mathrm{M}$ in a letter to WANL dated November 1, 1968 stated the ir agreement to the revised heat balance tabulations as presented in a sample calculation supplied by WANL to 
$3 \mathrm{M}$ in the October 29, 1968 interface meeting. Furthermore, although the accounting procedures for evaluating the lower converter flange differs between WANL and $3 M_{\text {r }}$ the two procedures were found by $3 \mathrm{M}$ to be consistent and result in the same test stand heat losses. With this agreement, the revised test station losses are presented in Table 3-7. With these agreed upon these revisions result in the net effect of a 3 watt reduction in test stand losses at EOL and a 5 watt reduction in test stand losses at BOL.

All data taken from the EMS testing has been summarized in tabular form. $3 \mathrm{M}$ will be supplied a copy of the raw converter data and the test point summaries for all data taken during the shock and vibration tests at the December 16 interface meeting. The converter power output and hot cap temperatures taken from the EMS tests are compared with PMC-IA component test results supplied by $3 \mathrm{M}$ in Figure 3-29 as a function of converter temperature drop. As is shown good agreement was obtained between the tests in the performance characteristics. The system tests show the converter operating slightly better than for component tests. This comparison will be supplied to $3 \mathrm{M}$ for their comments. Transmittal of the PMC- $1 B$ performance at EOL and BOL conditions was received by WANL from $3 \mathrm{M}$ on November 22, 1968. WANL evaluation and comparison of this data with PMC-1A is currently being performed.

Subtask 390 - Capsule Design and Development

Fueling of SNAP-23A Capsule

The first SNAP-23A capsule was fueled by ORNL late in the subject reporting period. The preliminary data measured by ORNL indicate that the capsule contains 1127 watts or 165,735 curies of strontium titanate. More detailed information will be presented in the next quarterly progress report.

\section{Capsule Component Fabrication}

The fabrication of liner tubes, shell cylinders, liner end caps, and shell end caps continued during the subject report period. Table 3-8 summarizes the capsule delivery status. Photographs of representative capsule components are shown in Figures 3-30 and 3-31. 
TABLE 3-7

SNAP-23A PMC-IA

REVISED TEST STATION LOSS

\begin{tabular}{|c|c|c|}
\hline & $B O L$ & EOL \\
\hline \multicolumn{3}{|l|}{ Test Future Loss } \\
\hline Upper & 9.00 & 7.33 \\
\hline Lower & 17.13 & 14.08 \\
\hline \multicolumn{3}{|l|}{ Net Boundary Transfer } \\
\hline Upper Boundary In & 2.95 & 2.52 \\
\hline $\begin{array}{l}\text { Upper Boundary Out } \\
\text { Net (IN-Out) }\end{array}$ & $\frac{7.97}{-5.02}$ & $\frac{6.56}{-4.04}$ \\
\hline Lower Boundary In & 7.78 & 6.83 \\
\hline Lower Boundary Out & 0 & 0 \\
\hline Net (IN-Out) & $\overline{7.78}$ & 6.83 \\
\hline Miscellaneous Loss & 4.60 & 3.70 \\
\hline Total Loss & $\overline{33.49}$ & $\overline{24.20}$ \\
\hline Power In - Total & 1088 & 860 \\
\hline Net & 1054.5 & 832.1 \\
\hline Power Out & 90.5 & 67.2 \\
\hline Efficiency & $8.58 \%$ & 8.06 \\
\hline
\end{tabular}


(Waboratory
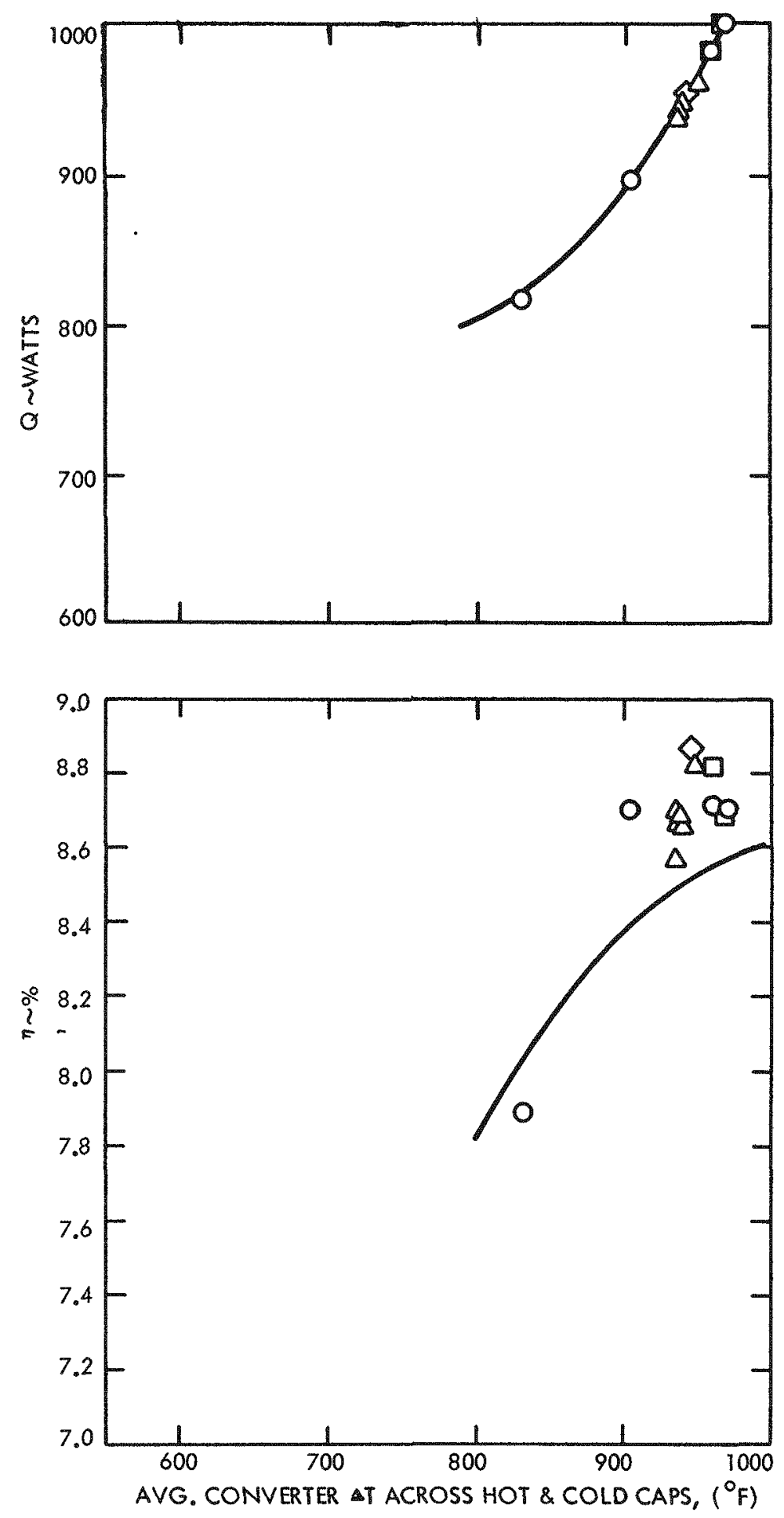

Figure 3-29. PMC-1A Converter Efficiency from EMS Measurements 
TABLE 3-8

CAPSULE FABRICATION STATUS

\begin{tabular}{|c|c|c|c|c|c|c|}
\hline Item & $\begin{array}{c}\text { Parts } \\
\text { Ordered }\end{array}$ & $\begin{array}{c}\text { Parts } \\
\text { Accepted }\end{array}$ & $\begin{array}{l}\text { Subassemblies } \\
\text { Fabricated }\end{array}$ & $\begin{array}{c}\text { Subassemblies } \\
\text { Shipped to ORNL }\end{array}$ & $\begin{array}{c}\text { Total ORNL } \\
\text { Delivery } \\
\text { Requirement }\end{array}$ & Comments \\
\hline $\begin{array}{l}\text { Liner Weld } \\
\text { Specimens }\end{array}$ & 13 & 13 & 3 & 10 & 10 & Complete \\
\hline $\begin{array}{l}\text { Shell Weld } \\
\text { Specimens }\end{array}$ & 21 & 21 & 6 & 15 & 15 & Complete \\
\hline $\begin{array}{l}\text { Half Length } \\
\text { Liners }\end{array}$ & 5 & 5 & 4 & 5 & 5 & Complete \\
\hline $\begin{array}{l}\text { Half Length } \\
\text { Shells }\end{array}$ & 5 & 5 & 4 & 5 & 5 & Complete \\
\hline $\begin{array}{l}\text { Full Length } \\
\text { Liners }\end{array}$ & 14 & 8 & 5 & 5 & 13 & $\begin{array}{l}3 \text { units returned } \\
\text { for rework; } 6 \\
\text { units being } \\
\text { inspected. }\end{array}$ \\
\hline $\begin{array}{l}\text { Full Length } \\
\text { Shells }\end{array}$ & 14 & 4 & 3 & 3 & 13 & $\begin{array}{l}5 \text { units returned } \\
\text { for rework; } 5 \\
\text { units being } \\
\text { inspected. }\end{array}$ \\
\hline
\end{tabular}




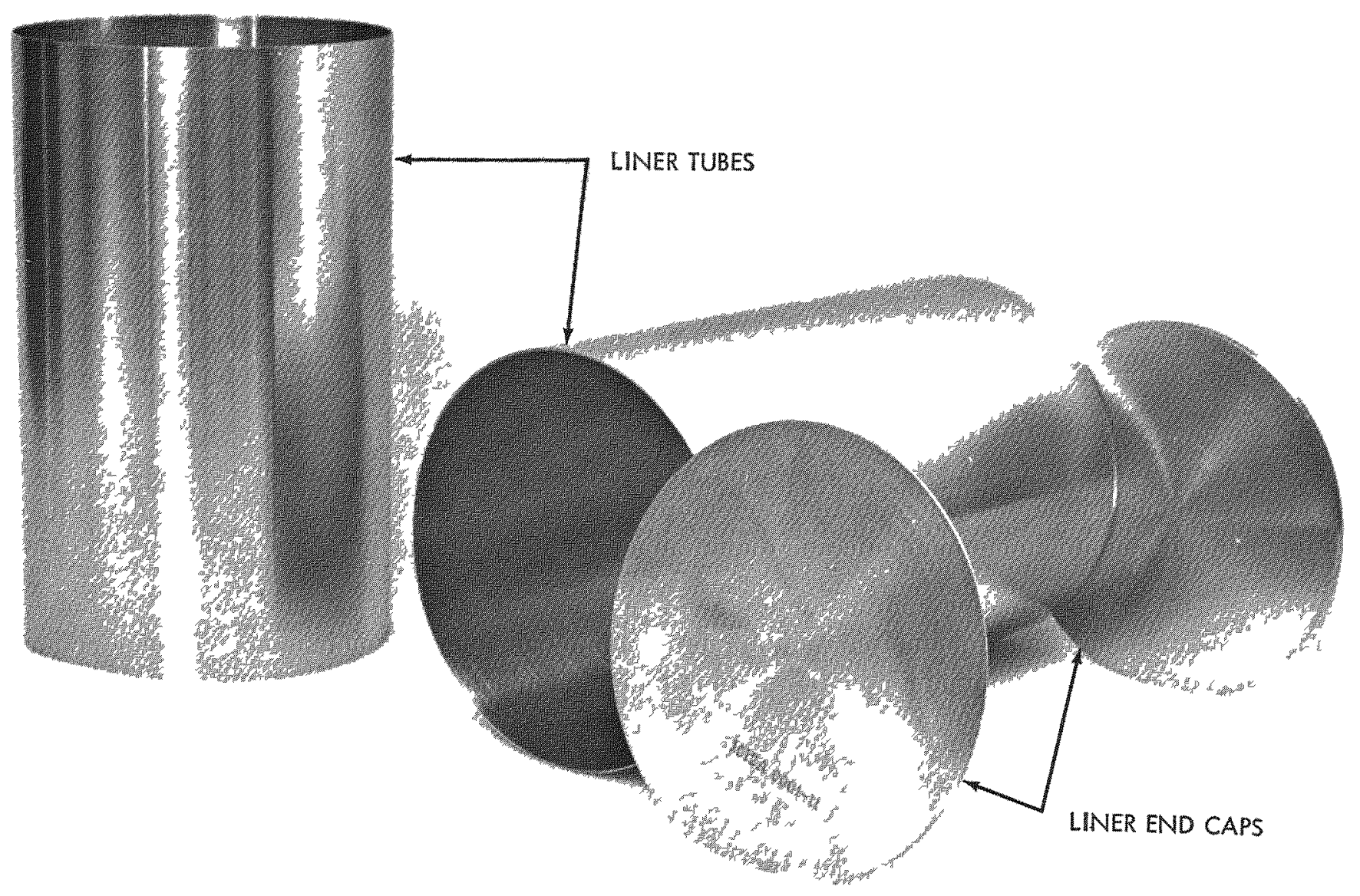

Figure 3-30. Liner Tubes and End Caps 


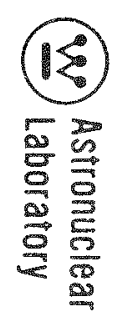

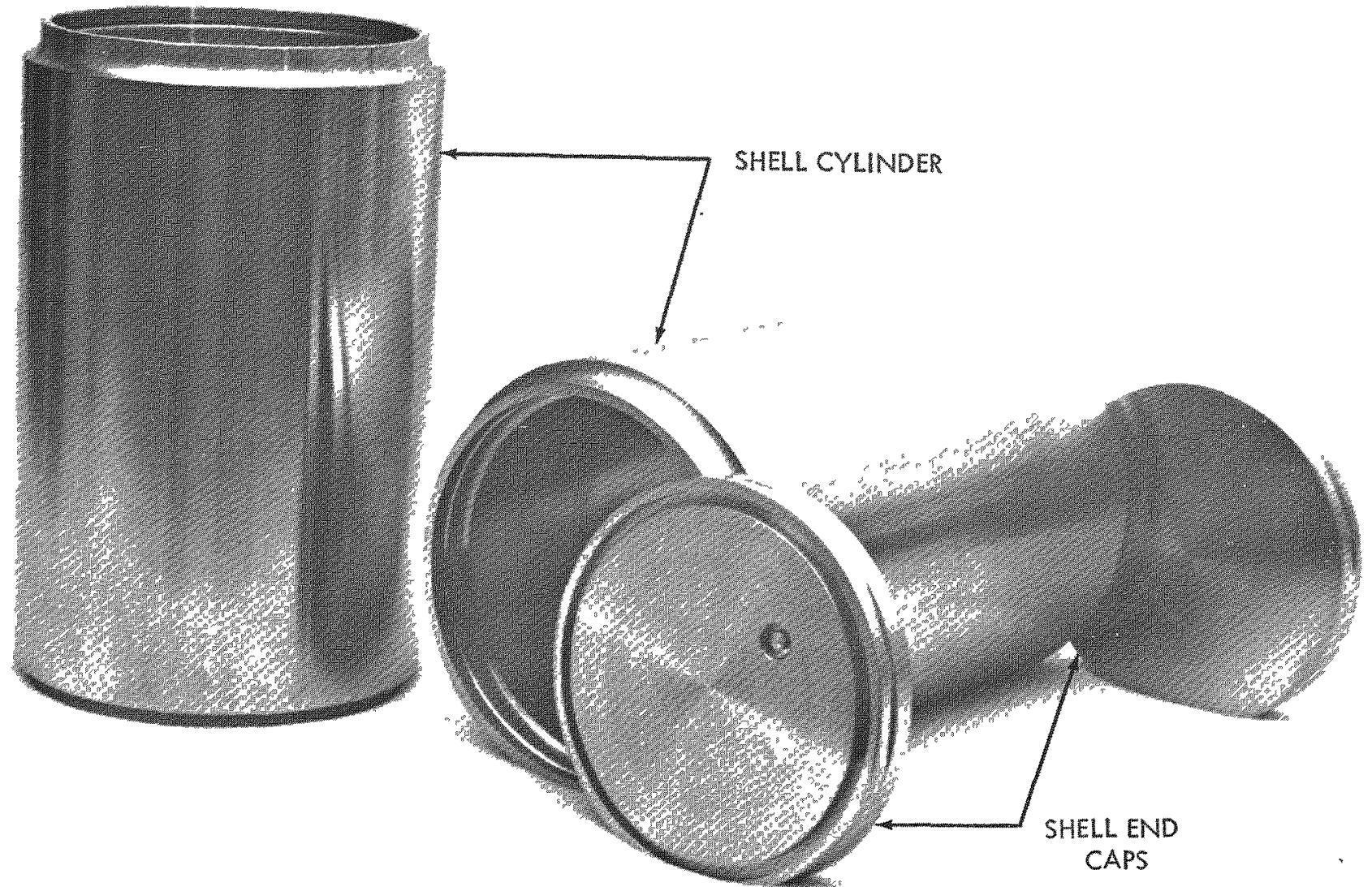

Figure 3-31. Shell Cylinders and End Caps 
Weld parameter finalization studies on full sized liner and shell subassemblies were completed during the subject reporting period.

The liner subassembly weld process development was completed and checked for quality during the previous reporting period. During this reporting period, four half-length and five full size liner subassemblies were fabricated for use by ORNL in their capsule fueling studies. The process used in the liner subassemblies consisted of the following steps:

1) All incoming parts are visually and dimensionally inspected for conformance to design requirements.

2) All components are then chemically cleaned using a Diversey process employing the following sequence:
a) degrease
b) alkali cleaning
c) descaling
d) brightening
e) three washes in distilled water
f) rinse in acetone
g) final rinse in methanol
h) forced air drying

3) The liner chills are then assembled to the liner tube, the liner end cap inserted into the tube, and the top chill positioned. See Figure 3-32.

4) The chamber is then evacuated and filled with argon gas.

5) The liner end cap is secured by tack welding it to the liner.

6) The end cap to liner weld is then made using the following parameters:
a) Speed - 19 seconds per revolution
b) Arc Gap - 0.025 inch
c) Electrode $-0.040 \mathrm{inch}$, two percent thoriated tungsten
d) Current - 55 amps
e) Arc Voltage - 12 volts
f) Cover Gas - argon at $18 \mathrm{ft}^{3} / \mathrm{hr}$ 
Q. Astronuclear

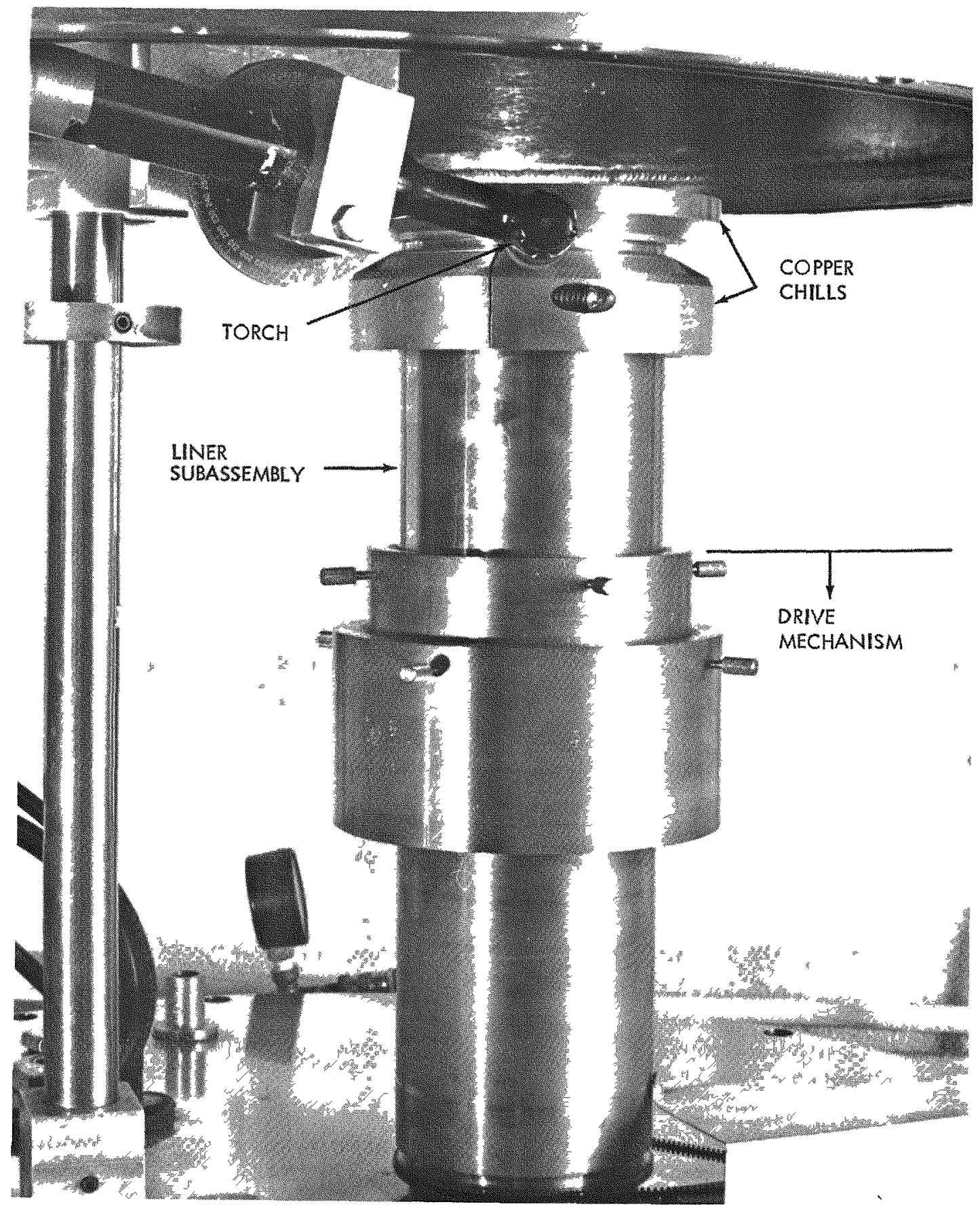

Figure 3-32. Welding of Liner Subassemblies 
7) The subassembly is then removed from the chamber, visually and dimensionally inspected, and dye penetrant tested for weld quality. The units are then recleaned using the process described above (with an additional vacuum treatment to dry the components). They are then readied for shipment to ORNL.

Some additional welding and inspection activities were required during this reporting period to finalize the shell end cap to shell joint. As reported in Ref. 1, some of the halflength shell subassemblies and welding specimens had penetrations as low as 0.100 inch $(0.110$ inch is desired). Hittman Associates originally planned to verify the weld penetration depth and defect characteristics using an ultrasonic inspection technique. To be meaningful, however, this inspection method must be correlated with actual destructive measurements. This correlation was to have been completed by ORNL. Due to schedule and funding requirements, ORNL was unable to initiate these ultrasonic inspection activities. As a result, Hittman Associates used several rejected (out of tolerance) capsule components to increase the penetration depth and assure quality using destructive analysis.

Four additional shell subassembly welds were made using these components. Single pass welds were employed with increasing current to evaluate the effects on penetration. The results are given in Table 3-9.

These welds were made on our new Auto Arc automatic welder. As a result, the currents used do not correspond to those previously reported for the $\mathrm{P} \& \mathrm{H}$ welder.

After completing the welds, the end caps were cut from the shell body, and destructively sectioned into 32 edges (in pie shaped segments) for metallographic inspection of penetration and welding defects. The depths of penetration for three of the four welds are given in Table $3-9$.

The higher current used for specimen No. 116 resulted in a deep, defect-free weld joint. With care in setup, no rollover of the outer edge of the shell lip should occur. Figure 3-33 shows typical photomicrographs of the No. 116 weld joint.

The process used to fabricate the shell subassemblies is similar to that described above for the liner subassemblies:

1) The parts are inspected and cleaned. 
(W) Astronuclear

Laboratory

TABLE 3-9

WELD PENETRATION OF CAPSULE SHELL WELDS (END CAP TO SHELL TUBE)

\begin{tabular}{|c|c|c|c|c|c|}
\hline \multirow[b]{2}{*}{ Sample Number } & \multirow{2}{*}{$\begin{array}{l}\text { Welding Current } \\
\text { (in amps) }\end{array}$} & \multicolumn{3}{|c|}{ Depth of Penetration (inches) } & \multirow[b]{2}{*}{ Comments } \\
\hline & & High & Low & Average & \\
\hline 113 & 249 & 0.108 & 0.088 & 0.098 & Poor \\
\hline 114 & 259 & \multicolumn{3}{|c|}{ Not Measured } & Poor \\
\hline 115 & 285 & 0.144 & 0.105 & 0.125 & Satisfactory \\
\hline 116 & 297 & 0.147 & 0.112 & 0.133 & Good weld \\
\hline
\end{tabular}




\section{(Q. Astronuclear}

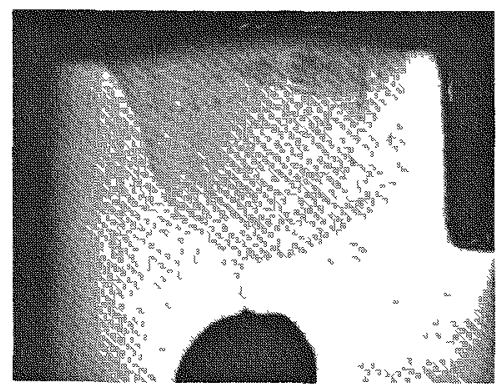

a. 0,147 Inch Penetration (High)

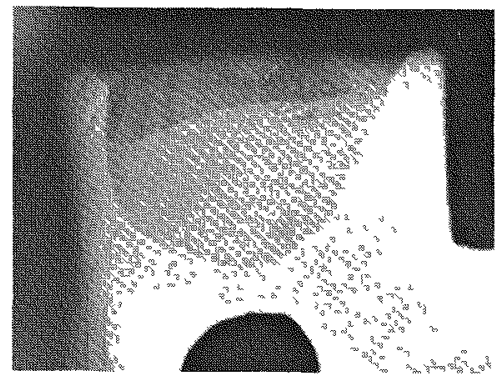

c. 0.141 Inch Penetration

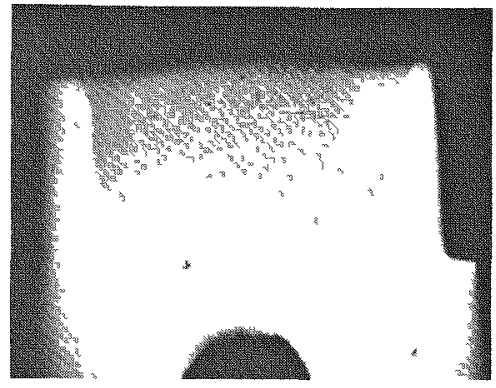

e. 0.136 Inch Penetration

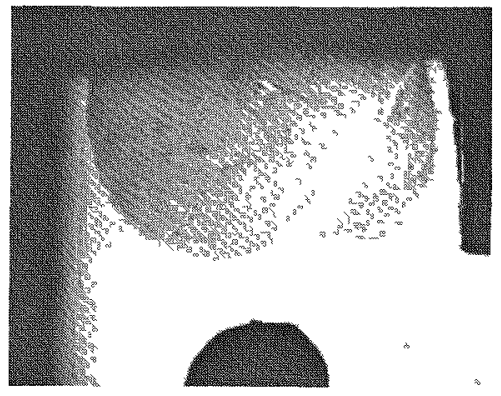

g. 0.133 Inch Penetration

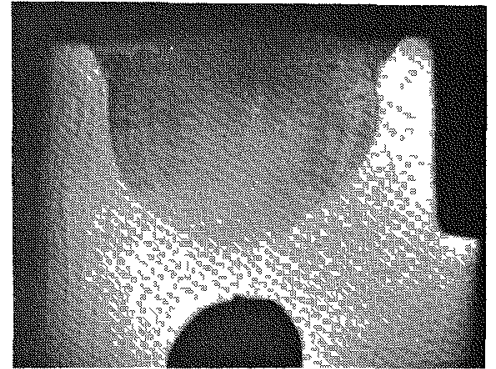

b. 0.146 Inch Penetration

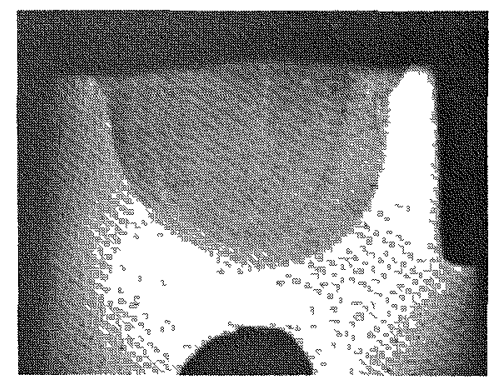

d. 0.138 Inch Penetration

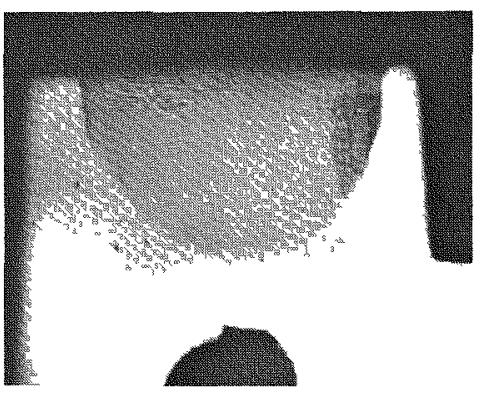

f. 0.133 Inch Penetration

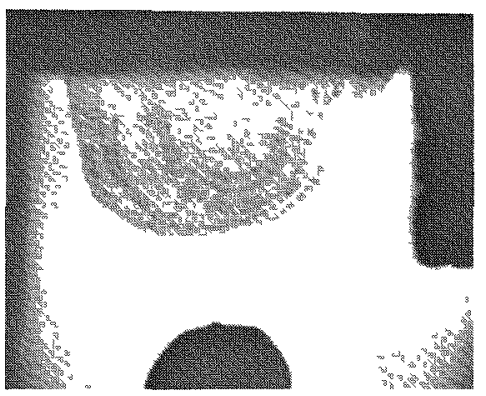

h. 0.113 Inch Penetration (Low)

Figure 3-33. Microphotographs of Capsule-End Cap Welds Transverse View 
2) The chills are fitted to the parts and the unit assembled with in the chamber as shown in Figure 3-34.

3) The chamber is evacuated, filled with argon, and the subassembly welded using the following parameters:

a) Speed - 36 seconds per revolution

b) Arc Gap - 0.020 inch

c) Electrode $-3 / 32$ inch, two percent thoriated

d) Current - 297 amps

e) Arc Voltage - 24 volts

f) Cover Gas - Argon - 90 percent helium

This work completes the subassembly fabrication studies for the present. While Hittman Associates' destructive analysis indicates that weld quality and penetration meet design requirements, the final weld certification was to have been made based upon an ultrasonic inspection. Since this is presently impossible, we cannot certify that the welds in the shell subassemblies meet the design requirements of 0.110 inch minimum penetration or that they are free of detrimental weld defects.

The following full sized subassemblies were fabricated by the final processes described above:

1) Five liner subassemblies (units No. 204, No. 205, No. 207, No. 208, and No. 209)

2) Three shell subassemblies (units No. 23-1, No. 23-2, and No. 23-3)

The remaining liner and shell subassemblies will be fabricated during December 1968.

\section{Capsule Component Tolerance Study}

A detailed capsule tolerance study was performed earlier in the subject program to establish the detailed capsule design and the shield internal cavity requirements. Table 3-10 summarizes the SNAP-23A heat source dimensions at $70^{\circ} \mathrm{F}, 700^{\circ} \mathrm{F}$, and $1070^{\circ} \mathrm{F}$ for the minimum and maximum tolerance cases. 
Astronuclear
Laboratory

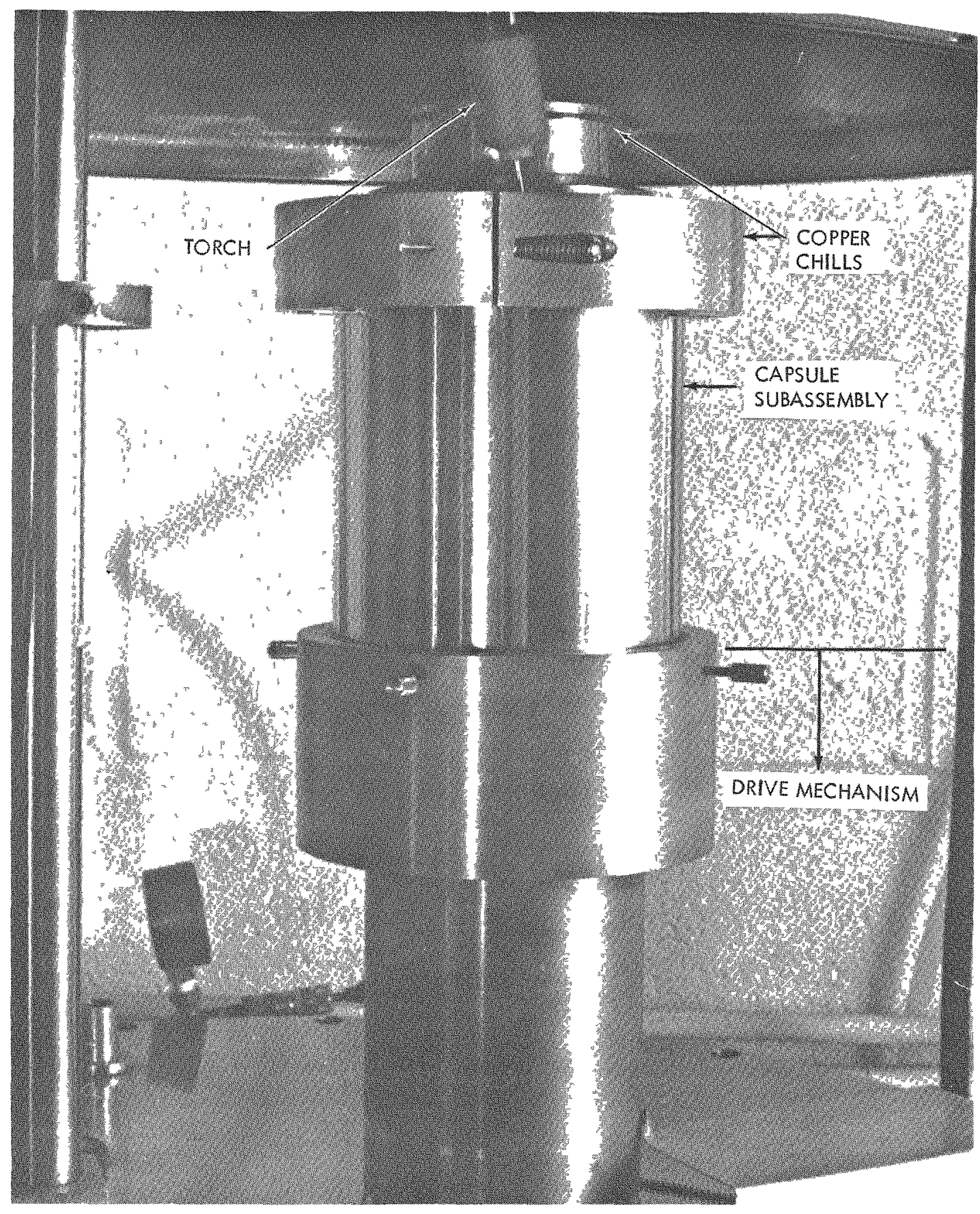

Figure 3-34. Welding Shell Subassemblies 
TABLE 3-10

SUMMARY OF SNAP-23A CAPSULE TOLERANCE STUDY

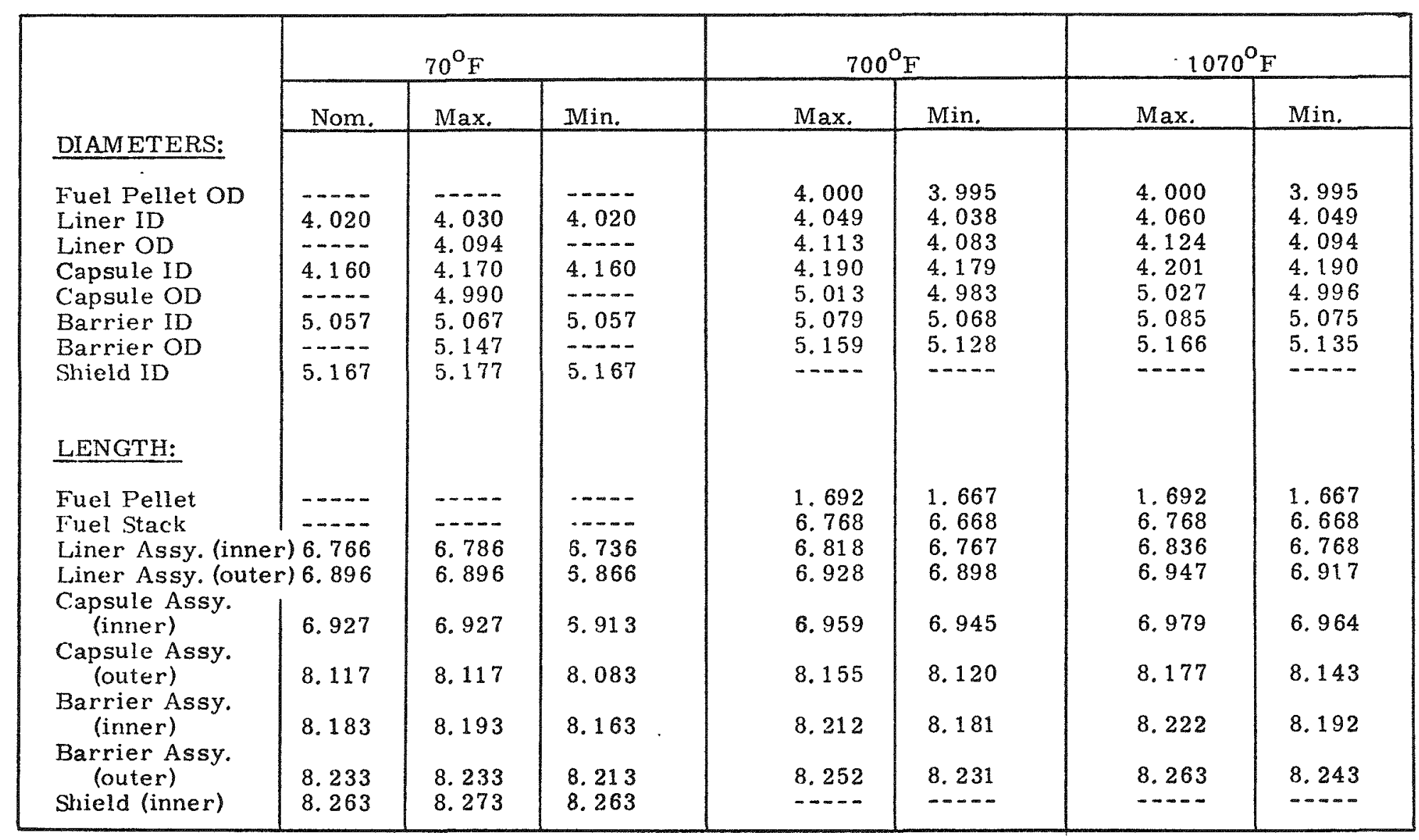




\section{Tantalum Diffusion Barrier}

A sketch was prepared to describe the Hittman Associates' proposed diffusion barrier design. Figure 3-35 illustrates the recommended design sized to fit into the PMS generator and house the SNAP-23A capsule. The proposed design is based upon the above dimensional tolerance study.

The proposed diffusion barrier is inserted into the shield assembly at $70^{\circ} \mathrm{F}$ with 0.020 minimum diametral clearance. The diffusion barrier assembly maximum length at $1070^{\circ} \mathrm{F}$ matches the cold shield cavity depth.

\section{Capsule Axial Exponsion Analysis}

A detailed capsule thermal expansion analysis was performed early in the subject reporting period using the actual dimensions of the capsule components sent to ORNL for fueling. Each major step of the fueling process has been simulated. The basic objective of the analysis was to establish the capsule axial gap requirements (pellet to liner and liner to shell) which provide fuel support during a postulated water burial environment without generating thermal expansion interference problems during encapsulation or during normal operation.

A multi-dimensional transient thermal program, TAP-4, was used to evaluate the time-temperature history during the different steps of fabrication. The axial growth due to thermal expansion was also programmed into the thermal models to provide an axial dimensional tolerance check during the different steps of fabrication. Thermal models were developed to simulate six steps of the fabrication process. These six models were run in a transient mode, using the temperatures from the previous step as the starting temperatures for the following run. The models used are similar to the capsule portion of the generator thermal model developed and described in the safety effort, Subtask 610. The different models are described below:

1) Fuel Filled Liner-End Cap Removed. It was assumed for this case that the four $\mathrm{SrTiO}_{3}$ fuel pellets to be used in the SNAP-23A capsule were fabricated individually and placed in the liner. The transient run was initiated when the last pellet was placed in the 


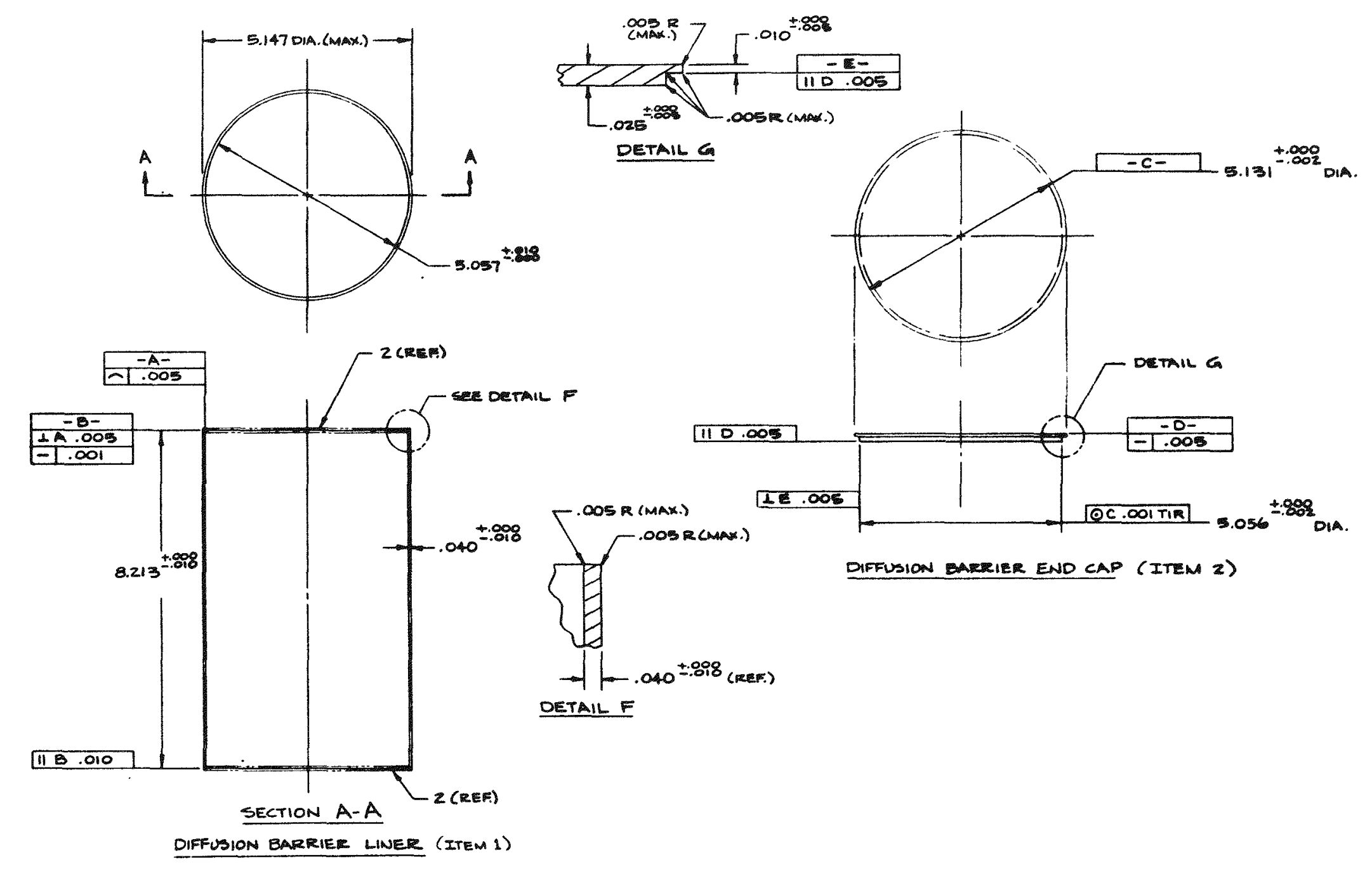

$\omega$
1
0
0

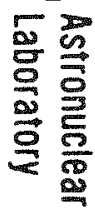

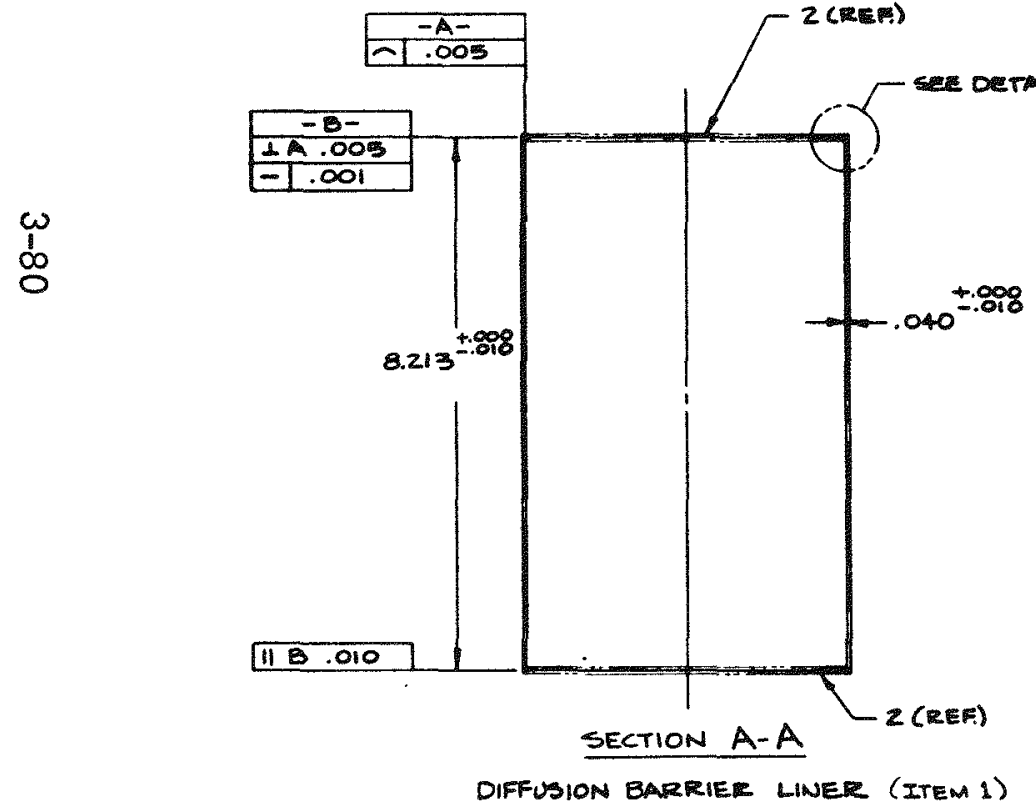

Figure 3-35. Diffusion Barrier Details 
liner. This model simulates fuel and liner with no closure end cap. Heat is transferred from the outer surface of the liner by natural convection and radiation to an ambient environment. Thermal energy is transferred from the cylindrical surface of the pellets to the liner by conduction and radiation through the air gap. The bottom of the fuel was assembled to be in contact with the liner at the bottom. A contact resistance was calculated based on the fuel weight. The transient time period assumed was 1.0 hour.

2) Liner Closure Welding. This model was used to simulate TIG welding to the liner end cap and a half-hour hold. The above model was revised to include the following changes: the liner end cap was connected to the liner, and heat removed from the liner by radiation and convection to the ambient environment. The total transient time period assumed was one-half hour.

3) Liner Assembly in Air. This model was prepared to simulate the liner assembly after it is welded closed and exposed to an air environment.

4) Shell Assembly. After the liner assembly is completed, it is assembled into the shell, the shell end cap is inserted into place, and the entire capsule is placed into the vacuum chamber. The chamber is then evacuated and the EB closure weld performed. A transient model was developed to simulate the evacuated period. A maximum time period of 1.5 hours was assumed.

5) Helium Fill and Fill Port Weld. Following the EB closure weld, the chamber is filled with helium. The fill hole in the shell end cap permits helium to flow into the interior of the capsule. The helium facilitates the transfer of heat from the liner to the capsule, minimizing internal temperatures during normal operation. The fill hole is TIG welded in this environment to form the final capsule closure. The model developed for this case was run assuming a 1.5 hour time period.

6) Water Quench. The next operation considered was the water quench which simulates the sea water burial case. It is at this point that a near solid height is desired.

A dimensional check was made during each time step calculated. The axial expansion and/or contraction of each node was calculated using the calculated temperature profile. The nodal axial expansion values were then summed algebraically to establish both 
the liner and the shell lengths. The capsule temperature profiles calculated are presented in Figure 3-36. Based upon this analysis, it was concluded that a 0.010 inch axial liner gap and a 0.030 inch axial capsule gap are required at the respective fueling points to meet the above constraint. The point of maximum expansion occurs at the end of the EB welding operation, which has been conservatively simulated by Step 4. Table 3-11 summarizes the capsule dimensions and the assumed fuel pellet height used in the analysis. Since the fuel pellet height is uncertain, the fabrication requirements determined by this analysis have been formulated in terms of gap requirements. 


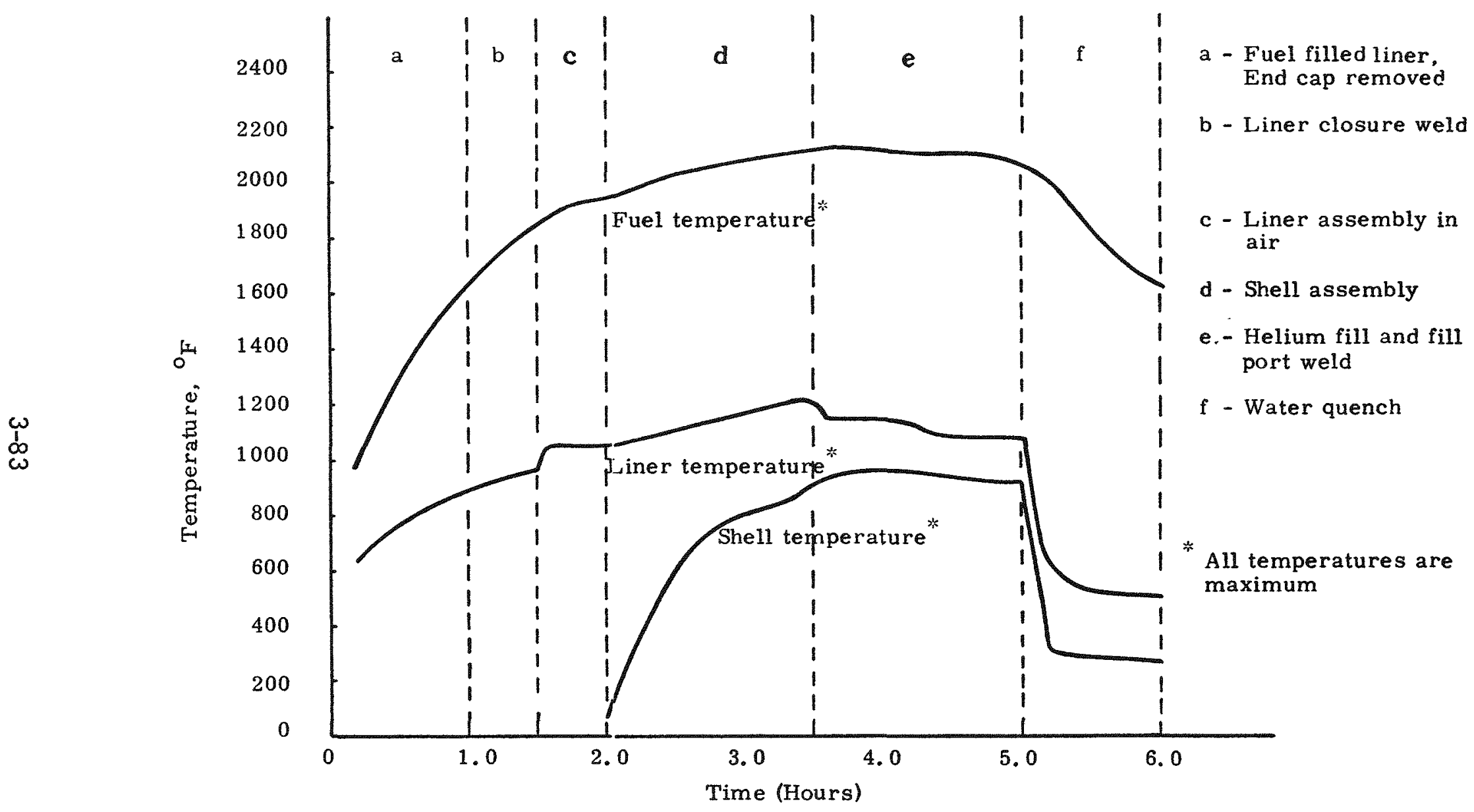

Figure 3-36. Capsule Temperature Profile During Fabrication 


\section{MATERIALS AND COMPONENT TESTING}

Subtask 410 - Materials Engineering and Testing

\section{Tasks Performed}

1) Inputs from the materials department were supplied to aid in establishing procedures for the following operations:

a) Design and assembly of gas supply and sampling manifolds for heat source and base assembly of the EMS.

b) Leak testing, internal cleaning, and purging to ensure that ultra-high purity gasses were supplied to the heat source and base assembly during EMS testing, and that meaningful gas samples could be collected at the times specified during the tests.

c) Establishing the procedure and supervising the collection of uncontaminated gas samples from the heat source and the base assembly during the EMS test.

d) Establishing the procedures to seal and weld the heat source and base assembly evacuation ports in preparation for shock and vibration testing.

e) Providing materials, configuration, and fabrication procedure selections to meet improved PMS performance goals assuring maximum reliability and optimum economy.

f) Providing materials selection, fabrication, and assembly problems and specification requirements for the PMS logic flow diagram.

g) Meeting with Johns-Manville to review and compare spherical insulation test data with data obtained by Johns-Manville. Various future test plans, such as recommended handling and heat treating procedures were discussed.

h) Transmitted tensile test results in the form of stress-strain curves obtained at WANL on U-8Mo in the $\gamma$ condition to Hittman Associates for the ir analysis of the impact properties of the alloy.

i) Inputs from the materials department to the PMS design were submitted.

i) Attempts were made to use existing U-8Mo tensile specimens in a modified form to generate shear data for Hittman Associates. $U-8 M 0$ is too notch-sensitive to allow shear data to be determined in this manner. A more suitable testing program is being pursued. 


\section{Spherical Insulation Test}

Testing of the Min-K 2000 continued during this reporting period. The spherical test apparatus containing Min-K 2002 was assembled and is currently being tested. Table 4-1 lists the test conditions of the data points recorded for both Min-K 2000 and Min-K 2002 during this quarter. Results of these tests and the relative effects of the environmental conditions are reported and analyzed under Subtask 340.

Assembly of Min-K 2002 was similar to that previously reported for Min-K 2000. The same thermocouple attachment schemes were used, although the position of the interfaces between insulation layers relative to the heater sphere was altered. Also, in order to collect data that were more easily reduced by the techniques developed in Subtask 340, thermocouples numbers $2,3,6,7,10$, and 11 were placed closer to the spherical heater. Figure 4-1 illustrates the location of the insulation interfaces, the thickness of each insulation layer, and the placement of the interior thermocouples relative to the heater-sphere-insulation interface.

\section{Compatibility Trials}

Compatibility tests to determine the best diffusion barrier between U-8Mo and copper at $1760^{\circ} \mathrm{F}$ have been started. Since flame sprayed coatings are one of the techniques which could be used to apply the barrier, U-8Mo specimens were sprayed with $\mathrm{Ta}, \mathrm{W}$, and $\mathrm{Al}_{2} \mathrm{O}_{3}$ to determine if these coatings would adhere. Standard laboratory techniques were utilized to apply these coatings. As will be evident from the following results, special techniques will have to be developed to successfully apply Ta and $\mathrm{Al}_{2} \mathrm{O}_{3}$ to $\mathrm{U}-8 \mathrm{Mo}$, should one of these coatings be necessary. The SNAP-21 program, however, uses an $\mathrm{Al}_{2} \mathrm{O}_{3}$ sprayed diffusion barrier which is applied by Linde; so this coating process, though proprietary, is state-of-the-art.

$\mathrm{U}-8 \mathrm{Mo}$ discs 0.75 inch diameter by 0.25 inch thick were abraded with emery cloth and flame sprayed with Metco high purity $\mathrm{W}_{1} \mathrm{Al}_{2} \mathrm{O}_{3}$, and Fansteel Ta powders. Two samples were produced with each coating. One set was submitted for macrophotographs and metallographic observation. The second set (excluding the $\mathrm{Al}_{2} \mathrm{O}_{3}$ which had spalled) was sealed in a quartz capsule backfilled with $1 / 3$ atmosphere of high purity argon at room temperature. These encapsulated specimens were subjected to the thermal history described in Table 4-2. 
TABLE 4-1

SPHERICAL INSULATION TEST DATA COLLECTED DURING REPORTING PERIOD

\begin{tabular}{|c|c|c|c|c|}
\hline \multicolumn{5}{|c|}{ Min-K 2000} \\
\hline Run No. & Atmosphere & $\Delta T(1-4)$ & Power & $\begin{array}{l}\text { Time at } \\
\text { Condition } \\
\text { (Days) }\end{array}$ \\
\hline $1-27$ & Vac. $(300 \mu)$ & $1200^{\circ} \mathrm{F}$ & 30.3 & 22 \\
\hline $1-31$ & $N_{2}(1 \mathrm{~atm})$ & $965^{\circ} \mathrm{F}$ & 30.0 & 8 \\
\hline $1-34$ & Vac. $(70 \mu)$ & $1212^{\circ} \mathrm{F}$ & 30.3 & 6 \\
\hline $1-40$ & Argon (1 atm) & $994^{\circ} \mathrm{F}$ & 30.0 & 6 \\
\hline$|-4|$ & Argon (1 arm) & $1156^{\circ} \mathrm{F}$ & 37.8 & 6 \\
\hline $1-42$ & Ambient Air & $1220^{\circ} \mathrm{F}$ & 46.6 & 8 \\
\hline $1-43$ & Vac. $90 \mu$ & $961^{\circ} \mathrm{F}$ & 20.7 & 7 \\
\hline $1-44$ & $N_{2}(1 \mathrm{~atm})$ & $1143^{\circ} \mathrm{F}$ & 43.5 & 4 \\
\hline \multicolumn{5}{|c|}{ Min-K 2002} \\
\hline Run No. & Atmosphere & $\Delta T$ & Power & $\begin{array}{l}\text { Time at } \\
\text { Condition } \\
\text { (Days) }\end{array}$ \\
\hline $2-4$ & Air (as assembled) & 918 & 30.3 & 11 \\
\hline $2-5$ & Air (as assembled) & 1182 & 43.0 & 7 \\
\hline $2-7$ & Vac. $(170 \mu)$ & 1198 & 30.2 & 12 \\
\hline $2-8$ & Argon (atm) & 1314 & 45.5 & 5 \\
\hline $2-9$ & Vac. $(90 \mu)$ & 1200 & 43.0 & 7 \\
\hline
\end{tabular}




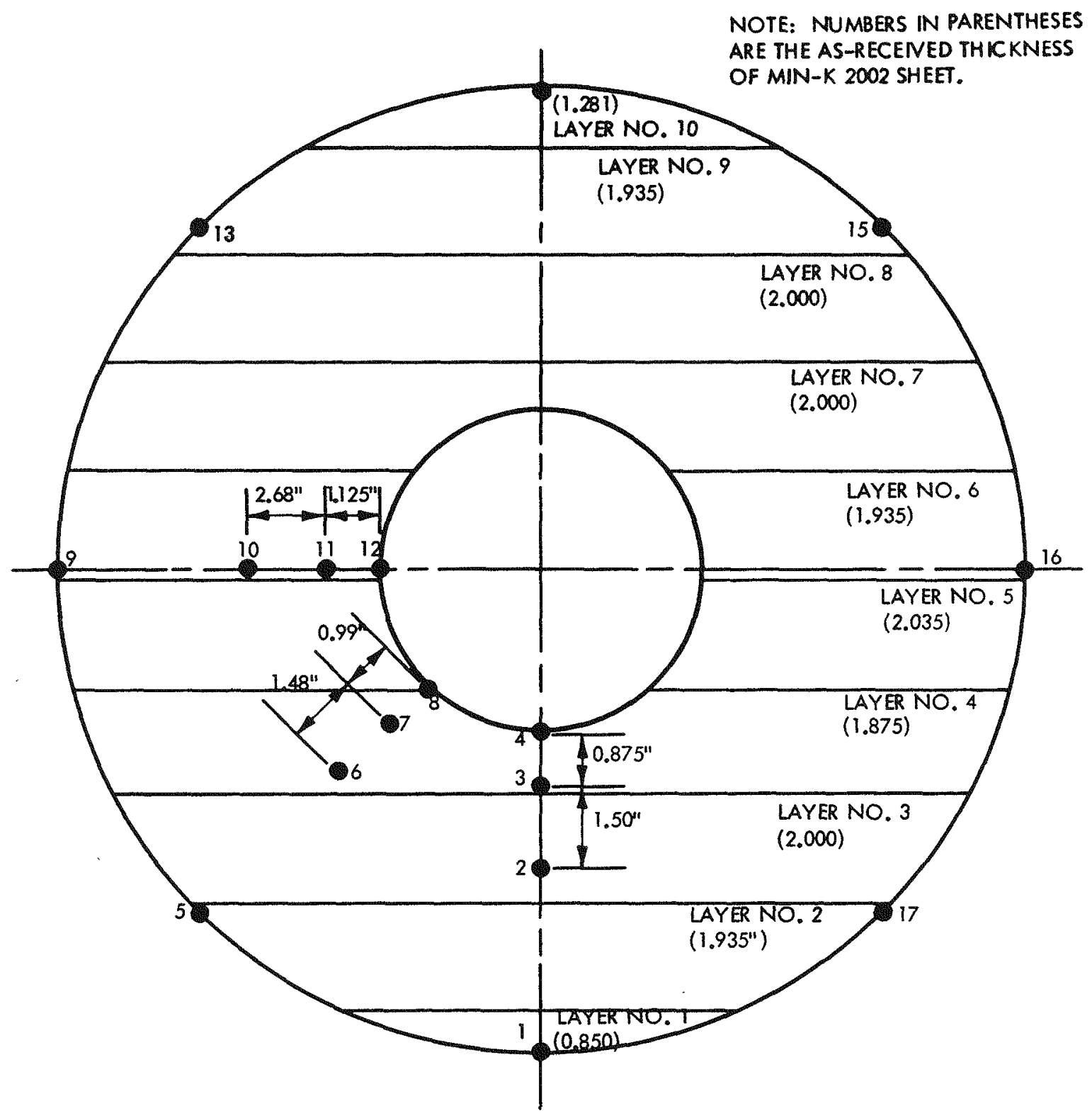

Figure 4-1. Drawing Showing Location of Thermocouples Relative to Interfaces Between Min-K 2002 in Spherical Insulation Test No. 2. 
TABLE 4-2

\section{THERMAL HISTORY FOR TO AND W COATING EVALUATION ON U-8Mo}

1) $600^{\circ} \mathrm{C}$ hold to form $\gamma$ phase

2) $500^{\circ} \mathrm{C}$ ageing to form $\gamma^{\prime}+a$ in 100 hours

3) Air cooling to room temperature

The thermal cycle was designed to determine if the dimensional changes that occur in U-8Mo during heating, cooling, and transformation affect the adherence of the coating.

Figures 4-2, 4-3, and 4-4 show, respectively, the $\mathrm{Ta}, \mathrm{W}$, and $\mathrm{Al}_{2} \mathrm{O}_{3}$ coatings that were applied to the U-8Mo. Note that the $\mathrm{Al}_{2} \mathrm{O}_{3}$ coating, Figure 4-4, although intact, did not adhere to the U-8Mo surface. After thermal exposure, routine handling caused the Ta coating to spall. All except a very small area was broken away from the U-8Mo surface.

Photomicrographs showing the coating/U-8Mo interface are presented in Figures 4-5, 4-6, 4-7, and 4-8. Before thermal exposure, $W$ and Ta are shown in Figures 4-5 and 4-6, respectively. Note that the Ta coating adheres over only a small area and the remainder of the coating is not attached to the surface even before the thermal exposure.

Figures 4-7 and 4-8 show the interfaces of the $W$ and Ta, respectively, after thermal exposure. The $W$ is still joined to the surface, while the Ta has completely spalled away. The coating density was $53 \pm 5$ percent of the theoretical density $(16.6 \mathrm{~g} / \mathrm{cc})$ for tantalum and $52 \pm 5$ percent of the theoretical density $(19.3 \mathrm{~g} / \mathrm{cc})$ for $W_{0}$ 
(2) Astronuclear
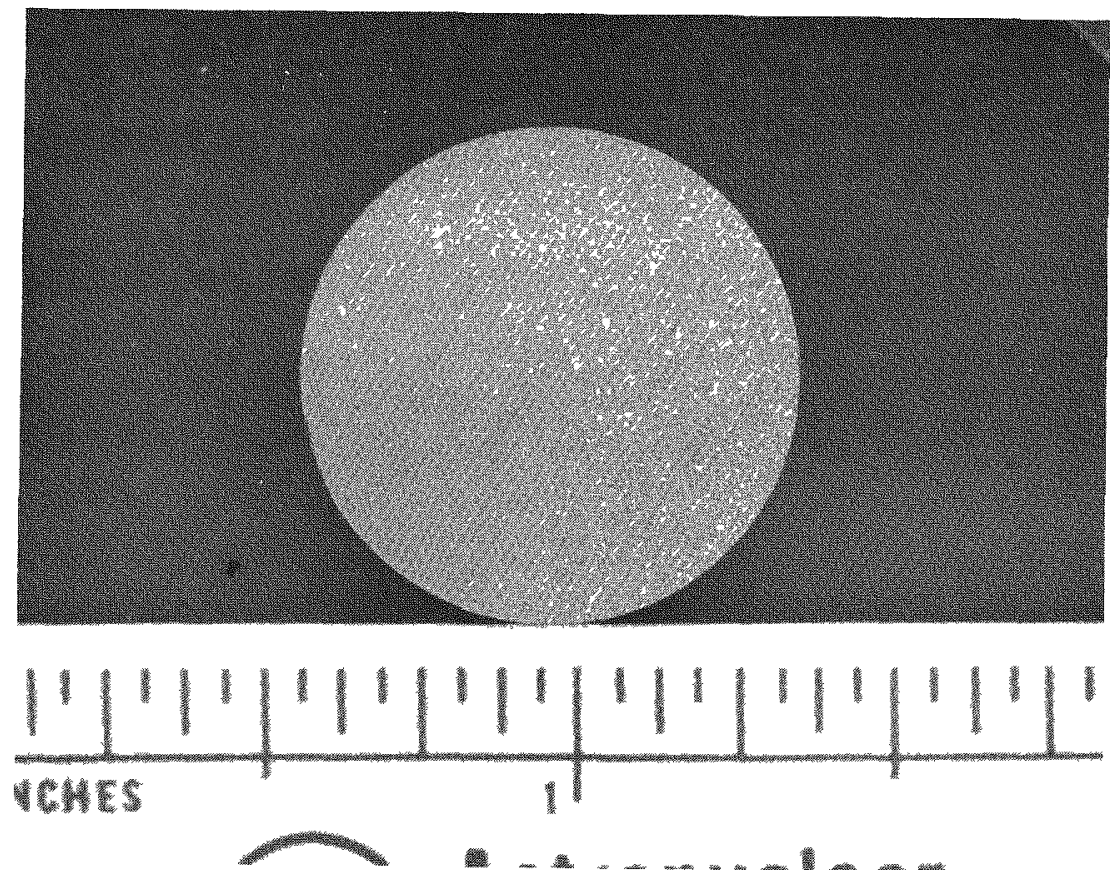

Figure 4-2. U-8Mo Flame Sprayed with Tantalum before Thermal Exposure
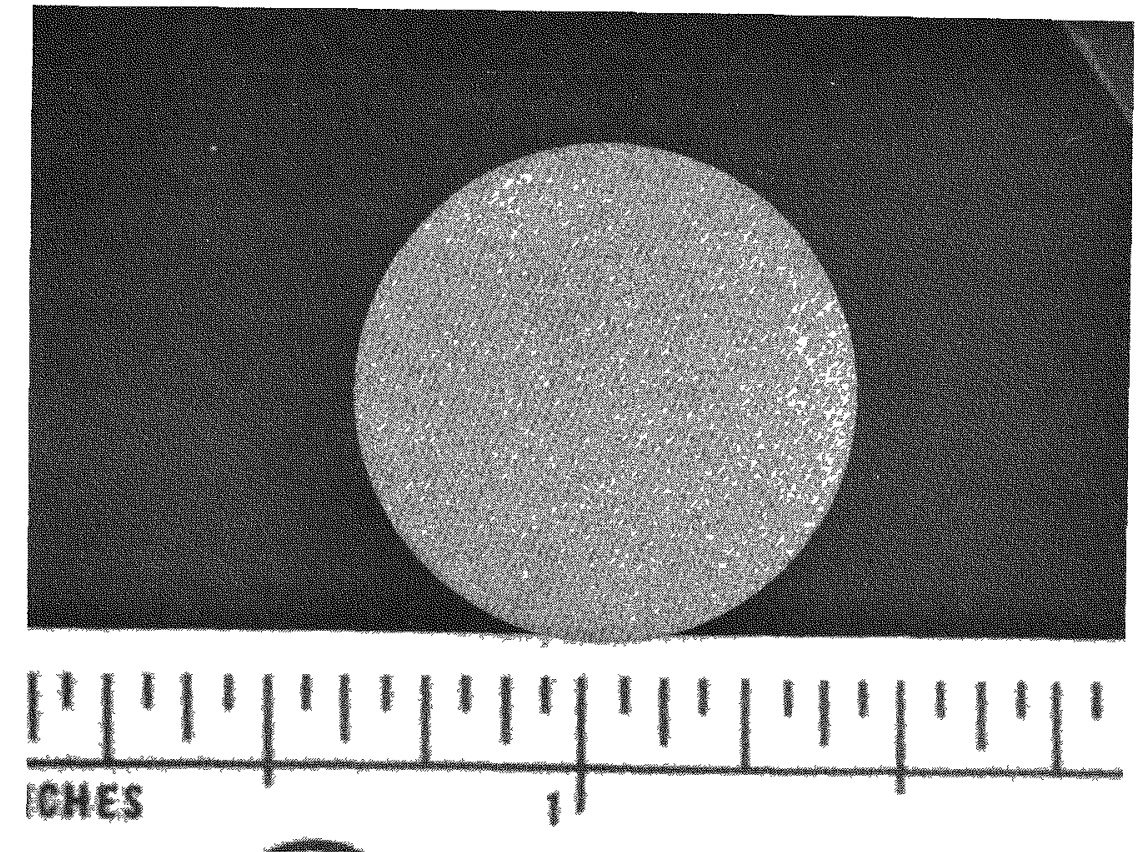

Figure 4-3. U-8Mo Disc Flame Sprayed with W before Thermal Exposure 


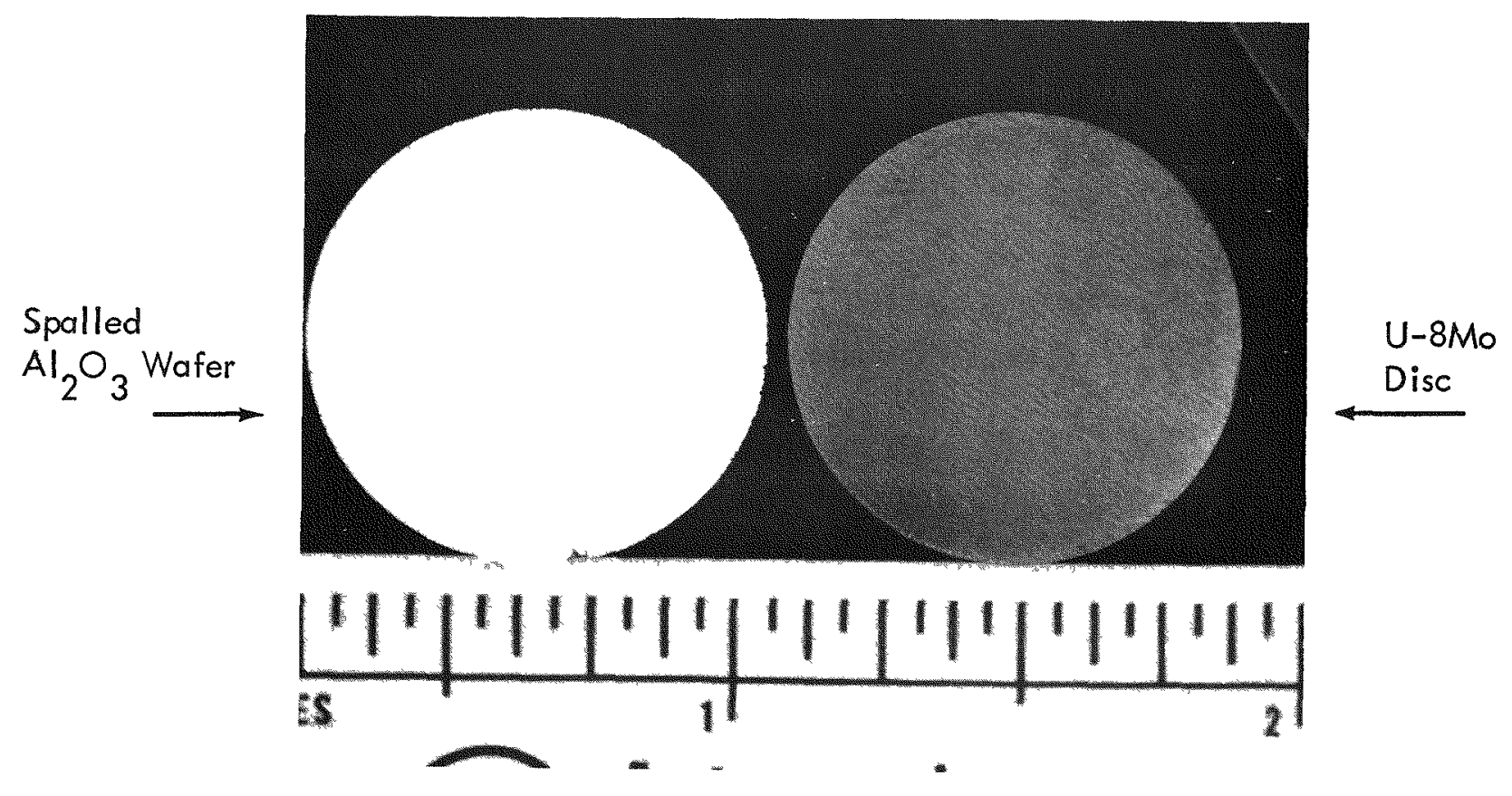

Figure 4-4. U-8Mo Disc Pictured with Spalled but Coherent $\mathrm{Al}_{2} \mathrm{O}_{3}$ Sprayed Layer

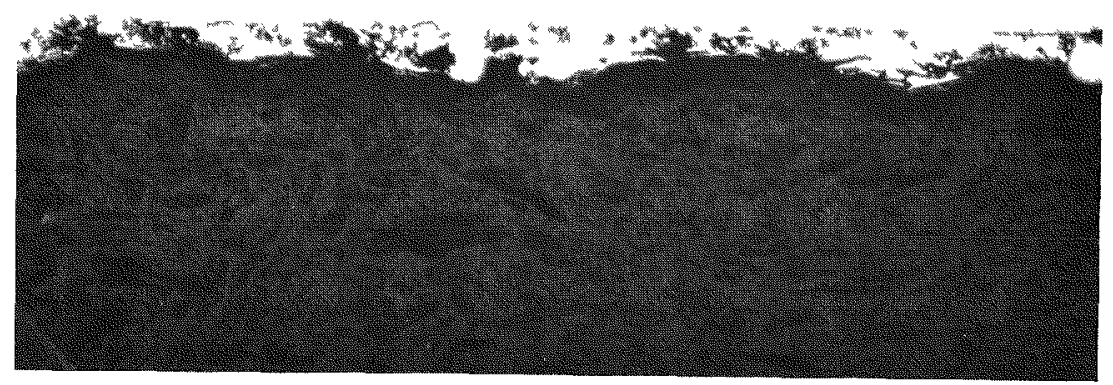

Figure 4-5. Microphotograph of Interface Between Flame Sprayed W Coating on a U-8Mo Substrate before Thermal Exposure 
Astronuclear

Laboratory

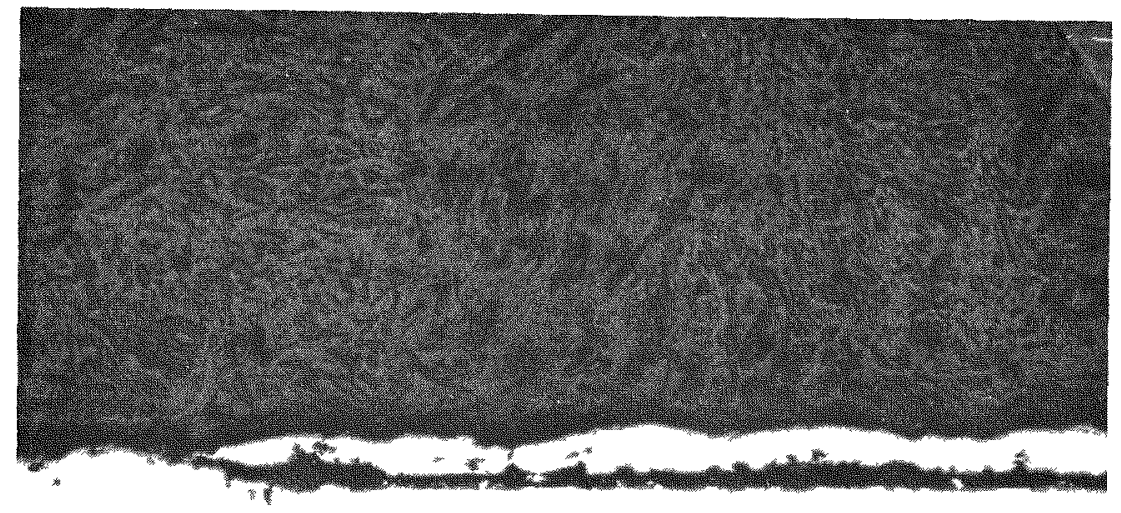

Mtg. Material

Ta Spray

U-8Mo

Substrate

Figure 4-6. Microphotograph of U-8Mo Flame Sprayed Ta Showing Non-

Adherence of Ta before Thermal Exposure

(100X)

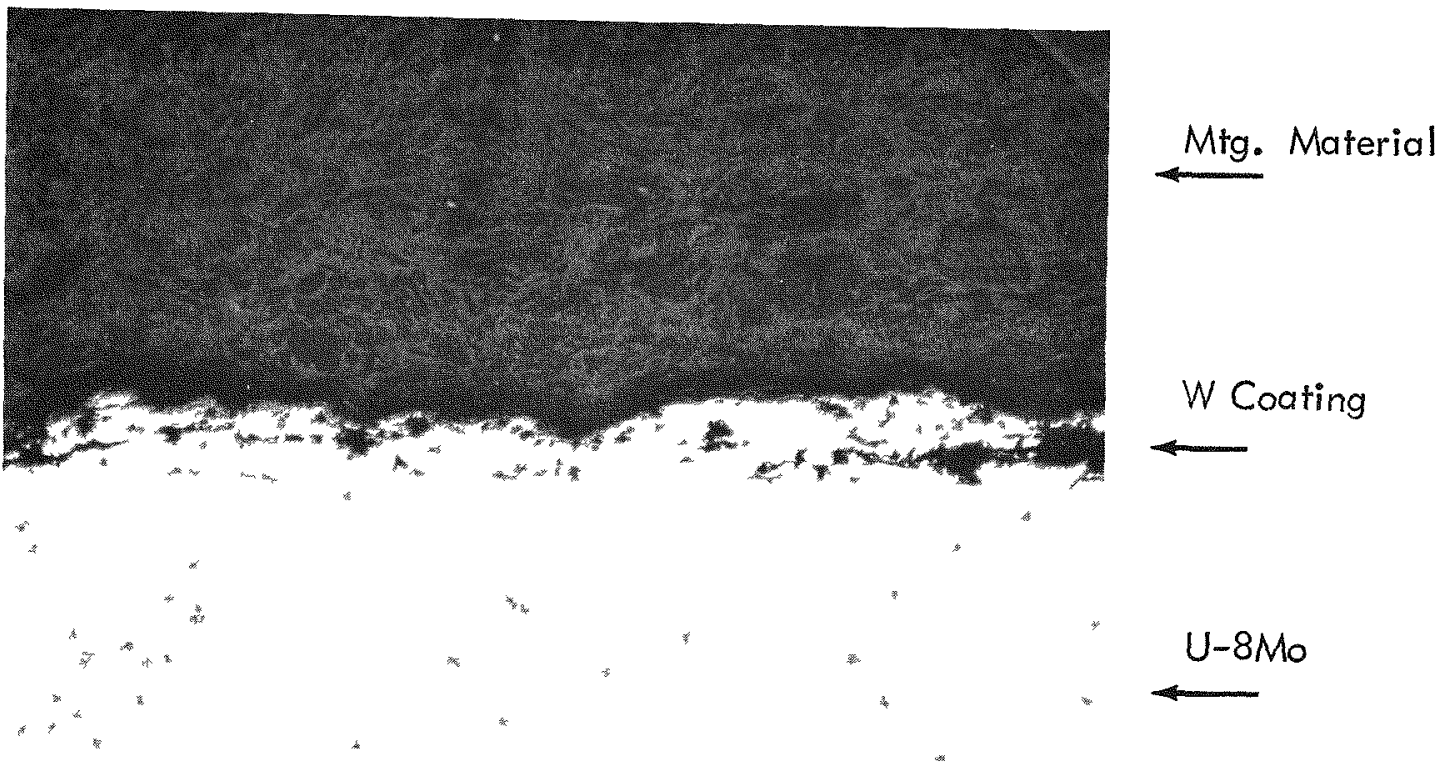

Figure 4-7. Microphotograph of U-8Mo Hame Sprayed with W Showing Coating Adherence after Thermal Exposure 


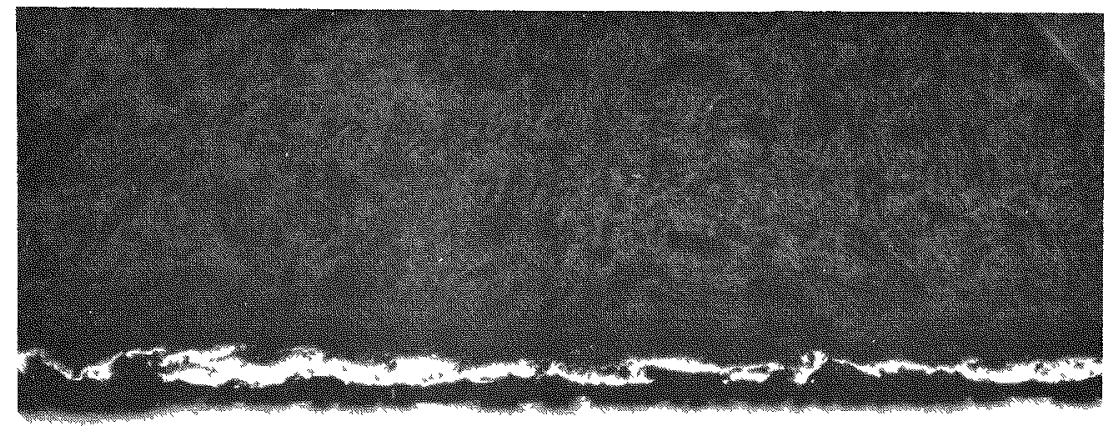

Figure 4-8. Microphotograph of Interface Between Flame Sprayed Ta Coating on U-8Mo Substrate after Thermal Exposure

\section{U-8Mo Oxidation Test}

Preliminary plans for conducting the radiation test on the PMS shield showed that the shield temperature would be high enough to cause rapid oxidation and the growth of loose oxide scales. Cladding or the use of an inert atmosphere to prevent excessive oxidation both appeared to create severe problems. As a result test were made to determine if the shield could be partially submerged in a water bath during the radiation test without excessive oxidation. Samples were submerged in $180^{\circ} \mathrm{F}$ water for 24 hours. The samples developed a very adherent light-yellowbrown oxide film. This suggests that the film is somewhat passive and will not cause and further deterioration or obvious problems. The proposed procedure for partial submergence in cooling water was therefore approved. 
Table 4-3 lists the dimensions and weight of the U-8Mo sample tested in 180 degree water. No dimensional changes were noted and no weight gain was measured. The microphotograph shown in Figure 4-9 indicates that no oxide film is visible at 500X. Figures 4-10 ( $a$ and $b$ ) are macrophotographs showing the U-8Mo sample before and after exposure to the 180 degree water bath. This evidence indicates that the oxide formed during the submersion in 180 degree water was very thin; on the order of several microns thick.

TABLE 4-3

EFFECT OF HOT WATER EXPOSURE ON THE OXIDATION OF U-8Mo

\begin{tabular}{|c|c|c|}
\hline & Before & After \\
\cline { 2 - 3 } Length & 2.00 inch & 2.00 inch \\
Diameter & & \\
Top & 0.2503 & 0.2503 \\
Middle & 0.2503 & 0.2503 \\
Bottom & 0.2501 & 0.2501 \\
Weight & 28.0298 grams & 28.0295 grams \\
\hline
\end{tabular}

U-8Mo Stress-Rupture Program

Creep and stress-rupture tests on U-8Mo were continued during the reporting period. Table 4-4 indicates the results and status of the program. The test time indicated is that time up to and including November 30, 1968. 
TABLE 4-4

(2) Astronuclear

U-8Mo CREEP-RUPTURE TEST RESULTS

\begin{tabular}{|c|c|c|c|c|c|}
\hline \multirow[b]{2}{*}{ Temperature } & \multirow[b]{2}{*}{$\begin{array}{c}\text { Metallurgical } \\
\text { Condition }\end{array}$} & \multirow[b]{2}{*}{$\begin{array}{c}\text { Stress } \\
\text { psi }\end{array}$} & \multicolumn{3}{|c|}{ Status } \\
\hline & & & $\begin{array}{c}\begin{array}{c}\text { Elongation } \\
\%\end{array} \\
\end{array}$ & $\begin{array}{l}\text { Time } \\
\text { (hours) } \\
\end{array}$ & $\begin{array}{l}\text { Minimum Creep } \\
\text { Rate, } \% / \text { hr. }\end{array}$ \\
\hline $1400^{\circ} \mathrm{F}$ & $\gamma$ & 2,000 & $133.4 \%$ & 4.6 & 14.5 \\
\hline $1400^{\circ} \mathrm{F}$ & $\gamma$ & 800 & \multicolumn{3}{|c|}{ (1120 hrs. and still on test) } \\
\hline $1200^{\circ} \mathrm{F}$ & $\gamma$ & 2,000 & $48.4 \%$ & 530 & 0.0382 \\
\hline $1200^{\circ} \mathrm{F}$ & $\gamma$ & 1,700 & \multicolumn{3}{|c|}{ (1230 hrs. and still on test) } \\
\hline $1000^{\circ} \mathrm{F}$ & $\gamma^{\prime}+a$ & 10,000 & 8.53 & 979 & 0.00619 \\
\hline \multirow[t]{3}{*}{$900^{\circ} \mathrm{F}$} & $\gamma^{\prime}+a$ & $10,000^{*}$ & 1.15 & 1142 & .00043 \\
\hline & & $12,500^{*}$ & .26 & 332 & .00055 \\
\hline & & $15,000^{*}$ & .21 & 434 & .00038 \\
\hline $900^{\circ} \mathrm{F}$ & $\gamma^{\prime}+a$ & 20,000 & \multicolumn{3}{|c|}{ (272 hrs on test) } \\
\hline
\end{tabular}

Note: Because of long rupture life at the initial stress level, multiple loadings are being used to determine creep rate versus stress at a constant temperature.

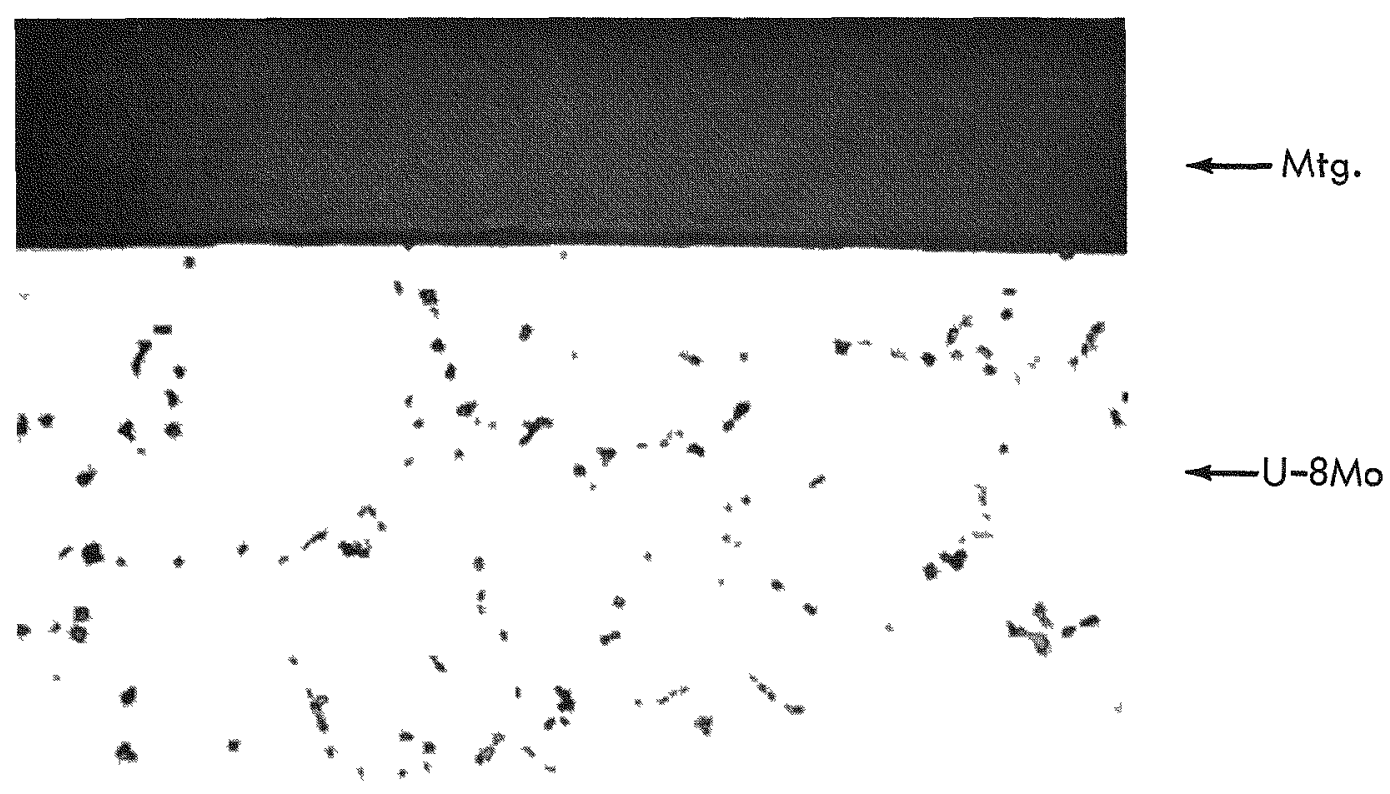

Figure 4-9. Microphotographs of Surface of U-8Mo Exposed to $180^{\circ} \mathrm{F}$ Water for 24 Hours 
(2) Astronuclear
Laboratory

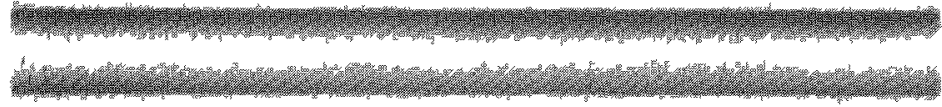

a) Before

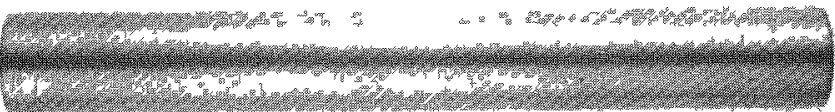

b) After

Figure 4-10 (a-b). U-8Mo Water Oxidation Sample Shown Before and After Exposure to 180 Degree Water for 24 Hours 
Subtask 415 - Heat Source Radiation Evaluation

The SNAP-23A biological shield assembly test was performed by ORNL on November 18, 1968. The object of this test was to determine the effectiveness of the SNAP-23A biological shield assembly for attenuating the radiation from the SNAP-23A $\mathrm{SrTiO}_{3}$ fuel capsule. The results of this radiation test will be used to evaluate the adequacy of the present shield design and the analytical methods used.

The function of the SNAP-23A biological shield is to reduce the nuclear radiation emitted by the $\mathrm{SrTiO}_{3}$ source to an acceptable level. An acceptable level, as defined by the Department of Transportation (DOT) regulations, results when:

1) Gamma radiation does not exceed 200 millirem per hour or the equivalent at any point on a readily accessible surface.

2) At any time during transport, the radiation dose rate at three feet from the external surface of the outside container does not exceed 10 millirem per hour or the equivalent.

The SNAP-23A shield was designed to meet these requirements.

The shield test conducted at ORNL involved the PMS biological shield (excluding clads) and the recently fueled SNAP-23A fuel capsule. The tantalum diffusion barrier and the exterior clads were omitted due to programmatic considerations. The characteristics of the SNAP-23A fuel capsule are briefly summarized in Table 4-5.

Two primary methods were used by ORNL to measure the radiation dose rates Cutie Pie survey instruments and thermoluminescence dosimetry, TLD. X-ray film was also used at some points to provide additional information and facilitate data correlation. The two Cutie Pie instruments were freshly calibrated by the ORNL radiological safety group using a standard source. 
TABLE 4-5

SNAP-23A FUEL CAPSULE CHARACTERISTICS

Fuel Form

Number of Pellets

Total Power

Total Curies

Materials

Outer Capsule Liner

Capsule Length

*Preliminary ORNL measurements
Sintered ${ }^{90} \mathrm{SrTiO}_{3}$ Pellets

4

1127 watts thermal *

$165,735^{*}$

Hastelloy-C

Hastelloy-C

8.026 inch cold 
Figure 4-11 and Table 4-6 illustrate the proposed dose rate measurement positions. Table 3-13 also summarizes the Hittman Associates" predicted dose rates and the corresponding ORNL Cutie Pie measurements. The TLD and film measurements will be completed shortly.

A preliminary comparison of the experimental results with the calculated values indicates excellent agreement at most points. It is apparent that the predicted values calculated at the top surface of the shield differ from the measured data by approximately a factor of two. The difference between the predicted and measured values decreases as the distance from the shield surface increases.

One possible reason for the noted surface difference lies in the fact that due to the finite size of the chamber of the Cutie Pie, it is impossible to make an accurate surface measurement. Also, the shield may be slightly thicker than that used in the analytical model due to machining tolerances.

A preliminary examination of points 31,37 , and 38 show that the measured dose rates are slightly higher than predicted. This indicates that we may be experiencing a small degree of streaming through the shield-shield plug interface. The values $20 \mathrm{~cm}$ and $50 \mathrm{~cm}$ from the surface are well with in acceptable limits.

In general, the preliminary data show that the present shield is capable of meeting the DOT dose rate requirements. 


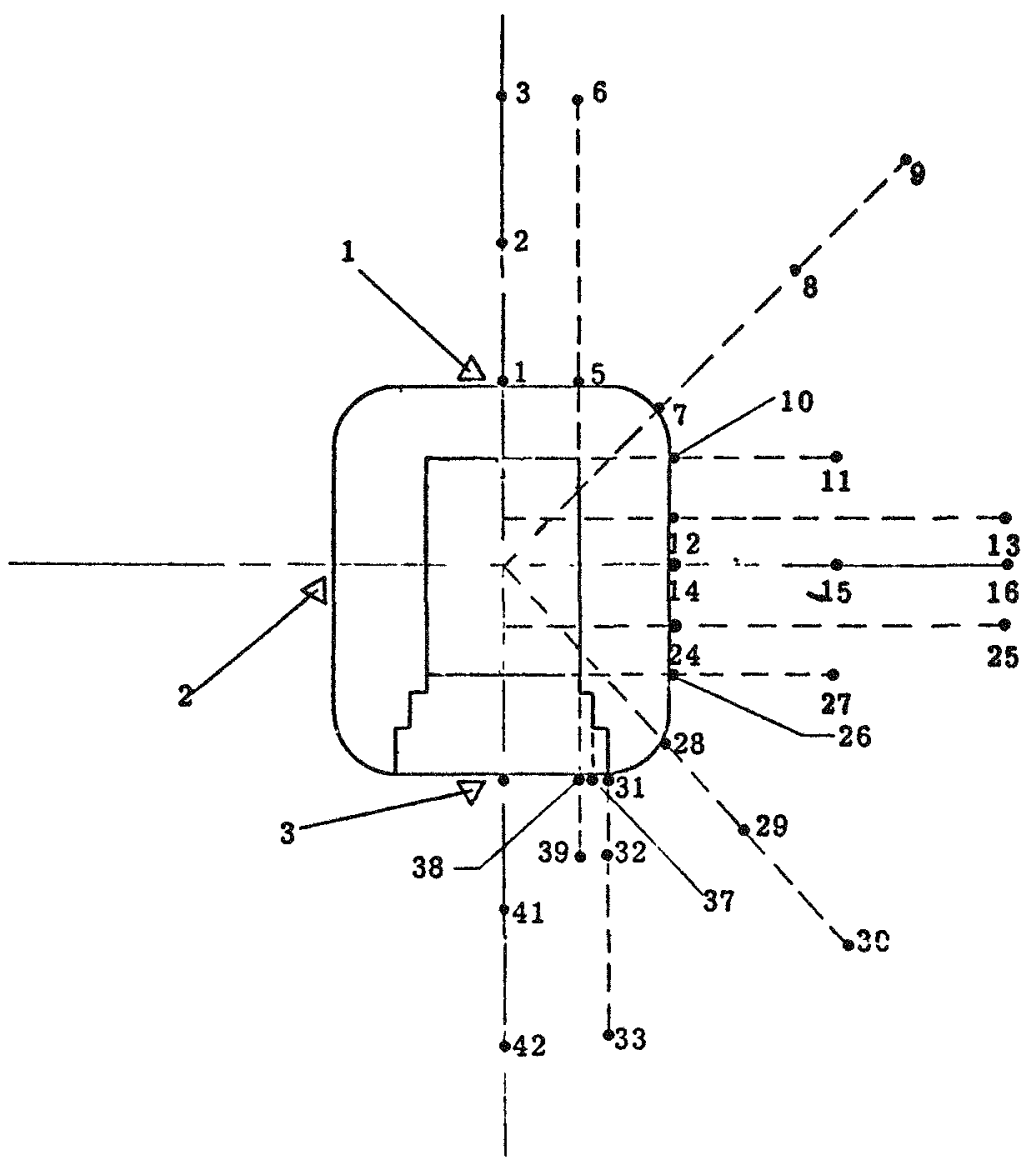

- Dose Rate Measurement Points

$\triangle$ Thermocouple Attachment Points

(two on each of the surfaces indicated)

Figure 4-11. SNAP-23A Shield-Dose Measurement Position 
TABLE 4-6

DOSE RATES FOR THE SNAP-23A SHIELD ASSEMBLY

\begin{tabular}{|c|c|c|c|c|c|}
\hline \multicolumn{6}{|c|}{ Preliminary Shield Test Results } \\
\hline $\begin{array}{l}\text { Dose Point } \\
\text { Number }\end{array}$ & $\begin{array}{l}\text { Distance } \\
\text { from Surface } \\
(\mathrm{cm})\end{array}$ & $\begin{array}{l}\text { Cufie Pie } \\
\text { No. } 1 \\
\text { (mrem/hr) }\end{array}$ & $\begin{array}{c}\text { Cutie Pie } \\
\text { No. } 2 \\
\text { (mrem/hr) }\end{array}$ & $\begin{array}{c}\text { Average Experi- } \\
\text { mental Result } \\
\text { (mrem } / \mathrm{hr} \text { ) }\end{array}$ & $\begin{array}{l}\text { Calculated } \\
\text { Value } \\
\text { (mrem } / \mathrm{hr} \text { ) }\end{array}$ \\
\hline 1 & 0 & 580 & 600 & 590 & 1127 \\
\hline 2 & 50 & 42 & 44 & 43 & 68 \\
\hline 3 & 100 & 18 & 18 & 18 & 22 \\
\hline 4 & 150 & --- & -- & -- & 10 \\
\hline 5 & 0 & 240 & 220 & 230 & 473 \\
\hline 6 & 100 & 15 & 16 & 16 & 21 \\
\hline 7 & 0 & 180 & 200 & 190 & 315 \\
\hline 8 & 50 & 20 & 20 & 20 & 15 \\
\hline 9 & 100 & 6 & 7 & 7 & 5 \\
\hline 10 & 0 & 200 & 240 & 220 & 249 \\
\hline 11 & 50 & 38 & 38 & 38 & 34 \\
\hline 12 & 0 & 385 & 390 & 388 & 431 \\
\hline 13 & 100 & 12 & 12 & 12 & 12 \\
\hline 14 & 0 & 400 & 400 & 400 & 475 \\
\hline 15 & 50 & 38 & 40 & 39 & 39 \\
\hline 16 & 100 & 12 & 12 & 12 & 12 \\
\hline 17 & 150 & 6 & 6 & 6 & 6 \\
\hline 24 & 0 & 320 & 320 & 320 & 341 \\
\hline 25 & 100 & 12 & 12 & 12 & 12 \\
\hline 26 & 0 & 220 & 220 & 220 & 249 \\
\hline 27 & 50 & 37 & 36 & 37 & 35 \\
\hline 28 & 0 & 240 & 250 & 245 & 304 \\
\hline 29 & 50 & 24 & 23 & 24 & 14 \\
\hline 30 & 100 & 8 & 10 & 9 & 4 \\
\hline 31 & 0 & 300 & 310 & 305 & 176 \\
\hline 32 & 20 & 78 & 70 & 79 & 54 \\
\hline 33 & 100 & 8 & 8 & 8 & 7 \\
\hline 37 & 0 & 220 & 240 & 230 & 217 \\
\hline 38 & 0 & 250 & 260 & 255 & 209 \\
\hline 39 & 20 & 73 & 70 & 72 & 67 \\
\hline 40 & 0 & 260 & 240 & 250 & 356 \\
\hline 41 & 50 & 26 & 26 & 26 & 24 \\
\hline 42 & 100 & 10 & 9 & 10 & 8 \\
\hline 43 & 150 & 4 & 5 & 5 & 4 \\
\hline
\end{tabular}

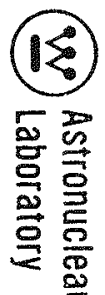




\section{SYSTEM DEVELOPMENT}

Subtask 510 - System Development

\section{Multiple Heater Verification}

The verification test purpose is to provide input into the EMS test plan and PMS design. The unit was processed in the same manner used for the EMS electrical heater assembly. Testing was conducted to simulate performance of the test unit in the SNAP-23A environment during static and dynamic modes of operation. This was to provide information to answer questions concerning operation of heaters side by side, restraining plates, helium atmosphere at temperatures of $1500^{\circ} \mathrm{F}$, life of Watlow heaters in a shock and vibration environment, characteristic of the heater assembly configuration, and to identify possible deposition of carbon contaminants.

The multiple heater verification testing is complete. The unit was subjected to a shock and vibration environment more severe than that required for EMS testing. The following tests were performed in the axial direction: three sweeps from 22 to 5 cps at $1.3 \mathrm{~g} \mathrm{~s}^{\mathrm{s}} \mathrm{s}$ three sweeps from 22 to $50 \mathrm{cps}$ at .051 inch displacement, and dwell at $50 \mathrm{cps}$ at .051 inch displacement. In the lateral direction the limits were: three sweeps from 19 to $5 \mathrm{cps}$ at $1.3 \mathrm{~g}^{\prime} \mathrm{s}$, three sweeps from 19 to $50 \mathrm{cps}$ at .072 inch displacement and dwell at $50 \mathrm{cps}$ at .072 inch amplitude. The heater was shocked three times in each direction to a level of $10 \mathrm{~g}$ peak in 10 milliseconds. This testing did not affect the performance of the unit. The heater assembly circuits are shown in Figures 5-1 and 5-2 before and after dynamic testing. 
(2) Astronuclear

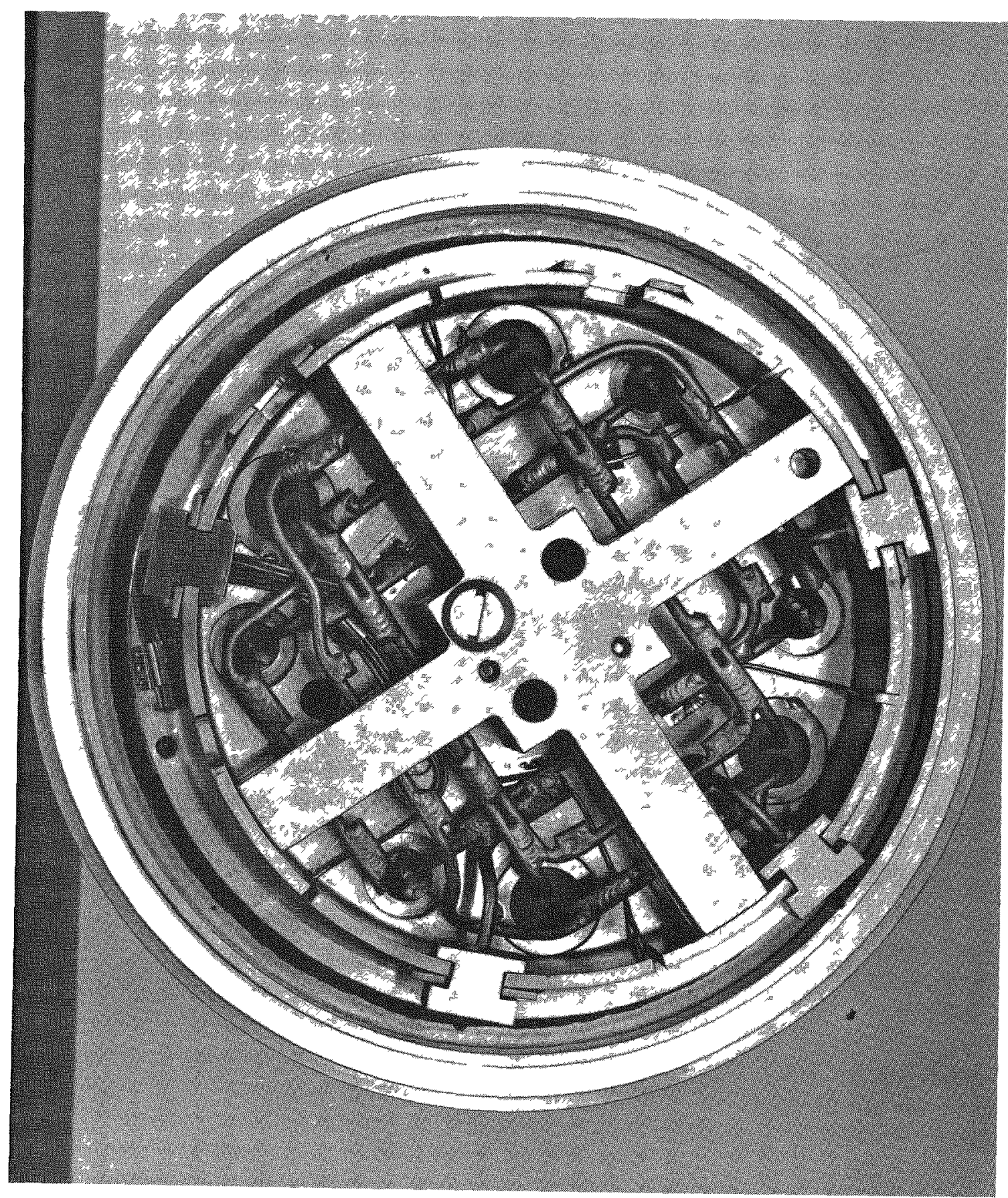

Figure 5-1. Multiple Heater Unit During Assembly - Before Test 
(29) Astronuclear

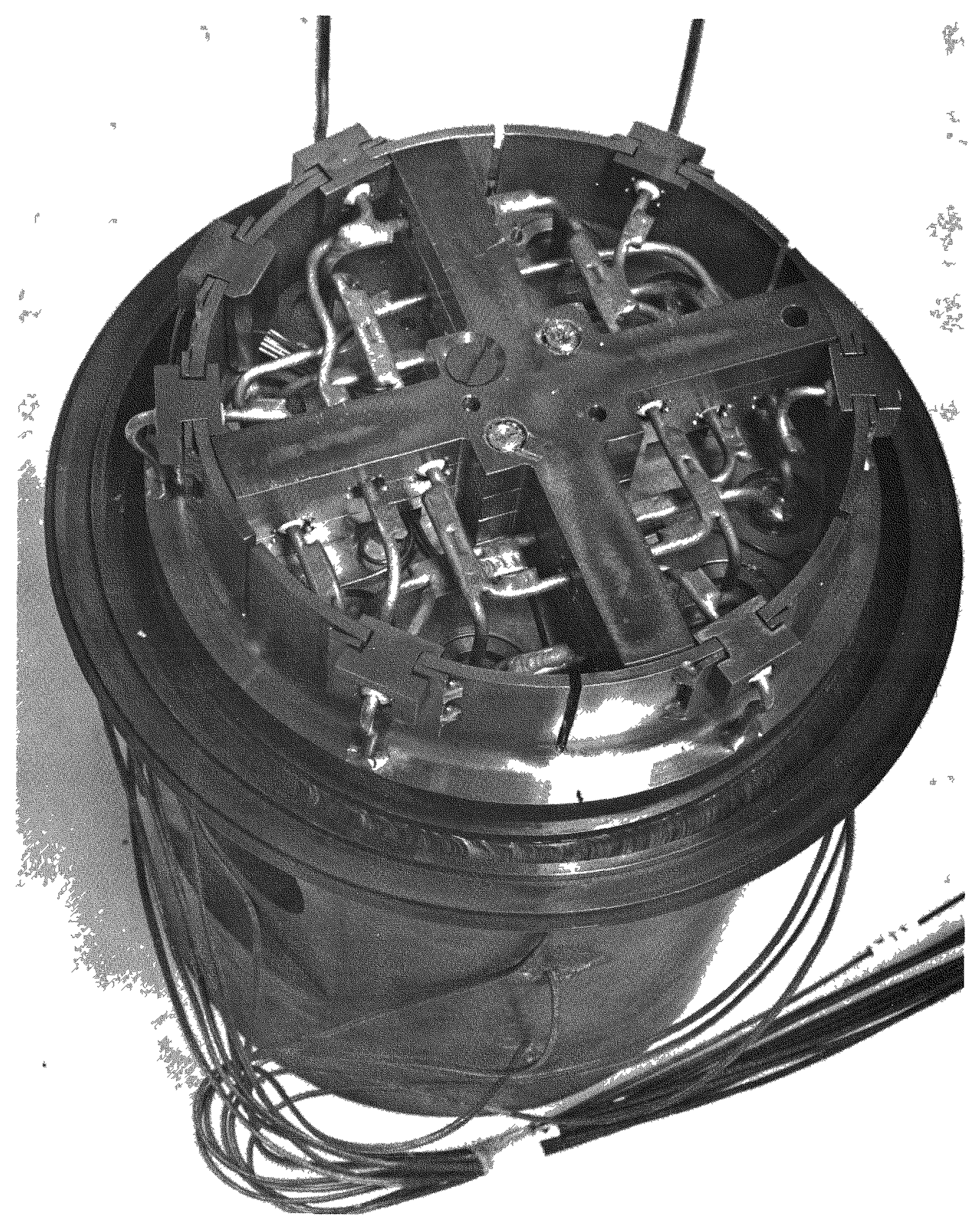

Figure 5-2. Multiple Heater Unit - After Test 


\section{EMS Three Point Thermal Test}

EMS testing started September 9, 1968. The system has logged over 500 hours at temperature since that time. The assembled SNAP-23A EMS rebuilt unit is shown in Figure 5-3 installed in the test area with instrumentation, power leads, and helium supply lines as required by EMSN-3 Rev. 1 ("Experimental Mockup System Thermal Performance Test Procedure"). Figures 5-4 and 5-5 illustrate the SNAP-23A test facility and power supply and control system respectively.

Thermal steady state data were taken at the following power levels*:

$$
898 \text { watts }
$$

$\begin{array}{ll}1112 \text { watts } & \text { Estimated EOL } \\ 1286 \text { watts } & \text { Intermediate level } \\ 1439 \text { watts } & \text { Estimated BOL }\end{array}$

System performance data have been transmitted to Systems Engineering for review and evaluation.

\section{EMS Base Assembly Test}

After preparation of the manifold to be used to change gases in the base assembly, the test was completed to the requirements prescribed by "Experimental Mockup System (EMS) Base Assembly Performance Test Procedure, EMSN-3A Rev. 1 " on October 25, 1968. A thermal steady state data point, an open circuit test, and gas samples were taken for all but the third event listed below.
1) Initial Evacuation
2) Backfill with Nitrogen
3) Second Evacuation
4) Backfill with Krypton

System performance data have been transmitted to Systems Engineering for review and evaluation.

*Not corrected for instrumented losses 


\section{QV Astronuclear}

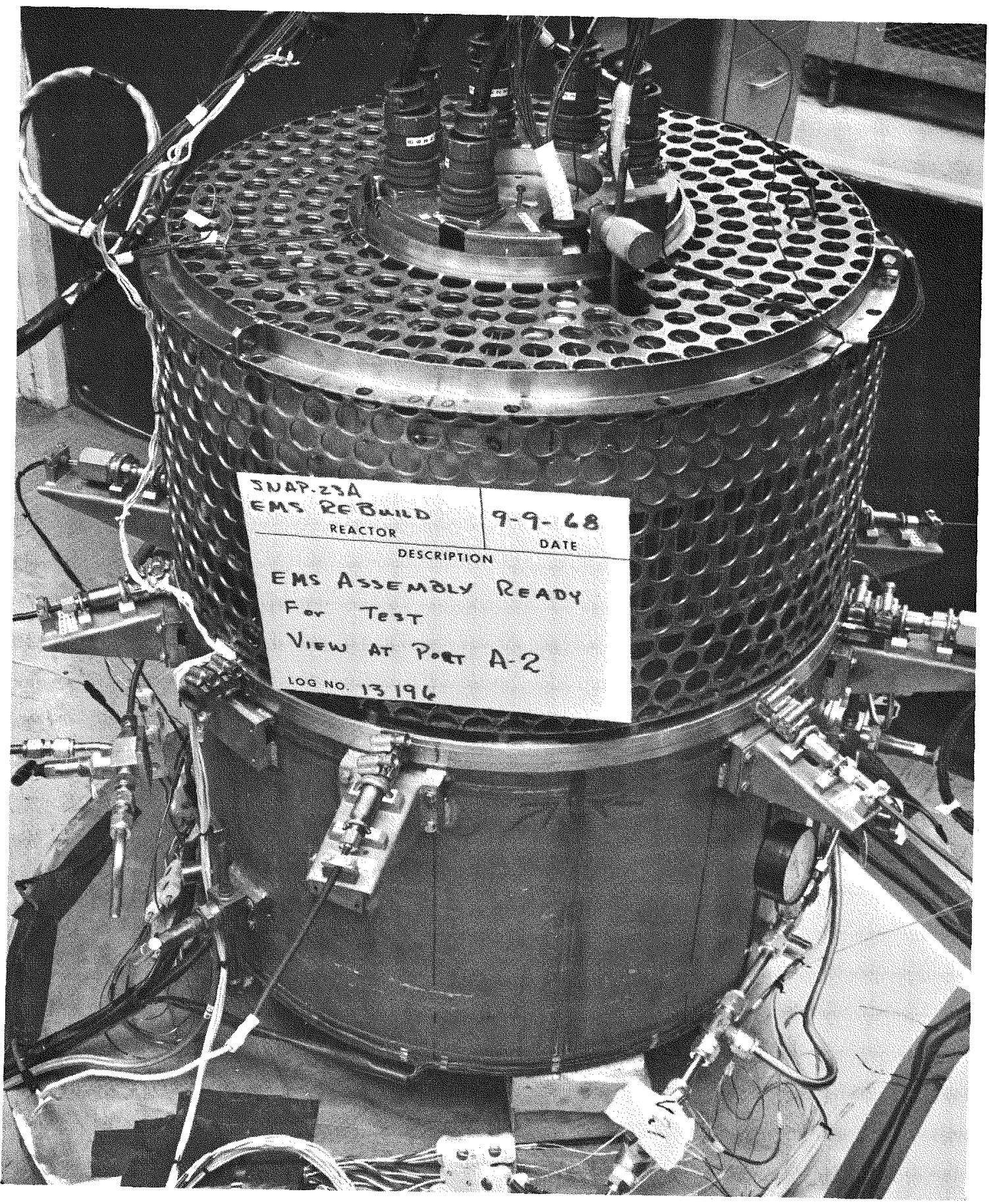

Figure 5-3. SNAP-23A Rebuilt EMS Ready for Thermal Tests 


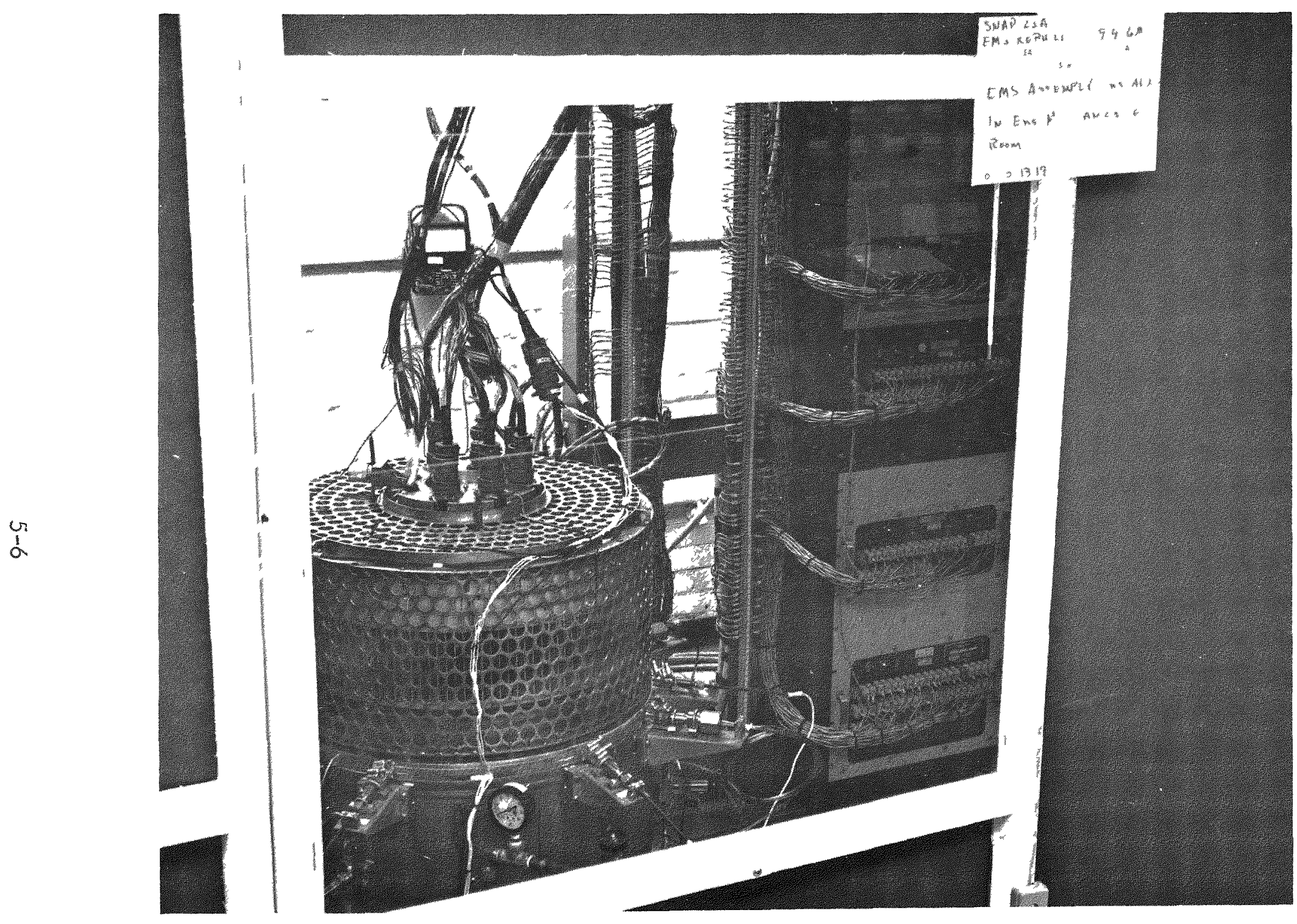

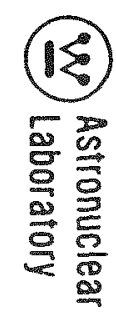

Figure 5-4. SNAP-23A Test Facility 
(20) Astronuclear

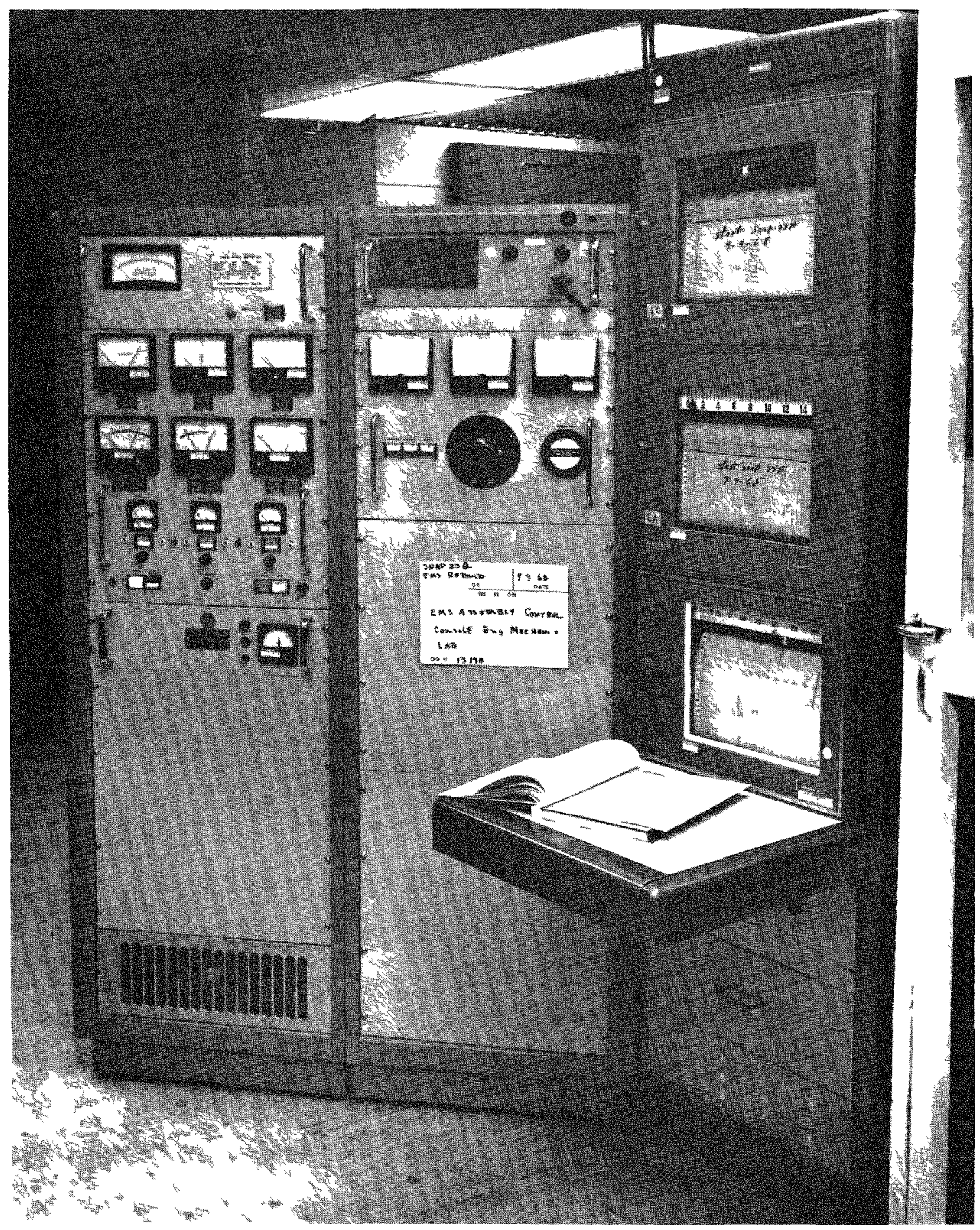

Figure 5-5. SNAP-23A Power Supply and Control System 


\section{EMS Shock and Vibration Testing}

The objectives of the tests were 1) to investigate the shock and vibration characteristics of the EMS, 2) to determine the capabilities and limitations of the system, and 3) to determine if performance degradation or malfunction will be encountered as a result of shock and vibration environments. The shock and vibration tests were conducted at the Engineering Mechanics Laboratory. The following results were obtained.

1) No visible damage was caused to the EMS by the shock environment.

2) There are no identifiable resonances over the range of frequencies tested for both the axial and lateral axis tests.

3) The maximum recorded amplification of 3 to 1 was obtained when the EMS was vibrated at $50 \mathrm{cps}$ in the lateral direction.

4) Particles of insulation material were loosened during vibration at higher frequencies. The helium leak rate increased during vibration in the lateral direction.

5) The maximum recorded amplification in the axial direction was 1.5 to 1 at $50 \mathrm{cps}$.

6) There were no changes in system characteristics and no visible structural damage noted during vibration in the axial direction.

$\underline{\text { Test Setup }}$

The test sequence consisted of first performing the lateral axis shock and vibration tests and then the axial shock and vibration tests. The lateral axis test setup shown in Figures 5-6 and 5-7 consisted of the EMS bolted to a base plate. The plate was mounted on four oil film slip tables. The slip tables were used to support the weight of the EMS and base plate while permitting unidirectional translation. Two electrodynamic vibration exciters, located on opposite sides of the base plate provided sinusoidal force inputs. 


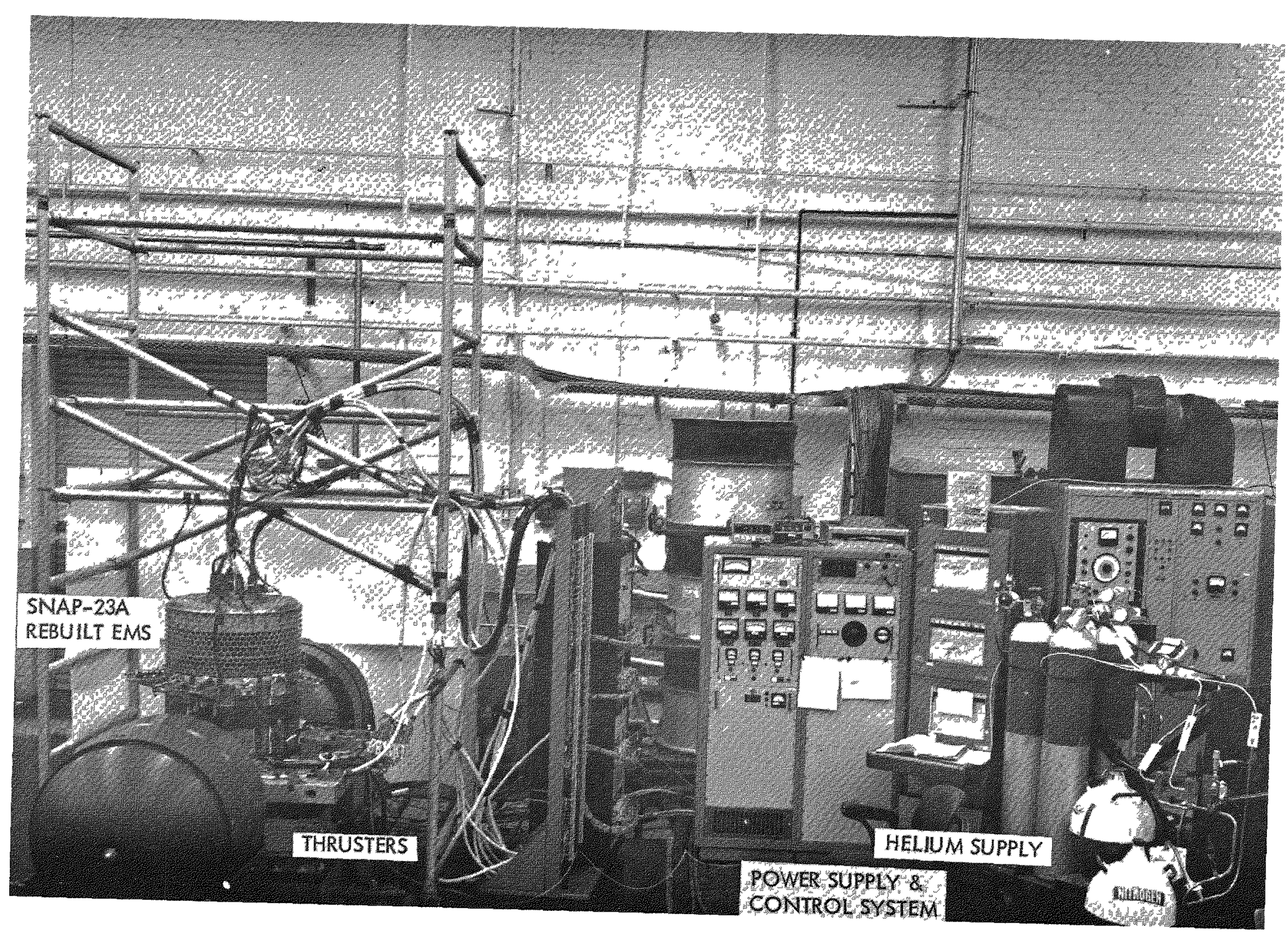

Figure 5-6. Radial Axis Test Setup for Shock and Vibration Tests 


\section{Astronuclear
Laboratory}

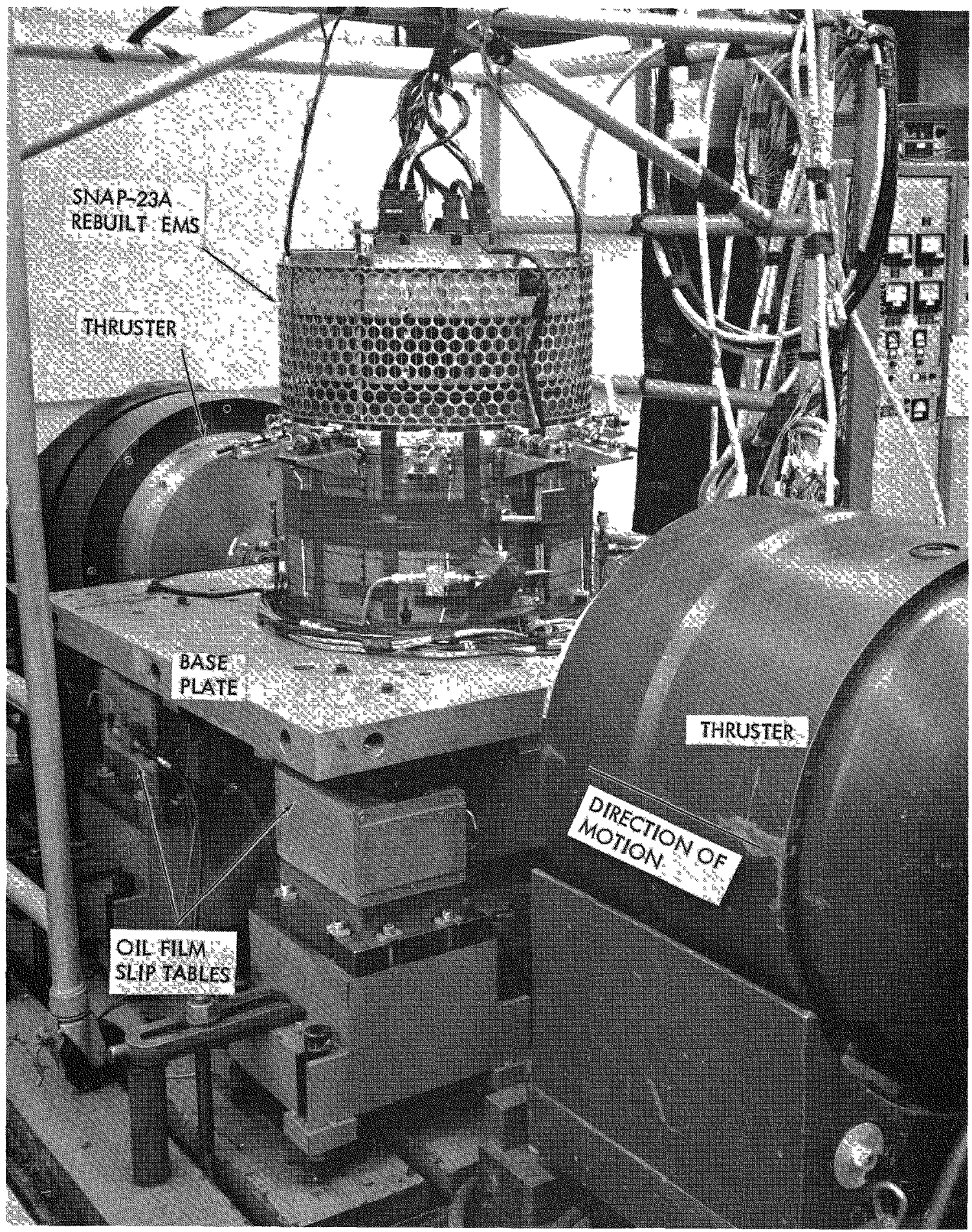

Figure 5-7. Radial Axis Test Setup 
The axial test setup, Figure 5-8, consisted of the EMS and base plate supported on four vibration isolators. Two electrodynamic vibration exciters were used to apply the vibratory inputs.

All shock and vibration testing was carried out with the electrical heat source operating at $\mathrm{BOL}$ power input.

\section{Instrumentation}

Transducers were attached to the EMS and base plate to monitor the response and control motions. Critical thermocouples, heater voltage, heater current, heater current leakage, heater source pressure, and base assembly pressure were defined in EMSN-3 Rev. 1 "Thermal Performance Test Procedure". The output signals from these components were recorded in the data acquisition room.

A triaxial accelerometer was installed on top of the rain cover flange above the converter. One accelerometer was mounted on the top radiator shroud, one on the dynamic test fixture adjacent to the thruster input fitting and one accelerometer on the base assembly. The output signals from the accelerometers, heat source pressure, and base assembly pressure were recorded on oscillograph and magnetic tape.

\section{Test Procedure}

The testing procedure followed the requirements of EMSN-3B Rev. 1 "Experimental Mockup System Shock and Vibration Test Procedure". The test sequence was: 1) calibrate the WANL equipment for generating the specified shock pulse by using a mass mockup with the same weight and center of gravity as the EMS, 2) after calibration, replace the mass mockup with the EMS before performing the shock tests and 3) conduct the vibration test. By using this sequence, first shock and then vibration, handling of the EMS was minimized. The same sequence was used for the horizontal direction followed by vertical direction. 
Astronuclear
Laboratory

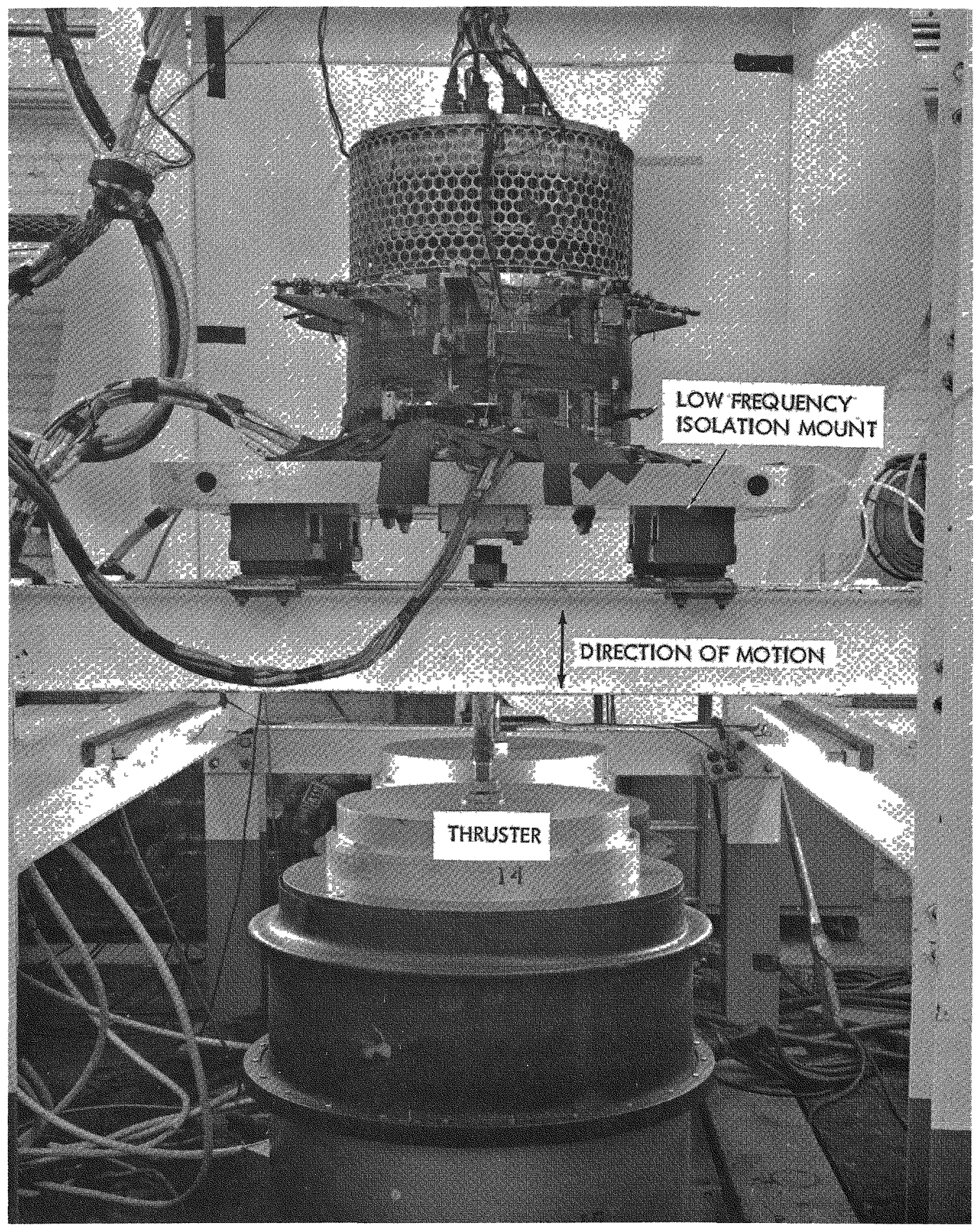

Figure 5-8. Axial Test Setup 
Shock Testing - The EMS was subjected to three shocks in two directions along each of two mutually perpendicular axes for 12 total shocks. Typical input shocks, having a peak value of $5 \mathrm{~g}^{4} \mathrm{~s}$ and a nominal duration of 10 mill iseconds are shown in Figure 5-9. Sinusoidal Cycling - The frequency of the applied vibration was cycled at a logarithmic rate. Three complete cycles from 5 to $50 \mathrm{cps}$ and return to $5 \mathrm{cps}$ were performed.

For the horizontal direction, three sweeps from 5 to $50 \mathrm{cps}$ and back to $5 \mathrm{cps}$ were performed at a sweep rate corresponding to 7.6 minutes duration; the three sweeps were repeated over the same frequency range but the cycling rate for each sweep was decreased to 15 minutes to comply with MIL-STD 810A. No identifiable resonances in the range of 5 to $50 \mathrm{cps}$ were noted. The response of the EMS is shown in the graph of Figure 5-10. The $x$ direction accelerometer was located at the top of the rain cover flange above the converter and was oriented in the direction of motion. The maximum amplification obtained was 3 to 1 when the EMS was vibrated at $50 \mathrm{cps}$. At frequencies of 38 to $50 \mathrm{cps}$ Min-K 2000 particles of insulation material escaped from the top plate thermocouple connectors. Some of the powder was deposited on the rain shield and is shown in Figure 5-11. During the final frequency sweep, in the horizontal direction, an increase in the helium leak rate caused a reduction in the heat frame temperature. Total test time along this axis was 67.8 minutes.

For the vertical direction, the sinusoidal cycling test consisted of three sweeps from 5 to $50 \mathrm{cps}$ and return to $5 \mathrm{cps}$ in 15 minutes. The response of the EMS is shown graphically in Figure 5-10 which is the frequency versus the ratio of $z$ direction accelerometer to the control accelerometer. A maximum amplification of 1.5 to 1 was obtained in the axial direction at a frequency of $50 \mathrm{cps}$.

No changes in system characteristics were noted and no visible structural damage was observed. Total test time in this axis was 45 minutes. 
(QV) Astronuclear

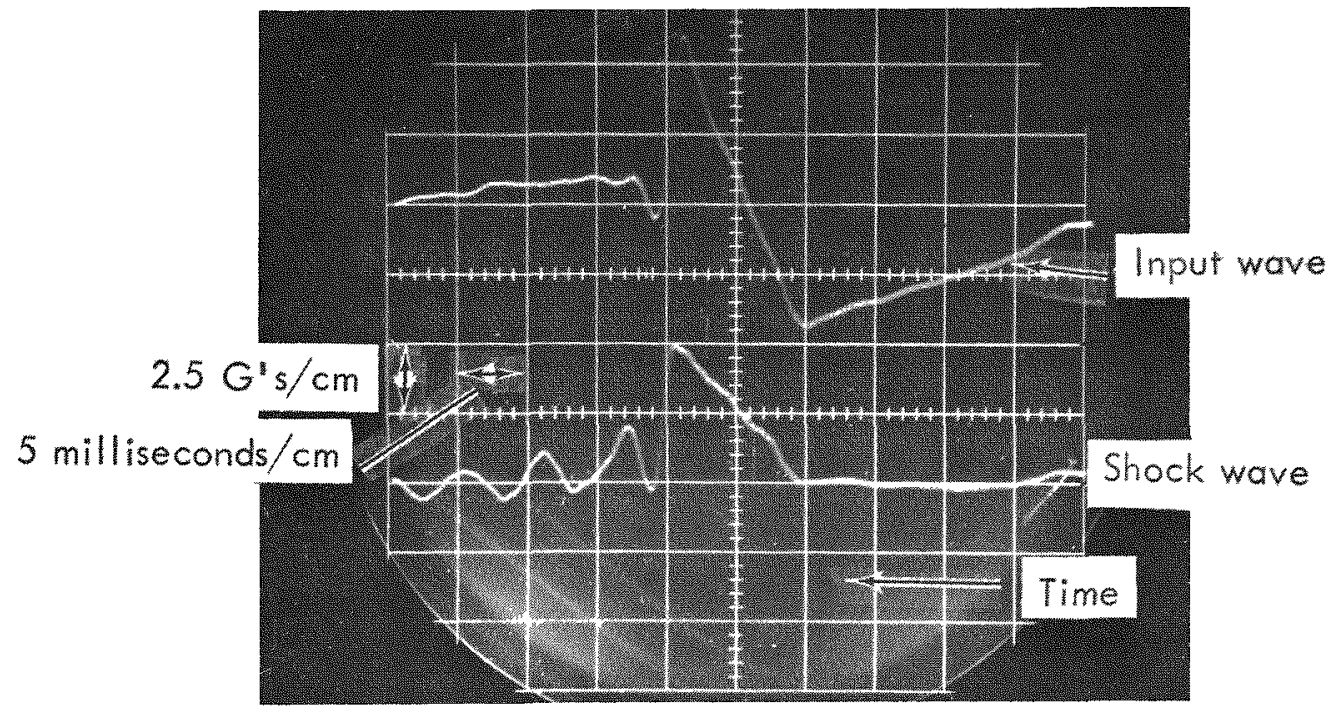

a) EMS in Horizontal Position

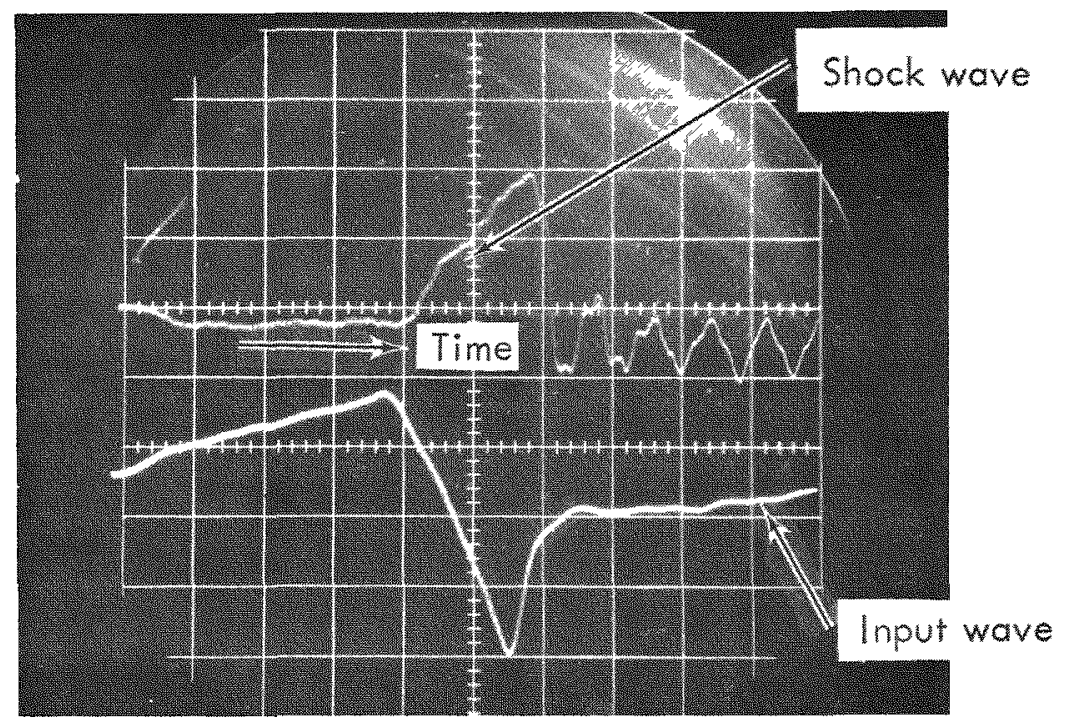

b) EMS in Vertical Position

Figure 5-9. Typical Input Shocks 


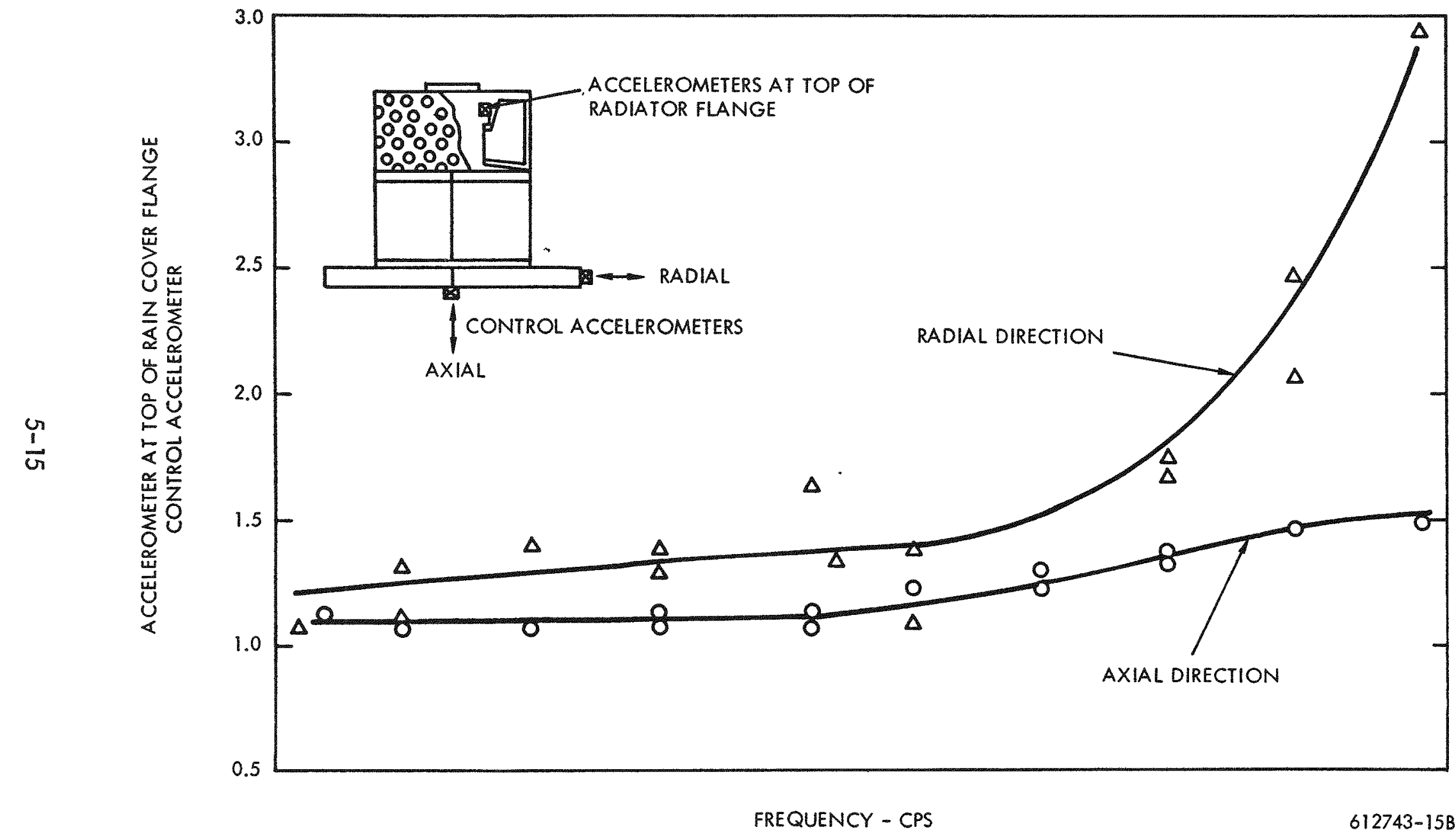

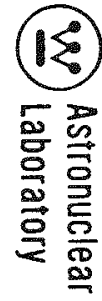

Figure 5-10. Frequency Vs. Ratio of Accelerometers on Radiator Flange to Control 


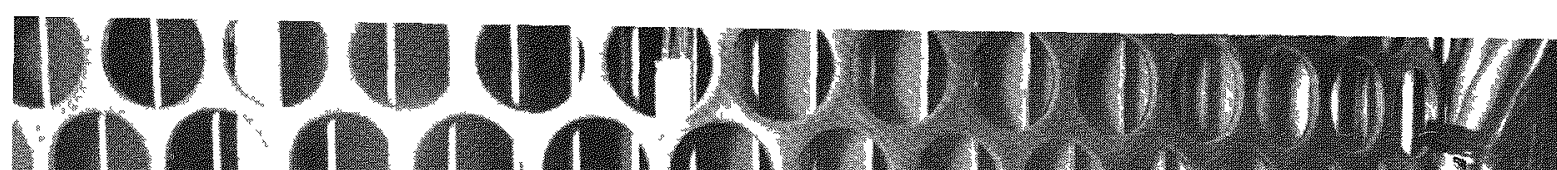

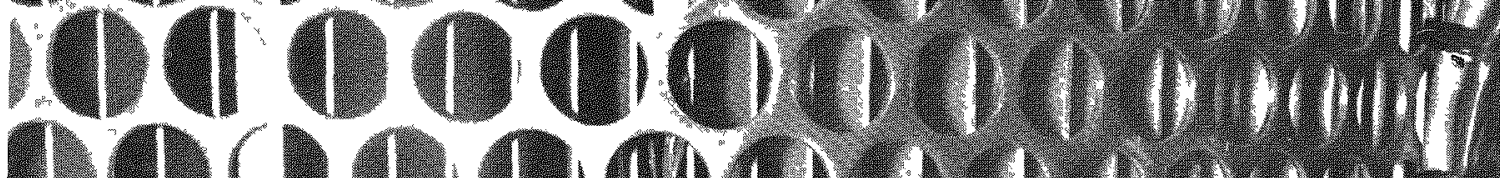

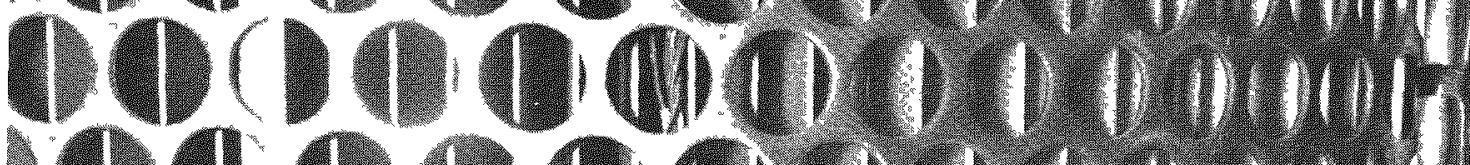

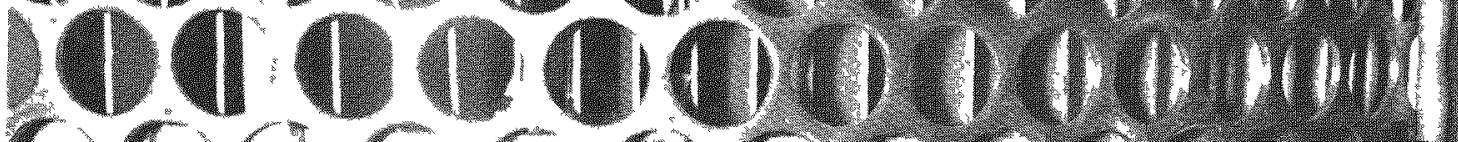

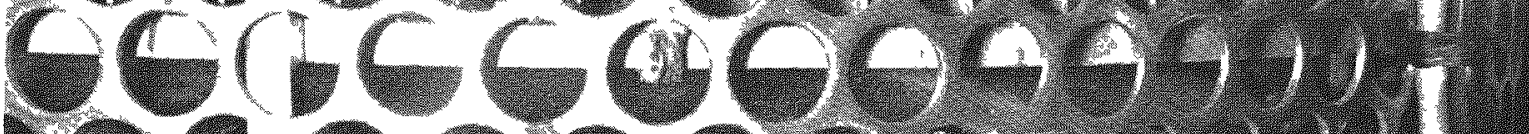

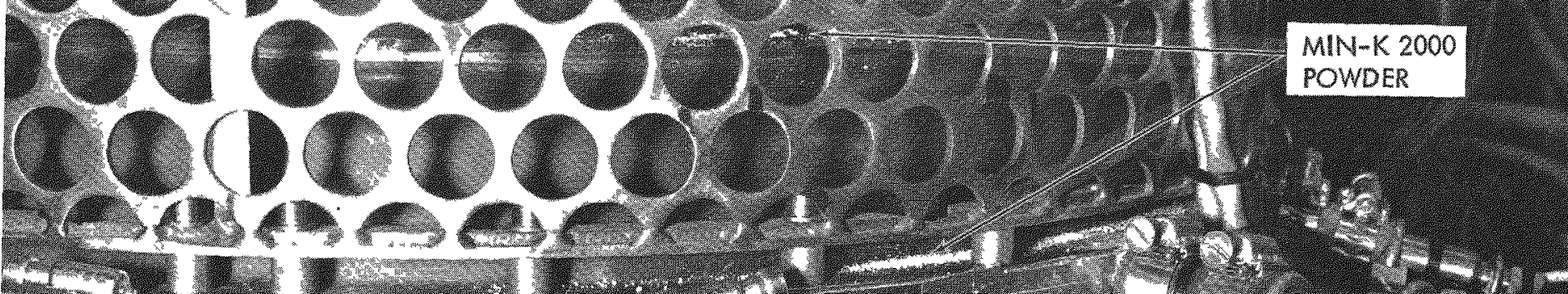

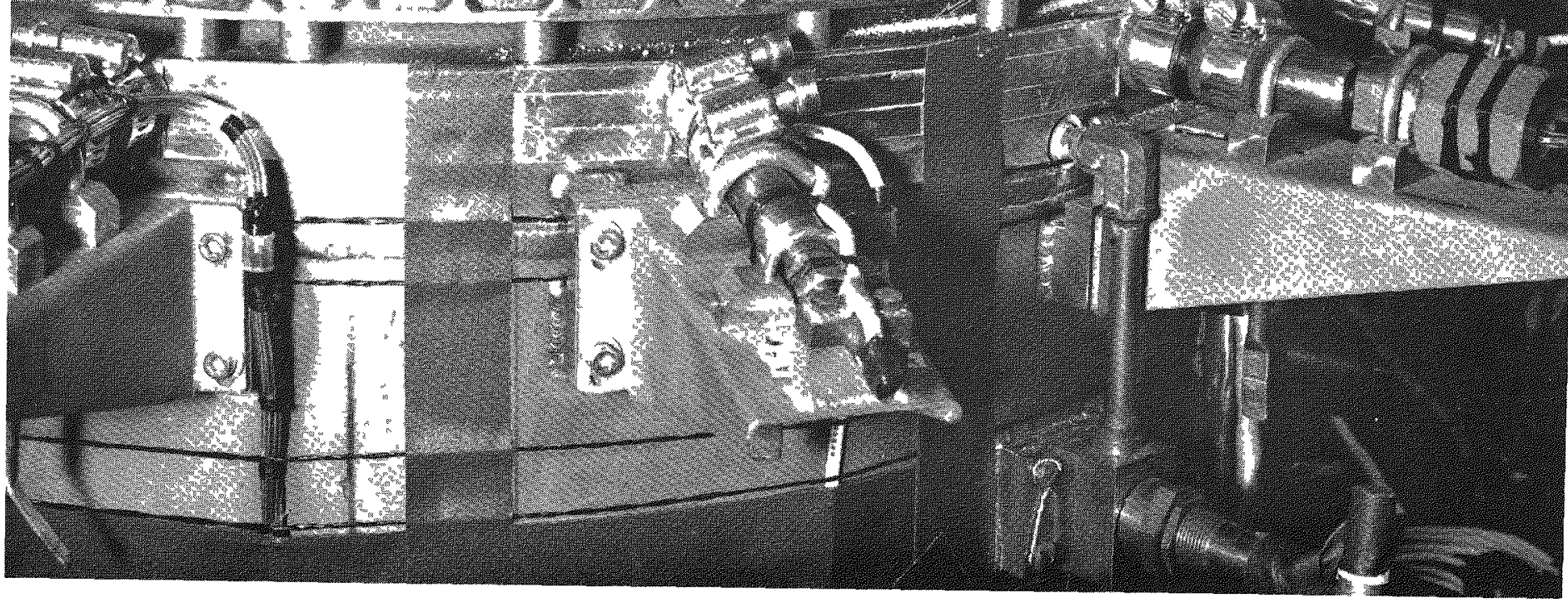

Figure 5-11. Min-K 2000 Powder Deposited on Rain Shield 


\section{SAFETY ANALYSIS}

Subtask 610 - Safety Analys is

The new updated thermal model has been developed to perform additional safety analys is on the SNAP-23A generator system. The model handles steady state and transient cases and provides more accurate temperature profiles in critical areas of the generator. Certain known limitations of the old thermal model have been revised. The old thermal model required considerable computer time to perform analysis of long real time problems. This problem was due to a low minimum time step within the computer model. In the new model, nodes have been selected to maximize the limiting time step, allowing analys is of long real times with reasonable machine times.

The new thermal model consists of 65 nodes and approximarely 140 connectors. The model is shown in Figure 6-1. The number of nodes has been selected to provide an optimum balance between accuracy and computer time. 


\section{(2) Astronuclear}

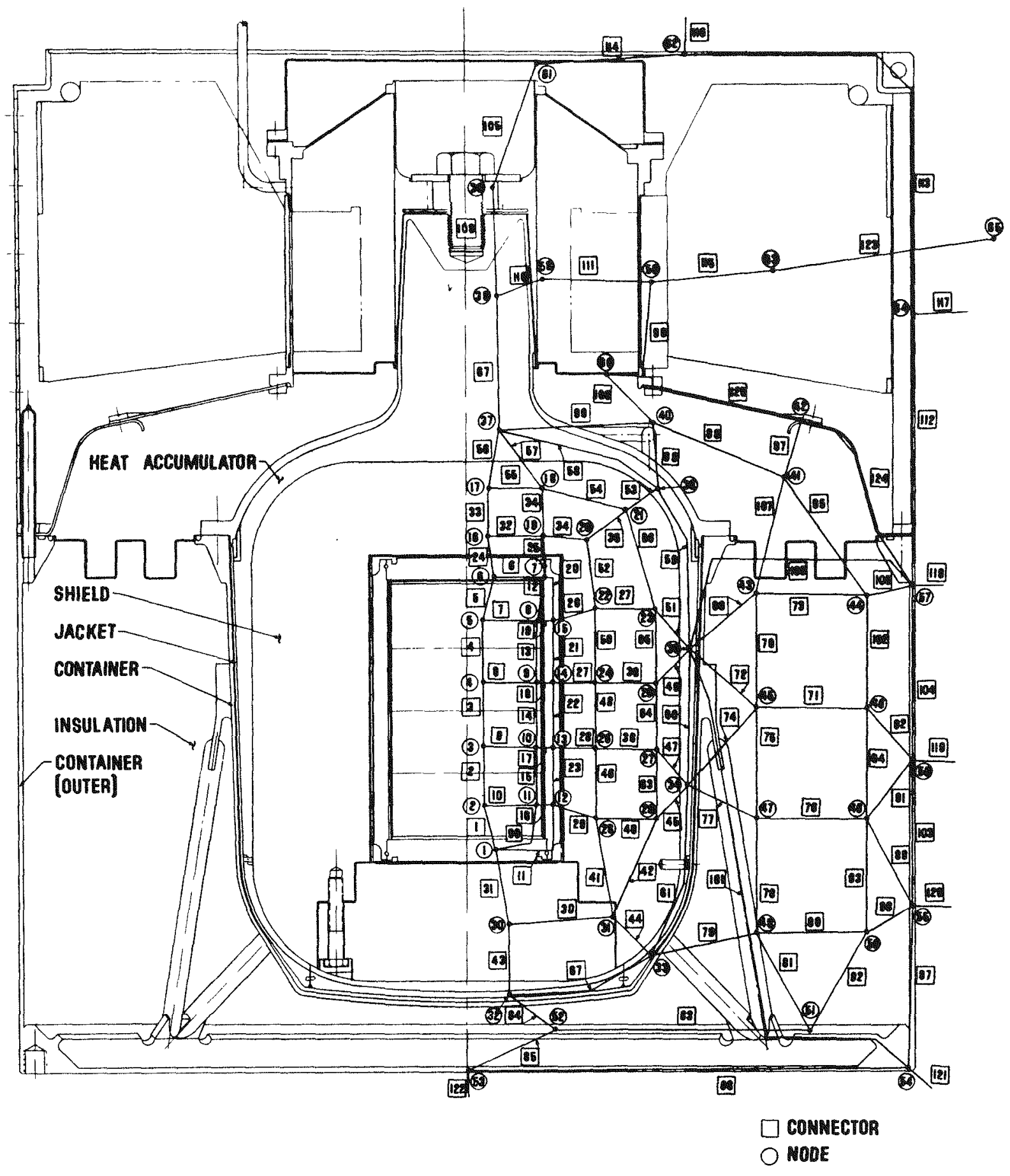

Figure 6-1. Safety Thermal Model 
The major areas of change have been:

1) The number of nodes and connectors used to mock up the capsule has been reduced. There were two major reasons for this reduction. First, fewer nodes adequately describe the capsule for safety oriented analyses. Secondly, the minimum time step in the old model was small because of small nodes in this region.

2) The number of nodes in the shield were increased because a better temperature profile through the shield is required.

3) The number of nodes in the copper heat accumulator has been reduced because of the small temperature gradients through the copper.

4) The number of nodes in the Min-K insulation was increased to give a more accurate temperature profile. The expected temperature profile and a best fit temperature profile with three nodal arrangements are shown in Figure 6-2.

As can be seen from Figure 6-2, the more nodes used, the more accurate the solution becomes. As the number of nodes increases, the running time correspondingly increases. Two concentric layers of nodes in the insulation were selected as a compromise. The connectors for the central fuel nodes have been calculated using a different approach. The equation used for the temperature difference across a cylindrical fuel volume with internal heat generation was:

$$
T_{\text {center }}-T_{r}=q^{\prime \prime \prime} \frac{r^{2}}{4 k_{f}}
$$

where:

$q^{\prime \prime \prime}$ is the volumetric heat generation rate

$r \quad$ is the radius of the fuel cylinder

$k_{f} \quad$ is the thermal conductivity of the fuel 
(2) Astronuclear

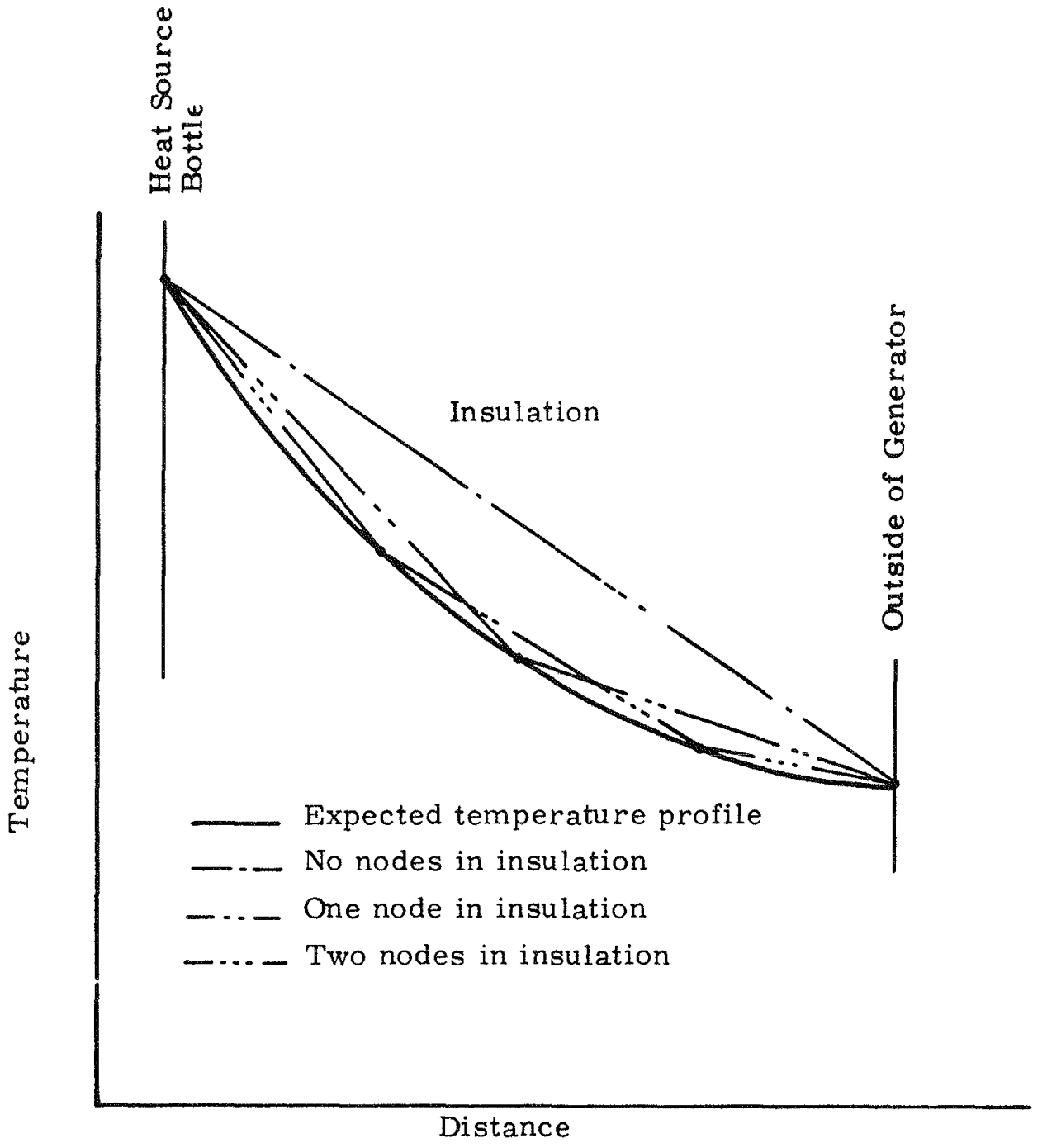

Figure 6-2. Temperature Profile Expected in Insulation 
The iteration equation used in the transient thermal solution is:

$$
T_{1}=\frac{Q_{1}+Y_{12} T_{2}}{Y_{12}}
$$

where:

$\begin{array}{ll}T_{1} & \text { is the temperature at node } 1 \\ T_{2} & \text { is the temperature at node } 2 \\ Y_{12} & \text { is the connector between node } 1 \text { and } 2 \\ Q_{1} & \text { is the heat generated at node } 1\end{array}$

The prevous equation can be solved for $\Delta T$ and equated to the equation for the $\Delta T$ in a fuel volume. The equation used to obtain the connector $Y_{12}$ is:

$$
Y_{12}=4 \pi L k_{f}\left[\frac{R_{1}{ }^{2}}{R_{h_{2}}}\right]
$$

where:

$L \quad$ is the length of the node

$R_{1} \quad$ is the radius to the outer border of node 1

$\mathrm{R}_{2}$ is the radius to node 2

Some of the latest configuration and property data changes incorporated into the new thermal model are:

1) Hittman Associates' most recent data on the radial gaps in the fuel capsule.

2) The most recent thickness and thermal data on the U-8Mo shield assembly.

3) The latest data on the $T / E$ module from $3 M$.

4) The latest thermal data on the Min-K insulation from WANL.

5) More detail on heat losses through structural numbers.

6) The latest data from ORNL on the $\mathrm{SrTiO}_{3}$ fuel. 
The steady state model has been checked out on the UNIVAC 1108. This model agrees with the temperature profiles predicted by the old model and actual data from the electrically heated generator. The transient model is being checked out. The new time step is approximately 0.01 hours real time per iteration. This time step will allow economic investigation of long real time transient problems.

\section{SNAP-23A Explosive Environments}

References 2 and 3 document the applicable environments for the SNAP-23A generator. It is reasonable to expect that terrestrial sites for extended operation will be safe because of prior investigation. On the other hand, transportation over the generator lifetime does not represent a controlled environment and does introduce the possibility of accidents resulting in explosions. Without completely reviewing environments, it suffices to say that a tank truck or airplane accident represents the major source of an explosive hazard. At least one major explosion accident with a propane carrier is known to have occurred some six years ago in Pennsylvania. In this particular case the truck, carrying 9000 gallons of liquid propane skidded, rolled over, ruptured and the contents subsequently exploded. The explosion apparently produced moderate overpressure at some distance, since it severly damaged nearby structures. (Ref. 4 presents an excellent pictorial description of overpressure effects on many structures exposed to nuclear blasts.) Propane should result in a somewhat greater TNT yield than gasoline, and thus the 9000 gallons (maximum ICC permitted load) seems to be a maximum credible environment.

1) TNT Yield. If the explosive is a bare spherical charge of TNT, overpressures are readily characterized. Unfortunately, this is not the case for the SNAP-23A system. The most difficult part of the overpressure determination is to estimate the equivalent TNT yield of the chemical involved. Usually, the yield has a very broad range and for this reason is characterized in probability terms. For example, the yield of a liquid oxygen and hydrogen explosion has been roughly determined through the work of Sandia and Douglas Corporations for the Saturn launch vehicle. This is illustrated in Figure 6-3. 


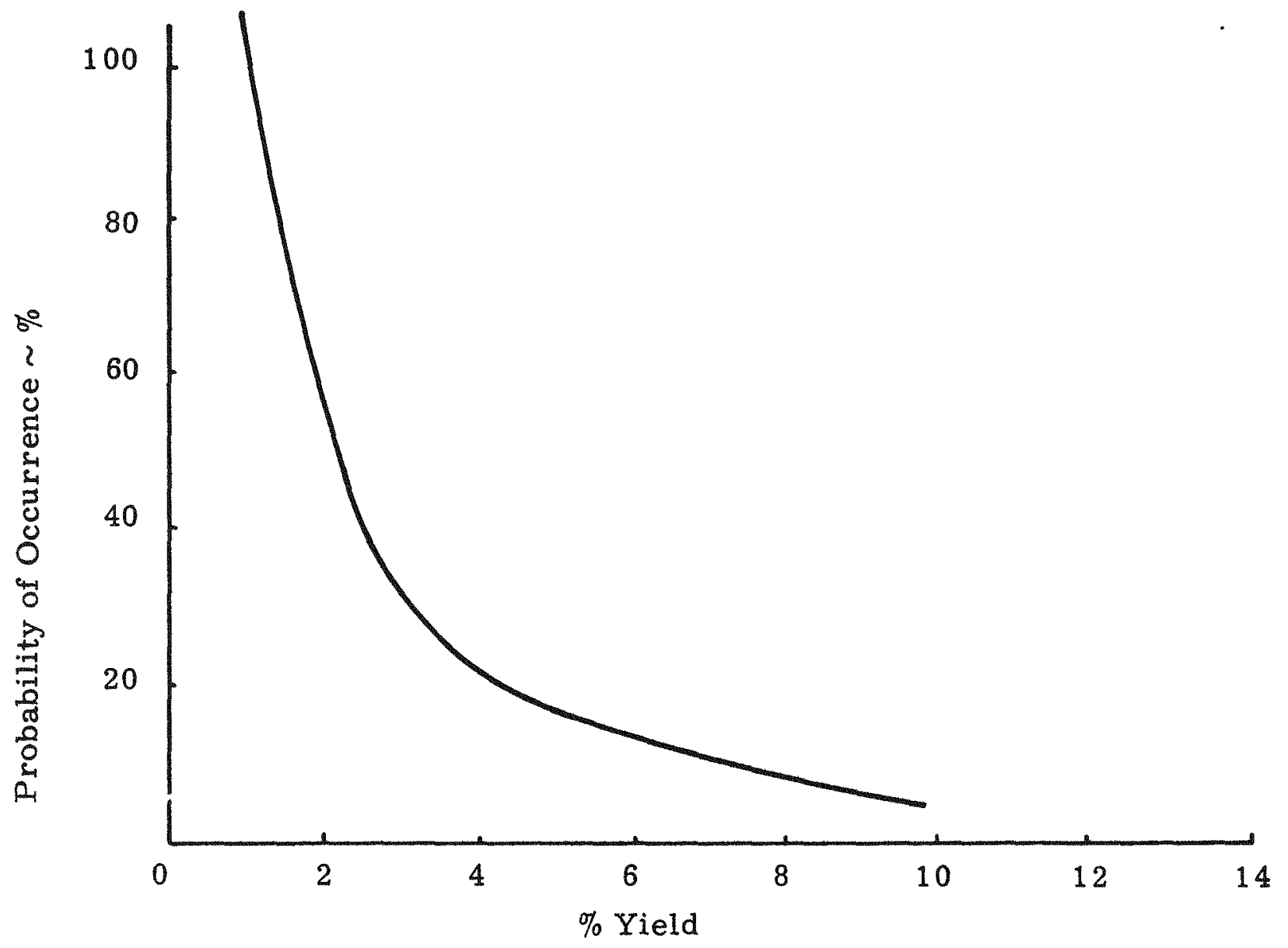

Figure 6-3. TNT Yield Occurrence Probability (Typical for $\mathrm{LO}_{2} / \mathrm{LH}_{2}$ ) 
The yield varies somewhat for different amounts of propellant involved (a mixing problem). Note that the effective yield of these liquid propellants is in the range of one to 15 percent. A solid propellant can be detonated to produce very high yields of 50 to 100 percent TNT depending on the propellant. On the other hand, the yield of typical terrestrial hydrocarbon fuels such as gasoline, butane or propane can be expected to be significantly lower than the yield of liquid propellants. Even with perfect mixing the flame speed of gasoline explosion, as occurs in an automobile engine, is relatively slow. The requirement to mix the fuel with air produces a low density mixture as compared to the compact TNT type explosive. Energy from a low density air fuel mixture will be released slowly. There is also a spatial relationship which must be considered in a fuel explosion. To achieve a 16:1 air fuel mixture for an optimum propane explosion requires substantial area. For 9000 gallons, this will be much greater than $20 \times 20 \mathrm{ft}$ and will not be circular. A $20 \mathrm{ft}$ distance from the explosion center will receive an overpressure much less than that at a $20 \mathrm{ft}$ distance from a TNT source of overall equivalent yield.

2) Close Field Liquid Propellant Explosion. Some evidence suggests that actual overpressures near a liquid propellant explosion are somewhat less than would be predicted by a straight TNT equivalence approach. Reference 4 explores this area in some detail. How close is "near" can be evaluated through the use of an equation. In this "close field", overpressures are less than predicted for TNT equivalence. In the "far field", TNT equivalence is adequate. The boundary separating the two regions is defined by:

$$
C F D=\text { close field distance }=\left(\frac{15 W}{\pi \rho_{0}}\right)^{1 / 3} \text { in feet }
$$

$W$ is the far field TNT yield and $\rho_{0}$ is ambient density.

Parametric curves in Reference 4 enables a TNT equivalent overpressure to be reduced for close field effects. The results are valid for $\mathrm{LH}_{2}-\mathrm{LO}_{2}$ and RPI-LO 2 propellant explosions. It is not known whether other fuel-oxidizer combinations (e.g., propane-air) will exhibit the same close field overpressure characteristics. 
3) Calculated Overpressure Estimates. The approach based on TNT equivalence can be used to define the overpressures produced by exploding 9000 gallons of propane. For estimating purposes, it will be assumed that the propane is released to the local area surrounding the carrier and the center of the resulting explosion is about 20 to 30 feet from the unsheltered SNAP-23A generator. Calculations of overpressure have been made with the aid of Table XI of Ref. 5. The equivalent TNT yield is not known, but a parametric approach can be used to establish that peak overpressures will be much less than the overconservative criterion applied to date (28,000 psi after Ref. 2).

Table 6-1 summarizes the explosion characteristics. Table 6-1 has been included primarily because it gives some insight to the way in which typical explosion parameters vary. While explosion is not a critical design environment for SNAP-23A, the approach is useful in evaluating heat sources of generators used in aerospace application. Calculated overpressure and reflected overpressure are shown in Figure 6-4.

The expected yield for hydrocarbon fuel explosions will be lower than indicated by Figure 6-3. Thus, a two percent TNT yield is a reasonable upper bound for a highly unlikely SNAP-23A environment. The maximum reflected pressure resulting from a two percent yield at 30 feet is 330 psi. Overpressure in the absence of a target will be typified by a response like that shown in Figure 6-5. However, the pressure loading which a cylindrical object will experience is indicated by Figure 6-6. The difference in shape between Figures 6-5 and 6-6 is due to the traverse of the spherical shock around the cylindrical SNAP-23A target.

All values in Table 6-1 and Figure 6-6 are calculated assuming no close field effect. Although no data exist to substantiate a reduction in TNT equivalence, it is likely that a close field does exist for propane-air. The following calculations are presented as representative of incorporating close field effects as given in Ref. 4.

Consider again the case for the propane two percent TNT yield at 30 feet.

$$
C F D=\left[\frac{(15)(860)}{\pi(0.002378)(32.2)}\right]^{1 / 3}=174 \mathrm{feet}
$$

Therefore, 30 feet is well within the close field region. 


\section{Q Astronuclear \\ Laboratory}

TABLE 6-1

EFFECT OF EXPLODING 9000 GALLONS OF PROPANE

\begin{tabular}{|c|c|c|c|c|c|c|c|}
\hline $\begin{array}{c}\text { Assumed } \\
\text { TNT Yield \% }\end{array}$ & $d$ & $\lambda$ & $d_{s}$ & $p / p o$ & $p$ & $p_{r}$ & $t_{d}$ \\
\hline 1 & 20 & 0.603 & 33.2 & 7.64 & 112 & 575 & 6.3 \\
2 & & 0.760 & 26.3 & 13.0 & 191 & 1130 & 5.7 \\
4 & & 0.957 & 20.9 & 19.7 & 290 & 1865 & 2.6 \\
8 & & 1.21 & 16.6 & 30.5 & 450 & 3100 & 1.0 \\
100 & & 2.80 & 7.2 & 142 & 2090 & 16170 & 2.1 \\
& & & & & & & \\
1 & 30 & 0.603 & 49.7 & 2.7 & 39.7 & 148.5 & 9.3 \\
4 & & 0.760 & 39.5 & 5.0 & 73.5 & 330 & 7.4 \\
8 & & 0.957 & 31.3 & 8.65 & 127 & 676 & 6.1 \\
100 & & 1.21 & 24.9 & 14.2 & 209 & 1260 & 5.6 \\
& & 2.80 & 10.7 & 70.3 & 1032 & 7700 & 1.4 \\
\hline
\end{tabular}

NOTES:

1) 9000 gallons propane $=43,800 \mathrm{lb}$.

2) Reference explosion is a $2000 \mathrm{lb}$. spherical charge of TNT

3) $p_{0}=14.7 \mathrm{psi}$

4) These data are not corrected for close field effects 


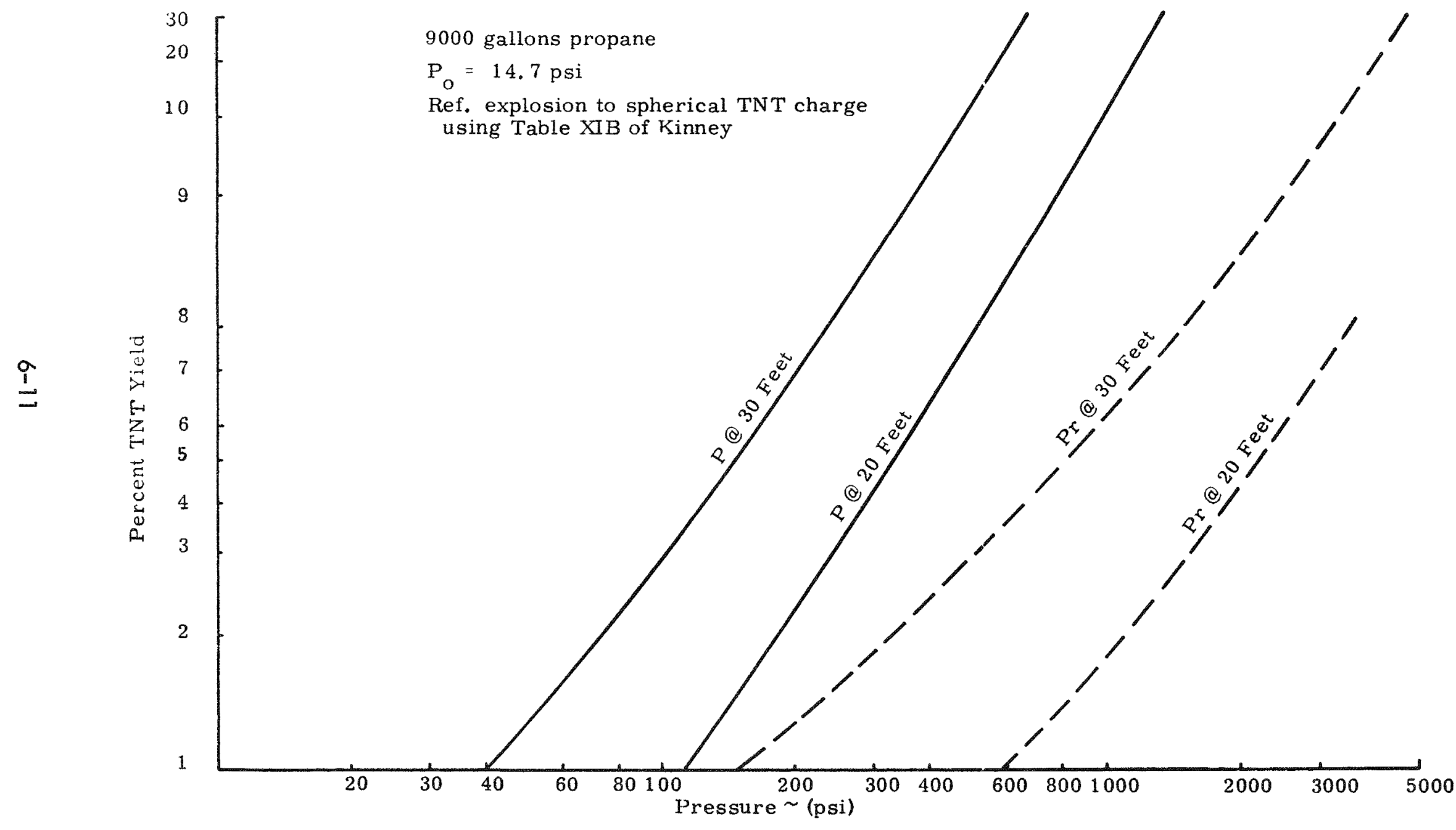

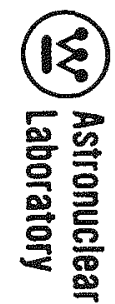

Figure 6-4. Effect of Yield on Peak Overpressure and Peak Reflected Overpressure 


\section{Q. Astronuclear

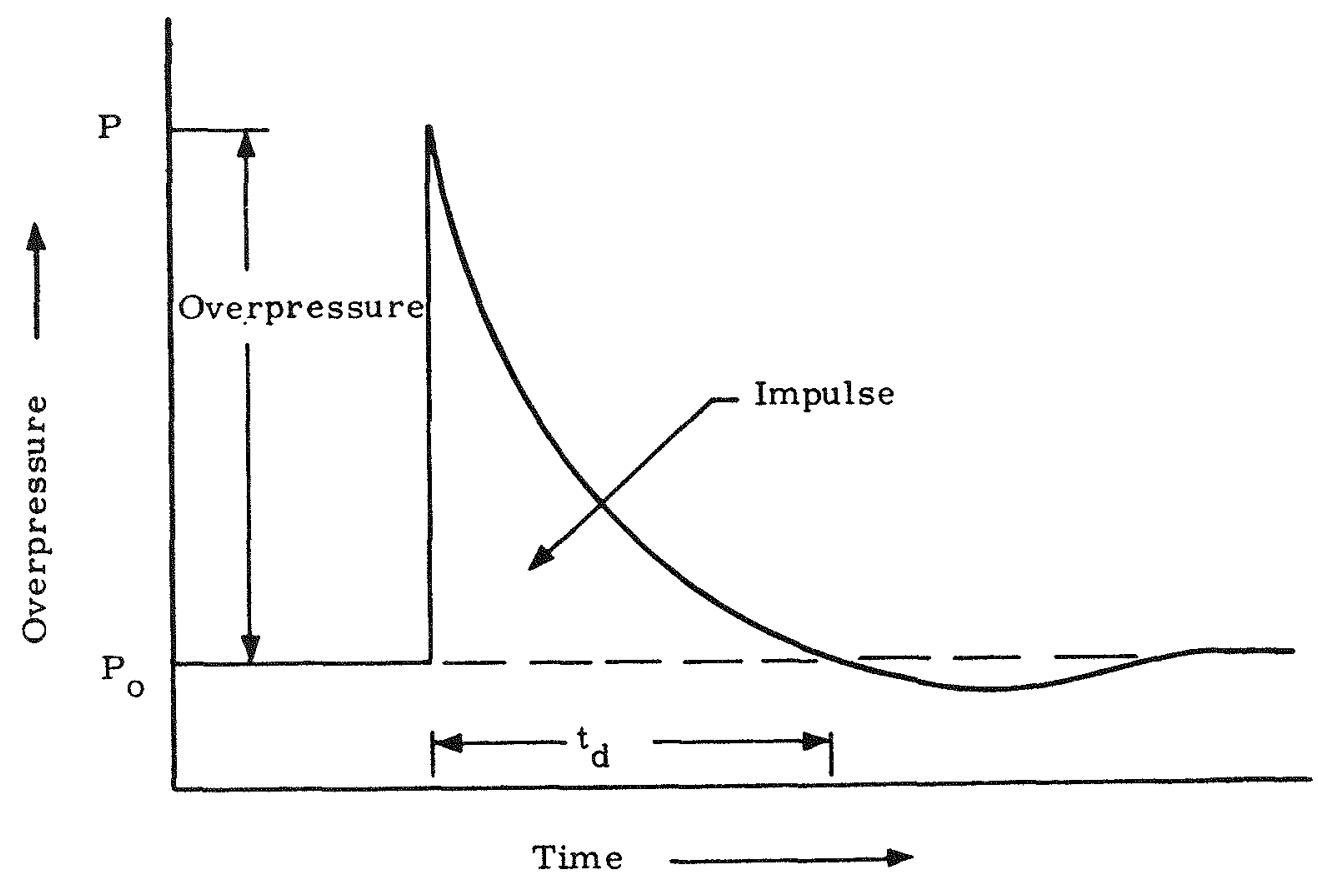

Figure 6-5. Typical Overpressure - Time History

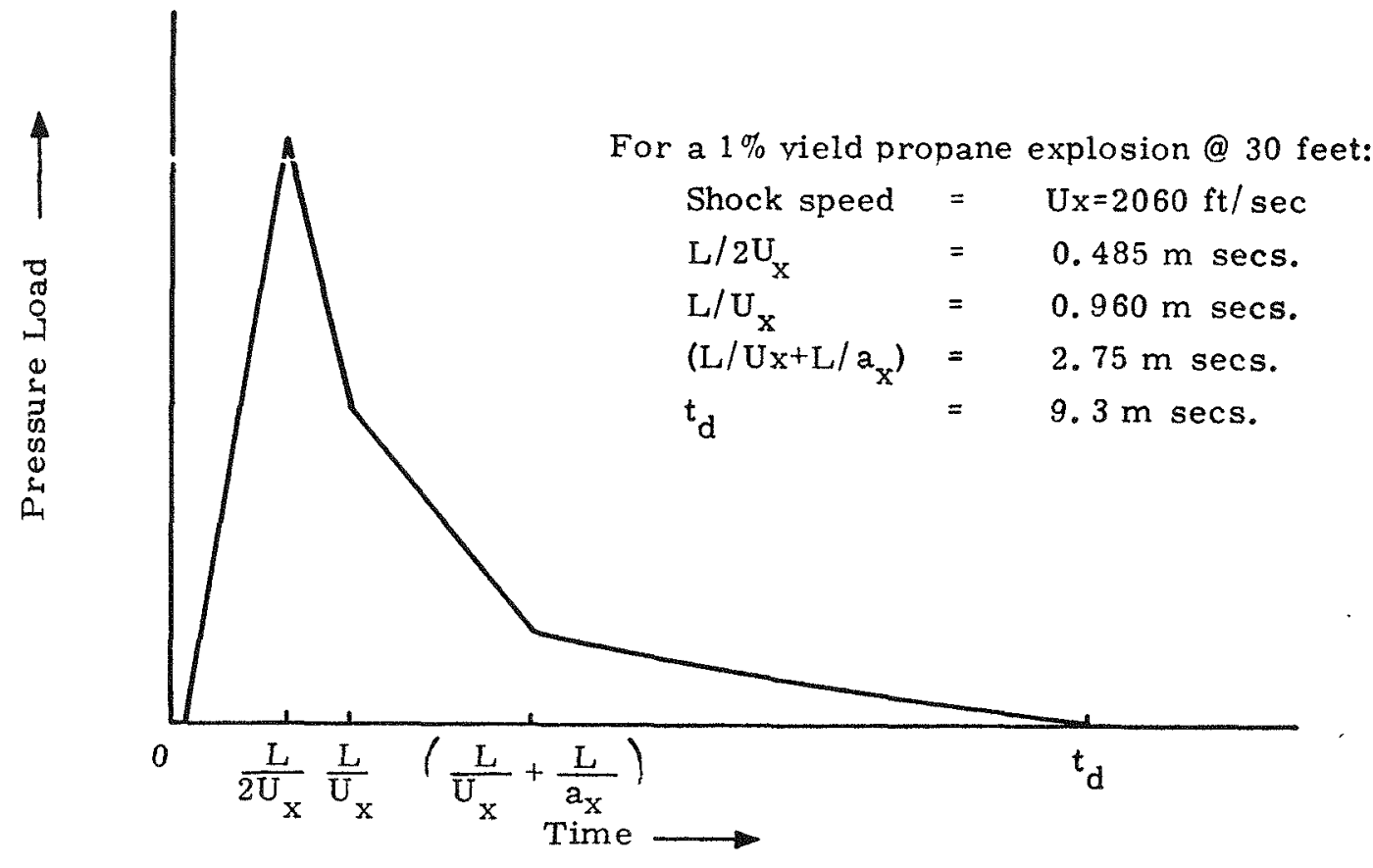

Figure 6-6. Dynamic Load for Cylindrical Structure 
From Figure $6-1$ of Ref. 4 , the effective reduction of $p$ is by $2 / 3$.

$p$ close field $=(2 / 3)(73.5)=49 \mathrm{psi}$

$\mathrm{p}_{\mathrm{r}}$ close field $=192 \mathrm{psi}$

4) Probability of a Severe Overpressure for SNAP-23A. Ref. 3 suggested some probability values for explosion during transport of the SNAP-23A generator. This subject has been reviewed and two significant additions added. These are the probability of achieving an arbitrary TNT yield value and some actual statistics for tank truck vehicles (Ref. 6). Consider the probability of achieving the two percent TNT yield overpressure for 9000 gallons of propane at a distance of 30 feet. The entire probability may be evaluated as follows:

$$
\begin{aligned}
& P=\quad \text { probability of achieving a two percent equivalent } \\
& \text { TNT yield at } 30 \text { feet from } 9000 \text { gallons } \\
& P=(P 1)(P 2)(P 3)(P 4)
\end{aligned}
$$

where:

$$
\begin{aligned}
& \mathrm{PI}=\text { accident in } 30,000 \text { miles of transport } \\
& =0.11 \text { (from References } 3 \text { and 7) } \\
& \text { P2 = accident producing secondary explosion } \\
& =0.00444 \text { (calculation from data in Ref. 6) } \\
& \text { P3 = achieving two percent equivalent TNT yield } \\
& <0.55 \text { from Figure 6-3. } \\
& \text { P4 = accident being with loaded propane truck or } \\
& \text { equivalent }<0.05 \text { (estimated from Ref. 6). }
\end{aligned}
$$

thus,

$$
\begin{aligned}
& P<(0.11) \quad(0.00444 \quad(0.55)(0.05) \\
& P<0.134 \times 10^{-4}
\end{aligned}
$$


Somewhat the same probability value will exist for other types of accidents at a distance of 30 feet. These include collisions with an empty truck where the maximum overpressure will be less.

5) Structural Response Due to Overpressure. The structural overpressure problem for cylinders has been approached experimentally by BRL and others. The approaches given in References 8 and 9 are representative of semi-empirical attack on determining target response.

Although the overpressure pulse is under 10 milliseconds for strong shocks, the results can nevertheless be catastrophic for weak structures. The radiator is the weak or vulnerable part of the SNAP-23A structure. If the overpressure comes from side on, the protective effect of the shipping container will be great. If the generator is mounted in a truck with a strong unitized enclosure, reflected overpressure will be avoided. A detailed evaluation is necessary before an exact level of overpressure can be established that will fail the thermopile. Assuming that the level is greater than 10 or 20 psf, the result can hardly be expected to influence the design. The holes in the radiator cover will probably have the effect of rapidly stabilizing pressure inside and outside. It is possible that traverse of the blast wave over the cover will not fail the radiator fin by drastic bending from root to tip. If the fins are firmly anchored at the root and are ductile, only severe and erratic local deformation may occur. On the other hand, failure may be a dynamic excitation as with aero flutter. The latter is possible for pulses of relatively longer duration, suggesting that the close in distances to the explosion are not necessarily the critical ones.

It is of interest to note that the maximum net load over a 2 foot $\times 2$ foot cylindrical object is on the order of 172,000 pounds for the $30 \mathrm{feet}$, two percent yield case. The load exists for a couple of milliseconds. This suggests that any truck in which the generator is carried could be displaced a substantial distance by large overpressure. The safety problem might then be primarily one of impact. 
6) Summary. For SNAP-23A, it does not seem worthwhile to pursue the overpressure environment further. The 28,000 psi failure criterion of Ref. 2 is completely erroneous but should not be replaced by another value of pressure which will also be impossible to substantiate. The analysis has shown that maximum reflected overpressure at 30 feet from the worst environment is 330 psi. At $20 \mathrm{feet}$, the reflected overpressure is 1100 psi. The probability of achieving these overpressures is estimated to be less than $0.13 \times 10^{-4}$. Since these numbers are large (but $<28000 \mathrm{psi}$ ), there is no sure way of evaluating their effect. Any type of severe overpressure can be expected to damage the carrier. It is suggested that since radiation is not the problem (but rather a slow overheat eventually leading to a possible compromise of shielding integrity) following explosion, procedural measures should be available to cool the generator until final disposition can be made. An examination and instrumentation evaluation are possible before overheat occurs.

Minor overpressures such as sonic booms are below the threshold of causing any fin damage and thus need not be considered. This is established in Ref. 3.

Should the need arise to revise existing documentation, the 28000 psi criterion should be deleted. In theory, at least, a criterion should precede the analysis and therefore procedures should cover severe accidents. A rough structural analysis of the fins inside the final shipping configuration should be performed. This analysis will hopefully supply a threshold value for overpressure and will serve the purpose of completely defining the SNAP-23A safe environments.

Impact Analysis

Impact analyses of the SNAP-23A generator and shield source mounted in the dual purpose container have continued. As a result of these calculations, a number of cask modifications have been recommended. The primary modifications to the heat source shipping container include the removal of the crash cage and some redesign of the cylindrical ends of the container. The inner support structure for the heat source has also been modified. 
The central support bars have been removed and a space frame added on the converter end of the heat source. The added support structure provided by these modifications is similar to the support frame at the base. Incorporation of this support serves two other purposes. First, the space frame attached to the converter end of the heat source affords additional sacrificial members which absorb impact kinetic energy in the event of an upside down impact. In doing so, the impact energy absorbed by the copper accumulator and the U-8Mo shield is reduced. Secondly, the framework is designed to facilitate handling and refueling operations during the heat source assembly.

Five impact conditions are being considered in the subject analysis. The impact magnitude corresponds to a postulated 30 foot free fall onto a non-yielding surface. Investigation into the transportation of radioactive materials indicates that the hypothetical 30 foot free fall is the most severe impact criterion to which the shipping container can realistically be designed. The five impact conditions being considered include four cases with an impact velocity of $44 \mathrm{ft} / \mathrm{sec}$ ( 30 foot drop) and one case where the package is dropped 40 inches onto a six inch diameter mandrel. Orientation of the container for the 30 foot free fall impact cases consist of top, bottom, side and corner impacts.

The basic approach used in the analys is is to allow sacrificial members to deform and crush, thereby dissipating the kinetic energy of the system and causing the impact to occur as a relatively long-time event.

The analysis determines the impact energy dissipated in the space frames at the onset of buckling. Once buckling is established it is assumed that the frame collapses with little additional energy dissipation by the members. In the bottom impact case, once buckling of the support frame is established and the energy required to initiate buckling determined, the remaining kinetic energy is dissipated in the crushing of the Min-K base. The forces and induced stresses in the U-8Mo shield during crushing of the Min-K are then determined and compared to the yield strength of the shield material. 
The top impact case determines the energy dissipated in buckling of the space frame by the same procedures described above. The remaining kinetic energy of the system is then dissipated by a Min-K plug (located between the accumulator and the top of the container) and deformation of the accumulator itself. The stresses induced in the shield material during this sequence are then determined and compared to the yield strength of the U-8Mo shield.

Side impact also utilizes buckling of the space frames. The stresses in the U-8Mo shield however are determined by the intensity of the stress wave resulting from the impact of the heat source with the surrounding sand. The sand, therefore, provides an acoustical impedence which limits the magnitude of the stress wave in the shield material.

Corner impact will probably occur by some combination of end-on and side impact and will also indicate the large deformation characteristics built into the design of the shipping container. The impact model is presently under development and the exact method of analysis is not finalized at present.

It appears at the present time that the 40 inches free fall onto a six inch diameter mandrel will puncture the container wall; however, integrity of the shield material will not be violated. The energy required to puncture the container and the additional shells surrounding the U-8Mo shield, as well as the shield itself, is considerably greater than that energy attained in a 40 inch free fall. 


\section{Subrask 640 - Safety Review}

A detailed review of the Preliminary Safety Analysis Report was continued during this period. Arrangements were made for AEC review of the PSAR and to receive RDT and DL\&R comments at the end of calendar 1968; this information is needed to identify any additional analyses required for safety approval and to prepare a Phase II Safety Program Plan. WANL/Hittman discussions were held with members of the DL\&R staff on the matter of a general license for SNAP-23A.

Prior Hittman analyses (WANL-3800-001) had evaluated the significance of gap width within the fuel capsule on fuel capsule temperature and concluded that no problems exist for anticipated assembly tolerances. A similar analys is has been performed to evaluate the temperature differential between the tantalum diffusion barrier and the uranium shield as a function of uranium emissivity for air and helium cover gases. The purpose of this analysis was to evaluate the thermal effects of a heat source rupture in which helium is replaced by air and to determine the significance of uranium emissivity since no value of this uranium property could be found in the literature. The results of this analysis are summarized in Figure 6-7 for the BOL condition when the shield surface temperature is approximately $1300^{\circ} \mathrm{F}$. It is evident that the value of uranium emissivity has little significance for a helium cover gas whereas it has considerable import when air is present. Although a temperature differential in the order of $200^{\circ} \mathrm{F}$ is possible from such an event, capsule temperatures would not be excessive and hence fuel containment would not be compromised. Of course, oxidation of the uranium would ultimately cause significant damage to the heat source and degradation of shielding effectiveness.

in anticipation of using a fueled heat source for the PMS program that will be accomplished in the later stages of Phase 1, an evaluation was performed of the design changes that must be made to the existing SNAP-23A configuration to satisfy safety requirements as indicated from Hittman safety analyses. 


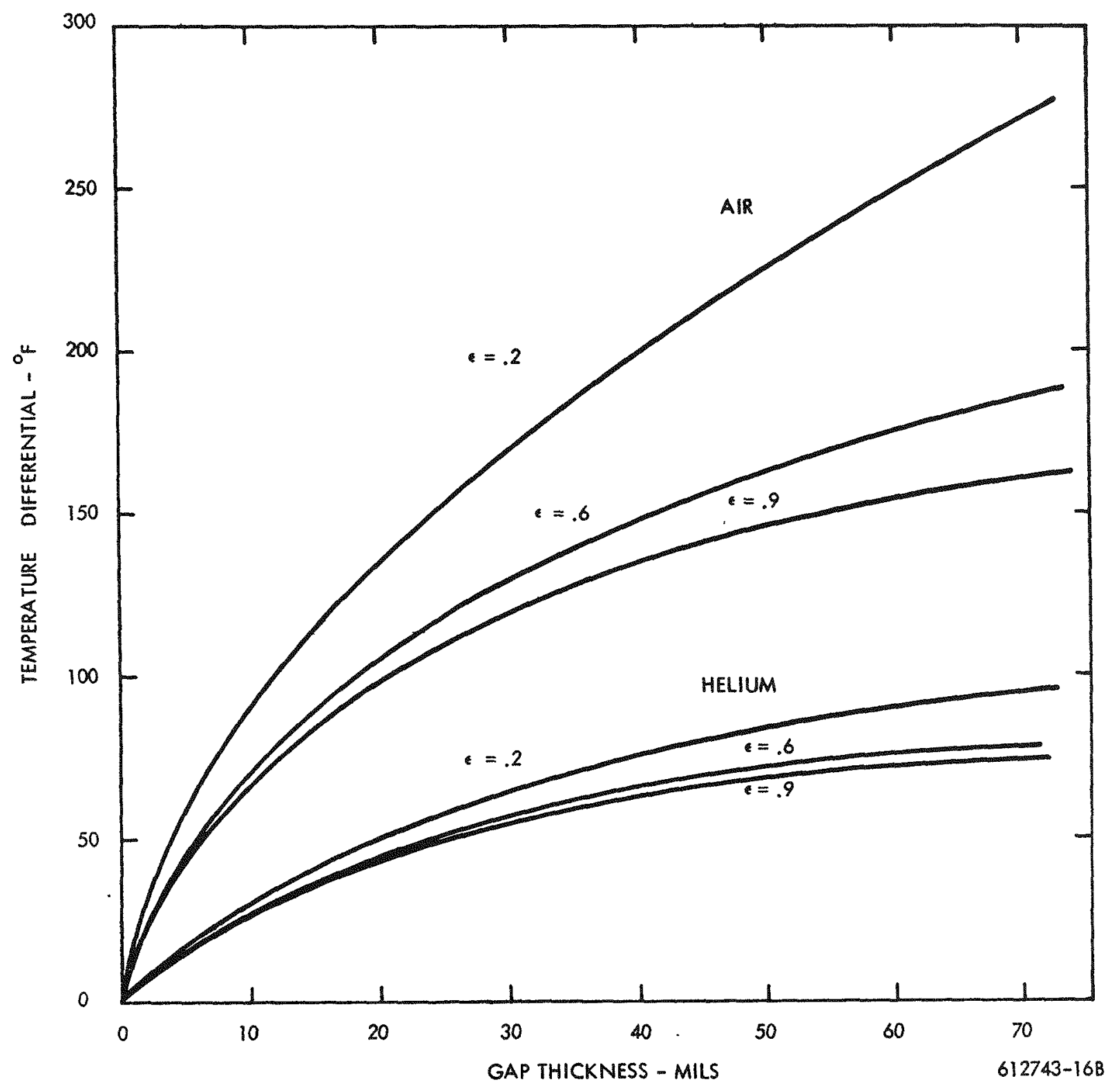

Figure 6-7. Temperature Differential Across Tantalum-U-8Mo Shield Interface Gap as a Function of Gap Thickness for Air and Helium Cover Gases at Various Assumed Uranium Emissivities 


\section{Heat Source Design Requirements}

Fuel containment must be maintained at all times during normal operation and during any credible accidents. Safety analyses of all accident environments associated with the handling, transportation, and testing of the heat source have not identified any circumstances whereby capsule integrity could be compromised. Earth burial has been classified as a special situation which will be avoided by the use of appropriate engineered safeguards. In the area of direct radiation, thermal damage to the shield during a 30 minute fire at $1475^{\circ} \mathrm{F}$ or structural failure resulting from various impact loads on the heat source must not cause the radiation level to exceed $1000 \mathrm{mrem} / \mathrm{hr}$ at 3 feet from the heat source. Safety analyses established that temperature limitations of critical components (including eutectic melting points at component interfaces) were not exceeded and that the shipping container could provide the required protection against excessive mechanical and thermal stresses. Although the $\mathrm{Cu} / \mathrm{U}$ eutectic would probably be exceeded in a 30 minute fire at $1850^{\circ} \mathrm{F}$, shield integrity is not required for this severe and highly unlikely accident (no credit has been taken for protection that would be afforded by insulation to be incorporated into shipping container).

Hence, the present heat source design with the protection provided by the shipping container will be able to meet all safety criteria imposed on the heat source assembly per se.

\section{Generator Design Requirements}

When the heat source assembly is mounted in the generator, normal operation of the generator or the occurrence of any credible accident must not result in loss of fuel containment. Removal of the complete converter from the heat source stud, as might be required during testing or in the field, would cause the steady state temperature at the shield/accumulator interface to reach a level approximately $50^{\circ} \mathrm{F}$ below the $\mathrm{Cu} / \mathrm{U}$ eutectic. Uncertainty in the analyses requires that melting be presumed to sccur. Since it will require many hours for the heat source to reach the $\mathrm{Cu} / \mathrm{U}$ eutectic melting point, procedural controls are quite feasible in avoiding this mode of heat source damage. 
An analysis of the effect of a loss of radiator, which could occur by mechanical damage or a high temperature fire, revealed that the Hastelloy- $C$ components would not melt. However, the inner surface of the U-Mo shield would reach a temperature only $70^{\circ} \mathrm{F}$ below its melting point. In view of the uncertainty in the calculations, it must be assumed that melting will occur and that molten uranium will flow around the tantalum diffusion-barrier can. The fact that the Uranium Hastelloy- $C$ system forms a low melting eutectic at $1370^{\circ} \mathrm{F}$ requires that the tantalum be sealed against molten uranium if fuel containment is to be maintained. Temperatures at the shield/accumulator interface are predicted to be approximately $250^{\circ} \mathrm{F}$ above the $\mathrm{Cu} / \mathrm{U}$ eutectic and at the melting point of copper. Gross melting of the shield is, therefore, anticipated and it is likely that the tantalum-clad capsule would be immersed in a liquid Cu/U eutectic. Since the thin tantalum diffusion barrier would be the only protection against chemical attack of the Hastelloy-C cpasule by the molten uranium alloy, it is concluded that a barrier should be interposed between the shield and accumulator. Shielding effectiveness would also be substantially reduced; the effect of the molten eutectic on the integrity of the heat source jacket would determine the amount of shielding that would remain in place. It should be noted that only a few centimeters of shielding are required to satisfy the emergency radiation criteria (1000 mrem $/ \mathrm{hr}$ at 3 feet). In any case, implementation of the fuel containment requirement simultaneously assures that shielding effectiveness will not be significantly reduced.

No other accidents or abnormalities such as an open circuit have been identified for which the safety criteria can not be satisfied.

It should be noted that the limitations of the analytical model, particularly the thermal impedance assumed for the damaged converter after a fire, could have a significant effect on the predicted results. System and component tests to verify the analytical model for off-design conditions would identify any model deficiencies and perhaps demonstrate that the consequences of the loss-of-radiator accident are not as severe as predicted. In the absence of such test data, however, the proposed safety-related design changes must be implemented on the basis of available safety analyses. 


\section{REFERENCES}

1. HIT-348, "SNAP-23A Quarterly Progress Report," August 1968.

2. HIT-248, "SNAP-23A Operations Analysis and Nuclear Safety Design Criteria," Revision A, June 8, 1967.

3. HIT-306, "SNAP-23A Preliminary Nuclear Safety Analysis," April 1968.

4. Bracco, F, V., "Air Blast Parameters Close to a Liquid Propellant Explosion," Wyle Laboratories Research Staff Report WR 66-3, January 1966.

5. Kinney, G. F., Explosive Shocks in Air, Macmillan Company, New York, 1963.

6. "Engineering and Safety Bulletin No. 72, "National Truck Carriers Inc., March 1968.

7. Leimkuhler, F. F., Trucking of Radioactive Materials: Safety Versus Economy in Highway Transport, The Johns Hopkins Press, Baltimore, Maryland, 1963.

8. Schuman, Wm. J., Jr., "The Response of Cylindrical Shells to External Blast Loading, "BRL Report No. 1461, Aberdeen Proving Ground, March 1963.

9. Neimi, R., R. Rabenau, "Blast Effects on Space Vehicle Structures, "NASA TND-2945, February 1966. 